\title{
System Losses Study - FIT (Fuel-Cycle Integration and Tradeoffs)
}

Steven J. Piet

Nick R. Soelberg

Samuel E. Bays

Robert S. Cherry

Denia Djokić

Candido Pereira

Layne F. Pincock

Eric L. Shaber

Melissa C. Teague

Gregory M. Teske

Kurt G. Vedros

September 2010

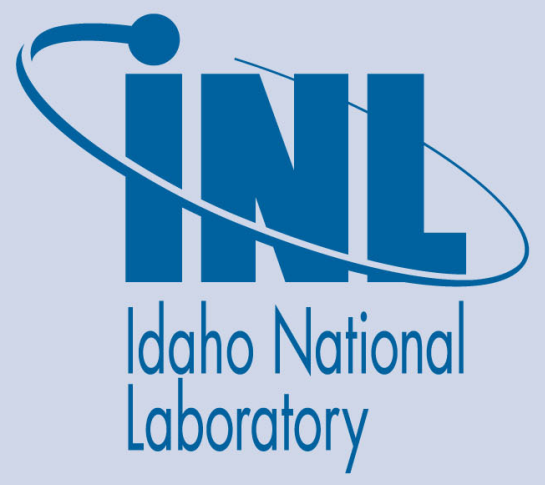

The INL is a U.S. Department of Energy National Laboratory operated by Battelle Energy Alliance 
INL/EXT-10-19788

FCRD-SYSA-2010-000140

\title{
System Losses Study - FIT (Fuel-Cycle Integration and Tradeoffs)
}

\author{
Steven J. Piet \\ Nick R. Soelberg \\ Samuel E. Bays \\ Robert S. Cherry \\ Denia Djokić ${ }^{1}$ \\ Candido Pereira ${ }^{2}$ \\ Layne F. Pincock \\ Eric L. Shaber \\ Melissa C. Teague \\ Gregory M. Teske \\ Kurt G. Vedros \\ ${ }^{1}$ University of California - Berkeley \\ ${ }^{2}$ Argonne National Laboratory \\ August 2010 \\ Idaho National Laboratory \\ Fuel Cycle Research and Development \\ System Analysis Campaign \\ Separations and Waste Form Campaign \\ Transmutation Fuels Campaign \\ Idaho Falls, Idaho 83415
}

Prepared for the

U.S. Department of Energy

Office of Nuclear Energy

Under DOE Idaho Operations Office

Contract DE-AC07-05ID14517 


\section{DISCLAIMER}

This information was prepared as an account of work sponsored by an agency of the U.S. Government. Neither the U.S. Government nor any agency thereof, nor any of their employees, makes any warranty, expressed or implied, or assumes any legal liability or responsibility for the accuracy, completeness, or usefulness, of any information, apparatus, product, or process disclosed, or represents that its use would not infringe privately owned rights. References herein to any specific commercial product, process, or service by trade name, trade mark, manufacturer, or otherwise, does not necessarily constitute or imply its endorsement, recommendation, or favoring by the U.S. Government or any agency thereof. The views and opinions of authors expressed herein do not necessarily state or reflect those of the U.S. Government or any agency thereof. 



\section{ACKNOWLEDGEMENTS}

David Shropshire led this activity until late February 2010, when he started a two-year assignment in the Netherlands, where he is thriving. We thank him and wish him continued good times and success.

Chemical separation experts Roger Henry and Dave Meikrantz were involved in this effort this fiscal year until their retirements in July. Prior to his retirement, Kent Williams was very helpful in suggesting information valuable for eventual economic/cost analyses. We hope all three are happy in retirement.

Heather Rohrbaugh did an excellent job in editing the August draft of this report. After reading the above acknowledgements - all people who have left - she wasn't sure she wanted to be listed here. But, she did a great job and we'd be remiss if we didn't acknowledge that. We hope she is available for a long time to come.

Finally, we thank Jack Law who performed a helpful review of this report. Now, if he could find someone in his department to walk in the shoes of Roger Henry and Dave Meikrantz ... 
This page intentionally left blank. 


\section{SUMMARY}

This team aimed to understand the broad implications of changes of operating performance and parameters of a fuel cycle component on the entire system. In particular, this report documents the study of the impact of changing the loss of fission products into recycled fuel and the loss of actinides into waste.

When the effort started in spring 2009, an over-simplified statement of the objective was "the number of nines" - how would the cost of separation, fuel fabrication, and waste management change as the number of nines of separation efficiency changed. The intent was to determine the optimum "losses" of TRU into waste for the single system that had been the focus of the Global Nuclear Energy Program (GNEP), namely sustained recycle in burner fast reactors, fed by transuranic (TRU) material recovered from used LWR UOX-51 fuel. ${ }^{\mathrm{a}}$ That objective proved to be neither possible (insufficient details or attention to the former GNEP options, change in national waste management strategy from a Yucca Mountain focus) nor appropriate given the 2009-2010 change to a science-based program considering a wider range of options.

Indeed, the definition of "losses" itself changed from the loss of TRU into waste to a generic definition that a "loss" is any material that ends up where it is undesired. All streams from either separation or fuel fabrication are products; fuel feed streams must lead to fuels with tolerable impurities and waste streams must meet waste acceptance criteria (WAC) for one or more disposal sites. And, these losses are linked in the sense that as the loss of TRU into waste is reduced, often the loss or carryover of waste into TRU or uranium is increased.

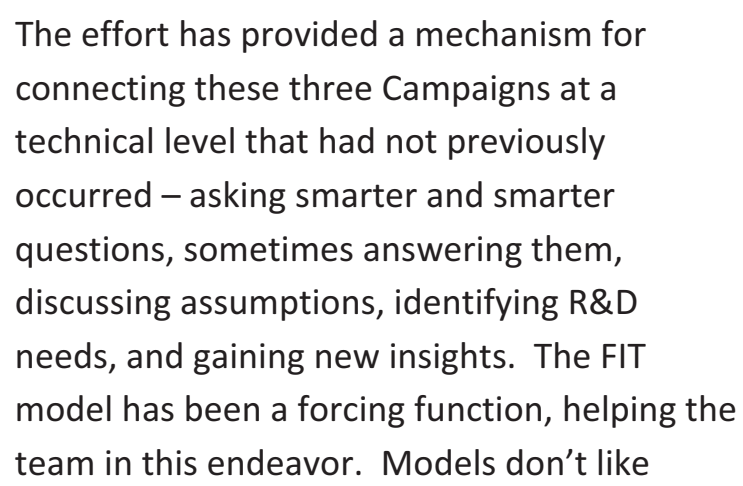

A major addition in FY 2010 was exploratory analysis of "modified open fuel" cycles, employing "minimum fuel treatment" as opposed to full aqueous or electrochemical separation treatment. This increased complexity in our analysis and analytical tool development because equilibrium conditions do not appear sustainable in minimum fuel treatment cases, as was assumed in FY 2009 work with conventional aqueous and electrochemical separation. It is no longer reasonable to assume an equilibrium situation exists in all cases.

This team effort has two types of value. The first are findings regarding the nature of the problem of fitting the fuel cycle together in multi-recycle scenarios, as described in Section 2. These findings both guided and resulted from the attempt to create the Fuel-cycle Integration and Tradeoffs (FIT) model, which is described in Section 3. The FIT model is a new attempt at integrating the fuel cycle at the level of chemical groups. By integration, we mean blending of feed streams, fuel fabrication, reactor, used fuel separation, and waste management. The second are quantitative analyses with the beta version of the FIT model, presented in Section 4. The model was not the task objective, its creation and use has been a tool toward the teams' objectives.

Figure S-1 illustrates the central challenge of the discharge side of nuclear fuel cycles - how can active radioactive materials "in service" be dispositioned? ${ }^{\mathrm{b}}$ All mass must eventually leave active status, to either be readied for recycling or permanently disposed. These questions arise: What options exist for

a. For this report, the nominal used fuel coming into the recycle loop is light water reactor (LWR) uranium oxide fuel at 51 MWth-day/kg-iHM burnup.

b. The central challenge of the upstream side of nuclear fuel cycles is obtaining materials that must be put into radioactive service. 
individual technologies, how should such options integrate to make a system, and when and for how long can materials be recycled? In short, what are the sagacious disposition options? This recycle losses study aims at answering those questions via time-independent, equilibrium analyses. Until materials are treated to achieve impurity limits, active materials cannot be re-used as new fuel, stored as recovered uranium (RU), stored as depleted uranium (DU), re-used as zirconium, re-used as graphite, used for non-energy applications, ${ }^{\mathrm{C}}$ etc. As this list shows, there are more materials to be considered than simply transuranic (TRU) elements. Fuel impurity limits are based on fuel fabrication, service conditions, and performance estimations. And, until any candidate materials are treated to comply with waste acceptance criteria (WAC), those active materials cannot be disposed as high-level waste (HLW), low-level waste (LLW) qualifying for near-surface burial, or intermediate categories. WAC are established by the waste receiver. Thus, separation produces two sets of products that must meet criteria: recycled materials and wastes. Loss of useful materials into wastes impact meeting WACs, and loss or carryover of non-useful materials into recycle fuel streams impact impurity limits; hence, these issues are linked.

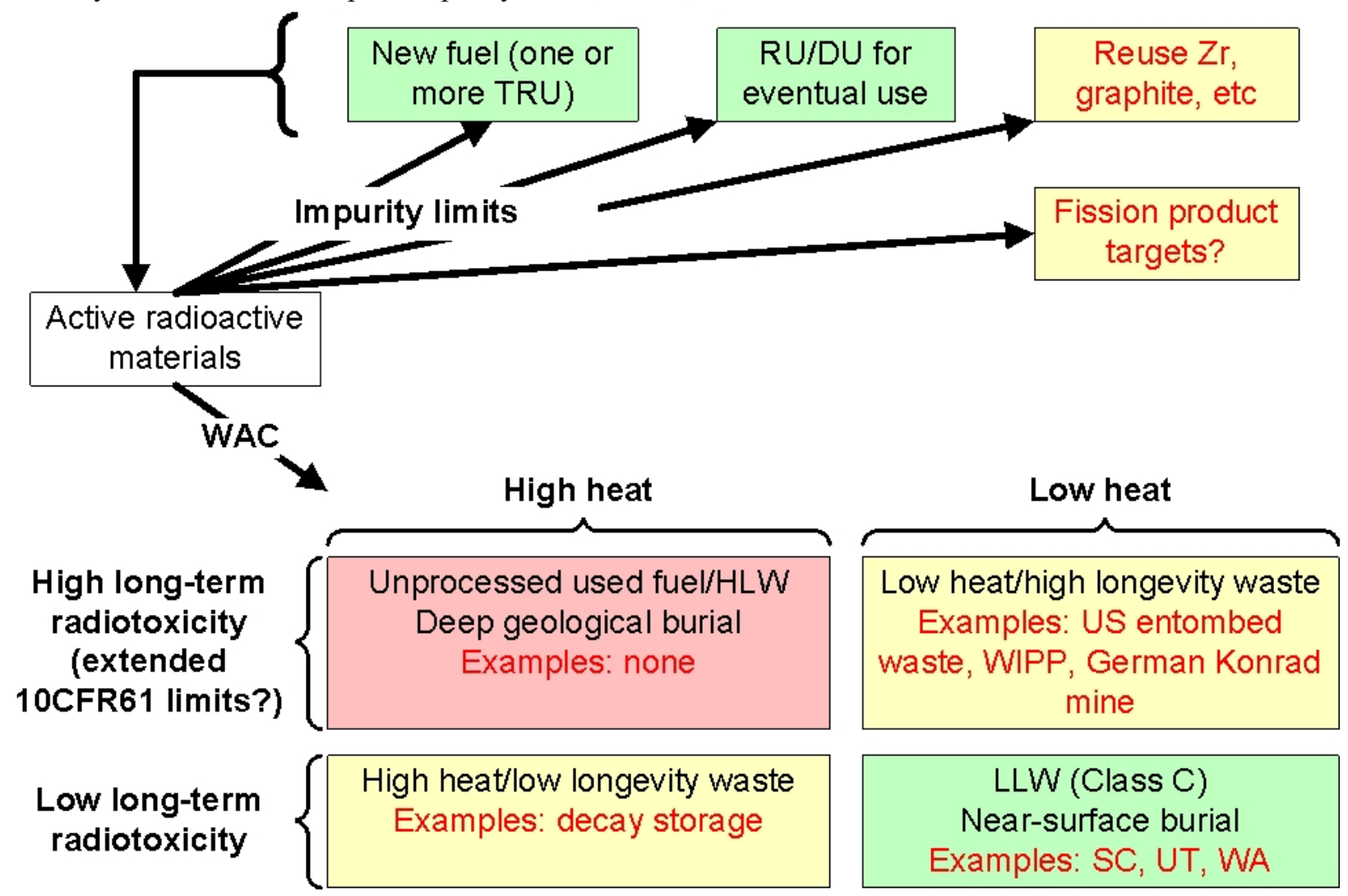

Figure S-1. Central challenge of the downstream side of nuclear fuel cycles

The FY 2009 losses study analyses were done piece-meal with sets of spreadsheets, expert judgments, and a Decision Programming Language mini-model (Shropshire 2009). We realized in FY 2010 that it was time to make a FIT model to automate our analyses and to harvest expert judgment in a more systematic way as we analyzed different aspects of material management within the fuel cycle and step

c. Although outside of our scope, we note that there is a wide range of potential non-fuel uses of material discharged from a reactor (cladding, fuel matrix materials such as zirconium in Zr-U-TRU fuels, graphite moderator), isotopes for non-energy nuclear applications such as medicine, food irradiation, and detectors, and non-radioactive service for lanthanides that do not have long-lived radioactive isotopes. Imagine nuclear-enhanced wind energy by using recovered neodymium, a main component of permanent magnets in wind turbines. The longest-lived artificial neodymium isotope is Nd-147 (10.98 day halflife). 
back to evaluate the impacts of higher level issues and drivers (e.g., fuel cycle selection that minimizes the generation of TRU, simplifies treatment for closure, minimizes or eliminates recycle, minimizes proliferation risk, etc.).

Our analyses are limited to:

- Commercial nuclear energy fuel cycles.

- Uranium-transuranic element fuel cycles (as opposed to thorium-uranium fuel cycles)

- Light water reactors and sodium-cooled fast reactors - we readily acknowledge that there are a wide range of alternatives to be studied in the future.

- Fast reactors that consume more TRU than they make, i.e., burner fast reactors as opposed to breeder fast reactors.

- Four used fuel treatment options: aqueous and electrochemical are taken as examples of traditional, full separation techniques and Atomics International reduction oxidation (AIROX) and melt-refining are taken as examples of limited separation, also known as minimum fuel treatment (MFT). There is a wide range of variations and alternatives to be studied in the future.

The rest of this summary pertains to six topics. Each pulls together information scattered throughout the report. In essence, these six topics are cross-cuts that pervade our analyses, results, and conclusions.

\section{Topic 1. The R\&D program must improve chemical completeness and consistency}

In fuel cycle systems, most of the elements from 1 (hydrogen) to 98 (californium) can be involved. Early in the Losses Study, we realized that we may have to consider any and all of these elements. Through our analyses and discussions, some things have come into sharper focus.

First, consider some trends in the periodic table.

Often, the sources of chemical elements are organized horizontally in the periodic table. For example, the first row of transition metals contains most of the constituents of steels, a likely source of impurities. The second full row of the periodic table (with the second row of transition metals) contains most of the fission products, a known source of impurities. Furthermore, when fission products decay into each other, they move left or right in the periodic table.

The behaviors and constraints of chemical elements are often organized vertically in the periodic table. For example, the halogens' column (Group 17) have similar chemical properties and indeed the 2009 working Fuels Campaign limits on metal fuels (Shropshire2009) constrain the TRU feedstock's content of $\mathrm{F}+\mathrm{Cl}+\mathrm{Br}+\mathrm{I}$ to $300-\mathrm{ppm}$ total, without regard to the mix among those elements, because of fuel cladding corrosion. The corresponding halogen limits on oxide fuels constrain TRU feedstock content of $\mathrm{F}+\mathrm{Cl}$ to $60 \mathrm{ppm}$; no limit is given for $\mathrm{Br}$ or I.

The above examples are indicative of several observations.

- Fuels campaign working limits are often for groups of elements that have similar impact on fuel performance, many of these limits include elements with different origins (fission products and non-fission products). Therefore, one must eventually analyze all impurities together. For example, it would be non-conservative to allocate or "use up" all of an impurity limit on fission product-origin impurities if there are other potential impurities in that group. For metal fuels, this means one would presumably not want to allocate the entire $300 \mathrm{ppm}$-halogen limit to only the fission products $\mathrm{Br}$ and $\mathrm{I}$, leaving no margin for $\mathrm{F}$ or $\mathrm{Cl}$. 
- The question is posed to the Fuels Campaign about exactly which elements belong in each chemical limit. For example, there is no explicit limit on Br and I for oxide fuel TRU feedstock, yet these are fission products and will appear in any recycle stream. Should they be added to the 60-ppm limit on $\mathrm{F}$ and $\mathrm{Cl}$ ?

The second complexity is the mis-match between those elements for which Fuels Campaign working limits exist versus those for which there is separation data.

- All former fuel specifications have dealt with impurities from mining, milling and enrichment operations. There has been far less consideration of transmutation fuels where a different set of impurities from fission products are the major concern.

- Typically, there are separation data for major fission products, but there are often not fuel impurity limits for those elements. Therefore, it is impossible t know if the separation efficiency is too tight or too loose for those elements. It would be incorrect to assume that a non-limited element is truly without limit. $\mathrm{Br}$ and I in oxide fuel TRU feedstock is an example; although they are not currently limited, we believe it is likely they should be included with the $\mathrm{F}$ and $\mathrm{Cl}$ limit. Tables 4-3 and 4-5 contain estimates of oxide and metal fuel impurities for which no current limit exists. For example, with uncertainties of at least a factor of 2 (up and down), we estimate Pd at $\sim 1000 \mathrm{ppm}$ in both types of fuels. Should there be a limit on Pd impurity? Also, Te appears to be an impurity in either oxide or metal fuel at hundreds of ppm, is this acceptable?

The two sets of Fuel Campaign working limits on impurities and the four sets of separation factors are summarized in Section 2 by color-coded Periodic Tables. So, the reader can see at a glance the degree of completeness, the presence or absence of trends, which elements are limited but have nil separation data, and which

- There are Fuel Campaign working limits for many elements for which there are little or no separation efficiency data. In some cases, there are limited data that have not yet been included in mass balances. For example, we find little or no separation data for first row transition metals in uranium-extraction (UREX+1), electrochemical, air reduction/oxidation (AIROX), or meltrefining, even though that row contain the major constituents of steel and nickel-based alloys $(\mathrm{Cr}$, $\mathrm{Mn}, \mathrm{Fe}, \mathrm{Co}, \mathrm{Ni})$. Here, "UREX +1 " refers to any of the process schemes that product uranium and mixed-TRU streams for recycle.

- Because fuel fabrication and performance are based on different chemical characteristics for oxide versus metal fuels, one cannot assume that elements of the same chemical group face comparable limitations in two different fuel types.

In short, there are little or no separation data for several elements the Fuels Campaign limits; and no limits for several elements for which there are separation data.

The third complexity is that chemical alteration to fuel and waste streams is not limited to separations. Most fuel fabrication methods include a feed conditioning step that involves dissolution or melting of the feedstock. This has to be considered in the proliferation risk assessments and the definition of "minimum fuel treatment." It also motivates integration of separation and fuel fabrication.

Uranium enrichment alters chemistry. We define four types of uranium: depleted uranium (DU) from enrichment, natural uranium (NU), enriched uranium (EU), and recovered uranium (RU) from separations. DU and EU are considered extremely pure, as they are the result of uranium enrichment, in 
which the uranium was fluoridated into $\mathrm{UF}_{6}$ gas. ${ }^{\mathrm{d}} \mathrm{NU}$ or RU will not be as pure. The differences in uranium isotopes among DU, NU, EU, and RU are naturally important; yet, Section 4 shows some differences between pure and impure uranium. Of course, NU or RU could be purified to the same degree as DU or EU.

Waste form fabrication also alters chemistry. So, combining these considerations, we make these observations and suggestions.

- Chemical analysis of fuel cycle options must include ore processing, enrichment, separations (if any), fuel fabrication, and waste form.

- The feasibility and performance of a set of technologies to make a fuel cycle cannot be established until the chemistry is analyzed all the way through.

- Assessments of technology availability and potential misuse for proliferation resistance evaluations should not be limited to used fuel separations.

In addition to the above observations on the completeness of data, we make these observations on the state of data.

- The experimental basis for quantifying the degree of separation of the lanthanides from actinides ranges from having data for several lanthanides from $U R E X+1$ tests to limited data for melt refining or AIROX or remains to be developed for some proposed separations. Often, the behaviors of all the lanthanides are extrapolated from data for only a few of them; yet, as is the case with transition metals and actinides that have multiple possible oxidation states, the behavior of individual lanthanide elements may vary from that of the others.

- The fate during separations of non-fission product impurities is often inadequately understood (e.g., C-14, Cl-36, and some elements that have concentration limits for fuel fabrication).

- Because separation techniques use different chemical characteristics (volatility, selective oxidation, complexation in nitric acid, etc.) one cannot assume that elements of the same chemical grouping (as we have defined them) behave the same in two different separation

It is important to understand the inherent properties and capabilities of a given separation technique, versus add-on possibilities via secondary processes. Likewise, it is important to understand how assumptions may be constraining possibilities. An assumption that looks relatively unimportant to one set of experts may have major ramifications to other disciplines. A techniques.

- UREX+1 variants have only been tested at the laboratory scale. Industrial implementation would likely require modifications (secondary processes) that address components that do not behave as expected in the conceptual process, such as molybdenum, ruthenium, etc. This would be true for any process, e.g. electrochemical separations, and is the case for Plutonium-Uranium Reduction Extraction (PUREX). If these secondary processes overwhelm the basic process, then the basic process should be reconsidered.

In this year, we spent considerable time analyzing AIROX and melt refining, which have been mentioned as possible "minimum fuel treatment" options as part of the modified open cycle strategy. We make these observations regarding chemical consistency and complexity. (Other observations are in later "topics" in the summary.)

d. Thus, the impurity level in uranium feedstock as a function of U235 enrichment has a spike at NU (impure), pure both above and below $0.71 \% \mathrm{U}-235$. 
- The definition and assessment of "minimum fuel treatment" must reflect both separation and subsequent fuel fabrication. For example, current TRISO fuel fabrication involves a dissolution step, apart from whether or not separation of used fuel is the source of the feed material.

- All fuel treatment methods (even minimum fuel treatment) have some chemistry associated with them, i.e., oxidation reactions to enable separation due to the variable volatilities among different chemical species in AIROX. Chemistry includes physical chemistry such as volatility as well as redox and solution chemistry.

- Elements that are not specifically limited in the current fuel impurity limits may need to be reconsidered if the program is to consider minimum fuel treatment options. For example, the only limits on noble metals - ruthenium, rhodium, palladium, silver, rhenium, osmium, iridium, platinum, gold - are for oxide fuels, specifically ruthenium for fissile displacement, and silver for undesirable oxides and fissile displacement. Minimum fuel treatment options typically do not remove noble metals. Thus, the question arises: would minimum fuel treatment approaches put so much noble metal content in oxide or metal fuels as to cause a problem? Or, would other hard-toseparate materials continue to be the limiting elements?

- The reasons for working limits on impurities in oxide and metal fuel feedstock include fabrication difficulties, formation of oxides/intermetallics, attack on fuel cladding, displacement of fissile content, and neutron absorption. If the program is to consider minimum fuel treatment options, solutions will have to be considered for many of these issues for particular combinations of fuels, fabrication technology, and separation technology.

\section{Topic 2. Don't forget the uranium}

Figure S-2 illustrates the basic mass flows in our analysis. It is the simplest framework on which we could base our analysis. Several user-defined inputs were fixed for the initial analysis - on technologies and parameter ranges for which we had the most knowledge and for which individual parts of the calculation could best be validated. The incoming used fuel is always LWR UOX-51 in this report. Separation of used UOX-51 starts a recycle loop with a fast reactor, which is always a fast reactor with a transuranic conversion ratio of 0.50 in this report. FIT will enable work on other cases.

e. AIROX does not remove the lanthanides, but it does remove $100 \%$ of the silver, so it might be expected that noble metals would not be limiting in such an approach. Melt refining (with an oxidizing crucible) does remove $\sim 95 \%$ of the lanthanides, so noble metals might be found to be limiting. 


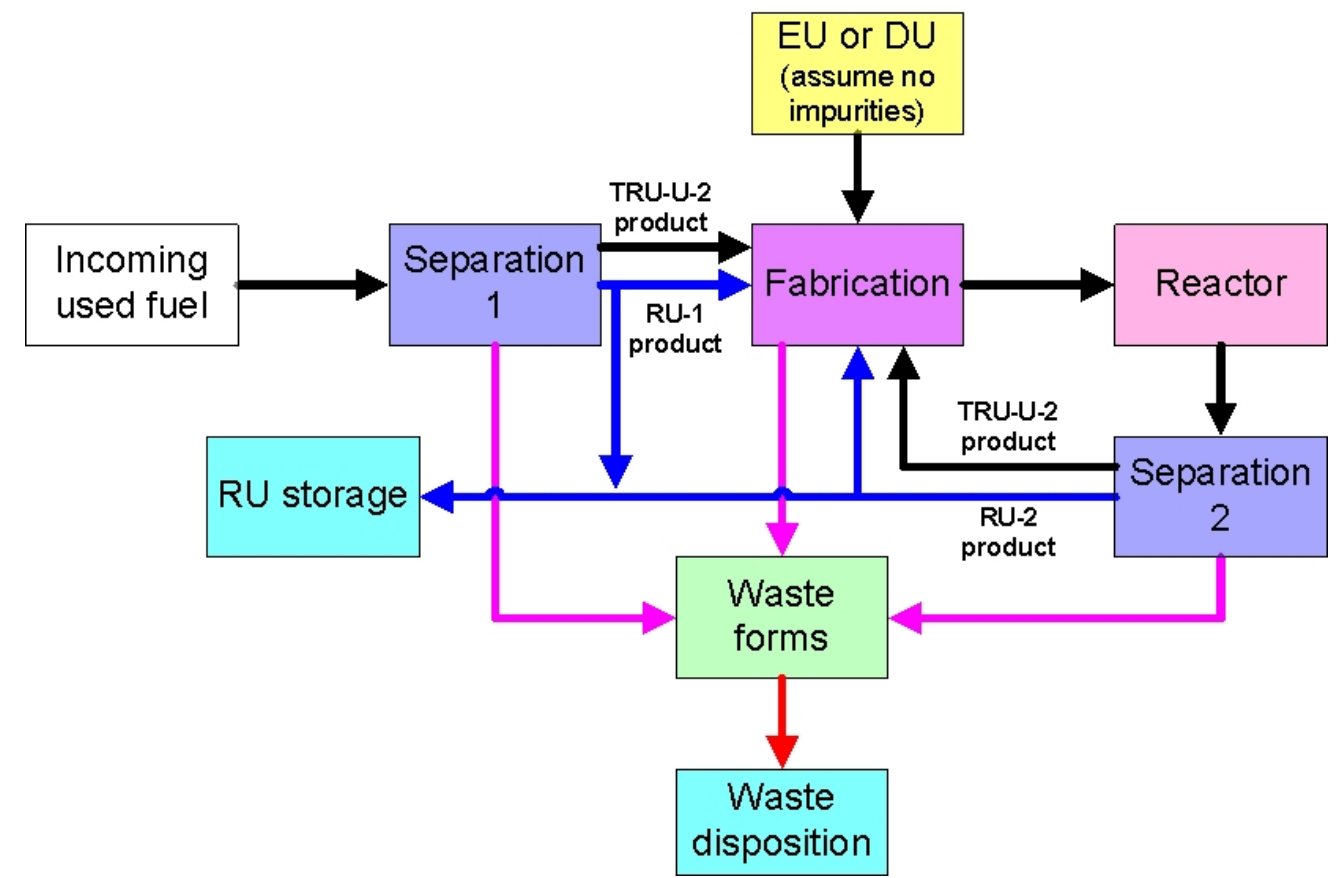

Figure S-2. Basic mass flows; our quantitative tool does not yet address EU feed as an option.

Note that separation-1 and/or separation-2 may have both a TRU-U product and a recovered uranium (RU) product. Fundamental reactor physics indicates that when recycling, there is excess uranium if the transuranic conversion ratio is less than 1 (i.e. burner reactors). If instead the reactor in the recycle loop is a breeder, the incoming feed does not have to be used fuel, it can be any type of uranium; we did not consider breeder reactors in our quantitative analyses.

Said another way, for burner reactors, there is always excess uranium. Therefore, in general, either RU-1 or RU-2 (from separation-1 and separation-2, respectively) must be non-zero so that excess uranium can be extracted from the system, i.e., either separation 1 or separation 2 must provide some degree of separation of $U$ from TRU. To use a separation technique that does not separate $U$ from TRU (AIROX, melt refining, etc), one of the following must be true.

1. The fuel is used in a reactor that requires less "octane" than where the TRU-U came from, e.g., used LWR is taken to the more neutron-efficient heavy water reactor (HWR).

2. A separate source of high "octane" $U$ or TRU is added to the TRU-U stream, requiring either high enriched uranium or some new source of TRU. This would be physically easy to do with melt refining; it is not so obvious how to do with AIROX.

3. It's a breeder reactor, in which case the incoming mass can be any uranium once in the "breeder" recycling loop. We mention this option for completeness, neither FIT nor our analyses to date have considered breeder reactors.

There are three ways to adjust the "octane" of nuclear fuel to make it strong enough (but not too strong) for use in a given reactor - uranium enrichment, TRU:U ratio, and adjusting the composition of minor actinides ( $\mathrm{Np}, \mathrm{Am}, \mathrm{Cm}-\mathrm{Bk}-\mathrm{Cf}$ ) versus plutonium. This study only used the TRU:U ratio as the

At the first iteration loop, there is no RU-2. Thus, AIROX and melt refining cannot be used on used LWR UOX-51 fuel if the product is intended for any reactor in which the TRU content is higher than the $1.3 \%$ TRU in used UOX-51, which includes all MOX or inert fuel matrix options in an LWR or HTGR, or any fast reactor previously studied. The only option would appear to be an HWR. 
AIROX and melt refining can be used in the recycle loop until impurities accumulate to a level such that adding the incoming fuel (with relatively low impurities) will not keep the recycling mass critical. Our rough estimate is that 3 recycles may be possible (the first recycle from used UOX-51 via UREX +1 plus two more with either AIROX of melt refining) provide that impurity-tolerant fuels are used.

Uranium must also be considered as a potential source of impurities. The 2009 Fuel Campaign working limits on TRU feedstock into fast reactor recycling was based on a particular fast reactor conversion ratio (hence TRU:U ratio of fresh fuel) and on assuming pure uranium feedstock such as depleted uranium. However, there are three good reasons why recovered uranium must be considered an option. First, if recovered uranium is not used, it must be stored (for eventual use in breeder reactors) or disposed; both have costs. Second, there are proliferation resistance motivations to keep as much uranium with TRU as possible, per assessment in some methodologies. That effectively means that at least some of the uranium in the fuel is RU, not DU. Third, in some technological options, separating U from TRU can imply increased cost.

So, our analysis considered both "DU feed" and "RU feed" cases. In the current separation flowsheets for UREX +1 and electrochemical separation, not only do the RU streams have impurities, but for some elements, they are higher than the TRU-U product stream. 


\section{Topic 3. The full recycle strategy requires ...}

Losses of waste elements into fuel must be such that the impurity limits are met for whatever fuel technology and performance levels are established. The new tool FIT allows estimation of the impurity concentrations, constrained only by mass balance and the requirement that the reactor in the recycling loop has fuel with estimated criticality (by 1-group cross section approximations) to match that of the original pure fuel specification.

Figure S-3 shows an example - the estimated lanthanide impurity in oxide fuel with DU feed, with RU feed, or AIROX treatment of used FR fuel. In all cases, UREX+1a is assumed for used UOX-51 fuel separation. FIT cannot provide a direct estimate of individual lanthanide elements to compare with the limits of $660 \mathrm{ppm}$ for the lowest-atomic-number lanthanides, lanthanum, cerium, praseodymium, neodymium, and samarium (the first lanthanides minus promethium, which does not occur in nature) and $132 \mathrm{ppm}$ for the later lanthanides, samarium, europium, gadolinium, and dysprosium (some but not all of the rest of the lanthanides). Instead, FIT estimates the total lanthanide impurity level, a reasonable approximation given the relative abundances from fission. The figure indicates that the lanthanide impurity limits are met for the working UREX+1a separation factors. The "AIROX" case uses UREX+1 separation for used UOX-51, thus, recycle-1 is the same as the "RU feed" case. Thereafter, the inability of AIROX to separate lanthanides from TRU cases the lanthanide content to increase rapidly. The total impurities reach $\sim 13 \%$ of fuel after two AIROX recycles (hence recycle number 3 ). Thereafter, our approximations indicate the fuel cannot be blended and remain adequately critical.

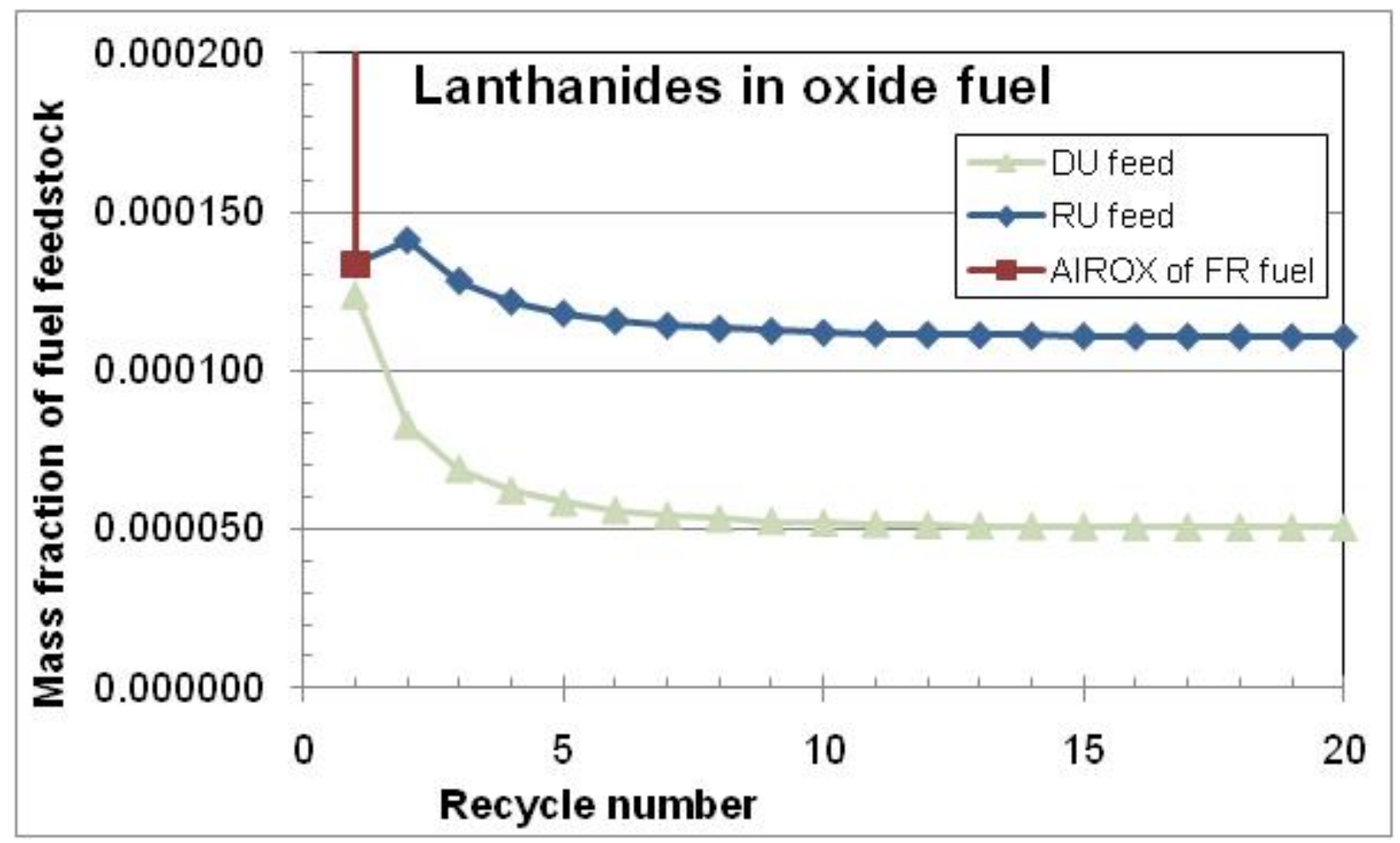

Figure S-3. Estimated lanthanide impurity in oxide fuels for fast reactor TRU CR=0.5.

Figure S-4 shows the same type of graph for metal fuels. Used UOX-51 is assumed separated by $\mathrm{UREX}+1 \mathrm{a}$ as in the previous example, but used fast reactor fuels are assumed separated by either electrochemical (in the "DU feed" and "RU feed" cases defined as in the previous example) or melt refining. The carryover of lanthanides into recovered uranium in electrochemical separation is at or 
below detection limits, therefore we have assumed in this calculation that only $0.1 \%$ of the lanthanides are in the RU stream. The low lanthanide impurity in the RU stream results in the "RU feed" case being only slightly higher than the "DU feed" case, unlike the previous example.

Because the electrochemical separation factors for the TRU-U product are still being determined, a conservative $5 \%$ of the lanthanides are assumed to be going into that product. This conservatism leads to exceeding the current 775-ppm working limit on lanthanides assumed for metal fuel. The little information available on melt refining indicates $\sim 99 \%$ removal of lanthanides. If true, the separation of lanthanides from TRU would be better than that in electrochemical; this causes the low lanthanide impurity for the melt refining case in the figure. The inability of melt refining to remove other impurities leads to the total impurity level to reach $\sim 8 \%$ after the third recycle (one from UREX +1 feed and two with a mix of UREX +1 and melt refining feed). At this point, FIT model indicates that the reactor core cannot be made critical again without abandoning the limited separation strategy. The available feed streams cannot be blended to make a fuel with reactivity equal to that of the original fuel recipe.

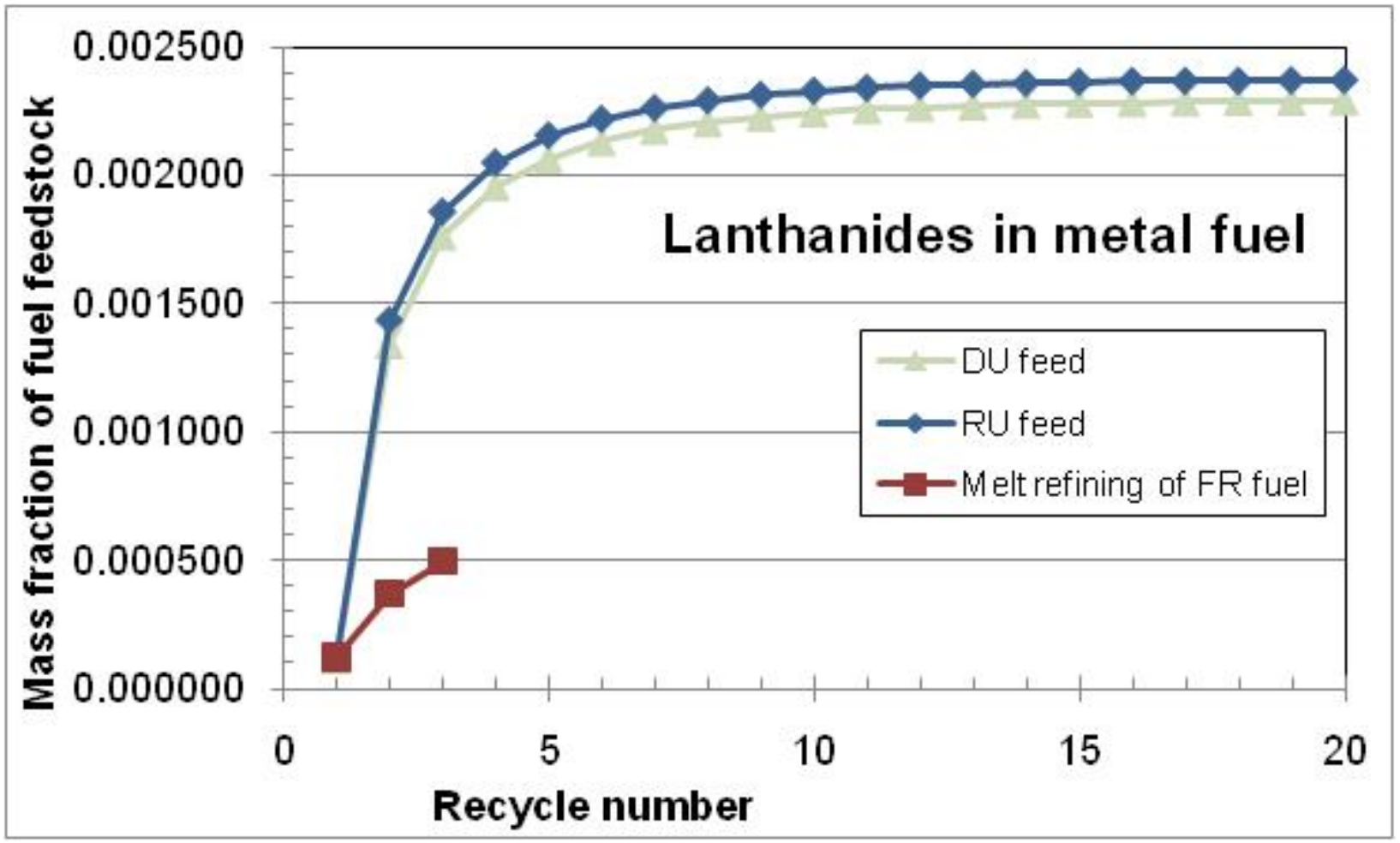

Figure S-4. Estimated lanthanides in metal fuels for fast reactor transuranic conversion ratio of 0.5 .

For sustained recycle, the following conclusions and observations can be drawn for the cases we analyzed - fast reactors at transuranic conversion ratio of 0.5 fed by separated used UOX-51 fuel. The results will of course change for other sets of parameters. Nonetheless, they do suggest increased attention to transition metals, in addition to the issue of lanthanides identified by the team in 2009 .

- Lanthanides - these are a potential problem in metal fuel with the assumed conservative working electrochemical separation values; the lanthanide impurity limit is met for oxide fuel with UREX+1 separation.

- Alkali metals (Group 1), only limited for oxide fuels - apparently met with working UREX+1a separation values. 
- Alkaline earth metals (Group 2), only limited for oxide fuels - met with working UREX+1a separation values.

- Molybdenum (metal) / molybdenum plus silver (oxide) - In both metal and oxide fuels, these elements are part of a group transition metal limit that contain potential impurities that are not fission products and therefore not addressed in this report. Thus, it is particularly worrisome if the fission product impurities alone exceed the working limits. This appears in the oxide/UREX +1 a system for the set of working separation factors. However, as explained in more detail in Section 4, all calculations involving transition metals are particularly uncertain. ${ }^{\mathrm{f}}$

- Ruthenium (only limited for oxide) - our first rough estimate for this transition metal shows its working limit is exceeded. However, this limit is apparently based solely on displacement of fissile content, so it may be too restrictive.

- Cadmium (metal) / cadmium plus tin (oxide) - In both metal and oxide fuels, these elements are part of a group transition metal limit, with both fission product and non-fission product elements. The estimated values for oxide exceed the working limit, but these estimates must be considered very uncertain because of the current approximations in FIT involving transition metals.

- Halogens - impurity limits appear easily met for both oxide and metal fuels.

- There are many elements that we estimate to have impurity levels in the range of 1 to $2000 \mathrm{ppm}$, see Tables 4-3 and 4-5. Are these acceptable?

In short, transition metal behavior in separations, tolerance in fuels requires, and analysis in FIT requires substantially more work.

\section{Topic 4. The modified open cycle strategy requires ...}

Assuming the modified open cycle strategy includes "minimum fuel treatment" options such as AIROX or melt refining, the fundamental need to make MOC options attractive are impurity-tolerant fuels and either the use of reactors that require lower TRU enrichment than used UOX-51 (1.3\% TRU) or a way to increase the reactivity of fuels made with minimum fuel treatment via addition of enriched uranium.

Fundamentally, high-impurities are analogous to extra long-life (extreme burnup) in that more unfissionable material accumulates in in-service fuel. Therefore, research and development (R\&D) thrusts like impurity-tolerant fuel matrices and clad coatings that protect against impurities may enable minimum fuel treatment and/or extreme burnup. Note that the Fuels Campaign seeks to determine how impurities generated during irradiation behave versus how impurities residual after separations behave.

The FY 2009 losses study report had an example. The underlying working explanation is that there may be two sets of lanthanide impurities, one mobile and one less mobile. Impurities in fuel feedstock when it is made into fuel are considered relatively mobile and concentrated and therefore likely to attack cladding. Impurities generated during fuel irradiation are considered relatively immobile as their original matrix was not disturbed. That is, the lanthanides limited to $4,000 \mathrm{ppm}$ are implicitly assumed to have been liberated from the microstructure in which they were created in a previous irradiation. This was the explanation for the 4,000-ppm limit on lanthanides as a processing impurity versus 40,000-ppm lanthanide generated during fuel irradiation.

The potential question for some types of "minimum fuel treatment" such as AIROX is whether residual impurities would behave more like high-impurity processing impurities (analogous to the 4,000-ppm limit) or more like in-situ generated impurities (analogous to the 40,000-ppm generated during

f. The working metal fuel limits to include molybdenum; we are aware that there is interest in using molybdenum as a metal fuel alloying agent, suggesting that the Mo limit may be incorrect. 
irradiation). This of course depends on how species and structure change during the candidate fuel treatment method. 


\section{Topic 5. More complete disassembly of used fuel would have advantages, and costs.}

The working fraction of input TRU thought to be in undissolved fuel solids in UREX +1 is considered to be $1 \%$. This is a factor of 10 higher than the $0.1 \%$ assumption in the 2008 DSARR report. And, the $0.1 \%$ value was to represent all losses of TRU into waste, separation, undissolved solids, and fuel fabrication.

The working fraction of input TRU thought to be in cladding or disposed salt in electrochemical separation is thought to be $0.7 \%$ to cladding and $0.1 \%$ to salt; again, an order of magnitude higher than the 2008 assumption.

The 2008 assumption of $0.1 \%$ is, of course, not a requirement nor even a guideline. But, the generally attractive waste management results of that study do depend on it. The working values of $1 \%$ and $0.8 \%$ $(0.7 \%+0.1 \%)$ could be lowered by new advances or changes in technology, such as a dissolution of undissolved solids by hydrofluoric acid, with corresponding costs and complexity. The details of such changes are beyond the scope of this report.

Other "solids" include cladding or fuel coatings. As discussed in Section 4, several of the working impurity limits in oxide or metal fuel pertain to the impact on cladding, not the fuel matrix itself. This must be remembered as alternative cladding/coatings are considered. For example, use of a more resistant coating/cladding can loosen working impurity limits. Consideration of a new coating/cladding should include its potential compatibility issues with fuel matrix plus fuel's likely impurities. For example, palladium is an issue in HTGR fuels due to attack on SiC. That would seem to be an issue if $\mathrm{SiC}$ is considered as a cladding option on other fuels at similarly high operating temperatures. This example is more relevant for TRU-based fuels than U-based fuels because the fission product yield for Pd is higher with Pu239 fission than U235 fission.

Meanwhile, it has come into sharper focus that more analysis is required of mass discharged from the reactor other than the fuel meat itself, such as cladding and fuel assembly structure. For example, in the case of HTGRs, there is the TRISO coating, carbon binder, and graphite blocks. These must be managed in some fashion: disposed directly with used fuel, separated from used fuel and disposed separately, or recycled. Figure S-5 shows the composition of used fuel assembly mass for a range of concepts. Although this report is limited to only the fuel meat, we call attention to the broader problem is managing the non-fuel masses denoted in the figure.

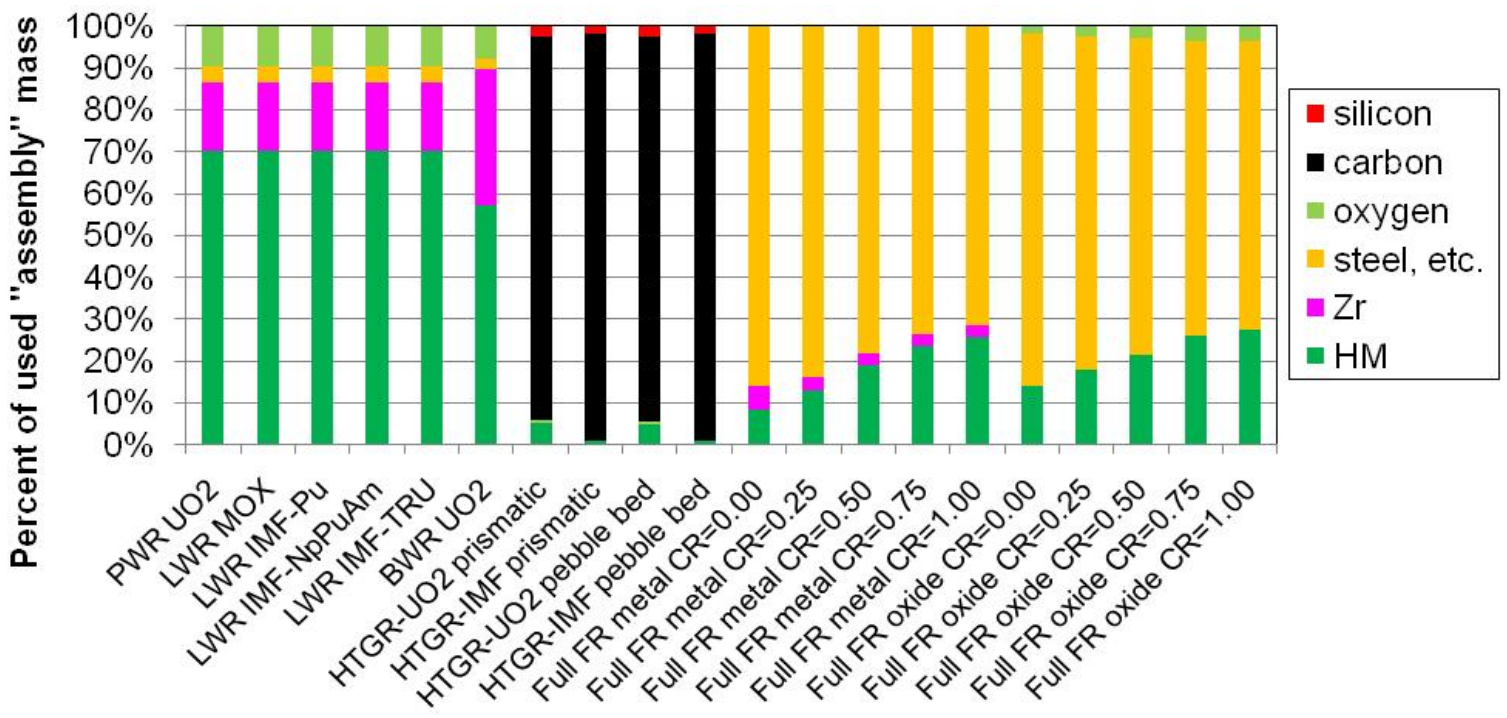


Figure S-5. Composition of used fuel assembly masses for a range of concepts. 


\section{Topic 6. Broad R\&D Questions}

Finally, we can identify broad R\&D needs, summarized in Table S-1. Detailed R\&D questions are found in Sections 4 and 5. As an example of broad R\&D topics, consider the third R\&D need in the table, to obtain separation factor details for a wider range of elements. Compare which elements are limited as impurities in the TRU feed stream for fuel fabrication (Section 2.3) versus which elements' separation factors are known for separation methods (Section 2.4). Even for conventional separation methods, there are impurity-limited elements for which we lack separation factors; perhaps these elements are indeed unimportant but it seems unusual that an element is limited in the separation product (fuel impurity) without knowing how that element behaves in the separation process. In addition, if the program now emphasizes minimum fuel treatment options, they would result in higher impurities of more elements in fuels so that more separation factors will be need to be studied.

More fully quantifying the chemistry for different separation techniques has several potential benefits. First, it may provide a basis for initial estimation of separation of elements for which there currently are no data. Second, a better definition of the relative importance of different elements among the full range of issues (fuel fabrication difficulties, cladding attack, etc.) provides a solid foundation for potentially modifying and combining parts of separation approaches (e.g., voloxidation with melt-refining). Third, proliferation risk assessments must not only consider a facility as designed, but also how a facility may be modified. That is, from chemical principles, a given approach such as volatility can separate some elements but not others. A facility designed to use a gas-phase process may not be particularly suited to for liquid separations that may be required for certain elemental separations. However, a facility designed to use volatility as one step in a series of separations may be changed to operate under conditions that differ from those for which it was initially designed. These matters are likely to become more important as the program considers minimum fuel treatment possibilities. 
Table S-1. High-leverage R\&D needs motivated by analyses to date.

\begin{tabular}{|c|c|}
\hline High-leverage common R\&D need & Explanation \\
\hline $\begin{array}{l}\text { Recycle fuels and reactor designs } \\
\text { that tolerate high levels of fission } \\
\text { products and other impurities in the } \\
\text { recycled feedstock. }\end{array}$ & $\begin{array}{l}\text { Either "minimum fuel treatment" approaches or ultra-high fuel } \\
\text { residence time (extreme burnup or battery reactors) increase } \\
\text { non-fuel material accumulation in in-service fuel. So, R\&D } \\
\text { thrusts like impurity-tolerant fuel matrices and clad coatings } \\
\text { that protect against impurities may enable minimum fuel } \\
\text { treatment and/or extreme burnup. }\end{array}$ \\
\hline $\begin{array}{l}\text { Fuel fabrication } R \& D \text { to better } \\
\text { define fuel impurity limits for } \\
\text { relevant fuel type options for a wider } \\
\text { range of chemical elements. }\end{array}$ & $\begin{array}{l}\text { The tolerable level of impurities are not always known for } \\
\text { elements reasonably expected to be present in recycle } \\
\text { materials, especially if minimum fuel treatment approaches are } \\
\text { used. This inhibits a comprehensive system analysis. }\end{array}$ \\
\hline $\begin{array}{l}\text { Separations } R \& D \text { to better define } \\
\text { and improve separations factors for } \\
\text { relevant options for a wider range of } \\
\text { chemical elements. }\end{array}$ & $\begin{array}{l}\text { The separation factors are not always known for elements that } \\
\text { are constrained in TRU product (impurity limits) or waste } \\
\text { forms (e.g., constraining the waste loading in glass). This } \\
\text { inhibits a comprehensive system analysis. }\end{array}$ \\
\hline $\begin{array}{l}\text { Waste management options designed } \\
\text { to lower waste disposal cost, reduce } \\
\text { waste radiotoxicity and dose, } \\
\text { increase waste form and disposal site } \\
\text { integrity (reduce heat), and better re- } \\
\text { use valuable fertile and fissile } \\
\text { materials. }\end{array}$ & $\begin{array}{l}\text { Truly taking advantage of recycling to reduce waste } \\
\text { management burdens and costs requires moving from a } \\
\text { prescriptive source-based definition of HLW to one based on } \\
\text { waste characteristics. If so, in the bounding case of several } \\
\text { separation steps and intermediate waste classification, creation } \\
\text { of HLW could conceivably be eliminated. }\end{array}$ \\
\hline $\begin{array}{l}\text { Analysis tools and methods that } \\
\text { allow comprehensive and systematic } \\
\text { examination of the disposition } \\
\text { options of all radioactive materials } \\
\text { (recycle, waste, etc.). }{ }^{\text {. }}\end{array}$ & $\begin{array}{l}\text { The central challenge of the discharge side of nuclear fuel } \\
\text { cycles: how can active radioactive materials "in service" be } \\
\text { dispositioned, what options exist for the system and the } \\
\text { individual technologies, how should those options integrate } \\
\text { with each other, when and for how long can materials be } \\
\text { recycled, what fraction of material should be disposed while } \\
\text { recycling occurs (i.e., what are the best disposition options)? }\end{array}$ \\
\hline
\end{tabular}

g. Example questions for oxide fuels: Are the two different sets of separation transition metal limits (titanium, vanadium, manganese, cobalt, copper, molybdenum, silver, tantalum, tungsten $=2000 \mathrm{ppm}$ and chromium, iron, nickel $=1500 \mathrm{ppm}$ ) required to be different? Are there limits for rubidium, cesium, and strontium as there are for other Group 1 and Group 2 elements? As the noble metals limited; minimum fuel treatment options tend not to remove them. Since zinc, cadmium, tin, and lead are limited, what about indium, which lies in-between? It would be easier if there was a single limit covering all the lanthanides, would this fit the data? Example questions for metal fuels: Some transition metals are limited, what about the others? Are the noble and other metals limited? Metalloids?

h. It is important to have better aqueous and non-aqueous process separation factor data on the impurities that impact fuels recycle and waste management. Other than uranium, plutonium, neptunium, from FP, lanthanides and actinides (together), all well-known separation factors from actual PUREX production scale processing, and all our other data comes from laboratory batch or very small scale process experiments. The FIT model will need to be validated with data from pilot processing experiments before it is able to reliably discriminate between alternatives. Pilot scale experiments on each new fuel cycle process are thus required.

i. Higher-level questions include: minimizing the amount of separations that may be needed (e.g., fuel cycles that need little or no separation [i.e. minimum fuel treatment]) and a simplified processing flow sheet is better than a very complex one that may require multiple separations. Lower-level questions include: development of near real-time sampling and analytical results to support process control and accountability; improvements in integrated process control systems relative to things like security, automated corrective action responses, preventive maintenance alerts, etc. 
Losses Study

September 15, 2010 
This page intentionally left blank. 


\section{CONTENTS}

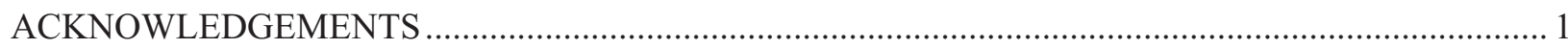

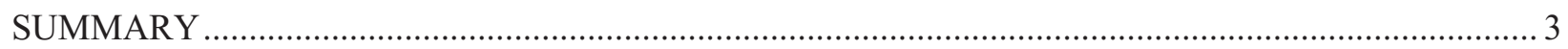

Topic 1. The R\&D program must improve chemical completeness and consistency ...................... 5

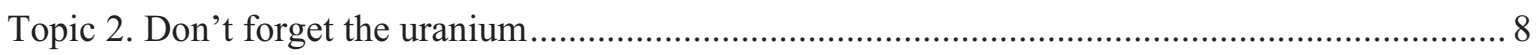

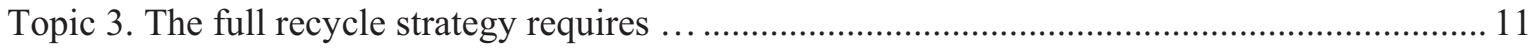

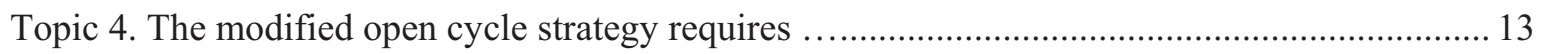

Topic 5. More complete disassembly of used fuel would have advantages, and costs. .................. 15

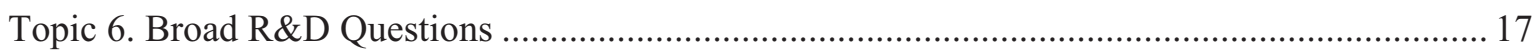

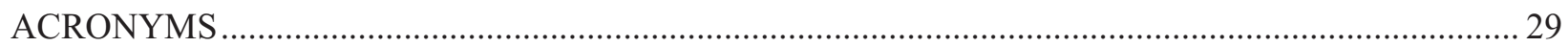

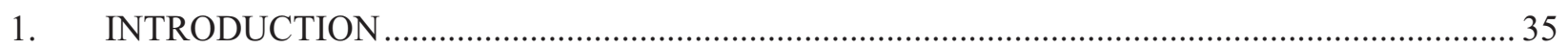

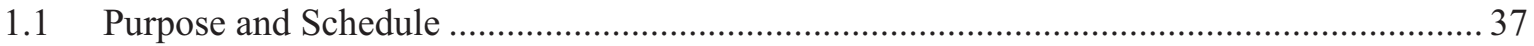

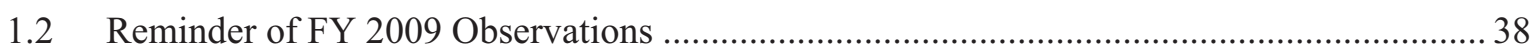

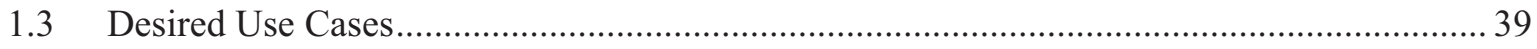

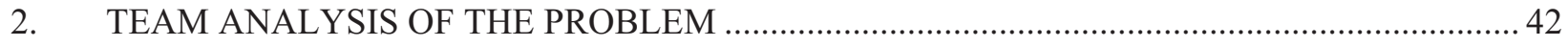

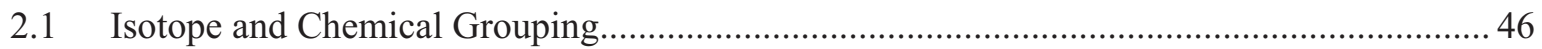

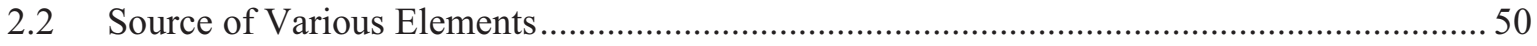

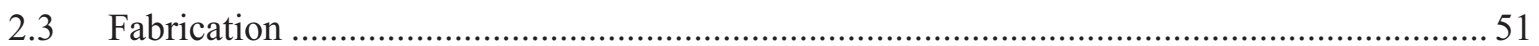

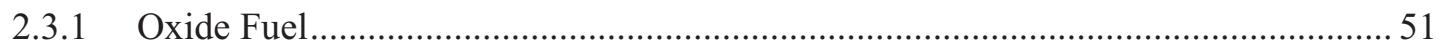

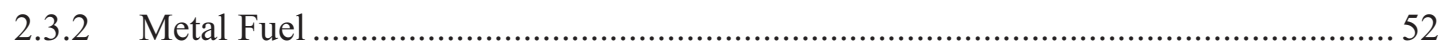

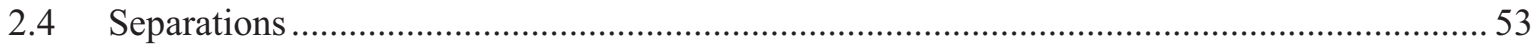

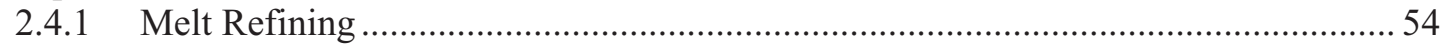

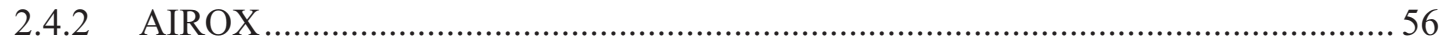

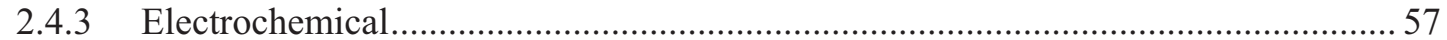

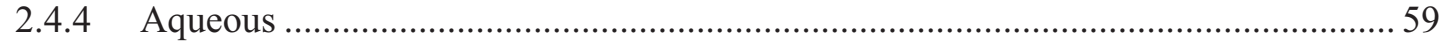

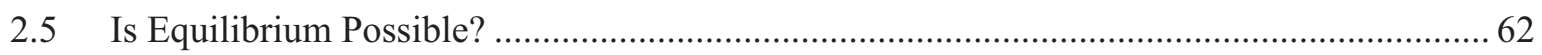

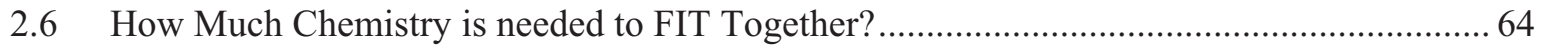

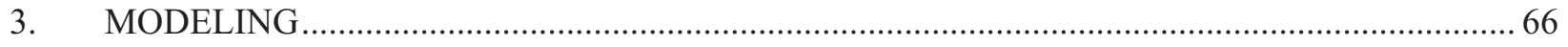

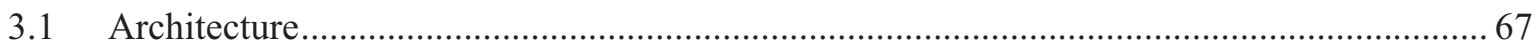

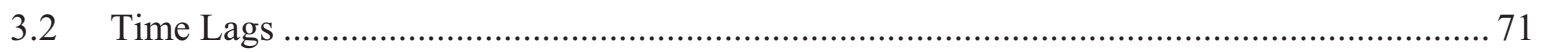

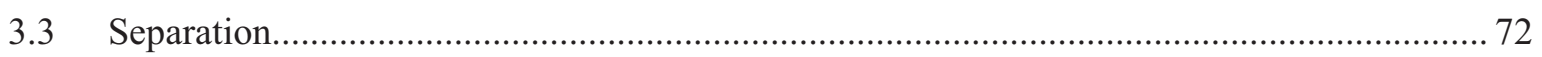

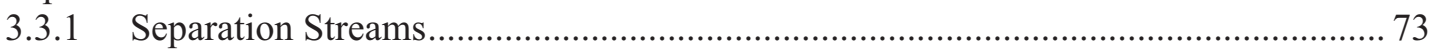

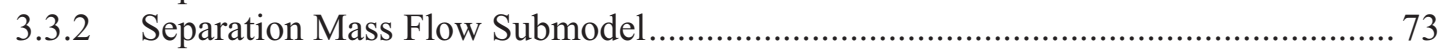

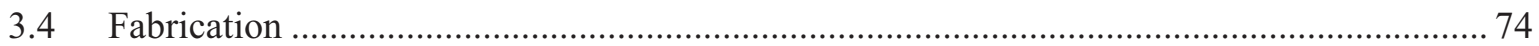

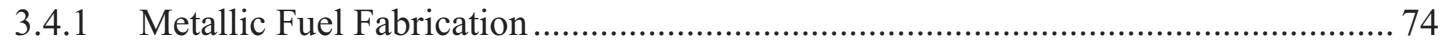

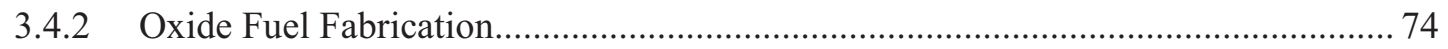

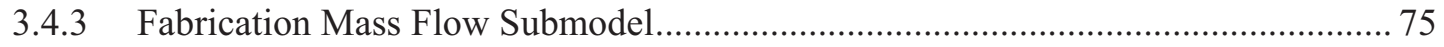

3.4.4 Future Additions to Fuel Fabrication Modules ....................................................... 77

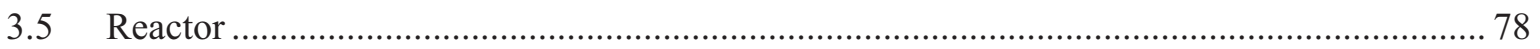




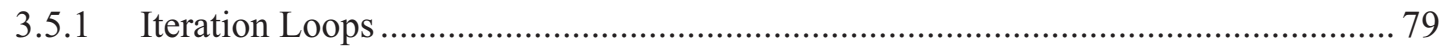

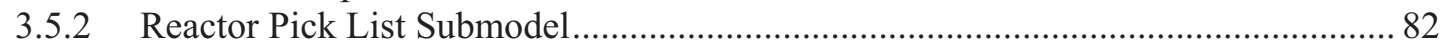

3.5.3 Fuel Composition Adjustment and Blending (Winery) Submodel ............................. 82

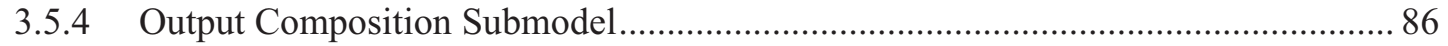

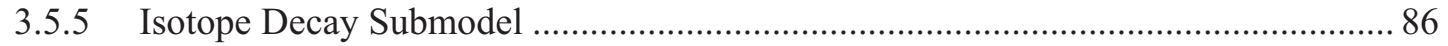

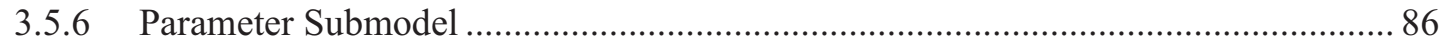

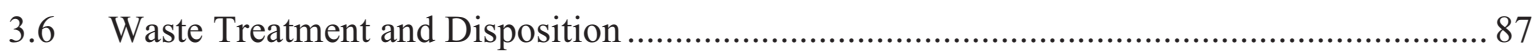

4. RESULTS

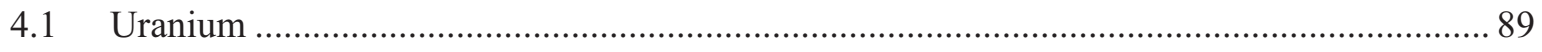

4.2 Additional Explanations That Help Clarify Results....................................................... 90

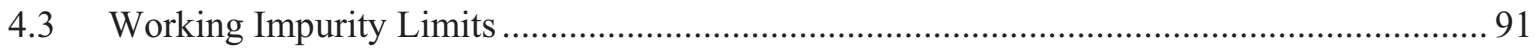

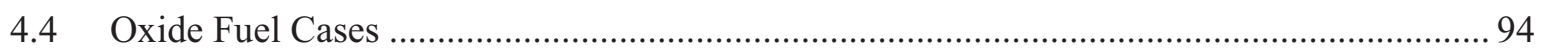

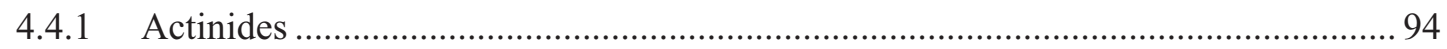

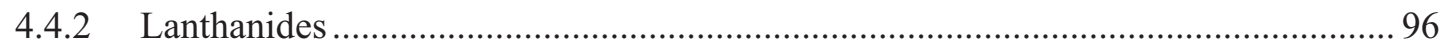

4.4.3 Alkali (Group 1) and Alkaline Earth (Group 2) Metals ........................................ 97

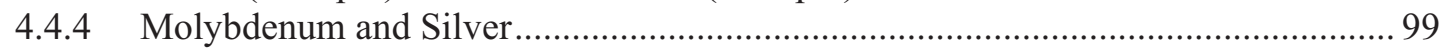

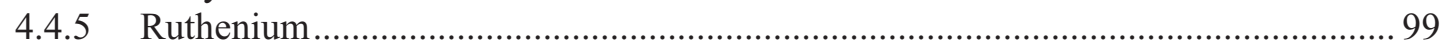

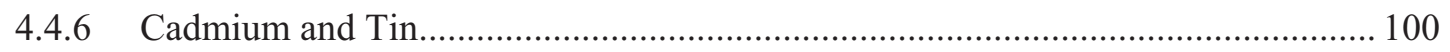

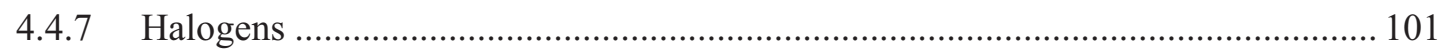

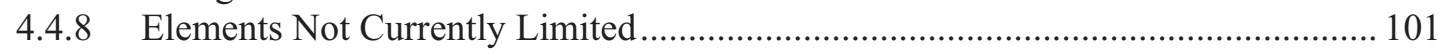

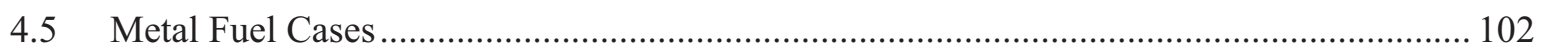

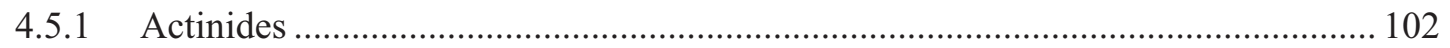

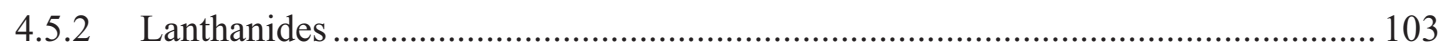

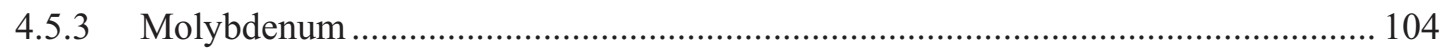

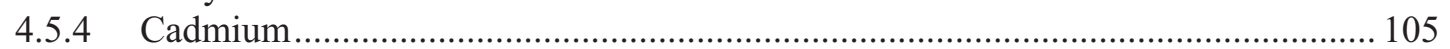

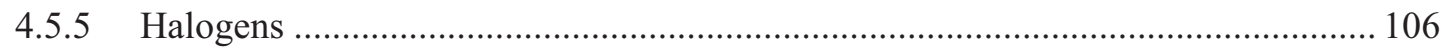

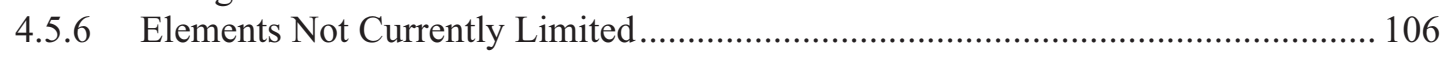

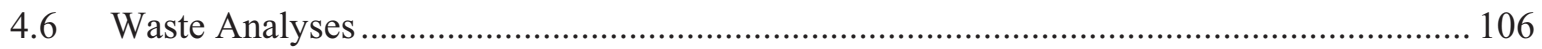

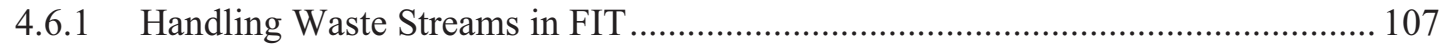

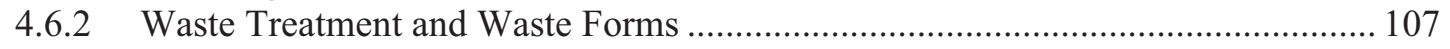

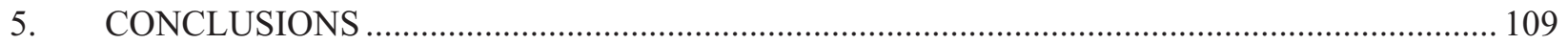

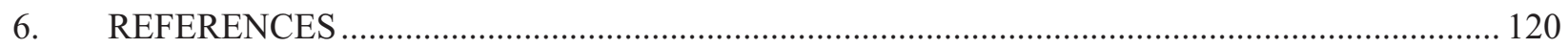

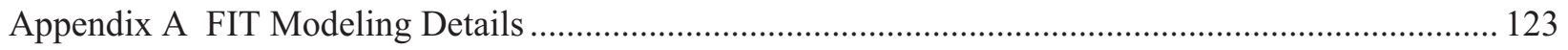

Appendix B Software Requirements Document for FIT ….............................................................. 131

Appendix C Equations for Time-Dependent Parameters ............................................................... 151

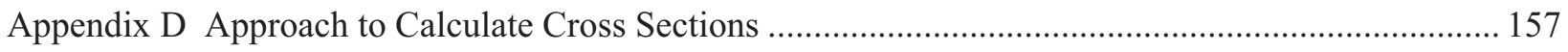

Appendix E Justification for Time-Independent Cross Sections ....................................................... 161 


\section{FIGURES}

Figure S-1. Central challenge of the downstream side of nuclear fuel cycles ........................................ 4

Figure S-2. Basic mass flows; our quantitative tool does not yet address EU feed as an option................9

Figure S-3. Estimated lanthanide impurity in oxide fuels for fast reactor TRU CR=0.5 ...................... 11

Figure S-4. Estimated lanthanides in metal fuels for fast reactor transuranic conversion ratio of

0.5 . 12

Figure S-5. Composition of used fuel assembly masses for a range of concepts. .................................. 16

Figure 2-1. Current chemical grouping of the Periodic Table for FIT purposes...................................... 49

Figure 2-2. Preliminary chemical grouping of the Periodic Table, showing individual elements...............50

Figure 2-3. Potential sources of elements; solvents and working fluids are not shown........................ 51

Figure 2-4. Working Fuel Campaign limit on TRU feedstock for oxide fuel (ppm).................................52

Figure 2-5. Working Fuel Campaign limit on TRU feedstock for metal fuel (ppm) ................................ 53

Figure 2-6. Separation figure illustrating melt refining-raw data only; values for actinides are percent recovered as product; values for everything else are percent removed from fuel product. 55

Figure 2-7. Separation figure illustrating melt refining; values for actinides are percent recovered as product; values for everything else are percent removed from fuel product...... 56

Figure 2-8. Separation figure illustrating AIROX. Values for actinides are percent recovered as product, values for everything else are percent removed from fuel product.

Figure 2-9. Used fuel components separated via free energy of formation at $500^{\circ} \mathrm{C}$. 58

Figure 2-10. Separation figure illustrating electrochemical separation. Values for actinides are percent recovered as product, values for everything else are percent removed from fuel product. 59

Figure 2-11. Separation figure illustrating aqueous separation. Values for actinides are percent recovered as product, values for everything else are percent removed from fuel product. 60

Figure 2-12. Number of recycles required to reach $90 \%$ of equilibrium. 63

Figure 2-13. Fraction of fuel that is impurity for a range of separation efficiencies. 64

Figure 2-14. Chemical complexity. 65 


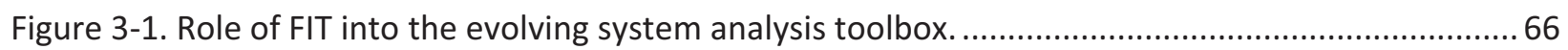

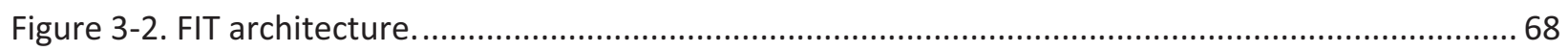

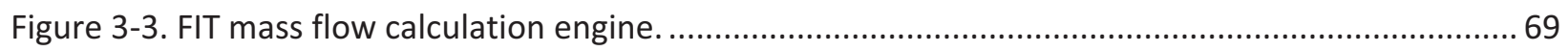

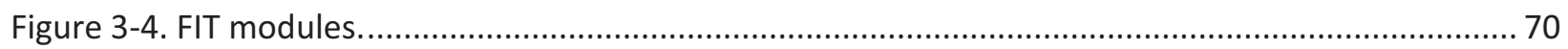

Figure 3-5. Technological choices (green) and information flows (red) overlaying mass flows

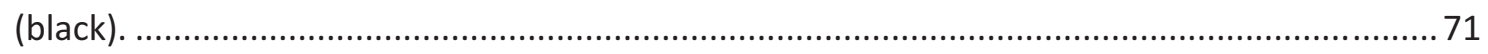

Figure 3-6. Screen capture of fabrication mass flow submodel summary sheet. ................................... 76

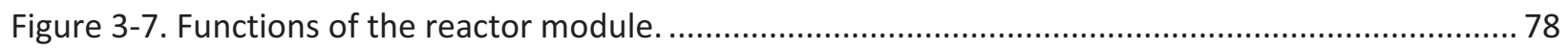

Figure 3-8. Mass flows showing possible feeds into fuel fabrication. .................................................... 79

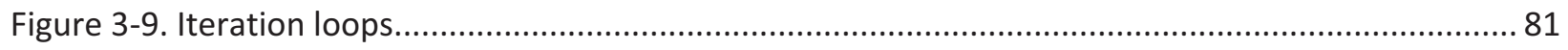

Figure 4-1. FIT infrastructure showing the types of data and calculations involved.............................. 88

Figure 4-2. Fraction of recovered and depleted uranium used at equilibrium in a system of used

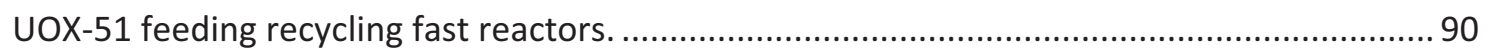

Figure 4-3. Estimated actinide composition in oxide fuels for fast reactor with TRU CR=0.5................95

Figure 4-4. Estimated composition of oxide fuels for fast reactor TRU CR=0.5 with AIROX treatment of used FR fuel and UREX+1 treatment of used UOX-51 fuel. ................................96

Figure 4-5. Estimated lanthanide impurity in oxide fuels for fast reactor TRU CR=0.5 ......................97

Figure 4-6. Estimated Group 1 and Group 2 impurities in oxide fuels for fast reactor TRU CR=0.5. ........98

Figure 4-7. Estimated molybdenum and silver in oxide fuels for fast reactor TRU CR=0.5; uncertainties are high.

Figure 4-8. Estimated ruthenium in oxide fuels for fast reactor TRU $C R=0.5$; uncertainties are high. 100

Figure 4-9. Estimated cadmium and tin in oxide fuels for fast reactor TRU $C R=0.5$; uncertainties are high. 101

Figure 4-10. Estimated actinides in metal fuels for fast reactor transuranic conversion ratio of 0.5 . 103

Figure 4-11. Estimated composition of oxide fuels for fast reactor TRU CR=0.5 with AIROX treatment of used FR fuel and UREX+1 treatment of used UOX-51 fuel. 103 
Figure 4-12. Estimated lanthanides in metal fuels for fast reactor transuranic conversion ratio of

0.5 . .104

Figure 4-13. Estimated molybdenum in metal fuels for fast reactor transuranic conversion ratio of 0.5 ; uncertainties are high. 105

Figure 4-14. Estimated cadmium in metal fuels for fast reactor transuranic conversion ratio of 0.5 ; uncertainties are high. 106

Figure 5-1. Central challenge of the downstream side of nuclear fuel cycles 110

Figure A-1. Flow of FIT model. 125

Figure A-2. Fuel fabrication module summary sheet...... 128

Figure B-1. Modeling pyramid diagram showing relative hierarchy of models. 134

Figure B-2. The FIT modeling domain. 135

Figure B-3. Proposed FIT variables and products/outputs. 138

Figure B-4. FIT model mass and information flow. 144

Figure B-5. Cost based on interim storage time of spent fuel before recycle. 148

Figure B-6. Waste inventory based on losses to HLW. 148

Figure E-1. Cross sections (in barns) of Group 1 as calculated by the isotope tool. 164

Figure E-2. Cross sections (in barns) of Group 2 as calculated by the isotope tool. 165

Figure E-3. Cross sections (in barns) of the lanthanides as calculated by the isotope tool 165

Figure E-4. Cross sections (in barns) of selected lanthanides as calculated by the isotope tool. 166

Figure E-5. Cross sections (in barns) of selected transition metals as calculated by the isotope tool...

Figure E-6. Cross sections (in barns) of selected transition metals as calculated by the isotope tool.

\section{TABLES}

Table S-1. High-leverage R\&D needs motivated by analyses to date.

Table 1-1. Task complexity change from FY 2009 to FY 2010. 


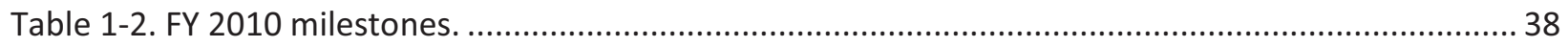

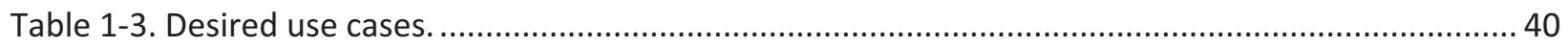

Table 2-1. Qualitative potential implications of "minimum fuel treatment" on fuel cycle components.

Table 2-2. Qualitative potential implications of "minimum fuel treatment" on fuel cycle objectives.

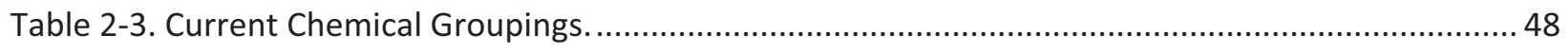

Table 2-4. Basis for separation using different techniques. ............................................................ 54

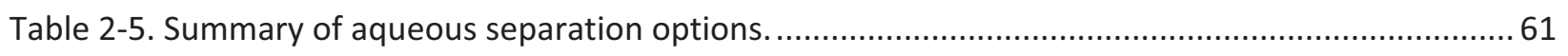

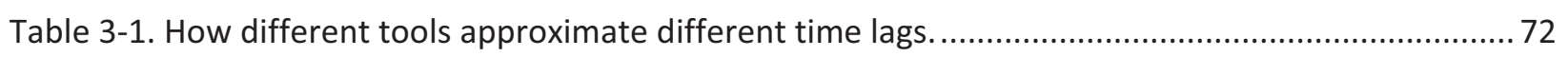

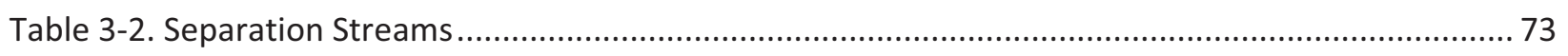

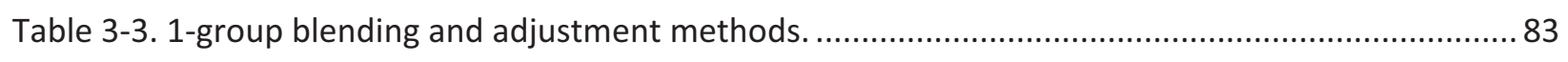

Table 4-1. Working limits for metal and oxide fuel impurities relevant to fission products.....................93

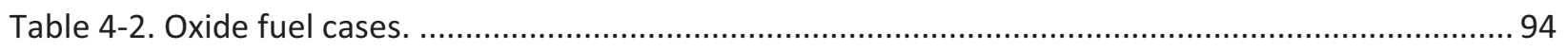

Table 4-3. Estimates of Fuel Impurities for which no oxide fuel limit exists (UREX+1 separation of

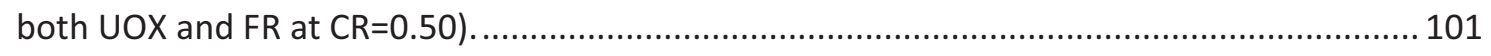

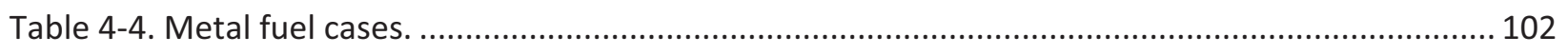

Table 4-5. Estimates of fuel impurities for which no metal fuel limit exists (UREX+1 separation of

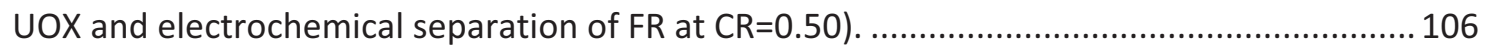

Table 4-6. Waste streams and waste forms in the FIT model. .......................................................... 108

Table 5-1. Task complexity change from FY 2009 to FY 2010........................................................... 109

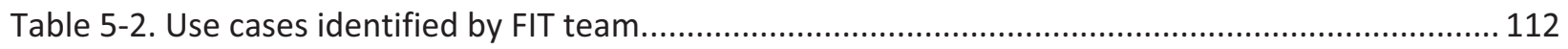

Table 5-3. Qualitative potential implications of "minimum fuel treatment" on fuel cycle components

Table 5-4. Qualitative potential implications of "minimum fuel treatment" on fuel cycle objectives. 115

Table 5-5. High-leverage R\&D needs motivated by analyses to date 116 
Table A-1. Uranium-oxide spent fuel inventory used in FIT model. .................................................... 126

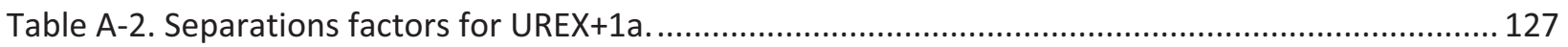

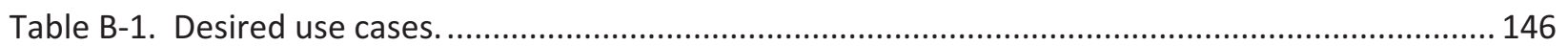


This page intentionally left blank 


\section{ACRONYMS}

\begin{tabular}{|c|c|}
\hline $\mathrm{AFCF}$ & Advanced Fuel Cycle Facility \\
\hline $\mathrm{AFCI}$ & Advanced Fuel Cycle Initiative \\
\hline $\mathrm{Ag}$ & silver \\
\hline AIROX & Atomics International reduction oxidation separation process \\
\hline $\mathrm{Al}$ & aluminum \\
\hline Am & americium \\
\hline ANL & Argonne National Laboratory \\
\hline at $\%$ & atomic percent \\
\hline $\mathrm{Bk}$ & Berkelium \\
\hline BSG & Borosilicate glass \\
\hline $\mathrm{C}$ & carbon \\
\hline CCD-PEG & cobalt dicarbollide-polyethylene glycol \\
\hline $\mathrm{Cd}$ & cadmium \\
\hline $\mathrm{Cf}$ & californium \\
\hline CFR & Code of Federal Regulations \\
\hline $\mathrm{Ci}$ & curie \\
\hline $\mathrm{Cl}$ & chlorine \\
\hline $\mathrm{Cm}$ & curium \\
\hline Co & cobalt \\
\hline COEX & Co-extraction (of uranium and plutonium) \\
\hline $\mathrm{Cr}$ & chromium \\
\hline CR & transuranic conversion ratio \\
\hline Cs & cesium \\
\hline DOE & Department of Energy \\
\hline DOT & Department of Transportation \\
\hline DP & decay product (of thorium, uranium, or TRU elements) \\
\hline DPL & Decision Programming Language \\
\hline DSARR & Dynamic Systems Analysis Report for Nuclear Fuel Recycle \\
\hline DSEF & Disposal Systems Evaluation Framework \\
\hline DU & depleted uranium \\
\hline EBR-II & Experimental Breeder Reactor-II \\
\hline Echem & electro-chemical \\
\hline
\end{tabular}




\begin{tabular}{|c|c|}
\hline ER & electro-refiner \\
\hline $\mathrm{Eu}$ & europium \\
\hline EU & enriched uranium \\
\hline FCF & Fuel Conditioning Facility \\
\hline FCR\&D & Fuel Cycle R\&D, component of FCT program \\
\hline FCT & Fuel Cycle Technology program \\
\hline $\mathrm{Fe}$ & iron \\
\hline FFP & fraction of fission product \\
\hline FFTF & Fast Flux Test Facility \\
\hline FIT & Fuel-cycle Integration and Tradeoffs \\
\hline FP & fission product \\
\hline FPEX & Fission Product Extraction \\
\hline FR & fast reactor \\
\hline FY & Fiscal Year \\
\hline GDSE & Generic Disposal System Environment \\
\hline GNEP & Global Nuclear Energy Partnership \\
\hline $\mathrm{Gr}$ & group - one of 18 columns in the Periodic Table \\
\hline GTCC & Greater-Than-Class C \\
\hline HEU & highly enriched uranium \\
\hline HEPA & high efficiency particular air, a time of high-efficiency air filter \\
\hline HLW & high-level waste \\
\hline HM & heavy metal (thorium, protactinium, uranium, or transuranics) \\
\hline HTGR & High Temperature Gas Reactor \\
\hline HWR & Heavy Water Reactor \\
\hline I & Iodine \\
\hline $\mathrm{iHM}$ & initial heavy metal, the heavy metal content prior to irradiation of fresh fuel \\
\hline INL & Idaho National Laboratory \\
\hline INEL & Idaho National Engineering Laboratory \\
\hline INEEL & Idaho National Engineering and Environmental Laboratory \\
\hline IWMS & Integrated Waste Management Strategy \\
\hline LEU & lowly enriched uranium \\
\hline LLW & low-level waste \\
\hline Ln & Lanthanide \\
\hline LWR & light-water reactor \\
\hline
\end{tabular}




\begin{tabular}{|c|c|}
\hline MB & mega bytes \\
\hline MFT & Minimum Fuel Treatment \\
\hline MIMAS & Micronization Master Blend \\
\hline MLLW & mixed low-level waste \\
\hline $\mathrm{Mn}$ & manganese \\
\hline Mo & molybdenum \\
\hline MOX & mixed oxide fuel \\
\hline MW & megawatt \\
\hline MWth & megawatt thermal \\
\hline MWe & megawatt electric \\
\hline NA & Not applicable \\
\hline $\mathrm{Nd}$ & Neodymium \\
\hline $\mathrm{NE}$ & nuclear energy \\
\hline $\mathrm{Ni}$ & nickel \\
\hline $\mathrm{Np}$ & neptunium \\
\hline NUEX & Neptunium (and Plutonium) extraction \\
\hline NU & natural uranium \\
\hline ORNL & Oak Ridge National Laboratory \\
\hline $\mathrm{Pa}$ & protactinium \\
\hline $\mathrm{Pd}$ & palladium \\
\hline ppm & parts per million \\
\hline $\mathrm{Pu}$ & plutonium \\
\hline PUREX & Plutonium Uranium Reduction Extraction \\
\hline QRL & Quality Review Level \\
\hline $\mathrm{R} \& \mathrm{D}$ & research and development \\
\hline $\mathrm{Rh}$ & rhodium \\
\hline $\mathrm{Ru}$ & ruthenium \\
\hline RU & recovered uranium \\
\hline $\mathrm{SC}$ & South Carolina, host of a low-level waste near-surface burial waste disposal site \\
\hline SFR & Sweden Final Repository for radioactive operational waste, began operation in 1988 \\
\hline SNF & Spent Nuclear Fuel \\
\hline SNM & special nuclear material \\
\hline $\mathrm{Si}$ & silicon \\
\hline $\mathrm{SiC}$ & silicon carbide \\
\hline
\end{tabular}


Sr strontium

TALSPEAK Trivalent Actinide Lanthanide Separation by Phosphoric Extractants and Aqueous Komplexes

SRS Savannah River Site

$\mathrm{t}_{\mathrm{rs}} \quad$ time from reactor discharge to separations

$\mathrm{t}_{\mathrm{sf}} \quad$ time from separations to fuel fabrication

$\mathrm{t}_{\mathrm{sw}} \quad$ time from separations to waste form fabrication

tbd, TBD to be determined

$\mathrm{T}_{1 / 2} \quad$ halflife

Tc technetium

Th thorium

TM transition metal

TMFP transition metal fission products

Tonne metric ton, $1000 \mathrm{~kg}$

TRISO Tristructural-isotropic, a type of micro fuel particle containing an oxide or oxycarbide kernel or fuel meat, surrounded by four layers of three isotropic materials - porous buffer layer of carbon, inner layer of dense pyrolytic carbon, ceramic layer of silicon carbide, and outer layer of dense pyrolytic carbon

TRU transuranic element (neptunium, plutonium, americium, curium, berkelium, californium)

TRUEX TransUranic Extraction

TRUMOX transuranic-bearing MOX

U uranium

UCB University of California-Berkeley

UDS undissolved solids

UOX uranium oxide fuel

UOX-51 uranium oxide fuel taken to a burnup of $51 \mathrm{MWth-day/kg-iHM}$

UREX Uranium Extraction

UREX+ Uranium Extraction-plus

U.S. United States

U-TRU uranium-transuranic

UT Utah, site of a low-level waste near-surface burial waste disposal site

VB Visual Basic

VISION Verifiable Fuel Cycle Simulation mode

WA Washington, site of a low-level waste near-surface burial waste disposal site

WAC waste acceptance criteria 


$\begin{array}{ll}\text { W.D. } & \text { waste disposal } \\ \text { W.F. } & \text { waste form } \\ \text { WIPP } & \text { Waste Isolation Pilot Project, a transuranic waste disposal site in New Mexico } \\ \mathrm{wt} \% & \text { weight percent } \\ \mathrm{Zr} & \text { zirconium } \\ \Delta \mathrm{G} & \text { change in free energy }\end{array}$


This page intentionally left blank. 


\section{SYSTEMS CAMPAIGN}

\section{SEPARATION CAMPAIGN}

FUELS CAMPAIGN

\section{SYSTEM LOSSES STUDY - FIT (FUEL-CYCLE INTEGRATION \& TRADEOFFS)}

\section{INTRODUCTION}

When this effort started in spring 2009, the broad context guiding the team included the following:

The major 2008 system analysis report was the Dynamic Systems Analysis Report for Nuclear Fuel Recycle (DSARR), see (Dixon2008). In it, a key assumption that drove many of the waste management results was that $0.1 \%$ of TRU in recycle streams would appear in waste; the other $99.9 \%$ retained in fuel products. The corresponding losses of waste into fuel streams were not addressed.

The program was focused on used UOX-51 fuel feeding into recycle by fast reactors with transuranic conversion ratio less than 1.0, i.e., burner reactors rather than breeder reactors.

There was strong focus on two waste management observations. For a waste to quality for near-surface burial per 10CFR61, the alpha-emitting TRU content must be below $100 \mathrm{nCi} / \mathrm{g}$-waste. And, numerous analyses indicated that the TRU loss to waste must be kept quite low to meet the decades-old idea of keeping residual waste radiotoxicity below that of natural uranium ore within 1000 years after reactor discharge.

These observations led to the basic and deceptively simple question: how does the cost of separation, cost of fuel fabrication, and cost of waste disposal vary with level of "losses", at this time primarily the losses of TRU into waste.

- Shortly after the team started in 2009 , five key observations arose that fundamentally changed the nature of the effort.

- There was a high premium for keeping waste impurities out of fuel because the Fuels Campaign was establishing working limits for oxide and metal fuel that did not look easy to meet.

- Both fuel streams and waste streams must be considered products. Both must meet one or more acceptance criteria. In the case of fuel, they are expressed as fuel impurity limits. In the case of waste, the criteria manifest as both classification rules that determine whether a given waste stream qualifies for near-surface burial or must be disposed by some other (presumably more expensive) method and "waste acceptance criteria" for different types of disposal sites.

- The values of loss of TRU into waste and the loss of waste into fuel are linked. Often, the lower one wants the loss of TRU into waste, the higher the loss of waste into fuel, and vice versa. Thus, even the original number-of-nines question could not be addressed without considering the impact of higher impurities as the amount of TRU in waste was decreased.

- The program was shifting from emphasis on fast reactor recycling fed by used UOX-51 fuel to a science-based program considering a wider and wider range of options.

In short, the team came to define "losses" as any material that ends up somewhere it is undesired. 
The FY 2009 exploratory analysis was limited to equilibrium analysis of the fast reactor recycling loop at transuranic conversion ratio of 0.5 , assuming incoming uranium and used UOX-51 TRU streams were pure. In essence, the only specific impurity in fuel that received much attention was lanthanides.

In FY 2010, it became clear that an analytical tool was required to consider a wider range of types of impurities and a wider range of technology options because the program was no longer focused on fast reactors by used UOX-51. That model is now called FIT, Fuel-cycle Integration and Tradeoffs.

The team nonetheless began FY 2010 by continuing to focus on the same basic case, burner fast reactors fed by used UOX-51, with two separation options, UREX+1 for used-oxide based fuels and electrochemical for used metal-based fuels. There was insufficient data to analyze other options. Even with those best-understood options, the team realized that a meaningful quantitative analysis of cost of separations, fuel fabrication, waste management, etc. as a function of the number of $9 \mathrm{~s}$ of separation efficiency was impossible. But, it was also no longer as important as the program has shifted from that single option with relatively early deployment to consideration of a wider range of options.

So, FY 2010 analysis concentrated on three thrusts.

- Go to a deeper level of chemical specificity, not just the lanthanides.

- Assemble a quantitative analysis model, FIT, based as much as possible on existing bits and pieces from the three campaigns involved.

- Begin consideration of other separation options, specifically "minimum fuel treatment" possibilities. We choose melt refining and AIROX as potential examples of minimum fuel treatment.

The result, this report, has two types of value. The first are observations and findings regarding the nature of the problem of fitting the fuel cycle together in multi-recycle scenarios, which is described in Section 2. They both guided and resulted from the attempt to create the FIT model (see Section 3). The FIT model is an unparalleled attempt at integrating the fuel cycle at the level of chemical groups. By integration, we mean the blending of feed streams, fuel fabrication, reactor, used fuel separation, and waste management. The second are quantitative analyses with the beta version of the FIT model, see Section 4. Table 1-1 summarizes the changes in fiscal year (FY) 2010 versus FY 2009. The increased complexity from FY 2009 required the creation of the FIT model. The model was not the task objective, its creation and use has been a tool toward the task's objectives. 
Table 1-1. Task complexity change from FY 2009 to FY 2010.

\begin{tabular}{|c|c|c|c|}
\hline Issue & \multicolumn{2}{|l|}{ FY 2009} & Comment \\
\hline $\begin{array}{l}\text { Basic model } \\
\text { structure }\end{array}$ & \multicolumn{2}{|c|}{$\begin{array}{l}\text { An incoming feed stream (e.g., separation product from } \\
\text { used UOX) and a recycling loop (e.g., fast reactor); the } \\
\text { only mass leaving the loop is waste generated by } \\
\text { separation and fabrication. }\end{array}$} & $\begin{array}{l}\text { Simplest possible substructure } \\
\text { of potentially complex } \\
\text { scenarios. }\end{array}$ \\
\hline $\begin{array}{l}\text { Reactor and fuel } \\
\text { types }\end{array}$ & \multicolumn{2}{|c|}{$\begin{array}{l}\text { Fast reactor with transuranic conversion ratio of } 0.50 \\
\text { (metal or oxide fuel) }\end{array}$} & $\begin{array}{l}\text { This is the case we know most } \\
\text { about and therefore have the } \\
\text { best chance to model with any } \\
\text { confidence. }\end{array}$ \\
\hline Separation types & Aqueous, electrochemical & $\begin{array}{l}\text { Aqueous, } \\
\text { electrochemical, air } \\
\text { oxidation (AIROX), } \\
\text { melt-refining }\end{array}$ & $\begin{array}{l}\text { AIROX and melt refining } \\
\text { added as candidate "minimum } \\
\text { fuel treatment" options. }\end{array}$ \\
\hline $\begin{array}{l}\text { Impurities in } \\
\text { incoming feed } \\
\text { stream }\end{array}$ & No & Yes & $\begin{array}{l}\text { This completes the scenarios } \\
\text { we started in FY } 2009 .\end{array}$ \\
\hline $\begin{array}{l}\text { Impurities in } \\
\text { recycling stream }\end{array}$ & \multicolumn{2}{|l|}{ Yes } & \\
\hline Chemical groups & 2 (actinides, lanthanides) & 15 & $\begin{array}{l}\text { Required to do meaningful } \\
\text { assessments of waste streams } \\
\text { (e.g., gases, metals, ceramics) }\end{array}$ \\
\hline Blending & Fixed ratio & $\begin{array}{l}\text { Blend among: } \\
\text { TRU-U-1 incoming } \\
\text { TRU-U-2 recycling } \\
\text { RU-1 incoming } \\
\text { RU-2 recycling } \\
\text { DU }\end{array}$ & \\
\hline State of system & Equilibrium & Recycle by recycle & $\begin{array}{l}\text { We realized three-quarters } \\
\text { through the year that the } \\
\text { equilibrium would not be } \\
\text { feasible for some minimum fuel } \\
\text { treatment cases. }\end{array}$ \\
\hline
\end{tabular}

As mentioned in Table 1-1, we used 15 chemical groups in our analysis; even that was not a fine enough "mesh" to fully link the two types of fuels (oxide and metal) and the four types of separations ( aqueous, electrochemical, AIROX, melt refining). To fully align and link the chemical behavior of the $2 \times 4$ combinations of fuel fabrication and separation technologies, analysis would probably have to be done at the level of 98 chemical elements (hydrogen to californium). We have resisted that level of complexity.

\subsection{Purpose and Schedule}

The work package for this study for FY 2010 states, "Expanded recycle losses study: Continue study started in FY 2009, expanding to fuel cycle systems beyond the concepts studied in FY 2009. Scope of work will be informed by final report on Losses Study in FY 2009, and will include application of the losses model to selected fuel cycles." There are three milestones for this work package, as listed in Table 1-2. This report meets the third milestone. 
Table 1-2. FY 2010 milestones.

\begin{tabular}{|l|l|l|l|l|}
\hline \multicolumn{1}{|c|}{ Date } & \multicolumn{1}{|c|}{ Name } & \multicolumn{1}{|c|}{ Number } & Lab & \multicolumn{1}{c|}{ Quality Review Level } \\
\hline May 14, 2010 & $\begin{array}{l}\text { Status report on recycle } \\
\text { losses study }\end{array}$ & M3 506030210 & INL & NA \\
\hline August 25, 2010 & $\begin{array}{l}\text { Draft report on recycle } \\
\text { losses study }\end{array}$ & M3 506 0302 09 & INL & NA \\
\hline September 15, 2010 & Recycle losses study & M2 506 03 02 01 & INL & QRL3 \\
\hline
\end{tabular}

The purpose of this study is to "Understand the broad implications of changes of operating performance and parameters of a fuel cycle component on the entire system." In particular, analyze the impact of changing the loss percent of wastes (fission products, impurities) into recycled fuel and the loss percent of fuel (uranium, transuranic [TRU]) into waste.

As part of FITing our efforts to the Department of Energy (DOE's) charged priorities, we have added exploratory analysis of candidates in the modified open fuel cycle category, a few with "minimum fuel treatment" as opposed to full aqueous or electrochemical separation treatment.

\subsection{Reminder of FY 2009 Observations}

Some of the key observations in FY 2009 were as follows:

- Losses count both ways (waste into recycled fuel, would-be fuel material into waste), both waste and recycled fuels are "products" that must meet criteria (impurity limits, waste acceptance criteria).

- Many issues identify the lanthanides as a key part of the puzzle. They are the toughest to separate from the actinides (TRU and uranium), represent the majority of neutron-absorption potential among fission products, have tight impurity limits in both oxide and metal fuel, and represent a significant waste mass that has the potential to be classified for near-surface burial or non-nuclear service.

- There are significant potential savings to be realized if future reactor programs are selected based on an integrated understanding of the fuel cycle costs and risks rather than just reactor performance.

- The holding pattern for U.S. commercial used fuel has created a data vacuum with regard to cost and risk issues related to the modified open and closed used fuel management approaches. Current modeling programs are hindered by a lack of historical U.S. data and demonstration data for the proposed new processing concepts. Thus, it follows that the initial benefit of modeling fuel cycles will be in the area of sensitivity testing to identify what variables have the greatest impact and highest potential for "value-added" results.

- Reducing the percent loss (waste into fuel, fuel into waste) has both costs and benefits.

- There are numerous higher level material management choices/issues that have much greater impact on cost than losses per se (e.g., the selection of a fuel that minimizes the generation of TRU and fission products, the decision to recycle or not and the number of separation steps and complexity of the processing flow sheet [number of output streams directly impacts the facility size]). The issues related to losses apply to all possible fuel cycle management scenarios. 


\subsection{Desired Use Cases}

Table 1-3 lists desired "use cases" for analysis. The "p" cases were done in FY 2009. To meet the FY 2010 milestone requirement, we must analyze at least one additional case. We focused and succeeded in analyzing four new cases, Cases $1 / 2$ and Cases $1 \mathrm{~m} / 2 \mathrm{~m}$. Cases 1 and 2 are the complete form of the "p" cases we analyzed in FY 2009, including both the fast reactor equilibrium portion of the Dynamic Systems Analysis Report for Nuclear Fuel Recycle (DSARR) 1-tier (uranium oxide fuel [UOX] to fast reactor) scenarios plus the step of separating UOX to feed into the fast reactor. The " $\mathrm{m}$ " cases led us into examination of minimum fuel treatment options. 
Table 1-3. Desired use cases.

\begin{tabular}{|c|c|c|c|c|c|}
\hline & $\begin{array}{l}\text { Feed } \\
\text { Fuel }\end{array}$ & $\begin{array}{l}\text { First } \\
\text { Separation }\end{array}$ & Recycle Fuel & $\begin{array}{l}\text { Recycle } \\
\text { Separation }\end{array}$ & Comment \\
\hline $1 \mathrm{p}$ & & & FR-oxide at $\mathrm{CR}=0.50$ & UREX+1 & \multirow[t]{2}{*}{ FY 2009 cases } \\
\hline $2 p$ & & & FR-metal at $\mathrm{CR}=0.50$ & Echem & \\
\hline 1 & UOX & UREX+1a & FR-oxide at $\mathrm{CR}=0.50$ & UREX+1 & \multirow{2}{*}{$\begin{array}{l}\text { Completes DSARR 1-tier } \\
\text { scenarios, forces allocation of } \\
\text { tolerable impurities between two } \\
\text { streams } \\
\text { Done, see Section } 4\end{array}$} \\
\hline 2 & $\mathrm{UOX}$ & UREX+1a & FR-metal at $\mathrm{CR}=0.50$ & Echem & \\
\hline $1 \mathrm{c}$ & UOX & UREX+1a & FR-oxide at $\mathrm{CR}=0.50$ & Echem & \multirow{2}{*}{$\begin{array}{l}\text { Cross compare fuel-separation, } \\
\text { putting echem with oxide fuel or } \\
\text { UREX with metal fuel adds } \\
\text { oxidation and reduction steps }\end{array}$} \\
\hline $2 \mathrm{c}$ & UOX & UREX+1a & FR-metal at $\mathrm{CR}=0.50$ & UREX+1 & \\
\hline $1 \mathrm{~m}$ & $\mathrm{UOX}$ & AIROX & FR-oxide at $\mathrm{CR}=0.50$ & AIROX & \multirow{2}{*}{$\begin{array}{l}\text { "Minimal fuel treatment" variants } \\
\text { Done, see Section } 4\end{array}$} \\
\hline $2 \mathrm{~m}$ & UOX & AIROX & FR-metal at $\mathrm{CR}=0.50$ & Melt refine & \\
\hline $1 \mathrm{t}$ & MOX & $\mathrm{UREX}+1 \mathrm{a}$ & FR-oxide at $\mathrm{CR}=0.50$ & UREX+1 & \multirow[t]{2}{*}{ DSARR 2-tier scenarios } \\
\hline $2 \mathrm{t}$ & MOX & UREX+1a & FR-metal at $\mathrm{CR}=0.50$ & Echem & \\
\hline $1 \mathrm{~h}$ & UOX & $\begin{array}{l}\text { UREX+1a } \\
\text { without CsSr } \\
\text { removal } \\
\end{array}$ & FR-oxide at $\mathrm{CR}=0.50$ & $\begin{array}{l}\text { UREX+1 } \\
\text { without CsSr } \\
\text { removal } \\
\end{array}$ & \multirow[t]{2}{*}{$\begin{array}{l}\text { Same as } 1 / 2 \text { except no } \mathrm{CsSr} \\
\text { removal }\end{array}$} \\
\hline $2 \mathrm{~h}$ & $\mathrm{UOX}$ & $\begin{array}{l}\text { UREX+1a } \\
\text { without CsSr } \\
\text { removal }\end{array}$ & FR-metal at $\mathrm{CR}=0.50$ & $\begin{array}{l}\text { Echem } \\
\text { without } \mathrm{CsSr} \\
\text { removal }\end{array}$ & \\
\hline $1 \mathrm{~s}$ & UOX & UREX+1a & FR-oxide at $\mathrm{CR}=0.50$ & UREX+1 & \multirow{2}{*}{$\begin{array}{l}\text { Same as above, but with longer } \\
\text { interim storage times }\end{array}$} \\
\hline $2 \mathrm{~s}$ & UOX & UREX+1a & FR-metal at $\mathrm{CR}=0.50$ & Echem & \\
\hline $1 \mathrm{a}$ & UOX & COEX & FR-oxide at $\mathrm{CR}=0.50$ & UREX+1 & \multirow[b]{2}{*}{$\begin{array}{l}\text { Enables evaluation of a first } \\
\text { separation case where other TRU } \\
\text { elements besides Pu are not } \\
\text { recovered for recycle, but sent to a } \\
\text { single borosilicate glass (BSG) } \\
\text { waste form along with Tc, } \\
\text { lanthanides, undissolved solids } \\
\text { (UDS), other fission products. }\end{array}$} \\
\hline $2 \mathrm{a}$ & $\mathrm{UOX}$ & COEX & FR-metal at $\mathrm{CR}=0.50$ & Echem & \\
\hline $1 \mathrm{n}$ & UOX & NUEX & FR-oxide at $\mathrm{CR}=0.50$ & UREX+1 & \multirow{2}{*}{$\begin{array}{l}\text { Enables evaluation of a first } \\
\text { separation case where all TRU } \\
\text { elements are recovered for recycle, } \\
\text { and a single BSG waste form } \\
\text { contains Tc, Ln, UDS, other fission } \\
\text { products (FP). }\end{array}$} \\
\hline $2 n$ & UOX & NUEX & FR-metal at $\mathrm{CR}=0.50$ & Echem & \\
\hline \multicolumn{6}{|c|}{$\begin{array}{l}\text { Use cases that include other advanced waste forms besides BSG (that can tolerate higher waste loadings, } \\
\text { high heat generation, etc.) are also interesting, but should probably not be included in this year's analyses, } \\
\text { until after the waste form experts makes more progress in this area. }\end{array}$} \\
\hline \multicolumn{6}{|c|}{$\begin{array}{l}\text { (no identifier) }=\text { the full } 1 \text {-tier DSARR scenarios } \\
\mathrm{a}=\text { COEX (did not come up with a descriptive letter) } \\
\mathrm{c}=\text { cross compare (use echem on oxide fuel, use UREX on metal fuel) } \\
\mathrm{h}=\text { hot (no CsSr removal) } \\
\mathrm{m}=\text { minimum fuel treatment } \\
\mathrm{n}=\text { NUEX }\end{array}$} \\
\hline
\end{tabular}


Losses Study

$\mathrm{s}=$ storage (more storage time than the 1-tier DSARR scenario)

$\mathrm{t}=$ two-tier DSARR scenario (LWR-UOX to LWR-MOX to fast reactor) 


\section{TEAM ANALYSIS OF THE PROBLEM}

The systems-fuels-separation team spent considerable time in FY 2010 analyzing the problem and there are many insights that do not require quantitative analysis using the FIT model, which is described later in this report. We first give the broad insights.

Section 2.1 explains how we analyzed and resolved the issue of which isotopes and chemical elements to analyze and how to group them. This pertains directly to which elements are most likely to have relatively low versus high uncertainties in FIT analyses.

Section 2.2 describes where various elements may arise.

Section 2.3 summarizes which elements are limited by current Fuels Campaign values for oxide and metal fuel.

Section 2.4 summarizes which elements we can analysis with separation data provided by Separation Campaign colleagues. As will be seen; there is a substantial mis-match. There are many fuel limits for which there are no separation data; there are separation data for elements that do not have fuel limits (but perhaps should).

Section 2.5 describes simplistic calculations regarding how chemical equilibrium is approached for the case of a single fuel and single impurity specie. These provided insights into what to expect from FIT modeling.

Section 2.6 describes our attempts to keep the quantitative analyses as simple as possible while doing adequate justice to the problem. We settled on a set of 15 chemical groups.

Our FY 2010 analyses continued from the FY 2009 analyses. Our observations in FY 2010 include the following:

1. The experimental basis for quantifying the degree of separation of the lanthanides from actinides ranges from having data for several lanthanides from UREX tests to relatively weak or remains to be developed. Often, the behaviors of the lanthanides are extrapolated from data for only a few of them; yet, as is the case with transition metals and actinides that have multiple possible oxidation states, the behavior of individual lanthanide elements may vary.

2. The reasons for working limits on impurities in oxide and metal fuel feedstock include fabrication difficulties, formation of oxides/intermetallics, attack on fuel cladding, displacement of fissile content, and neutron absorption. If the program is to consider minimum fuel treatment (MFT) options, solutions will have to be considered for many of these issues for particular combinations of fuels, fabrication technology, and separation technology.

3. Currently, there are no working limits for impurities in oxide and metal fuel feedstock for many chemical elements. Non-limited elements may need to be reconsidered if the program is to consider MFT options. For example, the only limits on noble metals - ruthenium, rhodium, palladium, silver, rhenium, osmium, iridium, platinum, gold - are for oxide fuels, specifically ruthenium for fissile displacement and silver for undesirable oxides and fissile displacement. Minimum fuel treatment options typically do not remove noble metals. Thus, the question arises: would minimum fuel treatment approaches put so much noble metal content in oxide or metal 
fuels as to cause a problem? Or, would other hard-to-separate materials continue to be the limiting elements?

4. Most fuel fabrication methods include a feed conditioning step that involves dissolution or melting of the feedstock. This has to be considered in the proliferation risk assessments and the definition of so-called "minimum fuel treatment." It also motivates integration of separation and fuel fabrication.

5. Adoption of "minimum fuel treatment" would drive new approaches for fuels and fuel fabrication because the impurity levels would be significantly higher.

6. Definition and assessment of "minimum fuel treatment" must reflect both separation and subsequent fuel fabrication. For example, current tristructural-isotropic (TRISO) fuel fabrication involves a dissolution step, apart from whether or not separation of used fuel is the source of the feed material.

More fully quantifying the chemistry for different separation techniques has several potential benefits. First, it may provide a basis for initial estimation of separation of elements for which there are not now data. Second, a better definition of the relative importance of different elements among the full range of issues (fuel fabrication difficulties, cladding attack, etc.) provides a solid foundation for potentially modifying and combining parts of separation approaches (e.g., voloxidation with melt-refining). Third, proliferation risk assessments must not only consider a facility as designed, but also how a facility might be modified. That is, from chemical principles, a given approach such as volatility can separate some elements but not others. A facility designed to use a gas-phase process may not be particularly suited to for liquid processes that may be required for certain elemental separations. However, a facility designed to use volatility as one step in a series of separations might be changed to operate under conditions that differ from those for which it was initially designed. These matters are likely to become more important as the program considers minimum fuel treatment possibilities.

1. All fuel treatment methods (even so-called minimum fuel treatment) have some chemistry associated with them (e.g., oxidation reactions to enable separation due to the variable volatility among different chemical species in AIROX).

2. The fate of non-fission product impurities is often inadequately understood (e.g., C-14, Cl-36).

3. Because separation techniques use different chemical characteristics (volatility, selective oxidation, complexation in nitric acid, etc.) one cannot assume that elements of the same chemical grouping (as we have defined them) behave the same in two different separation techniques.

4. Because fuel fabrication and performance are based on different chemical characteristics for oxide versus metal fuels, one cannot assume that elements of the same chemical group face comparable limitations in two different fuel types.

5. Build understanding and analysis step-wise.

6. Consider uncertainty ranges.

7. A key issue is how each subsystem or full system responds to perturbations, but that is beyond what we currently intend to study with the steady-state FIT model; it will await future Verifiable Fuel Cycle Simulation mode (VISION) analyses.

j. AIROX does not remove the lanthanides but does remove $100 \%$ of the silver, so it might be expected that noble metals would not be limiting in such an approach. Melt refining (with an oxidizing crucible) does remove $\sim 95 \%$ of the lanthanides, so noble metals might be found to be limiting. 
We have also identified these questions, which we would like to explore during FY 2011.

1. Proliferation resistance and physical protection - does "minimum fuel treatment" have benefits versus aqueous or electrochemical?

2. Reactor - quantify the increased TRU:uranium ratio or uranium enrichment as TRU degrades (from increased storage time) or impurities increase.

3. Separation -

- Which fuels and fuel cycle management options are the most user-friendly (i.e., treatment is simplified or minimized)?

- What are the losses into each waste and fuel stream?

- How does separation performance change as the quantity of recycling impurities increases?

- How does cost vary as losses change?

- How does cost vary with gamma/neutron dose?

4. Fabrication

- What happens to fuel fabrication and reactor performance if impurities in the feed stream are significantly higher than the working impurity targets?

- How does cost vary as impurities in the feed steam increase?

- How does cost vary with gamma/neutron dose?

- What dissolution or melting steps occur during fabrication (e.g., dissolution step in current TRISO fabrication)?

- What are the losses into each waste stream and fuel stream?

5. Waste form - can we get out of the heat-per-container trap?

6. Waste disposition - if waste classification is changed from source-based to characteristic-based, what benefits (and costs) arise?

Many of the above pertain to "minimum fuel treatment" such as AIROX or melt-refining. Tables 2-1 and 2-2 summarize initial qualitative analyses. Note that fundamentally high-impurities are analogous to extra long-life (extreme burnup) in that more non-fuel material accumulates in in-service fuel. Therefore, research and development $(\mathrm{R} \& \mathrm{D})$ thrusts like impurity-tolerant fuel matrices and clad coatings that protect against impurities may enable minimum fuel treatment and/or extreme burnup. The Fuels Campaign already has a question about how impurities generated during irradiation behave versus how impurities residual after separations behave. The example in our FY 2009 report was that the working impurity limit for lanthanides was $4,000 \mathrm{ppm}$, but $40,000 \mathrm{ppm}$ are generated during irradiation. These are viewed as consistent because the lanthanides addressed by the $4,000 \mathrm{ppm}$ limit are viewed as more mobile and concentrated and likely to attack cladding, whereas the lanthanides associated reaching 40,000 ppm during irradiation are viewed as relatively immobile - not all impurities - even of the same element behave the same. If instead there are impurities after MFT (such as AIROX-treated particles), are they more like the low-mobility 40,000 ppm-lanthanide because their original matrix was not as disturbed (as would be in full treatment) or more like the high-mobility 4,000 ppm-lanthanide impurity? 
Table 2-1. Qualitative potential implications of "minimum fuel treatment" on fuel cycle components.

\begin{tabular}{|l|l|l|}
\hline & \multicolumn{1}{|c|}{ Positive } & \multicolumn{1}{|c|}{ Negative } \\
\hline Reactor & $\begin{array}{l}\text { Some recycled impurities might serve } \\
\text { as burnable poisons. }\end{array}$ & $\begin{array}{l}\text { Higher impurities absorb more neutrons, } \\
\text { slight increase in TRU/U or U235/U } \\
\text { enrichment required. }\end{array}$ \\
\hline $\begin{array}{l}\text { Fuel } \\
\text { Seprication }\end{array}$ & $\begin{array}{l}\text { High impurities, but for same net } \\
\text { burnup, less gas generation and less } \\
\text { radiation damage to clad/coating. }\end{array}$ & $\begin{array}{l}\text { Impurity accumulation in fuel. } \\
\text { Impurity attack on cladding/coating. }\end{array}$ \\
\hline $\begin{array}{l}\text { Fewer, easier separations } \\
\text { Possibly no liquids (e.g., AIROX) }\end{array}$ & $\begin{array}{l}\text { Less efficient separations - potentially more } \\
\text { fission product contaminants in the recycled } \\
\text { actinide stream, and more TRU contaminants } \\
\text { in the waste streams, compared to full } \\
\text { separations. }\end{array}$ \\
\hline Waste forms & $\begin{array}{l}\text { Designs for capture and } \\
\text { immobilization of gaseous fission } \\
\text { products (C-14, H-3, I-129, and noble } \\
\text { gases) can be similar to current designs } \\
\text { for capturing gaseous species } \\
\text { containing these nuclides in full } \\
\text { separations processes. }\end{array}$ & $\begin{array}{l}\text { Waste forms for semivolatile and less- } \\
\text { volatile fission products may need to be } \\
\text { developed, as the groupings of these fission } \\
\text { products would be based on relative } \\
\text { volatility and reactivity, which is different } \\
\text { from fission products groupings based on } \\
\text { solubility in solvents used in full separations } \\
\text { processes. }\end{array}$ \\
\hline $\begin{array}{l}\text { Waste } \\
\text { disposal }\end{array}$ & $\begin{array}{l}\text { Partial separations processes may } \\
\text { enable easier regulatory and policy } \\
\text { conversion from source-based waste } \\
\text { definitions to waste definitions based } \\
\text { on characteristics that could impact } \\
\text { storage, disposal, and potential } \\
\text { hazard/risk to the environment and } \\
\text { public. }\end{array}$ & $\begin{array}{l}\text { Potentially more TRU contamination in } \\
\text { waste streams less efficiently separated from } \\
\text { recycle streams, compared to full separations } \\
\text { processes. }\end{array}$ \\
\hline
\end{tabular}

k. Some fission products can actually serve as the stabilizing isotope for the matrix itself (as opposed to residing in the dispersion kernel). For example, much of the lanthanides are neodymium isotopes (some are neutron poisons of course). Coincidently, this element may prove to make a more stable damage resistant inert matrix. Case in point (neodymium zirconate $=\mathrm{Nd}_{2} \mathrm{Zr}_{2} \mathrm{O}_{7}$ ) which is a pyrochlore compound of interest in the inert matrix community (ongoing research mainly at University of Florida). Also, lanthanides are likely to form oxide phases in oxide fuel (mobility and restructuring to be addressed). In metal fuels, lanthanides pose a fuel-cladding problem as they tend to try to trade places with iron in the cladding. 
Table 2-2. Qualitative potential implications of "minimum fuel treatment" on fuel cycle objectives.

\begin{tabular}{|c|c|c|c|}
\hline & Positive & Negative & Questions \\
\hline $\begin{array}{l}\text { Waste } \\
\text { management }\end{array}$ & $\begin{array}{l}\text { Partial separations processes } \\
\text { may enable easier regulatory } \\
\text { and policy conversion from } \\
\text { source-based waste } \\
\text { definitions to waste } \\
\text { definitions based on } \\
\text { characteristics that could } \\
\text { impact storage, disposal, and } \\
\text { potential hazard/risk to the } \\
\text { environment and public. }\end{array}$ & $\begin{array}{l}\text { Repeated recycle of } \\
\text { incompletely } \\
\text { separated impurities } \\
\text { may lead to more } \\
\text { activation and } \\
\text { accumulation of long- } \\
\text { lived fission products. }\end{array}$ & $\begin{array}{l}\text { Next step is FY } 2010 \\
\text { calculations that } \\
\text { examine impact of long } \\
\text { irradiation on impurities } \\
\text { to determine which } \\
\text { long-lived fission } \\
\text { products decrease and } \\
\text { which increase. }\end{array}$ \\
\hline $\begin{array}{l}\text { Proliferation and } \\
\text { physical } \\
\text { protection }\end{array}$ & $\begin{array}{l}\text { Some minimum fuel } \\
\text { treatment options may be } \\
\text { very difficult to alter to } \\
\text { provide high grade weapon } \\
\text { usable material } \\
\text { Higher radiation fields in } \\
\text { recycled material }\end{array}$ & $\begin{array}{l}\text { Safeguard } \\
\text { measurements may be } \\
\text { more difficult. }\end{array}$ & $\begin{array}{l}\text { What do metrics and } \\
\text { methodologies say? }\end{array}$ \\
\hline $\begin{array}{l}\text { Uranium } \\
\text { utilization }\end{array}$ & $\begin{array}{l}\text { Lower risk of proliferation for } \\
\text { partial separations processes } \\
\text { may enable faster or more } \\
\text { widespread acceptance of } \\
\text { used fuel recycling and fast } \\
\text { reactor designs, enabling fuel } \\
\text { cycles that can achieve higher } \\
\text { uranium utilization than } \\
\text { practical for once-through } \\
\text { fuel cycles. }\end{array}$ & $\begin{array}{l}\text { More neutron } \\
\text { absorption by } \\
\text { impurities will slightly } \\
\text { decrease uranium } \\
\text { utilization. }\end{array}$ & $\begin{array}{l}\text { Challenge development } \\
\text { of minimum fuel } \\
\text { treatment options to } \\
\text { maximize neutron } \\
\text { absorber removal at } \\
\text { minimum cost. }\end{array}$ \\
\hline Economics & Lower separation cost. & $\begin{array}{l}\text { Higher fuel fabrication } \\
\text { cost; potentially higher } \\
\text { waste disposition cost. }\end{array}$ & \\
\hline Safety & $\begin{array}{l}\text { In some minimum fuel } \\
\text { treatment versions, there is no } \\
\text { handling or spills of } \\
\text { radioactive waste during } \\
\text { separations. }\end{array}$ & $\begin{array}{l}\text { Increased levels of } \\
\text { contaminants in both } \\
\text { recycle and waste } \\
\text { streams may affect } \\
\text { how those streams can } \\
\text { be safely handled. }\end{array}$ & \\
\hline
\end{tabular}

The rest of this section pertains to defining isotope and chemical grouping, and then analysis of how well the four representative separation techniques can be analyzed with that approach.

\subsection{Isotope and Chemical Grouping}

The use cases identified in Section 1 involve four separation approaches: AIROX, melt refining, electrochemical, and aqueous. Aqueous separations processes can vary widely in function and resultant separated recycle and waste streams; the most reasonably comprehensive (complex) of these, UREX $+1 \mathrm{~A}$, is used in the model to encompass the range of potential aqueous separations processes. 
A central topic in the first half of FY 2010 was the level of disaggregation or grouping for future systematic analyses. Chemical behavior is central to fuel performance, separation, waste forms, waste disposal performance, etc. In principle, to comprehensively model fuel cycle behavior, we would have to separately model all 99 elements from hydrogen to einsteinium; however, we wish to avoid this. The stable and neutron-rich radioactive isotopes (those preferentially created as fission products) and those associated with actinides number perhaps 1600 isotopes; there is no need to track them all. Alternatively, we considered very simple groupings such as actinides, lanthanides, alkali metals (Group 1), alkaline earth metals (Group 2), halogens (Group 17), inert gases (Group 18), and then everything else.

We considered individual elements that have special roles in fuel cycle analyses, for example:

1. Zirconium is the primary constituent of Light-Water Reactor (LWR) fuel cladding and any fuel cycle analysis that considers LWRs must accommodate it.

2. Molybdenum and ruthenium, rhodium, and palladium constrain the loading of waste into the classical waste form of glass, but in two different ways.

3. Technetium is a special waste stream in the UREX family of separation options; it is not found in nature. Tc-99 is often a dominant waste management concern.

4. Hydrogen and carbon are ubiquitous, key constituents in separation chemistry.

We began with the chemical groupings being used in VISION, the Fuel Cycle Transmutation Library, and other tools (herein referred to as the Set of 81 because there are 81 items) some individual isotopes and some mass treated as stable (Piet 2009a) with two eventual modifications. First, although the Set of 81 has the important radioactive isotopes for the actinides, the actinide decay products, and fission products; it was not designed to be inclusive of key impurity isotopes. Therefore, we anticipate eventually having to add key isotopes from steel and other major sources of non-fission-product impurities. Second, the mass treated as stable in the Set of 81 needs further division because of different chemical behavior, and therefore we will split the fission product "stable" masses as follows:

- Glass constraining transition metals $\rightarrow$ Mo versus $\mathrm{Ru}+\mathrm{Rh}+\mathrm{Pd}$

- "Transition metal other" $\rightarrow$ non-metals (As, Se), metalloids (In, Sn, Sb), noble (Ag), and residual transition metals $(\mathrm{Nb}, \mathrm{Cd})$

Table 2-3 shows the current chemical groupings for FIT. 
Table 2-3. Current Chemical Groupings.

\begin{tabular}{|c|c|}
\hline Chemical Grouping & Comment \\
\hline - & Ubiquitous \\
\hline $\begin{array}{l}\text { Non-metal } \\
\text { Impurities (C-14, C, N, O, P, S) } \\
\text { Fission products (Se-79, Se-stable) }\end{array}$ & Split Se stable from current box of TM-stable \\
\hline $\begin{array}{l}\text { Group } 1 \\
\text { Alkali metals (Li, Na, K, Rb-stable, Cs-134, 135, } \\
\text { 137, Cs-stable) }\end{array}$ & \multirow{3}{*}{$\begin{array}{l}\text { Split Group } 1 \text { versus } 2 \text { because of electrochemical and melt } \\
\text { refining results. This is trivial for the Set of } 81 \text { because } \mathrm{Rb}- \\
\text { stable and Cs-stable are already differentiated from Sr- } \\
\text { stable and } \mathrm{Ba} \text {-stable in the Set of } 81 \text {. } \\
\mathrm{Li}, \mathrm{Na}, \mathrm{K}, \mathrm{Be}, \mathrm{Mg}, \mathrm{Ca} \text { are not fission products and will be } \\
\text { very low mass. }\end{array}$} \\
\hline Group 2 & \\
\hline $\begin{array}{l}\text { Alkaline earth metals (Be, } \mathrm{Mg}, \mathrm{Ca}, \mathrm{Sr} 90, \text { Sr-stable, } \\
\text { Ba-stable) }\end{array}$ & \\
\hline $\begin{array}{l}\text { Group } 17 \\
\text { Impurities (F-stable, Cl-36, Cl-stable) } \\
\text { Halogen fission products (I-129, I+Br stable) }\end{array}$ & $\begin{array}{l}\mathrm{Cl} 35 \text { is an important impurity in some assessments, } \\
\text { activates to } \mathrm{Cl}-36 . \mathrm{F} \text { and } \mathrm{Cl} \text { are key processing elements } \\
\text { (molten salt, echem salt). Do not split I-stable from Br- } \\
\text { stable in the main FIT mass flow, but they can always be } \\
\text { split in specific modules if needed. }\end{array}$ \\
\hline $\begin{array}{l}\text { Group } 18 \\
\text { Noble gases (He-4, Ne+Ar, Kr-81, Kr-85, Kr+Xe } \\
\text { stable) }\end{array}$ & $\begin{array}{l}\text { He4 from actinide decay. } \mathrm{Ne}+\mathrm{Ar} \text { will be zero. } \\
\mathrm{Kr} 81 \text { and } \mathrm{Kr} 85 \text { fission products. }\end{array}$ \\
\hline \multicolumn{2}{|l|}{ Transition metal Zr $=$ Zr-93, Zr-95, Zr-stable } \\
\hline \multicolumn{2}{|l|}{ Transition metal Tc $=$ Tc-99 } \\
\hline $\begin{array}{l}\text { Transition metals } \\
\text { First row Mn-54, Mn-56, Fe-55, Co60, TM-other } \\
\text { Second row Nb-94, Nb-stable, Mo-stable, Cd- } \\
113 \mathrm{~m}, \text { Cd-stable } \\
\text { Third row Hf+Ta+W, Hg }\end{array}$ & $\begin{array}{l}\text { Steel-related isotopes (Mn-54, Mn-56, Fe-55, Co-60, Nb- } \\
\text { 94) not yet tracked. } \\
\text { Split Mo from current glass-constrain-stable, and split Nb } \\
\text { and Cd from current TM-other } \\
\text { Hf, Ta, W are not fission products }\end{array}$ \\
\hline $\begin{array}{l}\text { Metalloids } \\
\text { Low-Z impurities (B, Si, Ge, As) } \\
\text { Fission products (Sb-125, Sb+Te-stable) }\end{array}$ & $\begin{array}{l}\mathrm{B}, \mathrm{Si}, \mathrm{Ge} \text { and } \mathrm{As} \text { are not significant fission products. } \\
\mathrm{Split} \mathrm{Sb}+\mathrm{Te} \text {-stable from current TM-other }\end{array}$ \\
\hline $\begin{array}{l}\text { Other metals } \\
\text { Low-Z impurities }(\mathrm{Al}, \mathrm{Ga}) \\
\text { Fission products }(\mathrm{Sn}-126, \mathrm{In}+\mathrm{Sn} \text {-stable })\end{array}$ & $\begin{array}{l}\mathrm{Al} \text { and } \mathrm{Ga} \text { are not fission products } \\
\mathrm{Split} \mathrm{In}+\mathrm{Sn} \text {-stable from current } \mathrm{TM} \text {-other }\end{array}$ \\
\hline $\begin{array}{l}\text { Noble metals } \\
\text { Second row }=\mathrm{Ru}-106, \mathrm{Pd}-107, \mathrm{Ru}+\mathrm{Rh}+\mathrm{Pd}+\mathrm{Ag}- \\
\text { stable } \\
\text { Third row noble metals }=\mathrm{Re}+\mathrm{Os}+\mathrm{Ir}+\mathrm{Pt}+\mathrm{Au} \\
\end{array}$ & $\begin{array}{l}\text { Split } \mathrm{Ru}+\mathrm{Rh}+\mathrm{Pd} \text {-stable from current glass-constrain-stable. } \\
\text { Move } \mathrm{Ag} \text { from } \mathrm{TM} \text {-other to here, but in any case its mass is } \\
\text { low. } \\
\mathrm{Re}, \mathrm{Os}, \mathrm{Ir}, \mathrm{Pt}, \mathrm{Au} \text { are not fission products }\end{array}$ \\
\hline $\begin{array}{l}\text { Lanthanides }=\text { Ce144, Pm147, Sm146,147,151, } \\
\text { Eu154,155, Ho166m, lanthanide-stable }\end{array}$ & $\begin{array}{l}\text { Do not split first half from second half of the lanthanides. } \\
\text { Include Y }\end{array}$ \\
\hline Metalloid decay products $(\mathrm{Po})$ & \multirow{4}{*}{$\begin{array}{l}\text { Actinide decay products } \\
\text { Mass of Tl, Po, At, Rn, Fr mass is essentially zero }\end{array}$} \\
\hline $\begin{array}{l}\text { Other metal decay products }(\mathrm{Tl}, \mathrm{Pb}-206, \mathrm{~Pb}-207, \\
\mathrm{Pb}-208, \mathrm{~Pb}-210, \mathrm{Bi}-209)\end{array}$ & \\
\hline Group $17-18$ decay products $(\mathrm{At}, \mathrm{Rn})$ & \\
\hline Group $1+2$ decay product (Fr, Ra226, Ra228) & \\
\hline $\mathrm{Ac}=\mathrm{Ac}-227$ & \multirow[t]{6}{*}{ Actinides } \\
\hline $\mathrm{Th}=\mathrm{Th}-228,229,230,232$ & \\
\hline $\mathrm{Pa}=\mathrm{Pa}-231$ & \\
\hline $\mathrm{U}=\mathrm{U}-232,233,234,235,236,238$ & \\
\hline $\mathrm{Np}=\mathrm{Np}-237$ & \\
\hline $\mathrm{Pu}=\mathrm{Pu}-238,239,240,241,242,244$ & \\
\hline
\end{tabular}




\begin{tabular}{|l|l|}
\hline $\mathrm{Am}=\mathrm{Am}-241, \mathrm{Am}-242 \mathrm{~m}, \mathrm{Am}-243$ & \\
\cline { 1 - 1 }$=242,243,244,245,246,247,248,250$ & \\
\cline { 1 - 1 } $\mathrm{Bk}=$ Bk-249 & \\
\hline Cf $=$ Cf-249,250,251,252 & \\
\hline
\end{tabular}

Figures 2-1 and 2-2 show the same groupings as Table 2-3, with the same color scheme, but in a graphical form and without denoting individual isotopes. Figure 2-1 shows the groupings by name, and Figure 2-2 by the symbol of individual elements. We are partially through the process of determining whether this set of chemical groupings will work for AIROX, electrochemical, melt-refining, and aqueous. It should work reasonably well for aqueous because the original Set of 81 was developed with aqueous experts with that application in mind.
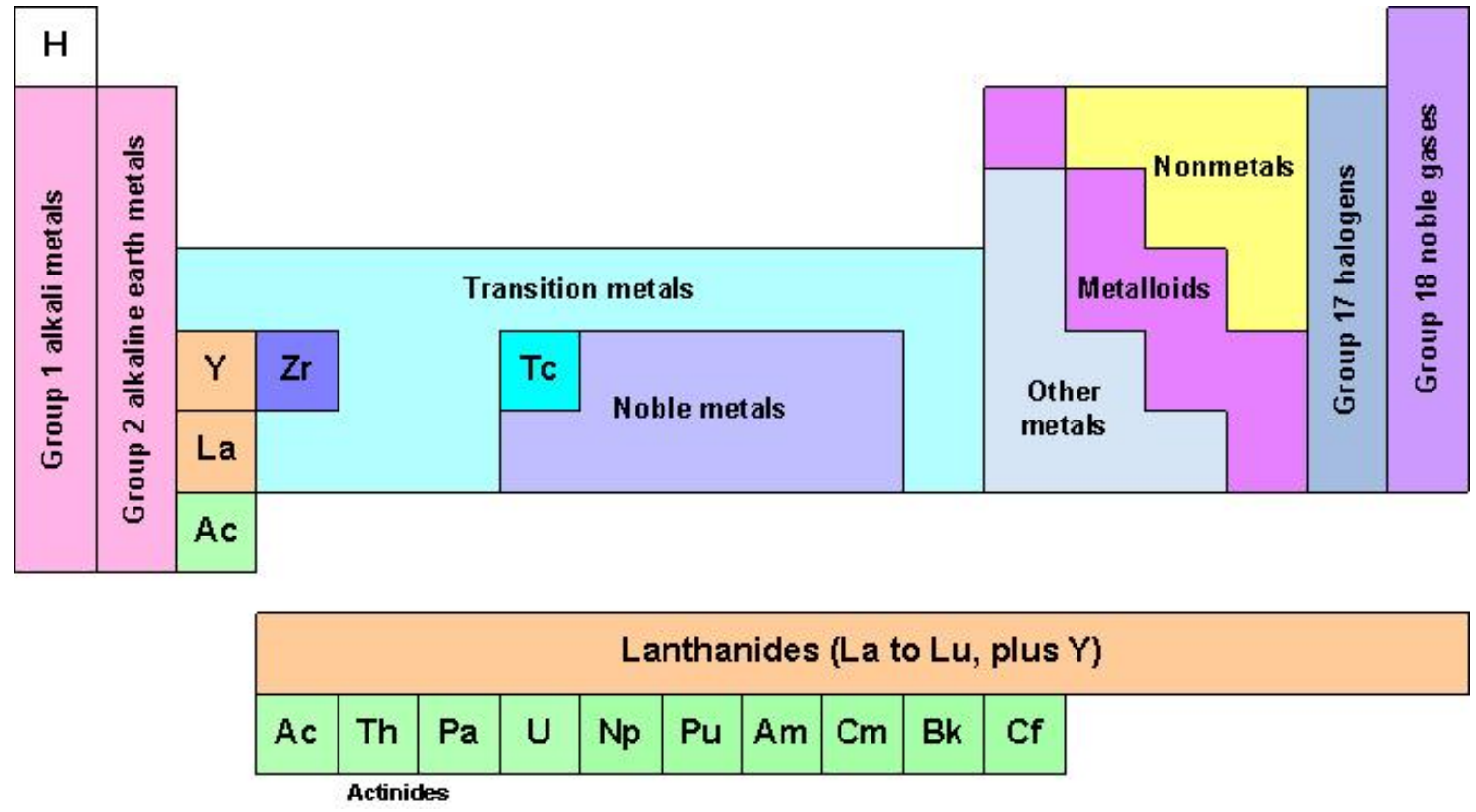

Figure 2-1. Current chemical grouping of the Periodic Table for FIT purposes. 


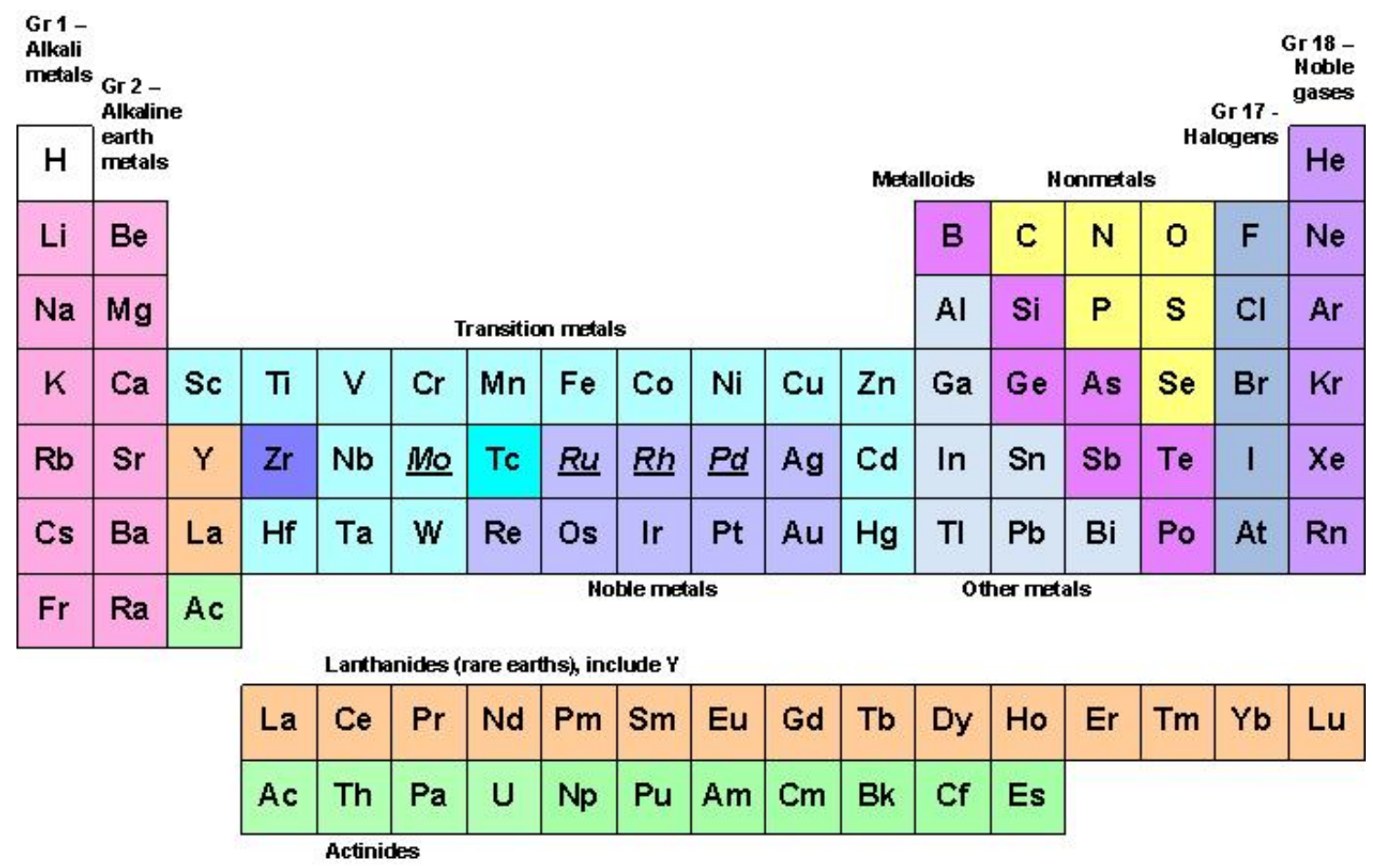

Figure 2-2. Preliminary chemical grouping of the Periodic Table, showing individual elements.

\subsection{Source of Various Elements}

The use cases identified in Section 1 involve four separation approaches: AIROX, melt refining, electrochemical, and aqueous. It is appropriate to consider what processes may produce any element in the Periodic Table. Figure 2-3 shows potential sources from actinides (and decay products); fission products; fuel matrix/clad/coating, and other impurities. The specific impurity sources from solvents and working fluids are not shown. In broad terms, starting with lithium (Element 3), the sources are impurities, fission products, impurities, actinide decay products, and the actinides. 


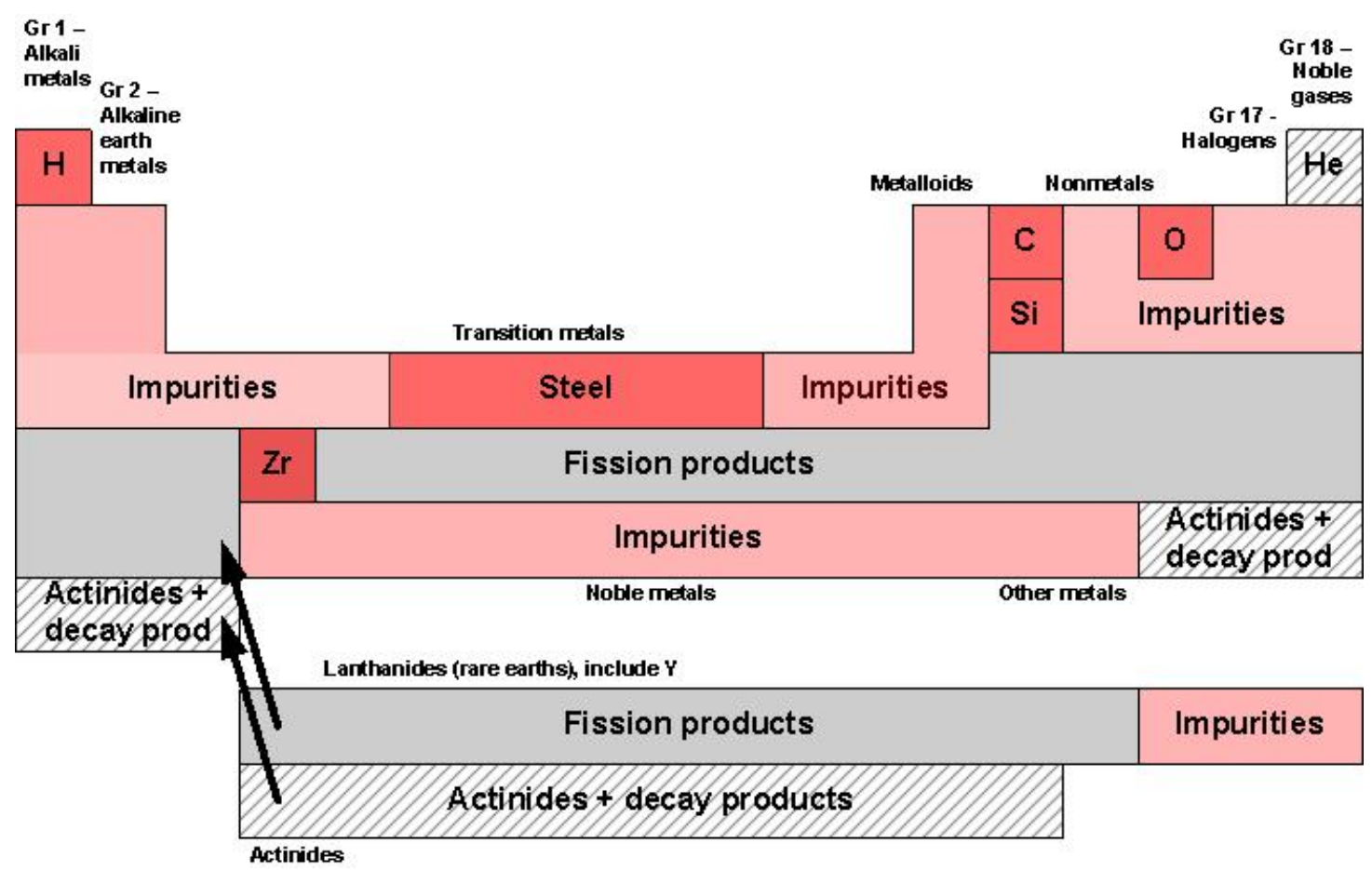

Figure 2-3. Potential sources of elements; solvents and working fluids are not shown.

A broad observation is that the different sources tend to align horizontally in the Periodic Table, whereas the chemical behaviors tend to align vertically in the Periodic Table.

\subsection{Fabrication}

In FY 2009, the Fuels Campaign provided their working limits for oxide and metal fuel impurities - both the quantitative limit and the rationale (Appendix A, Shropshire 2009). Of course, as research proceeds, both the quantitative limits and the rationale may change. Nonetheless, the next two subsections examine the data for insights on chemical grouping and on the causes of the limits. The causes of the limits must be understood so the high-impurity cases posed by MFT approaches can be analyzed.

\subsubsection{Oxide Fuel}

There are five types of issues that motivate the working limits on oxide fuels: fabrication difficulties, forming oxides or intermetallics in the fuel, attack on cladding, reduction in fissile content (by displacing fissile atoms), and neutron absorption. Neutron absorption refers to both the sheer number of neutrons absorbed and therefore wasted, but also (in the case of some of the lanthanides) impact the neutron spectrum by absorption in the resonance region. The potential methods to deal with each of there in highimpurity fuels differ. Fabrication difficulties would require either more expensive fabrication or new methods. Undesirable oxides and intermetallics can affect fuel fabrication, but also the fuel longevity. Cladding attack might motivate a fuel/clad barrier to be developed or fuel lifetime could be quite reduced. Reduction in fissile content and neutron absorption require adjustment in fuel content and/or reactor physics design.

Figure 2-4 shows the working limits for oxide fuel using the Periodic Table graphic, with the same color coding as Figures 2-1 and 2-2. The first observation is that less than half of the elements have limits at present. Comparison with Figure 2-3 shows that less than half of the fission products are limited; elements related to steel (a logical source of impurities) and the lighter elements are generally limited. 

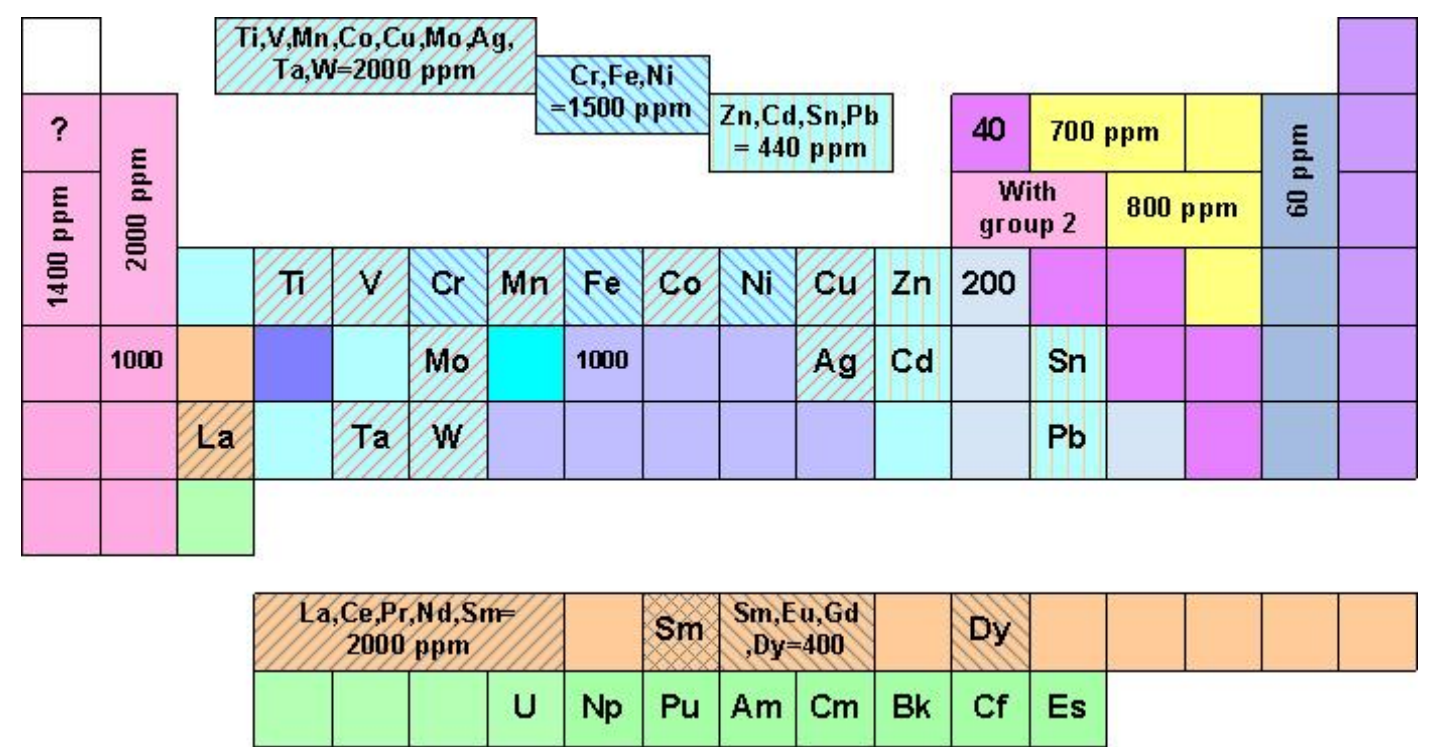

Figure 2-4. Working Fuel Campaign limit on TRU feedstock for oxide fuel (ppm).

Starting at the upper left portion of the Periodic Table, consider a few observations. The limit on alkali metal lithium is unknown. The next alkali metals (Group 1), sodium and potassium, form compound oxides, which can melt or decompose at temperatures below the fuel sintering temperature, causing fabrication issues. Aluminum is a liquid metal embrittlement agent on fuel cladding; its 2000-ppm limit also includes beryllium, magnesium, silicon, calcium, but these four elements apparently merely displace fissile content. Non-metals phosphorus and sulfur are limited to $800 \mathrm{ppm}$ because they form unstable low melting point compounds increasing fabrication difficulty.

There are three group limits for different sections of the transition metal portion of the Periodic Table. A 2000-ppm limit covers titanium, vanadium, manganese, cobalt, copper, molybdenum, silver, tantalum, tungsten, which form undesirable oxides in the fuel and affect the total impurities displacing fissile content. A 1500-ppm limit covers chromium, iron, nickel, which form undesirable intermetallics in the fuel and affect the total impurities displacing fissile content. And there is a 440-ppm limit on zinc, cadmium, tin, and lead, which form oxides that decompose at temperatures below fuel sintering temperature causing fabrication issues. Also, the transition metal ruthenium is limited to $1000 \mathrm{ppm}$ to minimize displacement of fissile content.

The 60-ppm limit on halogens (fluorine, chlorine) is to prevent fuel cladding corrosion. It is not known if this limit covers other halogens such as bromine and iodine.

Promethium does not appear in nature, presumably the reason it is not included in the $2000 \mathrm{ppm}$ limit for the first five lanthanides. That limit stems from the ability of these elements to form oxide hydrates and oxides that make control of oxygen:metal ratio difficult in pellet sintering. Terbium lies between samarium, europium, gadolinium, and dysprosium, but it is not included in their 400-ppm limit. These are restricted as thermal neutron resonance absorbers.

\subsubsection{Metal Fuel}

Figure 2-5 is analogous to Figure 2-4, but for metal fuel instead of oxide fuel. The first observation is that there are limits for fewer elements. Indeed, other than the lanthanides, few of the fission products are limited. Concentrations of lanthanides form low melting eutectics with fuel cladding. Due to their lack of dispersion, lanthanide impurities arising from recycled fission products that appear in TRU feedstock are more detrimental to fuel performance than lanthanide impurities formed in situ as fission products. 

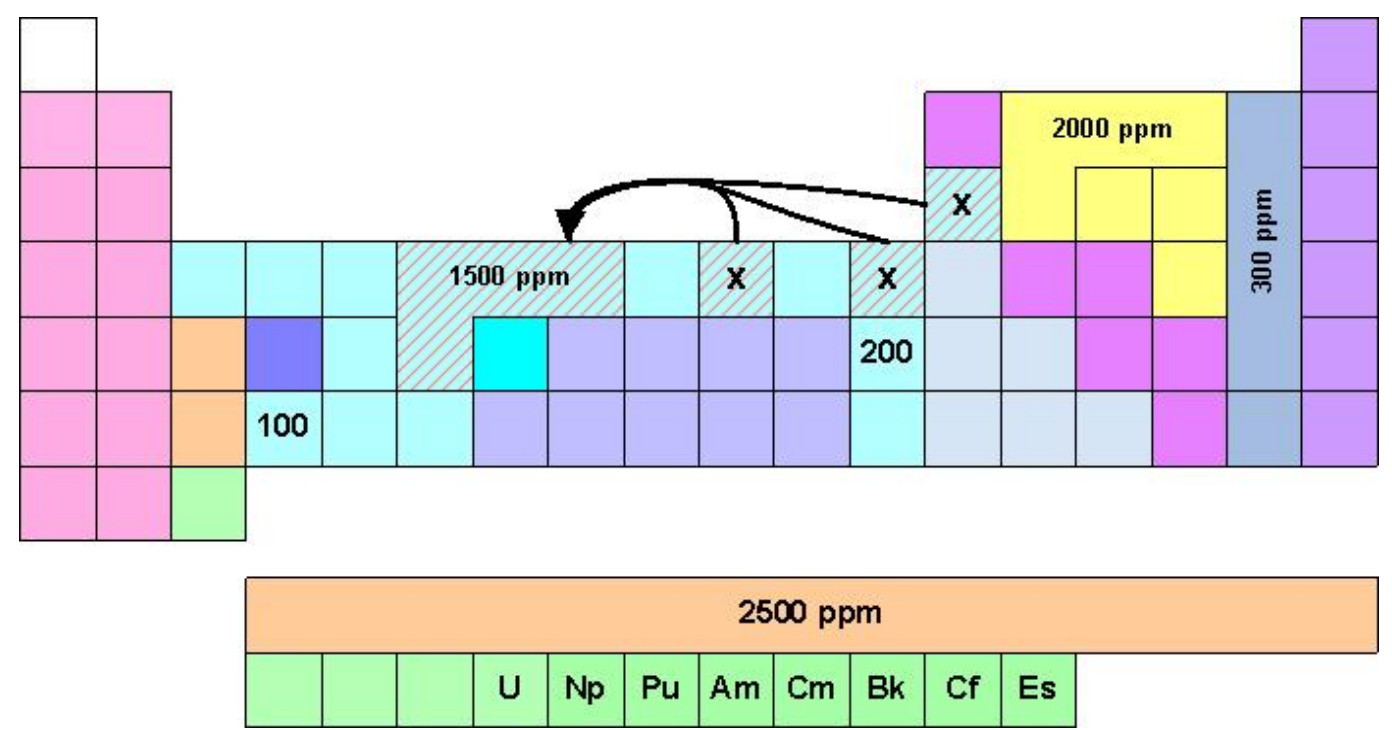

Figure 2-5. Working Fuel Campaign limit on TRU feedstock for metal fuel (ppm).

Like oxide fuels, halogens are limited to prevent fuel cladding corrosion. This 300-ppm limit includes fluorine and chlorine, but unlike the metal fuel limit, also it explicitly includes bromine and iodine.

Non-metals carbon, nitrogen, oxygen, and silicon are limited to minimize interaction with fuel alloy components. Silicon is especially problematic in combination with zirconium.

Cadmium is used in electrochemical separation, and its carryover into the feed stream is limited to 200 ppm.

Certain transition metals - aluminum, chromium, manganese, iron, nickel, zinc, and molybdenum - form undesirable intermetallics in the fuel and affect the total impurities, thereby displacing fissile content.

Hafnium appears with zirconium in zirconium-bearing ores, and is apparently limited due to its high neutron absorption.

\subsection{Separations}

The following four subsections summarize the elements that are separated from the balance of the fuel materials by each of the separation processes.

Table 2-4 provides an overview of the four separation methods. This is a first step at examining each separation option to identify which underlying chemical properties are the basis for each (e.g., ionic size, complexation, volatility, valence states, and variability of valence states. This would seem to be a pathway toward identifying how a facility using a given approach may be modified — an important question in proliferation risk assessments. That is, from basic chemical principles, a given approach such as volatility can separate some elements or groups of elements but not others. For example, a facility designed to use only volatility differences would likely not be particularly easy to modify to instead use differences in valence states as a basis for separations. However, a facility designed to use volatility as a separation approach for a given set of conditions (temperature, oxygen pressure, etc.) might be relatively readily modified to operate the process under another set of conditions.

Alternatively, in some proliferation risk assessments UREX is given little credit relative to PlutoniumUranium Reduction Extraction (PUREX) because with a slight modification to the process chemistry, the existing equipment within a UREX plant can be reconfigured to produce a plutonium stream like a 
PUREX plant. ${ }^{1}$ However, the required reconfiguration of both process flows and equipment is not insignificant. So, it would seem that in assessing any chemical treatment option, there are two types of questions: (1) What products is the plant designed to produce, and what does that imply for diversion, theft, transport, etc.? (2) What products could be produced with relatively few physical or process changes that enable diversion or theft? It is this second question that weakens the proliferation-resistance advantage for UREX and which must be assessed for any separation or fuel treatment option.

Table 2-4. Basis for separation using different techniques.

\begin{tabular}{|c|c|c|c|}
\hline Method & Basis for separation & Elements & Comment \\
\hline Melt refining & $\begin{array}{l}\text { Volatilization of halogens, inert gases, } \\
\text { etc. } \\
\text { Requires metallic/reduced fuel feed } \\
\text { Selective oxidation followed by } \\
\text { volatilization or formation of solids } \\
\text { (removed as dross). } \\
\text { Species concentration must exceed } \\
\text { solubility in the melt to be removed. }\end{array}$ & $\begin{array}{l}\text { Lanthanides, Groups } \\
1,2,17,18 \text {, } \\
\text { cadmium, tellurium, } \\
\text { yttrium, thorium, } \\
\text { americium }\end{array}$ & $\begin{array}{l}\text { Data for tests with oxide } \\
\text { crucible as the source of } \\
\text { oxygen. }\end{array}$ \\
\hline AIROX & $\begin{array}{l}\text { Volatilization of either reduced or } \\
\text { oxidized species. } \\
\text { Separation achieved due to high volatility } \\
\text { of fission product species relative to } \\
\text { uranium oxide. }\end{array}$ & $\begin{array}{l}\text { Tritium (radioactive } \\
\text { hydrogen) } \\
\text { Krypton, I2, 95\% of } \\
\text { Cs, } 50 \% \text { of } \\
\text { ruthenium, lesser } \\
\text { removal of } \\
\text { tellurium, } \\
\text { technetium, } \\
\text { cadmium, indium }\end{array}$ & $\begin{array}{l}\text { Multiple oxidation and } \\
\text { reduction cycles at } 400- \\
600^{\circ} \mathrm{C} \text {. Lanthanides } \\
\text { oxidize, but their } \\
\text { volatility is too low at } \\
\text { such temperatures to } \\
\text { facilitate removal from } \\
\text { the used fuel. }\end{array}$ \\
\hline Electrochemical & $\begin{array}{l}\text { Dissolution in molten alkali metal salt. } \\
\text { Volatilization of some species. } \\
\text { Electrochemical reduction step for oxide } \\
\text { fuels. } \\
\text { Selective deposition based on differences } \\
\text { in redox potential (free energy). }\end{array}$ & $\begin{array}{l}\text { Uranium, actinides, } \\
\text { some fission } \\
\text { products, iodine, } \\
\text { Group } 18\end{array}$ & $\begin{array}{l}\text { At present, lanthanides, } \\
\text { fission products, Groups } \\
1 \text { and } 2 \text { remain in salt. }\end{array}$ \\
\hline Aqueous & $\begin{array}{l}\text { Volatilization pretreatment to remove } \\
\text { tritium (voloxidation). } \\
\text { Acid dissolution. } \\
\text { Separation primarily by solvent } \\
\text { extraction (ion exchange for technetium), } \\
\text { of ionic species from aqueous solutions; } \\
\text { extent of separation controlled by acidity, } \\
\text { valence, complexation, and other factors. }\end{array}$ & $\begin{array}{l}\text { Uranium, } \\
\text { technetium, } \\
\text { cesium, strontium, } \\
\text { minor actinides, } \\
\text { tritium, } \\
\text { iodine, } \\
\text { Group 18, } \\
\text { lanthanides* }\end{array}$ & $\begin{array}{l}\text { Separation scheme is } \\
\text { tailored to desired } \\
\text { product slate, but only } \\
\text { uranium, and plutonium } \\
\text { recovery data at } \\
\text { production scale. }\end{array}$ \\
\hline
\end{tabular}

\subsubsection{Melt Refining}

Figure 2-6 shows data for melt refining of metal fuel (Hesson1963). The data are the percent of elements removed from the molten used fuel. The removal fractions for elements within a chemical grouping are the same with two exceptions. First, the actinides thorium and americium behave differently from the

1. This of course begs the question of what does "slight modification" mean. Significant (in the plant sense) processing changes likely have to be made, though chemical modifications are relatively small. Additional cycles and tanks and piping are required. So it ultimately depends on how easy these changes are to implement, how long they take to implement, how easy they would be to detect, etc. However, there are of course stronger similarities between PUREX and UREX than a dry process like melt refining. 
other actinides. Since these two elements are addressed in FIT by individual isotopes, not the broad group of actinides (Th-228, 229, 230, 232; and Am-241, 242m, 243), their different removal fractions can be easily modeled. Second, tellurium is removed (95\%) but antimony is not; this is only a modeling difficulty if the mass of antimony is significant and it has important impurity limits.

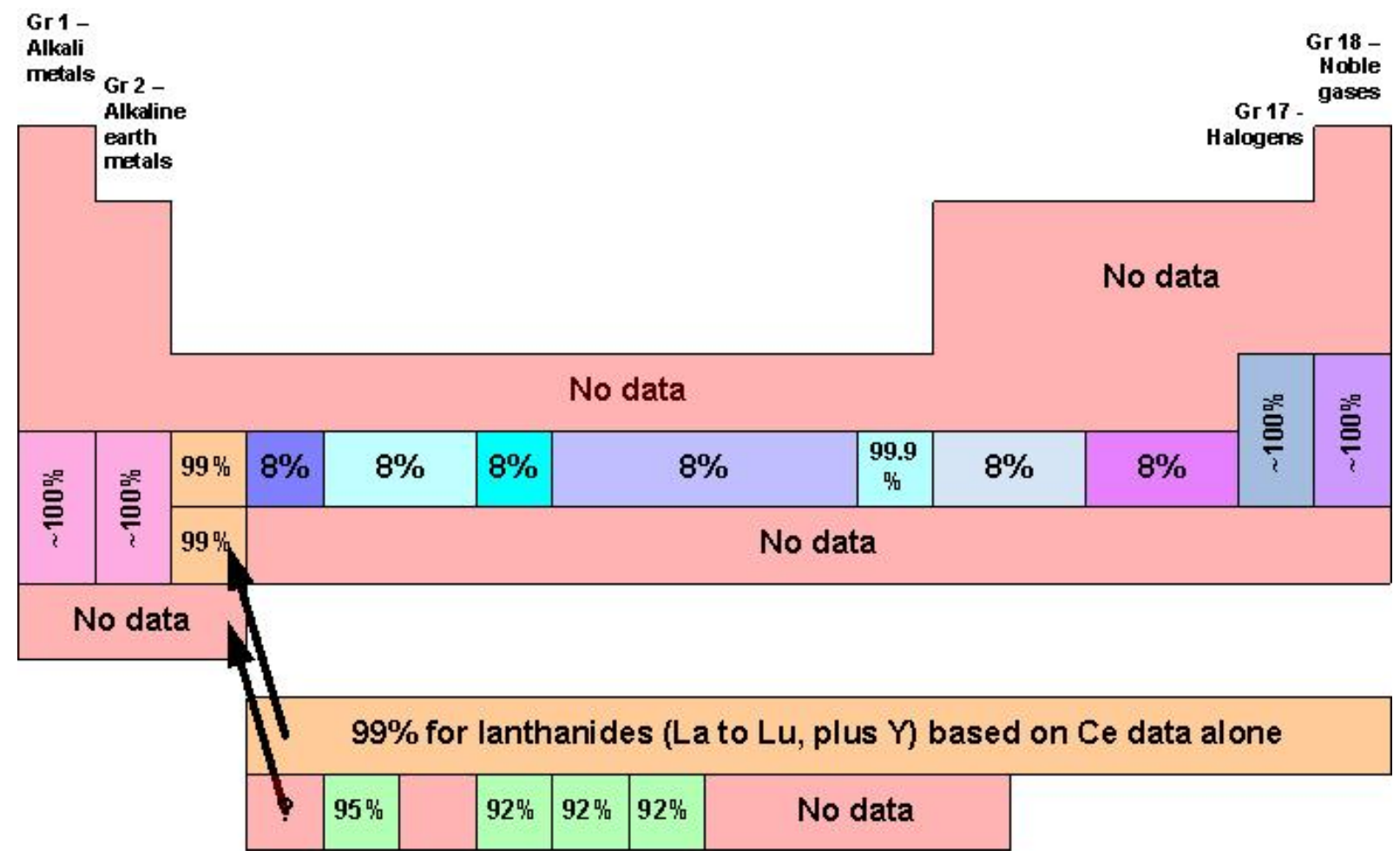

Figure 2-6. Separation figure illustrating melt refining — raw data only; values for actinides are percent recovered as product; values for everything else are percent removed from fuel product.

Figure 2-7 shows the same data as Figure 2-4, but with the "no data" elements shown explicitly. In lieu of other data, chemical analogs (elements within the same chemical group) will be assigned removal fractions equal to those as shown. The point is that there is at least one data point for each chemical group. 

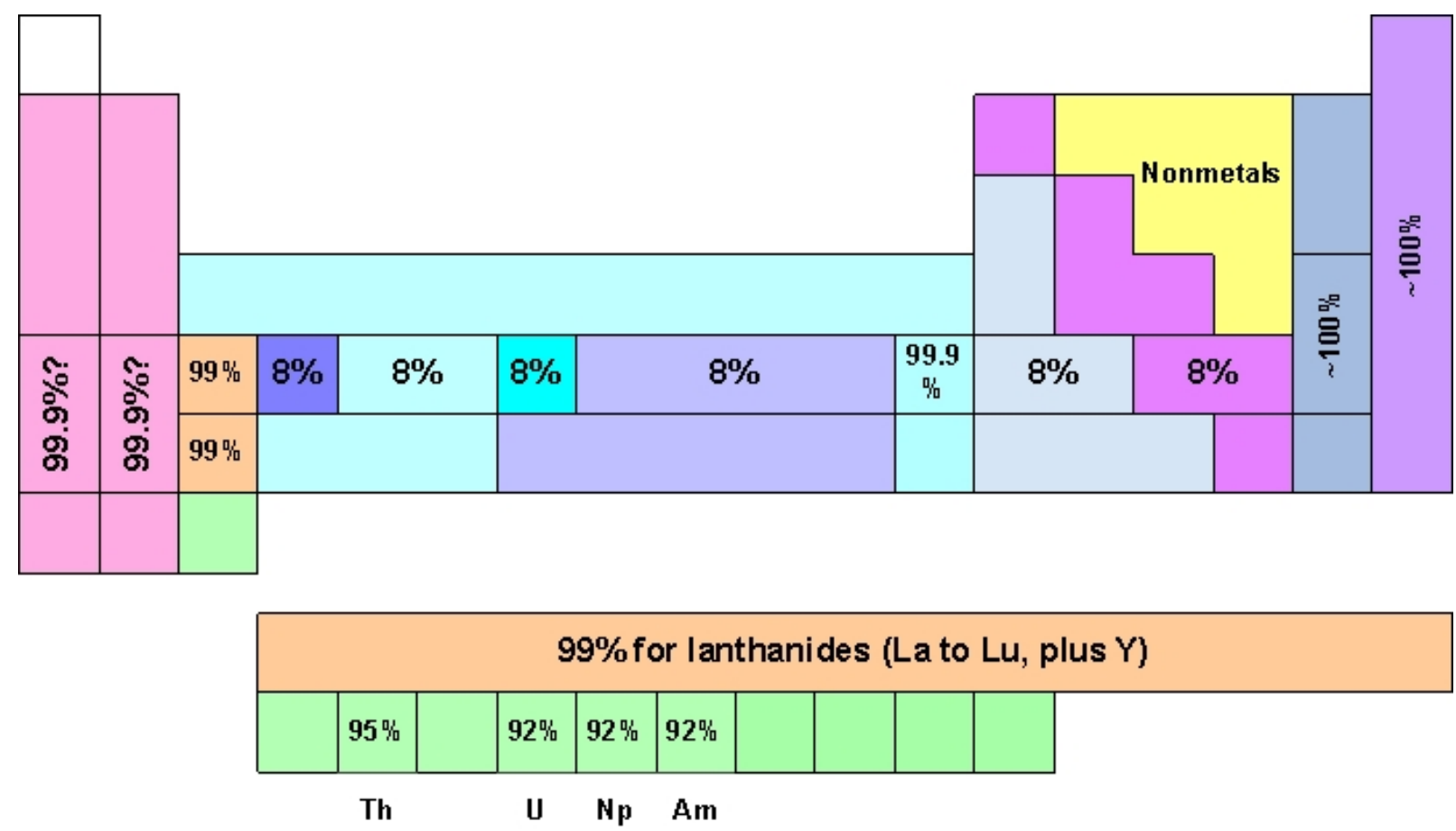

Figure 2-7. Separation figure illustrating melt refining; values for actinides are percent recovered as product; values for everything else are percent removed from fuel product.

Few observations can be made about melt refining simply from this figure.

- Because $95 \%$ of the lanthanides are removed, most of the neutron-absorbing fission products in used fuel are removed including Ce-144, one of the highest gamma-emitting fission products, and its progeny. This is beneficial from the standpoint of reducing gamma dose from this material, but is detrimental from the proliferation resistance and physical protection standpoint as it effectively removes a "self-protecting" dose.

- Few of the transition and noble metals are removed, and the associated impurities reduce fuel performance. This apparently was why melt refining was dropped from consideration for treatment of EBR-II spent fuel in favor of pyroelectrochemical processing. However, the impurities were not detrimental as uranium alloying materials up to $5 \mathrm{wt} \%$, since this uranium alloy achieved burnups above 8 at\% (i.e., $75 \mathrm{MWth}$-day $/ \mathrm{kg}$ )

- Since $95 \%$ of the americium is removed, the residual actinide-rich mass is primarily uranium and plutonium with the small mass amounts of neptunium, curium, berkelium, and californium. How this will be viewed from a proliferation resistance and physical protection standpoint is unknown.

\subsubsection{AIROX}

Figure 2-8 shows preliminary data for AIROX (i.e., what fraction of impurities and fission products are removed from used fuel) (Christian 1999). Data exist for most of the chemical groupings. But, generally there are few data points within a given chemical group; therefore, we do not know the actual variation within that group. With the sole exception of the second row noble metals, the removal fraction for all elements in a given grouping are effectively the same within the data available. For the second row noble metals, ruthenium is $22 \%$, rhodium, and palladium are not removed, and $\sim 100 \%$ of the silver is removed. Radiologically, the only key isotopes in that grouping are Ru-106 and Pd-107. 


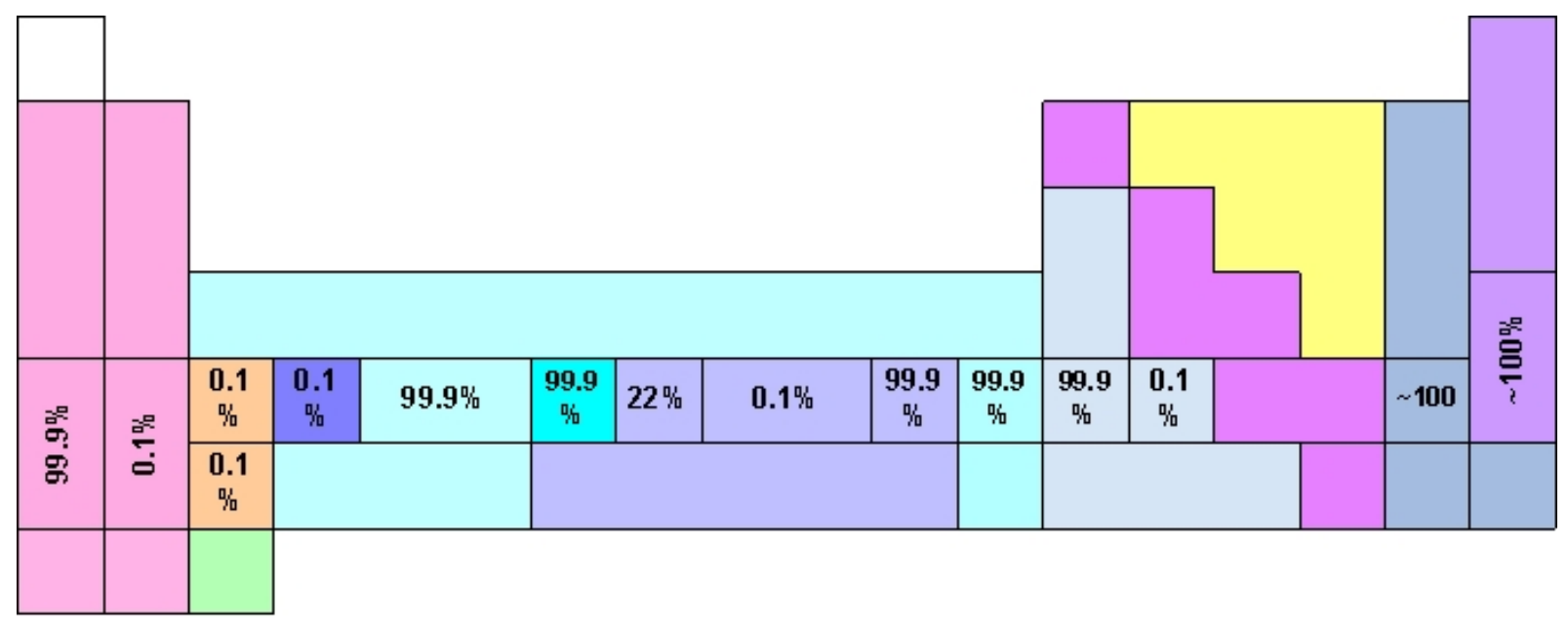

Nil separation of the lanthanides ( $L a$ to $L u$, plus $Y$ ) $=0.1 \%$

\section{Assume $99.9 \%$ retention}

Figure 2-8. Separation figure illustrating AIROX. Values for actinides are percent recovered as product, values for everything else are percent removed from fuel product.

\subsubsection{Electrochemical}

Development of a treatment process for sodium-bonded metallic fast reactor fuel using electrorefining has been investigated intermittently for over 2 decades. The main steps in the process currently under investigation include the electrochemical separation of useable materials from used fuel in a medium of molten chloride salt and a subsequent separation of residual salt from the recovered metal using a hightemperature process. As illustrated in Figure 2-9, the electrochemical separation is based on the free energy of the formation of chloride compounds at $500^{\circ} \mathrm{C}$. The products recovered include uranium (designated RU for recovered uranium as opposed to uranium that is enriched (EU), depleted (DU), or natural (NU)) or uranium-zirconium (RU-Zr) metal and a uranium-transuranic (U-TRU) metal. The UTRU product should be generally pure, based on thermodynamic models, and experiments are currently being conducted to verify the model predictions. The salt-metal separation is accomplished via a hightemperature process based on differences in either volatility or density. The process produces two primary waste streams: fuel cladding and fission-product laden salt. The fuel cladding contains the noble metal fission products and some residual actinides. The salt contains the active metal and lanthanide fission products and some actinides, but the actinides are stripped from the salt and returned to the electrorefiner before the salt is discarded. 
Figure 2-9. Used fuel components separated via free energy of formation at $500^{\circ} \mathrm{C}$. 

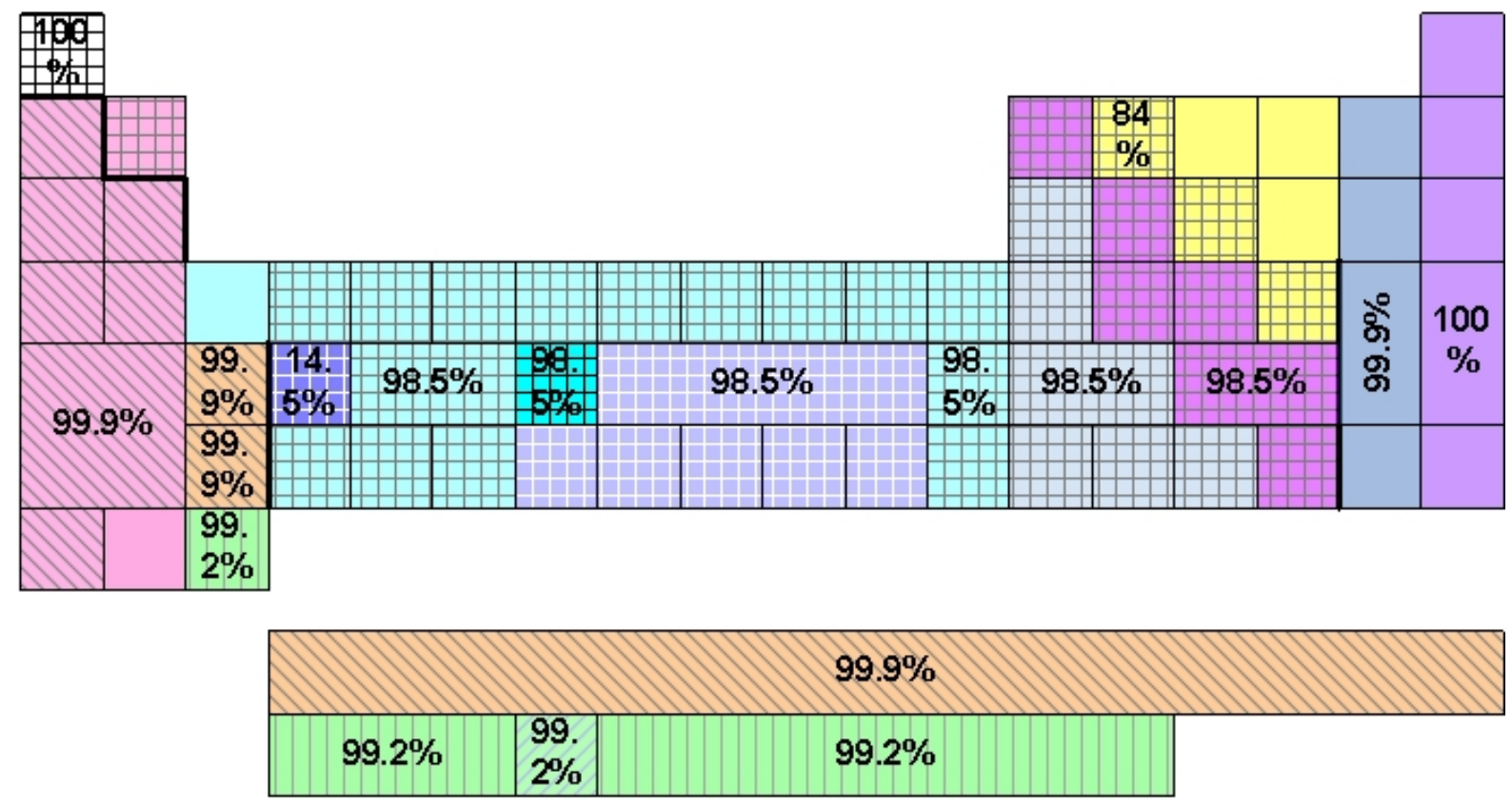

\section{$\mathrm{He} \quad$ Noble gases}

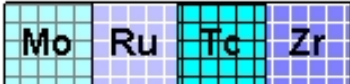

Relatively unstable chlorides, retained with cladding materials in the anode basket $\rightarrow$ metal waste

\section{U Recovered by a solid cathode as uranium product}

\section{Np Recovered by liquid cadmium cathode together with uranium}

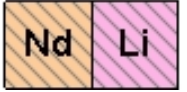

\section{Relatively stable chlorides, accumulated in the molten salt $\rightarrow$ ceramic waste}

Figure 2-10. Separation figure illustrating electrochemical separation. Values for actinides are percent recovered as product, values for everything else are percent removed from fuel product.

\subsubsection{Aqueous}

UREX+ (URanium EXtraction-plus) represents a number of potential flow sheets for the processing of commercial LWR spent fuel. It consists of combinations of solvent extraction processes that are designed to achieve targeted separations. These processes are denoted UREX+, reflecting the initial extraction of uranium. The UREX+ processes are distinguished from PUREX by the fact that they do not separate pure plutonium.

Figure 2-11 summarizes data for aqueous UREX separation. Tritium, the halogens and noble gases are separated as part of the pretreatment process, voloxidation. Any remaining volatile species are evolved during dissolution of the fuel. The other groups in Figure 2-11 can be linked with the processes described below. Because there is significant flexibility in process design and chemical pretreatment, very high recoveries are expected for essentially all of the products of interest. Unlike the other separation techniques, Group 1 and 2 elements behave similarly, with recoveries greater than $99 \%$. Separation of the 
lanthanides from the actinides is very high, with less than $0.05 \%$ of lanthanides remaining with the TRU elements after processing.
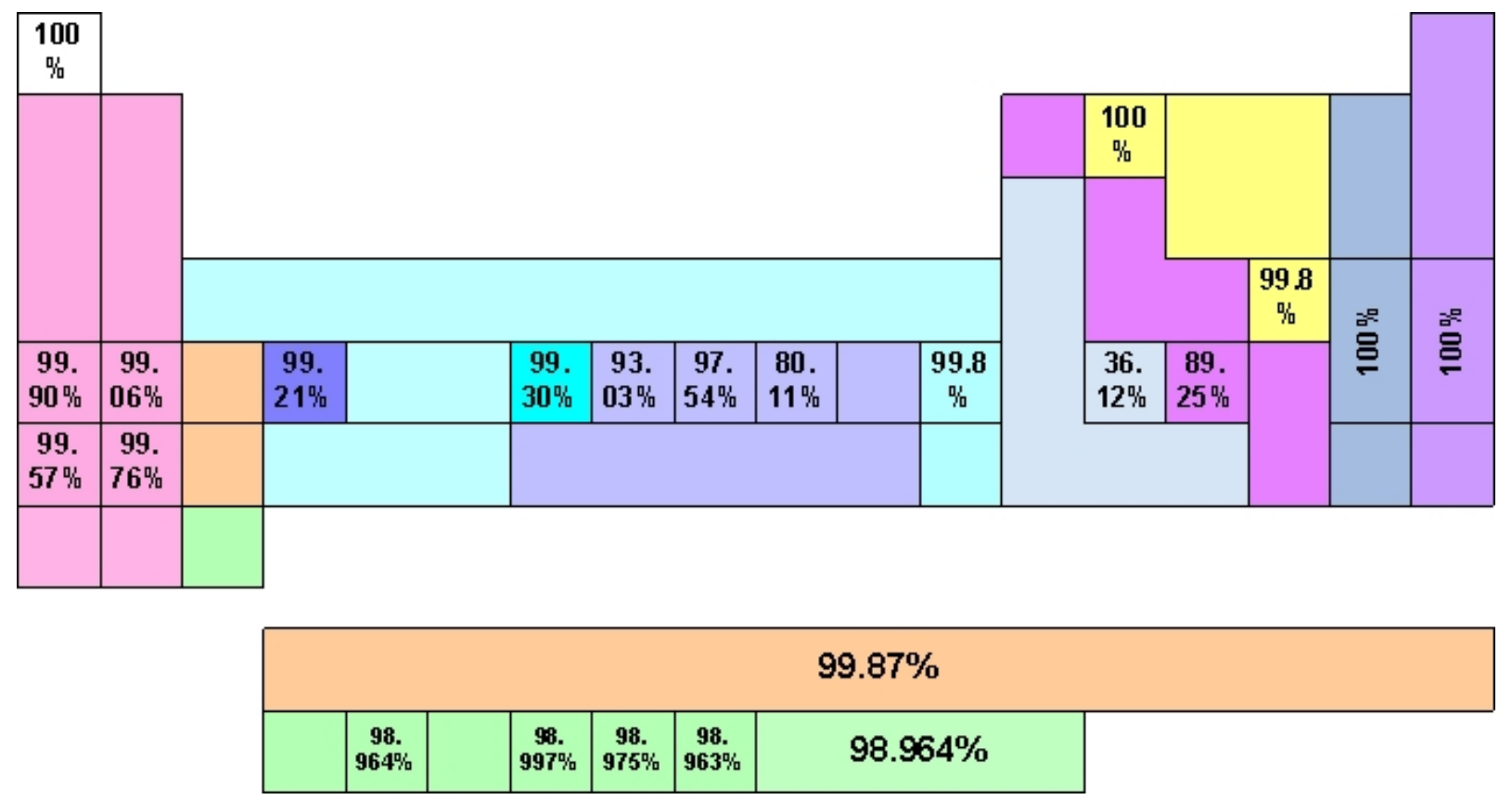

Figure 2-11. Separation figure illustrating aqueous separation. Values for actinides are percent recovered as product, values for everything else are percent removed from fuel product.

Table 2-5 summarizes various aqueous separation options, indicating which products are provided. Each of the UREX+ processes was designed for different recycle scenarios. The UREX $+1,1 \mathrm{a}$, and $1 \mathrm{~b}$ processes are intended for group extraction of the transuranic elements. The recovered transuranics are combined with uranium and fabricated into fresh fast reactor fuel. In UREX $+1 b$, uranium is combined with the TRU elements prior to solidification. The UREX $+2 / 2 \mathrm{a}$ and $+3 / 3$ a processes are designed for thermal recycle of plutonium and neptunium. The UREX +4 and 4 a processes allow for burning americium in specially-designed target assemblies. In the three alternatives designated "a," uranium is added to the plutonium/neptunium product in-process rather than to the plutonium/neptunium product. The residual fission products remaining after these separation steps are comparatively benign (low radiation level and heat generation rate) and can be immobilized at high concentrations in durable ceramic waste forms. Pre-treatment of the fuel captures the volatile fission products I-129, tritium, C-14, krypton, and xenon. As we sagaciously advance with the various use cases, we will have to identify which variant(s) to consider. $\mathrm{UREX}+1 \mathrm{~b}$ and $\mathrm{UREX}+2 / 3 / 4 \mathrm{a}$ are variations in which uranium is recovered with the TRU elements for proliferation risk reduction.

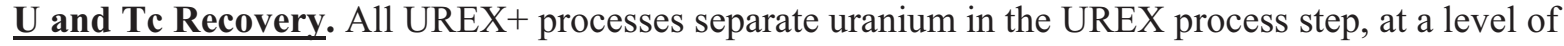
purity that permits (1) re-enrichment, (2) storage in unshielded facilities for near-term or future use, or (3) disposal as low-level waste. The long-lived fission products iodine and technetium are recovered in the front-end processes and the UREX process step, respectively, and immobilized in durable waste forms. Technetium is recovered by anion exchange.

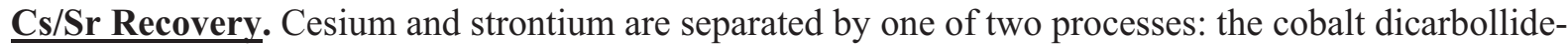
polyethylene glycol (CCD-PEG) process or the FPEX (Fission Product Extraction) process. The separation step can be omitted with no detrimental effect on downstream processes. 
TRU Recovery. In UREX $+1 \mathrm{a}$ and $1 \mathrm{~b}$ the transuranic elements are extracted in a two-step process, while UREX+1 eliminates the second step. In UREX $+1 b$, uranium is added to the TRU product prior to solidification. The first step, TRansUranic Extraction (TRUEX), efficiently separates the transuranics from all fission products except the lanthanide elements. In UREX +1 , the actinide-lanthanide product is solidified for interim storage. In UREX $+1 \mathrm{a}$ and $1 \mathrm{~b}$, the actinide/lanthanide product from TRUEX is the feed to the second step, TALSPEAK (Trivalent Actinide Lanthanide Separation by Phosphoric Extractants and Aqueous Komplexes). The TRU product stream is converted to a stable form for fuel fabrication. The concentrated lanthanide stream is combined with the TRUEX raffinate and converted to a high-level waste form, yet to be defined.

Plutonium/Neptunium Recovery. In the UREX+2, 3, and 4 options, NPEX is run prior to TRUEX to separate plutonium and neptunium, with or without uranium, from the other fuel components. In $\mathrm{UREX}+2$ and $2 \mathrm{a}$, the americium/curium/lanthanide product is converted to a solid form for storage._For $\mathrm{UREX}+3,3 \mathrm{a}$ and 4, 4a, the TRUEX and TALSPEAK are then run sequentially with TALSPEAK yielding an americium/curium product that is solidified for target fabrication.

Americium/Curium Recovery. For UREX+3, 3a and UREX+4, 4a, the TRUEX and TALSPEAK processes are run identically to that used for UREX $+1,1 \mathrm{a}$, and $1 \mathrm{~b}$ - the sole difference being the absence of plutonium and neptunium from the TALSPEAK TRU product. In UREX +4 and $4 \mathrm{a}$, the americium/curium product from the TALSPEAK process is further treated to separate americium from curium. The two products would be solidified with the americium forming a precursor for target fabrication and curium converted to a waste form for disposal. Currently, there is no process that has been developed at the lab-scale that has demonstrated applicability to large-scale operations.

Table 2-5. Summary of aqueous separation options.

\begin{tabular}{|c|c|c|c|c|c|c|c|c|}
\hline & $\begin{array}{c}\text { Product } \\
1\end{array}$ & $\begin{array}{c}\text { Product } \\
2\end{array}$ & $\begin{array}{c}\text { Product } \\
3\end{array}$ & $\begin{array}{c}\text { Product } \\
4\end{array}$ & $\begin{array}{l}\text { Product } \\
5\end{array}$ & $\begin{array}{l}\text { Product } \\
6\end{array}$ & $\begin{array}{c}\text { Product } \\
7\end{array}$ & $\begin{array}{c}\text { Product } \\
8\end{array}$ \\
\hline UREX+1 & \multirow{9}{*}{ Uranium } & \multirow{9}{*}{ Technetium } & \multirow{9}{*}{$\mathrm{CsSr}$} & TRU/Ln & FP & & & \\
\hline $\mathrm{UREX}+1 \mathrm{a}$ & & & & TRU & \multirow{2}{*}{$\mathrm{FP} / \mathrm{Ln}$} & & & \\
\hline UREX+1b & & & & U/TRU & & & & \\
\hline UREX+2 & & & & $\mathrm{Pu} / \mathrm{Np}$ & \multirow{2}{*}{$\mathrm{Am} / \mathrm{Cm} / \mathrm{Ln}$} & \multirow{2}{*}{ FP } & & \\
\hline UREX+2a & & & & $\mathrm{U} / \mathrm{Np} / \mathrm{Pu}$ & & & & \\
\hline UREX+3 & & & & $\mathrm{Pu} / \mathrm{Np}$ & \multirow{2}{*}{$\mathrm{Am} / \mathrm{Cm}$} & \multirow[b]{2}{*}{$\mathrm{FP} / \mathrm{Ln}$} & & \\
\hline UREX+3a & & & & $\mathrm{U} / \mathrm{Np} / \mathrm{Pu}$ & & & & \\
\hline UREX+4 & & & & $\mathrm{Pu} / \mathrm{Np}$ & \multirow{2}{*}{$\mathrm{Am}$} & \multirow{2}{*}{$\mathrm{Cm}$} & \multirow{2}{*}{$\mathrm{FP} / \mathrm{Ln}$} & \\
\hline UREX+4a & & & & $\mathrm{U} / \mathrm{Np} / \mathrm{Pu}$ & & & & \\
\hline PUREX & Uranium & & & $\mathrm{Pu}$ & & & & \multirow{2}{*}{$\begin{array}{l}\mathrm{Tc} / \mathrm{CsSr} / \\
\mathrm{NpAmCm} / \\
\mathrm{FP} / \mathrm{Ln}\end{array}$} \\
\hline COEX & $\mathrm{U} / \mathrm{Pu}$ & & & & & & & \\
\hline
\end{tabular}




\begin{tabular}{|c|c|c|c|c|c|c|}
\hline NUEX & & & $\mathrm{U} / \mathrm{Nn} / \mathrm{P}_{1}$ & \multirow{3}{*}{$\mathrm{Am} / \mathrm{Cm}$} & \multirow[b]{2}{*}{$\mathrm{Np}$} & \multirow{2}{*}{$\begin{array}{l}\mathrm{Tc} / \mathrm{CsSr} / \\
\mathrm{FP} / \mathrm{Ln}\end{array}$} \\
\hline NUEX+1 & $\mathrm{U} / \mathrm{Pu}$ & & & & & \\
\hline $\mathrm{NUEX}+2$ & $\mathrm{U} / \mathrm{Pu}$ & Tc & & & $\mathrm{Np}$ & $\begin{array}{l}\mathrm{CsSr} / \\
\mathrm{FP} / \mathrm{Ln}\end{array}$ \\
\hline $\begin{array}{l}\mathrm{FP}=\text { Fiss } \\
\text { noble gas } \\
\mathrm{Ln}=\text { Lant }\end{array}$ & $\begin{array}{l}\text { produ } \\
\text { nides }\end{array}$ & & & & & (iodine, \\
\hline
\end{tabular}

\subsection{Is Equilibrium Possible?}

To reconsider whether equilibrium is possible with minimum fuel treatment cases, we constructed a simple spreadsheet model with the following approximations.

- Single fission product impurity species, a fraction $\times$ of the total.

- Fast reactor with a fixed burnup (f) (i.e., each pass through the reactor f percent of the initial TRU+U is converted to fission products). For illustration purposes, we set this to $14 \%$, consistent with the $\mathrm{CR}=0.5$ cases being analyzed.

- The separation efficiency(s) is fixed, the amount of an impurity that is retained in the fuel recycle stream is s times the mass flow.

- The composition after separation from recycle $\mathrm{N}$ is the incoming composition for recycle $\mathrm{N}+1$.

Then, we derive the following:

1. The increase in impurities coming out of the reactor is $f(1-x)$, or $f$ times the fuel fraction of the incoming fuel.

2. The output composition is given by $x+f(1-x)$, or the input impurity plus what is created in the reactor.

3. The fraction of impurities after separation is given by $(1-s)[x+f(1-x)]$.

4. The equilibrium fraction of impurities is given by (1-s) $f /[(1-s) f+s]$.

Figure 2-12 shows the calculated number of recycles to reach $90 \%$ of equilibrium impurity fraction. Recall from earlier in Section 2 that in minimum fuel treatment cases, the separation efficiency varies from $\sim 0 \%$ to $\sim 100 \%$. At $100 \%$, the equilibrium output fraction is 0.00 and it is reached on the first recycle. At $0 \%$ separation efficiency, the equilibrium impurity fraction is 1.00 impurity; 16 recycles are required to reach $90 \%$ of 1.00 or an impurity fraction of 0.90 . 


\section{\# to reach $90 \%$ of equilibrium}

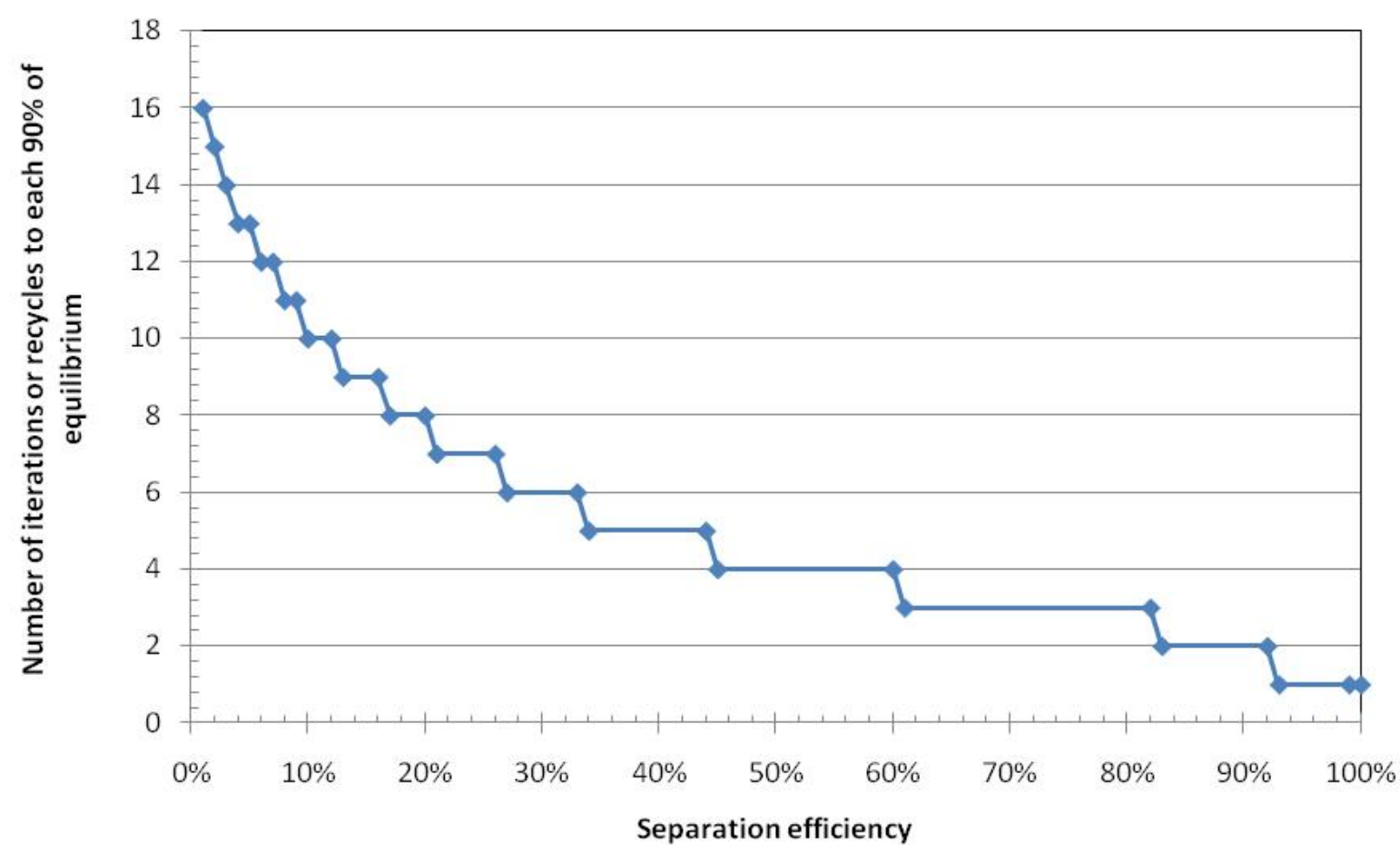

Figure 2-12. Number of recycles required to reach $90 \%$ of equilibrium.

Figure 2-13 shows the fraction of fuel that is impurity for a range of separation efficiencies as a function of the number of recycles. In this example, the initial impurity was $1 \%$ of the fuel. The equilibrium impurity fraction is independent of this number. A separation efficiency of about $93 \%$ is sufficient to keep the impurity fraction at $1 \%$ indefinitely (with $14 \%$ burnup). In traditional chemical separation techniques (aqueous and electrochemical) in which separation efficiencies are significantly over $90 \%$, the situation should remain stable. Indeed, with $99 \%$ removal, the actual equilibrium impurity fraction is only $0.14 \%$, or $1 \%$ of the assumed $14 \%$ burnup.

However, with minimum fuel treatment cases, the separation efficiencies for a significant fraction of fission products is sometimes quite low, approaching $0 \%$. Even at $10 \%$ separation efficiency, the fuel will quickly be mostly impurity.

Equilibrium is a reasonable condition for traditional separation approaches, but not for the minimum fuel treatment technologies considered here. 


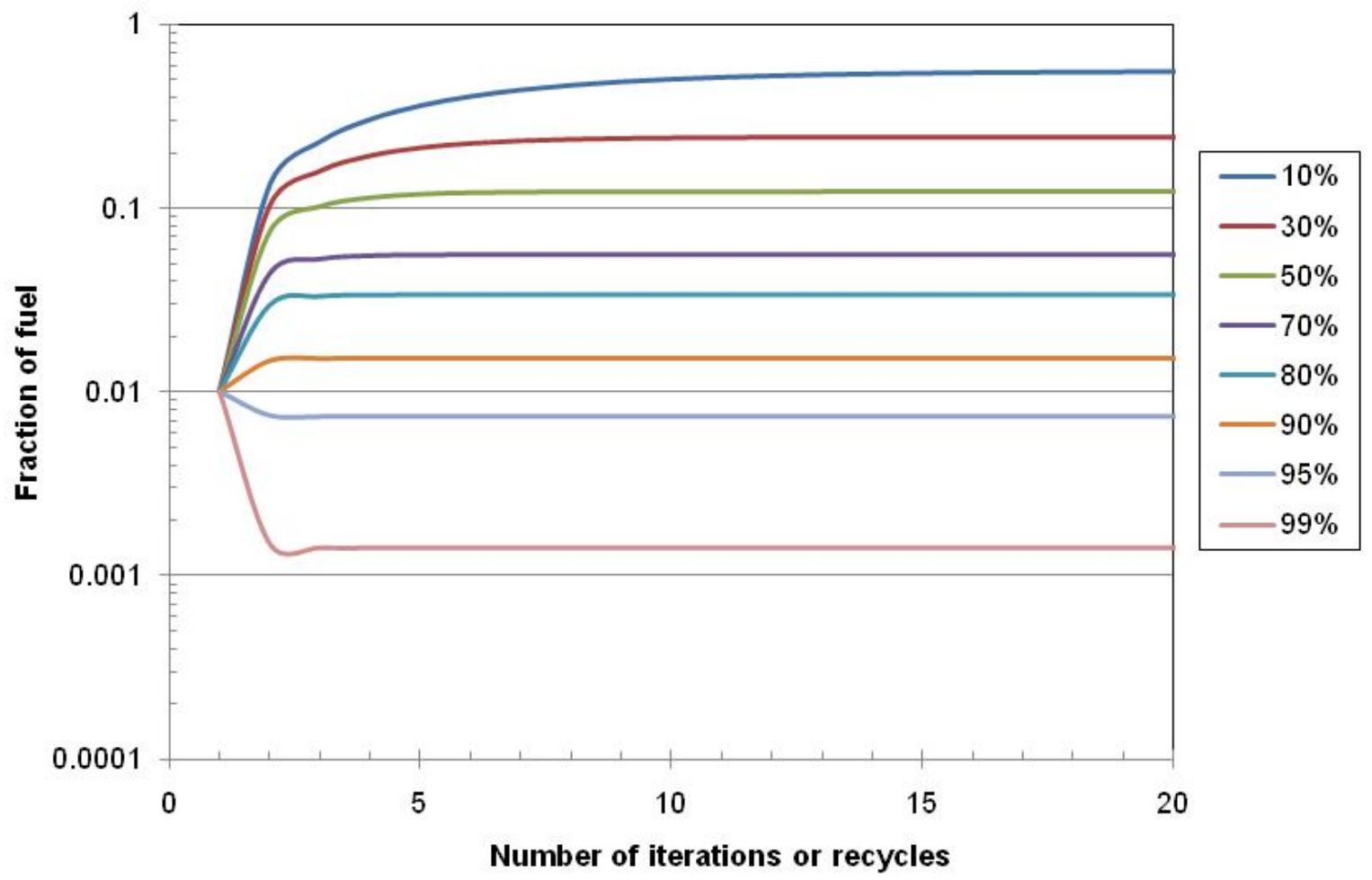

Figure 2-13. Fraction of fuel that is impurity for a range of separation efficiencies.

\subsection{How Much Chemistry is needed to FIT Together?}

The preceding equilibrium example also helps illustrate why multiple chemical groups must be studied. No option has low separation efficiency for every chemical group. In addition to the separation efficiency variation by chemical group, the neutron absorption and the impurity impact on fuel fabrication vary by chemical groups. In FY 2010, we attempted to start with a small number of chemical groups, but found difficulties and eventually settled on the Set of 15 in Figure 2-1. These are as follows:

Alternatively, we decided that we needed this degree of chemical complexity. As indicated previously in this section, we have found that even this number of chemical groups does not allow complete alignment among the two fuel fabrication options and four separation options. In hindsight, it may have been easier to simply analyze all 98 chemical elements. 


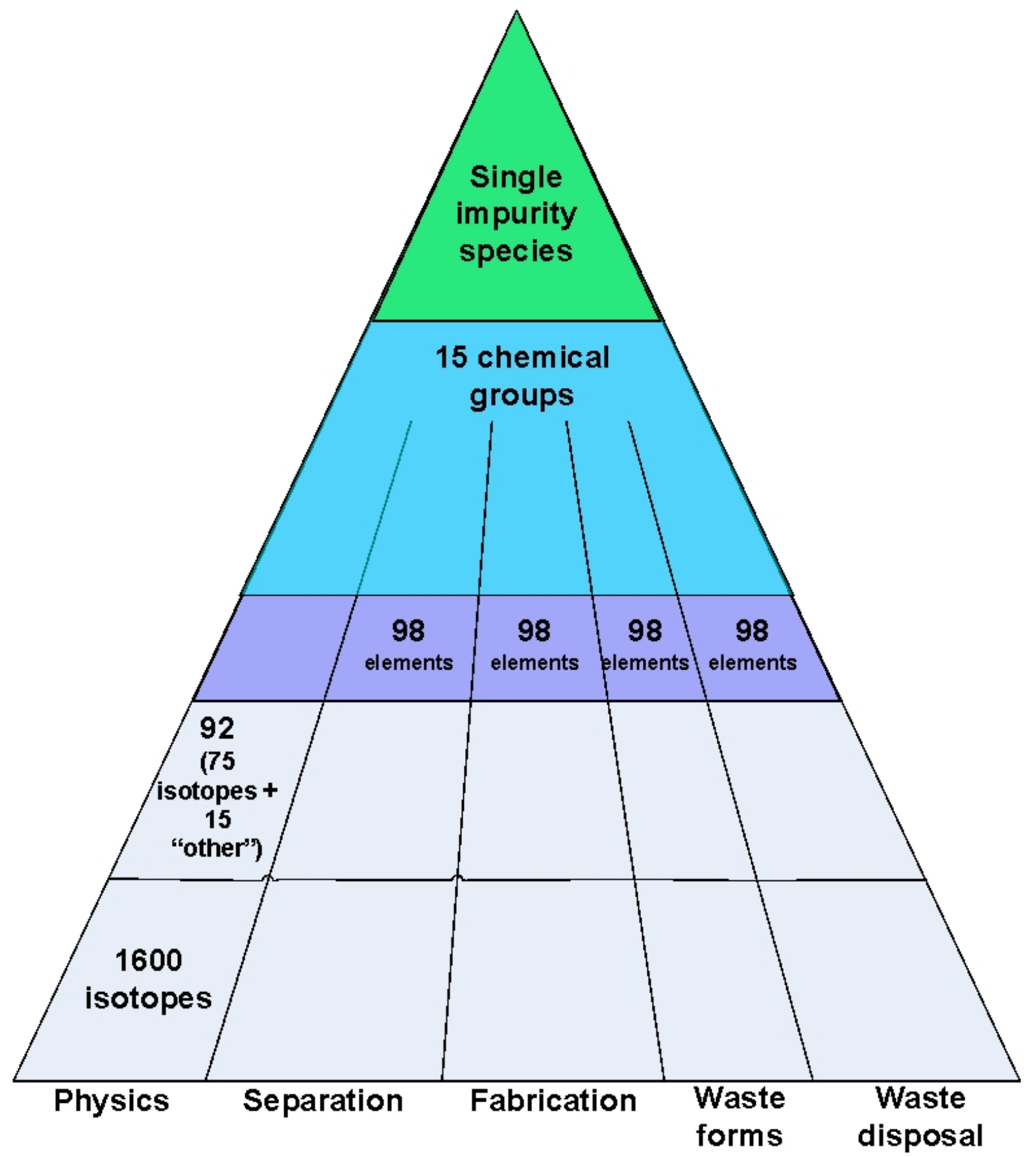

Figure 2-14. Chemical complexity. 


\section{MODELING}

In FY 2009, we analyzed the losses of well-defined Global Nuclear Energy Partnership (GNEP)-type options. We have concluded that an integrated analysis tool is required for more systematic analysis of a much broader range of options, which we originally called SLAM (System Losses and Assessment Model), but now call FIT. Additional information is in Appendix A.

Figure 3-1 shows how FIT corresponds into the evolving system analysis toolbox. The bottom part of the pyramid is analyses, tools, and data done by the other research campaigns.

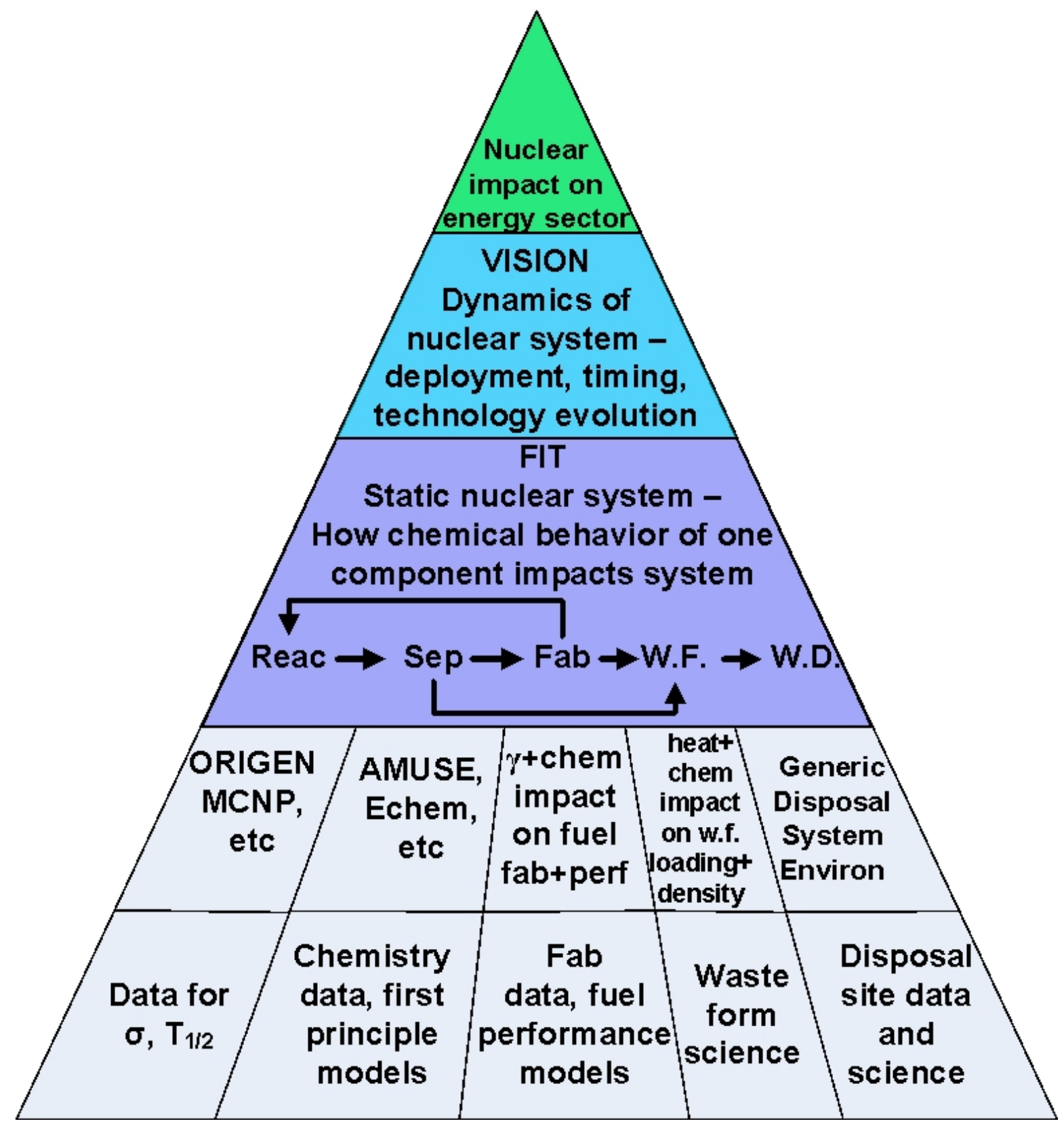

Figure 3-1. Role of FIT into the evolving system analysis toolbox. 
Many of the individual models within FIT actually have three potential roles in the pyramid, which will typically be achieved in a sequential order:

1. As standalone tools that "bridge" from lower-level tools and enable rapid response and parameter studies.

\section{As components to FIT}

3. As components or source algorithms for VISION.

As an example, there is now a stand-alone Excel spreadsheet tool for calculating isotope decay and isotope-specific time-dependent parameters such as heat, radiotoxicity, gamma emission, and neutrons (Bays2010). This tool has have two manifestations in FIT. First, the decay capability in that tool has been extracted and simplified for FIT purposes and time scales (decay up to a few hundred years). Second, the tool has been used to calculate look-up tables of heat, radioactivity, gamma emission, and neutrons for chemical groupings up through the waste management time frame. This tool has the same two manifestations for VISION: a check of the isotope decay in VISION and the method for calculating isotope-coefficients that are now in use in VISION.

This approach of having three venues for such a tool provides maximum flexibility and allows us to continue building tools step-by-step, validating and learning as we go.

Our work suggests that a key issue throughout the pyramid is the proper "linkage" from one level to the next, where "linkage" is not to imply a direct coupling of 1 bit of software to another, but rather any means of transferring information up and down the pyramid. Options can include the following:

- Single integrated suite of software that can be used at one level or another.

- Direct coupling of software modules (i.e., higher-level software calls lower-level software).

- Simplified versions of models from one level incorporated into the next higher-level model (i.e., simplified form $[0.1 \mathrm{MB}]$ of the stand-alone isotope decay spreadsheet [ $>80 \mathrm{MB}]$ incorporated into FIT).

- Look-up tables produced from one level called by the higher-level model (i.e., fuel composition input/output recipes produced from reactor physics models will be used in FIT).

- Approximated algorithms produced by one level of understanding incorporated into higher-level model.

\subsection{Architecture}

Figure 3-2 shows the planned eventual architecture for FIT involving a mass flow calculation engine (FY 2010) and a solver (future years). 


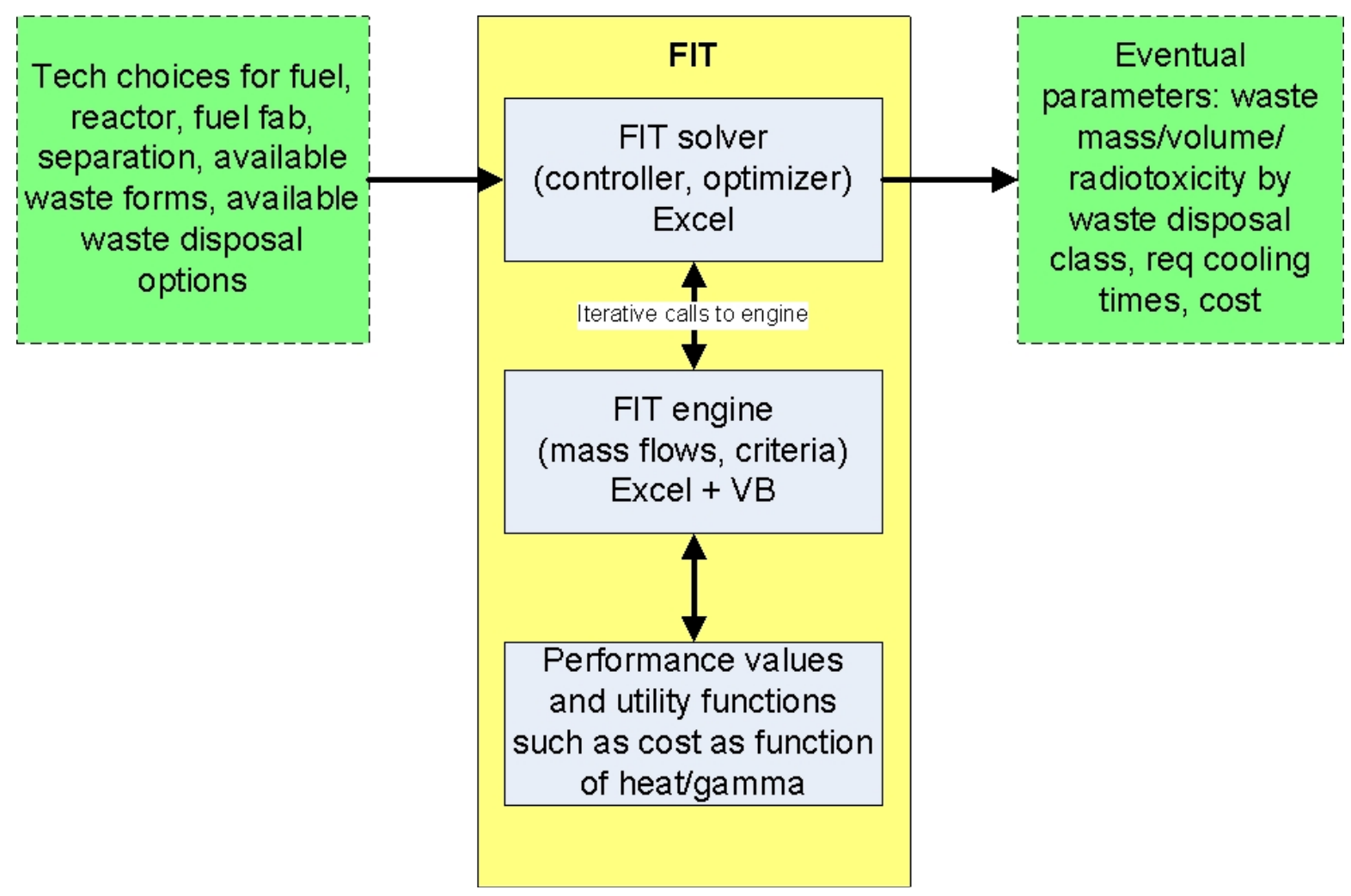

Figure 3-2. FIT architecture.

Figure 3-3 shows the basic architecture for the mass flow engine, which is the focus of FY 2010 work. When a scenario involves additional steps (e.g., the 2-tier options of LWR-UOX to LWR-MOX to FR), the intent is to use the mass engine in two steps: the UOX/MOX step and the MOX/FR. 


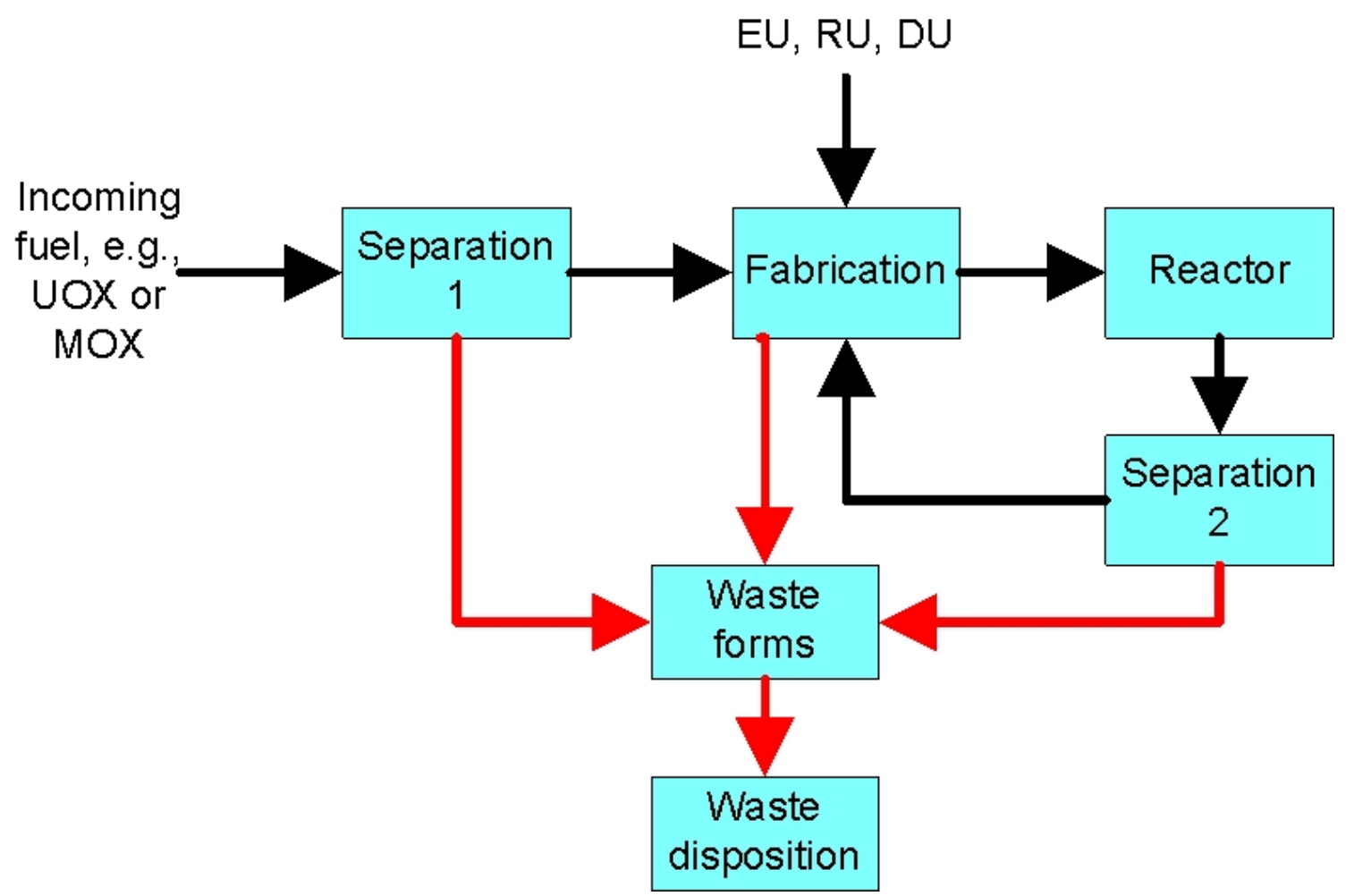

Figure 3-3. FIT mass flow calculation engine.

Figure 3-4 shows more detail of the mass and information flow in the FIT model. It shows the main unit operations modules in the FIT model. Each module is a location where process streams are chemically or physically changed. Inputs are shown coming in the left side of each of the grey module boxes. Outputs are shown coming out of the right side of each module. User inputs/choices the green boxes coming into the top of the modules indicating that some features are user defined.

There are at least five places in the FIT model that would include storage of material/waste. A simplified decay/ingrowth calculation will be performed for these storage steps for radioactive elements in the inventory following the FIT model.

The format or layout of the FIT model is generic enough to cover the anticipated multiple use cases. However, it was not intended to be suitable for studying once-through cases. 

Model Inputs

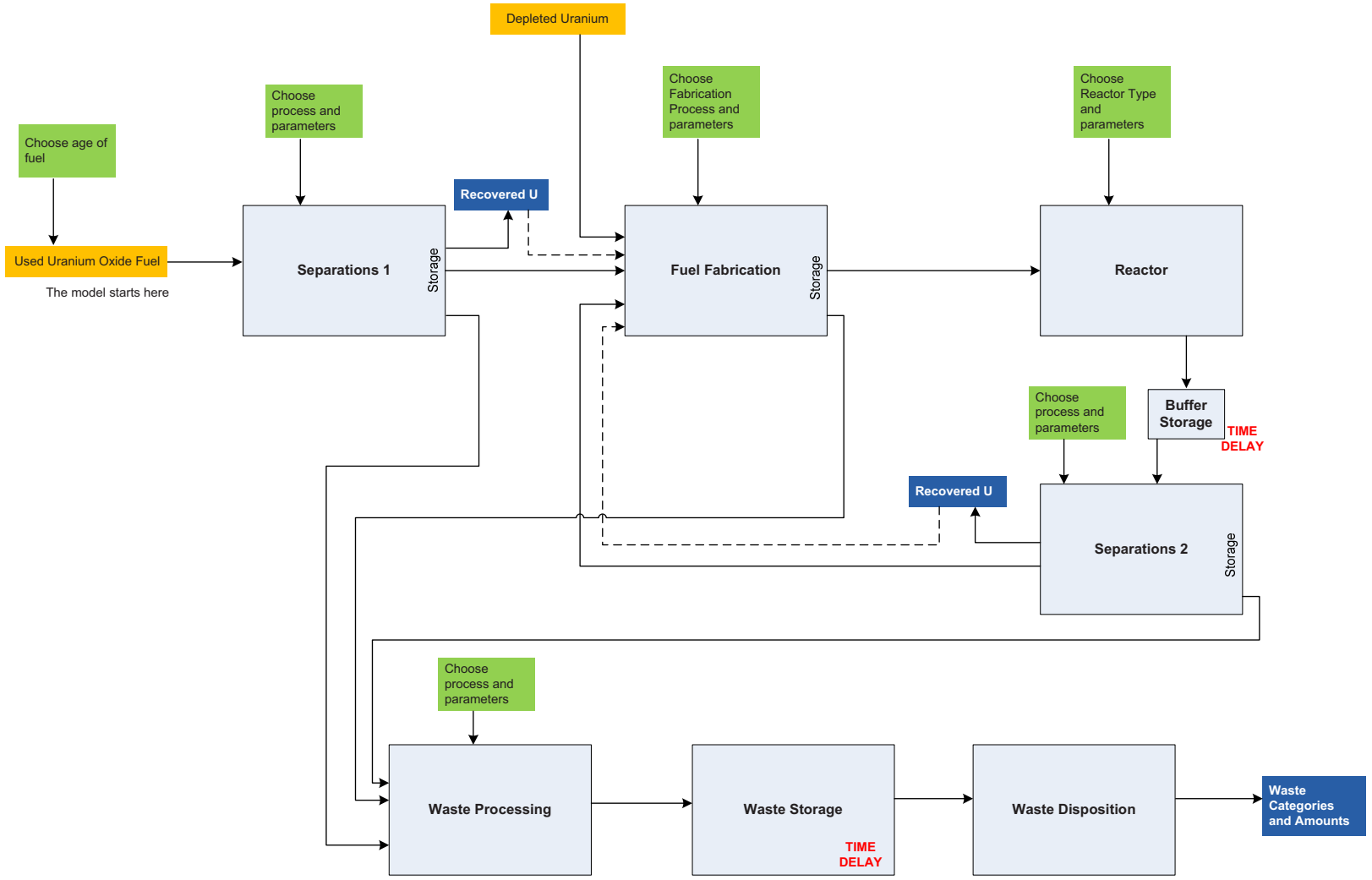

Figure 3-4. FIT modules.

Figure 3-5 shows a preliminary assessment of choices (green) and information flows (red) on top of the mass flows (black). Team discussion made it obvious that no two people viewed the information steps the same (i.e., what decisions lead to what). That realization generated the need for a "solver" that will be able to use the mass engine from different perspectives. 


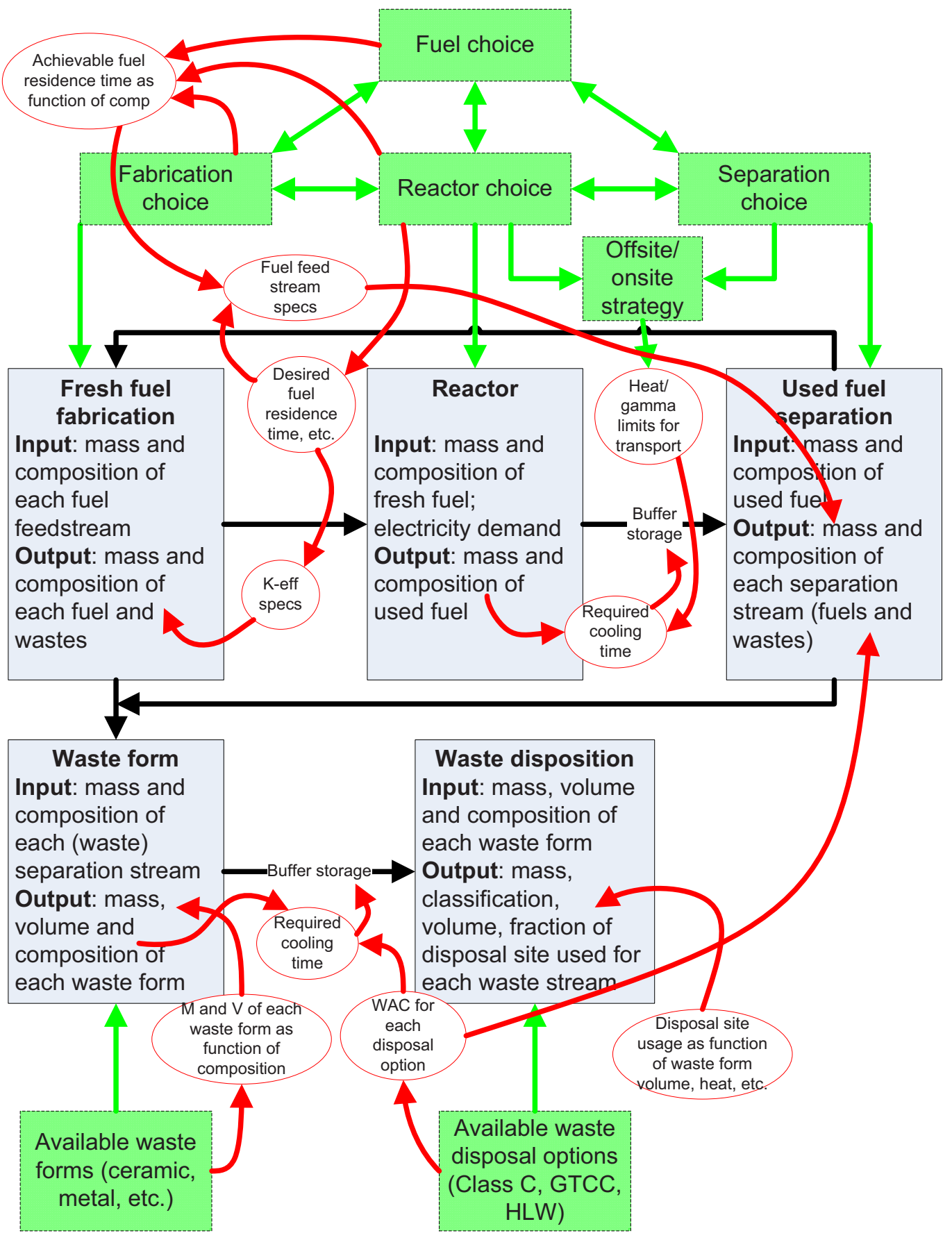

Figure 3-5. Technological choices (green) and information flows (red) overlaying mass flows (black).

\subsection{Time Lags}

"Time" is a critical factor in FIT, even when we were considering it an equilibrium-only model. The same issue exists in the stand-alone Isotope Parameter and Decay Tool (Bays 2010) and VISION (Jacobson 2010). Table 3-1 summarizes what the time lags are and which approaches and approximations are used. 
Table 3-1. How different tools approximate different time lags.

\begin{tabular}{|c|c|c|c|c|}
\hline & & Stand-alone Tools & FIT & VISION \\
\hline $\begin{array}{l}\text { From reactor } \\
\text { to separations }\end{array}$ & $\mathrm{t}_{\mathrm{rs}}$ & $\begin{array}{l}\text { Isotope parameter } \\
\text { and decay tool }\end{array}$ & Simplified decay tool & $\begin{array}{l}\text { Isotope decay built into } \\
\text { model }\end{array}$ \\
\hline \multirow{3}{*}{ Separations } & & \multicolumn{3}{|c|}{ Apply separation matrix to composition that exists at time of separations. } \\
\hline & & \multicolumn{3}{|c|}{$\begin{array}{l}\text { Calculate heat and other parameters by then-current composition (which } \\
\text { accounts for } \mathbf{t}_{\mathrm{rs}} \text { impact on reactor output composition) } \times \text { time-independent } \\
\text { parameters by isotope. } \\
\text { Heat, gamma, neutron emission, etc., for short-lived progeny must be } \\
\text { included with parent. Otherwise, progeny are not included with parent. }\end{array}$} \\
\hline & na & \multicolumn{3}{|c|}{ Isotope decay during separation steps is not estimated. } \\
\hline $\begin{array}{l}\text { From separations } \\
\text { to fuel fab }\end{array}$ & $t_{\mathrm{sf}}$ & $\begin{array}{l}\text { Isotope parameter and } \\
\text { decay tool }\end{array}$ & Simplified decay tool & $\begin{array}{l}\text { Isotope decay built into } \\
\text { model }\end{array}$ \\
\hline \multirow{3}{*}{ Fuel fabrication } & & \multicolumn{2}{|c|}{$\begin{array}{l}\text { Blend } U \text {, TRU according to adjusted input } \\
\text { recipes to keep k constant with original input } \\
\text { recipe at time } \mathbf{t}_{\mathrm{sf}}+\mathbf{t}_{\mathrm{fr}} \text {. }\end{array}$} & $\begin{array}{l}\text { Blend } U \text {, TRU according } \\
\text { to unadjusted input } \\
\text { recipes (for now). }\end{array}$ \\
\hline & & \multicolumn{3}{|c|}{$\begin{array}{l}\text { Calculate generation of heat and other metrics that impact the cost and } \\
\text { proliferation resistance of fuel fabrication by then-current composition } \\
\text { (which accounts for } \mathbf{t}_{\text {sf }} \text { impact on reactor output composition) } \times \text { time- } \\
\text { independent parameters by isotope. }\end{array}$} \\
\hline & na & \multicolumn{3}{|c|}{ Isotope decay during fuel fabrication steps is not estimated. } \\
\hline $\begin{array}{l}\text { From fuel fab } \\
\text { to reactor }\end{array}$ & $\mathrm{t}_{\mathrm{fr}}$ & $\begin{array}{l}\text { Isotope parameter and } \\
\text { decay tool }\end{array}$ & Simplified decay tool & $\begin{array}{l}\text { Fuel is fabricated on a } \\
\text { as-needed basis, } \\
\text { insignificant isotope } \\
\text { decay }\end{array}$ \\
\hline \multirow{3}{*}{ Reactor } & & \multicolumn{2}{|c|}{ Input and output given by adjusted output recipe } & \multirow{2}{*}{$\begin{array}{l}\text { Input and output given } \\
\text { by unadjusted output } \\
\text { recipe (for now) }\end{array}$} \\
\hline & & \multicolumn{2}{|c|}{$\begin{array}{l}\text { Output actinides given by Mr.Tau depletion } \\
\text { calculation. For now, } \mathrm{FP}_{\mathrm{adi}}=\mathrm{FP}_{\text {unadiusted }}+\mathrm{FP}_{\text {input }} \\
\text { Soon, add lumped FP to expanded Mr.Tau. }\end{array}$} & \\
\hline & & \multicolumn{3}{|c|}{ Isotope decay in reactor is accounted for in the physics calc. } \\
\hline $\begin{array}{l}\text { From separation } \\
\text { to waste fabrication }\end{array}$ & $\mathrm{t}_{\mathrm{sw}}$ & $\begin{array}{l}\text { Isotope parameter and } \\
\text { decay tool }\end{array}$ & Simplified decay tool & $\begin{array}{l}\text { Waste fabrication is } \\
\text { assumed to occur } \\
\text { immediately after } \\
\text { separation, with } \\
\text { insignificant isotope } \\
\text { decay. }\end{array}$ \\
\hline $\begin{array}{l}\text { Waste } \\
\text { characteristics }\end{array}$ & & \multicolumn{3}{|c|}{$\begin{array}{l}\text { Parameters for time into the future calculated by Isotope Parameter and } \\
\text { Decay Tool } \times \text { inventory (e.g., radiootoxicity at } 1000 \text { years into the future). } \\
\text { Values for progeny must be kept with parent. }\end{array}$} \\
\hline
\end{tabular}

\subsection{Separation}

The first separations module developed with input from Separations Campaign allows the user to choose the separations process (UREX+1a, AIROX, COEX, NUEX). 


\subsubsection{Separation Streams}

The input fuel is separated into the 14 separation streams in Table 3-2 based on split factors for the chosen separations process. Table 3-1 is intended to reflect the generic types of mass flows from separation or fuel fabrication. Thus, there must be sufficient flexibility to account for all mass that comes into or goes out of separation, fuel fabrication, or reactor modules in FIT. Each of these streams includes the full list of 81 possible radionuclides from the input fuel.

Table 3-2. Separation Streams

\begin{tabular}{|c|c|}
\hline Separation streams & Comment \\
\hline Fuel & $\begin{array}{l}\text { If fresh, fuel after fabrication and before reactor insertion. } \\
\text { If used, fuel removed from a reactor before either } \\
\text { mechanical or chemical separation }\end{array}$ \\
\hline Segregated metal hardware & \multirow[b]{2}{*}{$\begin{array}{l}\text { Fuel assembly structure, in-core structure, moderator } \\
\text { blocks, etc., mechanically removed from fuel before } \\
\text { chemical separation. The implication is that such material } \\
\text { has no direct fuel contamination. Examples include non- } \\
\text { fuel zones of fast reactor fuel and graphite moderator } \\
\text { blocks in High-Temperature Gas-Cooled Reactor } \\
\text { (HTGR). }\end{array}$} \\
\hline Segregated nonmetal hardware & \\
\hline Metal cladding/coating & \multirow{2}{*}{$\begin{array}{l}\text { Fuel cladding (e.g., steel for FR, Zr for LWR) or coating } \\
\text { (e.g., SiC clad for LWR, TRISO for HTGR) not removed } \\
\text { before chemical separation. }\end{array}$} \\
\hline Nonmetal cladding/coating & \\
\hline Depleted uranium (DU) & A possible input stream to fuel fabrication \\
\hline Recovered uranium (RU) & $\begin{array}{l}\text { RU can go into fuel fabrication, indefinite storage, and/or } \\
\text { waste disposition }\end{array}$ \\
\hline U-TRU Product1 & Recovered TRU, possibly with some RU co-recovered \\
\hline U-TRU Product2 & $\begin{array}{l}\text { Optional second stream with TRU (i.e., minor actinides if } \\
\text { separated from } \mathrm{Pu} \text {, possibly with some RU co-recovered) }\end{array}$ \\
\hline Captured gaseous isotopes & $\begin{array}{l}\mathrm{H}-3, \mathrm{C}-14, \mathrm{Kr}-85 \text {, other noble gases, I-129, other halogen } \\
\text { gases that are captured, solidified, and disposed as waste }\end{array}$ \\
\hline Effluents released to atmosphere & $\begin{array}{l}\text { Fluids that are not captured from the facility (i.e., gases if } \\
\text { not captured) }\end{array}$ \\
\hline Technetium & Optional stream of Tc \\
\hline Cs-Sr & Optional stream of $\mathrm{Cs}, \mathrm{Sr}, \mathrm{Rb}$, and $\mathrm{Ba}$ isotopes \\
\hline Lanthanides & Optional stream of La thru Lu (plus Y) \\
\hline \multicolumn{2}{|l|}{ Undissolved solids (UDS) } \\
\hline Raffinate/residual process fluids & $\begin{array}{l}\text { Any collection of separated material that does not fit into } \\
\text { the above categories }\end{array}$ \\
\hline Spent solvents & Acids, salts, etc. \\
\hline Operational wastes & Filters, booties, etc. \\
\hline
\end{tabular}

\subsubsection{Separation Mass Flow Submodel}

Separation is modeled in FIT by a matrix. The rows are the various isotopes and chemical groups. The columns are the resulting streams, including both fuel products (TRU-U and recovered uranium) and various waste streams. The sum of the values in each row must equal $100 \%$ so that no mass is lost. 
A fundamental assumption is that these separation percentages are constant as the composition varies. For example, the fraction of lanthanides that go into TRU-U is the same regardless of how high the incoming lanthanide fraction might be.

Where no data exist in a chemical group, we used the values for other elements in the same chemical group.

Some source documents indicate $\sim 100 \%$ or $\sim 0 \%$ removal or retention. For our purposes, we did not believe it appropriate or realistic to use $100 \%$ and $0 \%$. We made a team decision that $100 \%$ would be replaced with $99.9 \%$ and $0.1 \%$ respectively. This is sufficient for a first analysis of the various cases and the results indicate where improved values would have value.

\subsection{Fabrication}

\subsubsection{Metallic Fuel Fabrication}

Fabrication of metallic nuclear fuel for transmutation applications was developed in the 1960s and 1970s to produce a product that could be irradiated to high heavy metal burnup. It was also demonstrated at the Experimental Breeder Reactor-II (EBR-II) that the fuel could be separated and re-fabricated in a hot cell and reused in the reactor, with the recycled fuel performance to the same reactor specifications as the original cold-fabricated fuel. Future fuel fabrication of this type of metal fuel would incorporate process improvements designed to simplify the fabrication processing and minimize waste generation from the process.

The essential process uses metal feedstock to make U-TRU-Zr metallic fuel slugs using an induction melting technique with either injection or bottom casting. The TRU feedstock is provided by either aqueous or pyrochemical processing of spent LWR fuel and consists of plutonium, americium, neptunium, and curium, and also comes from recycled U-TRU-Zr materials (casting heels, fuel slug end crops, out-of-dimension fuel slugs, etc.).

After casting into molds, fuel slugs are cooled, demolded and sheared to length to produce the basic metallic fuel. These slugs are stacked in a cladding jacket containing bond sodium, the jacket is seal welded, and then the jacket is heated to melt the sodium and settle the bond sodium. The nearly finished fuel rod is then treated to ensure that a good thermal bond is created between fuel, the bond sodium, and the cladding. The fuel is intentionally smaller in diameter than the inner diameter of the cladding to allow for fuel swelling, and the bond sodium is therefore required to transfer heat produced in the fuel to the cladding/reactor coolant.

The fabrication process is relatively simple, and high yields can routinely be achieved. Recycle of most scrap materials is done internally with return to the melting operation.

The high vapor pressure of americium would cause significant americium losses if casting melts were held at high temperature for long periods in an open casting process. For this reason a process modification to a pressurized casting system, with bottom tapping furnaces is being developed for future processes.

\subsubsection{Oxide Fuel Fabrication}

Currently, mixed oxide (MOX) fuel is made by mixing plutonium oxide and uranium oxide, pressing the powder into pellets, then sintering to final density. MOX fuel demonstration programs began in the U.S. and Europe in the 1960s with the Fast Flux Test Facility (FFTF) reactor in the U.S. irradiating more than 63,000 MOX pins. By the mid-1970s, the U.S. nuclear industry was ready to implement a large-scale MOX utilization program. Events at the time altered the direction of the nuclear industry in the US; however, Europe and Asia continued to develop MOX fuel programs, which dominate the fast reactor 
market today with fuel produced for the SNR-300 reactor in Germany, the Phénix and Super-Phénix reactors in France, and others in Russia and Japan.

The U.S. MOX fuel fabrication process is derived from the processes used to fabricate LWR (thermal) MOX fuel rods in Europe. Hundreds of metric tons of MOX fuel have been fabricated and irradiated in Europe. The fabrication process used in Europe by the French and Belgians is known as the MIMAS (Micronization Master Blend) process. The process enables a sintered material recycle stream $(\sim 11 \%)$ within the process that helps stabilize process parameters and results in a very high material yield ( $>99 \%)$ to final fuel pellets. The process for fabrication of transuranic-bearing MOX (TRUMOX) fuel for fast reactors is expected to be similar but complicated by the need for remote fabrication operations.

The process begins with an oxide TRU feedstock, which will come from separations of used LWR fuel. The first chemical step is adjusting the feedstock oxygen to metal ratio to 2.0 . The powder is then prepared into fuel pellets using traditional ceramic processing techniques. The primary steps in the pellet fabrication are powder milling/mixing, slugging, pressing, binder burn-out, sintering, and pellet grinding.

\subsubsection{Fabrication Mass Flow Submodel}

The TRU product stream passes into the either the metal fuel fabrication module or oxide fuel fabrication module developed with Fuels Campaign input. The modules are fuel mass balance that calculates the inputs and outputs of every unit process connected with fuel fabrication.

The steady state calculated mass balance being used for the metal fuel process in the FIT model calculates fuel fabrication product, recovery, and waste outputs on the basis of fuel materials, requirements, and components input to the system. The mass balance allows fuel fabrication to be handled as a black box in the overall fuel cycle when evaluating changes external to the fuel process. The balance, however, also has a full set of internally adjustable rate functions for dealing with rejects, recycle, recovery, and waste generation. These internal functions may be modified if desired to calculate how changes within the fuel process can alter the external modules of the fuel cycle.

Figure 3-6 shows the summary sheet of the mass balance of what the user sees as inputs and outputs from this model. 

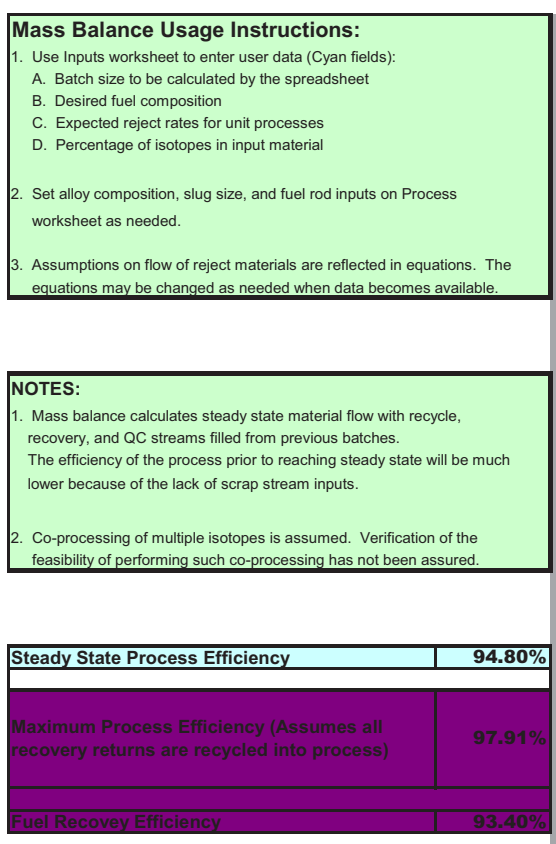
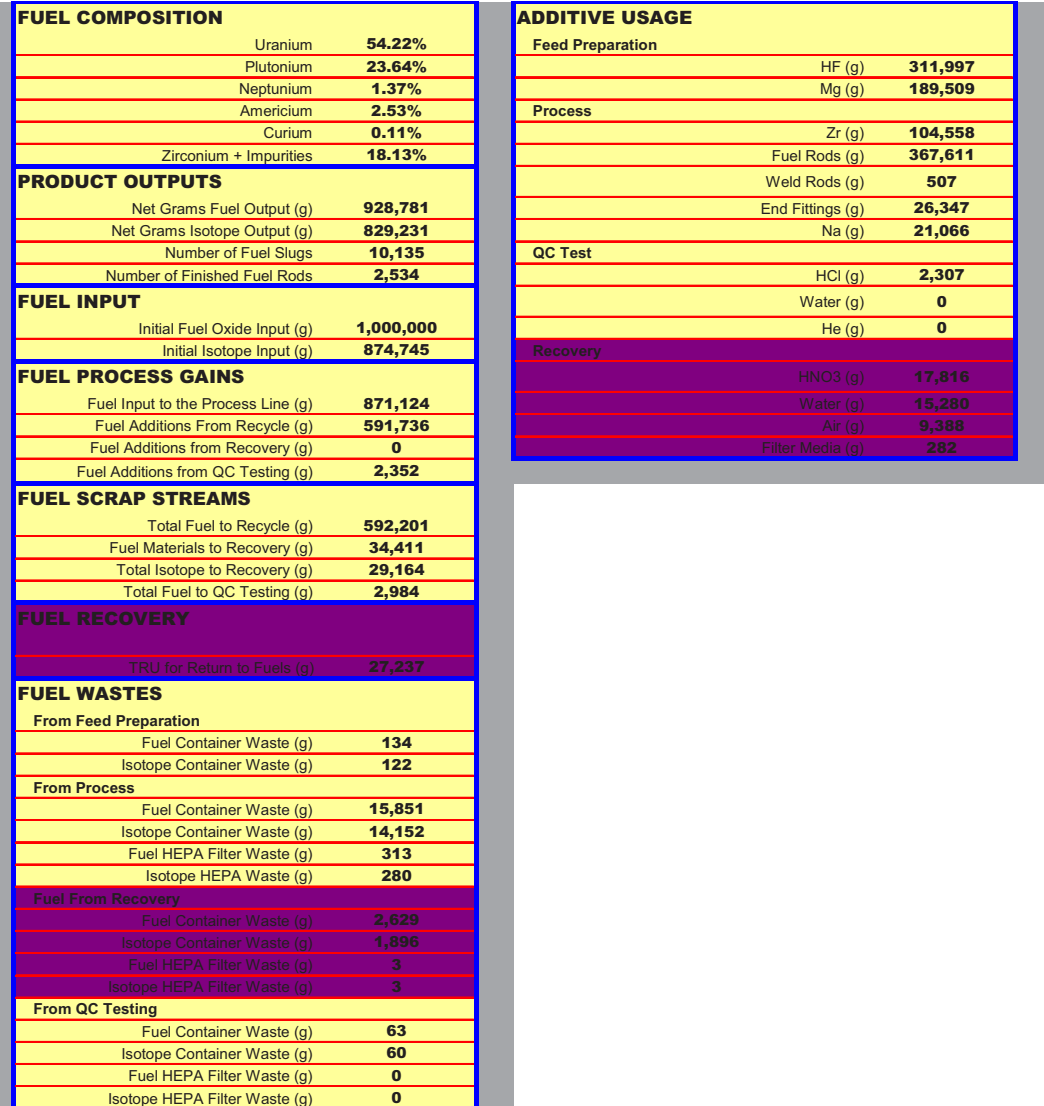

Figure 3-6. Screen capture of fabrication mass flow submodel summary sheet.

The following model assumptions are applicable to both metal and oxide fuel modules.

- Helium gas generated during storage of separated TRU products, is "removed" during feed conditioning therefore does not carry through fuel fabrication.

- TRU inputs to fuel fabrication will come from commercial and fast reactor separations facilities. The required feed composition for fuel fabrication will be specified by the downstream reactor and achieved by blending TRU separations products with separated and/or virgin depleted uranium with their associated impurity contents.

- In general, impurities $>0.3 \mathrm{~mol} \%$ are specifically called out in the mass balance. Remaining impurities are totaled and included as other.

- Lanthanides at any concentration are tracked due to their high potential impact on fuel performance.

- Molybdenum-ruthenium-rhodium were grouped together as one category since they are chemically similar and make up a significant portion of the impurities entering the fuels processes.

- Reject rates for various steps in the fabrication process were "assumed" based on general fabrication knowledge. These rates can be updated as additional data becomes available, or arbitrarily varied to see the impact of reject rates on the overall fuel cycle. Additionally, the disposition of rejects as scrap recycle, scrap for recovery, or waste was also assumed, and can be changed. 
- For the mass balance the recycle and recovery streams are considered continuous/steady state.

- TRU impurities, other than helium, are currently assumed to pass through the fuel fabrication process and become part of the final fuel form. Additional technical work is needed to before the model can be adjusted to show disproportionate losses of impurities during specific processes such as oxide dissolution/precipitation in feed conditioning, and melting/casting or oxide sintering in fabrication.

- TRU impurity levels are not currently tied to fuel reject rates by process; although it is known that excessive quantities of certain impurities will cause changes and higher reject rates in some fuel fabrication processes. Additional technical work is needed to quantify the threshold concentrations of impurities required to adversely affect process performance.

- Only grams of fuel waste were tracked, additional contaminated waste streams such as crucibles and high efficiency particular air (HEPA) filters were not tracked.

The following assumptions were made specific to oxide fuel fabrication.

- Assumed that separations were carried out at a separate facility location, then stored and Department of Transportation (DOT) shipped to the fuel facility for fabrication. This approach forces implementation of DOE-Standard (STD)-3013, "Stabilization, Packaging, and Storage of Plutonium-Bearing Materials," the shipping and storage requirements for TRU product. Therefore dissolution, precipitation, and reduction of feedstock are required for initial fuel feed conditioning to provide a usable TRU input material. This feed conditioning sequence is expected to have a significant TRU reject rate to recovery or waste for undissolved solids. If separations occurred on the same facility site and could be relatively close coupled with fuel fabrication, implementation of the STD-3013 requirements could be relaxed and the dissolution/precipitation/reduction steps with associated TRU losses could be eliminated.

- Oxide fuel scrap recovery is essentially a miniature separations capability within the fuel fabrication facility for dealing with scrap materials that are chemically or isotopically out of specification. Collocation of separations and fuels facilities may allow direct return of these scrap materials to the separations facility where the most appropriate processes and equipment are already available to complete the recovery. This would simplify the fuel facility and should reduce overall fuel cycle costs.

The following assumptions were made specific to metal fuel fabrication.

- Assumed direct oxide reduction for feed preparation. If material could be provided from separations in metallic form, this reduction step and associated waste/losses could be eliminated.

\subsubsection{Future Additions to Fuel Fabrication Modules}

Currently the impurity content of the feed material passes directly through the fabrication module without impacting reject rates. However, impurities in feed streams may significantly impact reject rates for certain processes if threshold concentrations are reached. Technical work on fuel fabrication will eventually allow insertion of mathematical functions showing differential loss of impurities in certain fuel processes and correlating impurity levels with fuel reject/waste rates. Increasing the level of impurities adversely impacts the efficiency at which both metal and oxide fuels can be produced; and above some threshold concentration may make fabrication of acceptable fuel impractical.

Future work will also develop improved methods to incorporate production cost throughout the fabrication model to determine how much extra cost would be incurred if reject rates increase (for any reason, including increased impurity content). 


\subsection{Reactor}

Figure 3-7 shows the various functions of the reactor module, as follows:

1. Iteration loop control

2. Reactor pick list. Select a set of baseline fuel parameters from a library of options - fuel residence time, input/output composition, burnup, etc.

3. Fuel composition adjustment and blending (winery). Provide instruction to the fuel fabrication module on how the baseline composition changes based on how parameters in the analysis differ from those in the selected library case (e.g., more impurities), in particular how to change the TRU:uranium ratio to account for impurities (library cases generally have no impurities) or more/less aging of perishable fuel isotopes. Initial approach is to keep k-effective constant by changing TRU-U (or U-235/uranium if enriched uranium fuel).

4. Output composition. Provide the output composition to the separation module. Initial approach has two parts. The output fission products are the input fission products (from fabrication) plus those generated by fission (from the baseline output composition for pure feedstock). The output actinides are generated with the Mr. Tau depletion tool (Bays 2010).

5. Isotope decay. Perform decay calculations in multiple parts of FIT for time periods up to a few centuries to account for possible storage of active materials.

6. Parameters. Provide parameters describing heat, radiotoxicity, etc., for mixtures of isotopes in various parts of the FIT model.
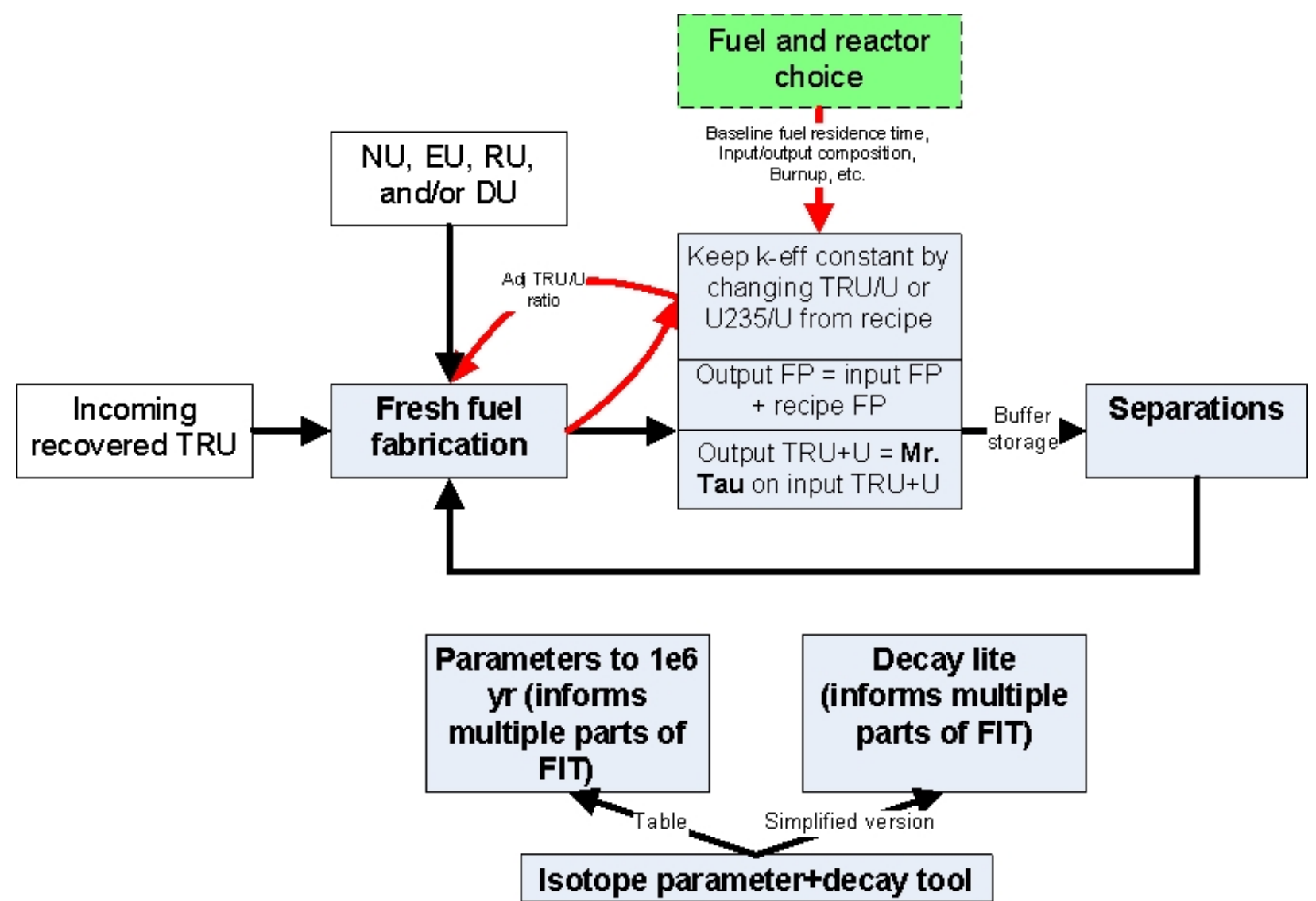

Figure 3-7. Functions of the reactor module. 


\subsubsection{Iteration Loops}

Figure 3-8 shows a more accurate version of the mass flows. In particular, note the following:

- Each separation facility can product TRU-U, RU, and waste streams.

- The fabrication facility can blend one or both TRU-U, one or both RU, enriched uranium (EU), and/or DU.

- All of the above except EU and DU are assumed to have impurities.

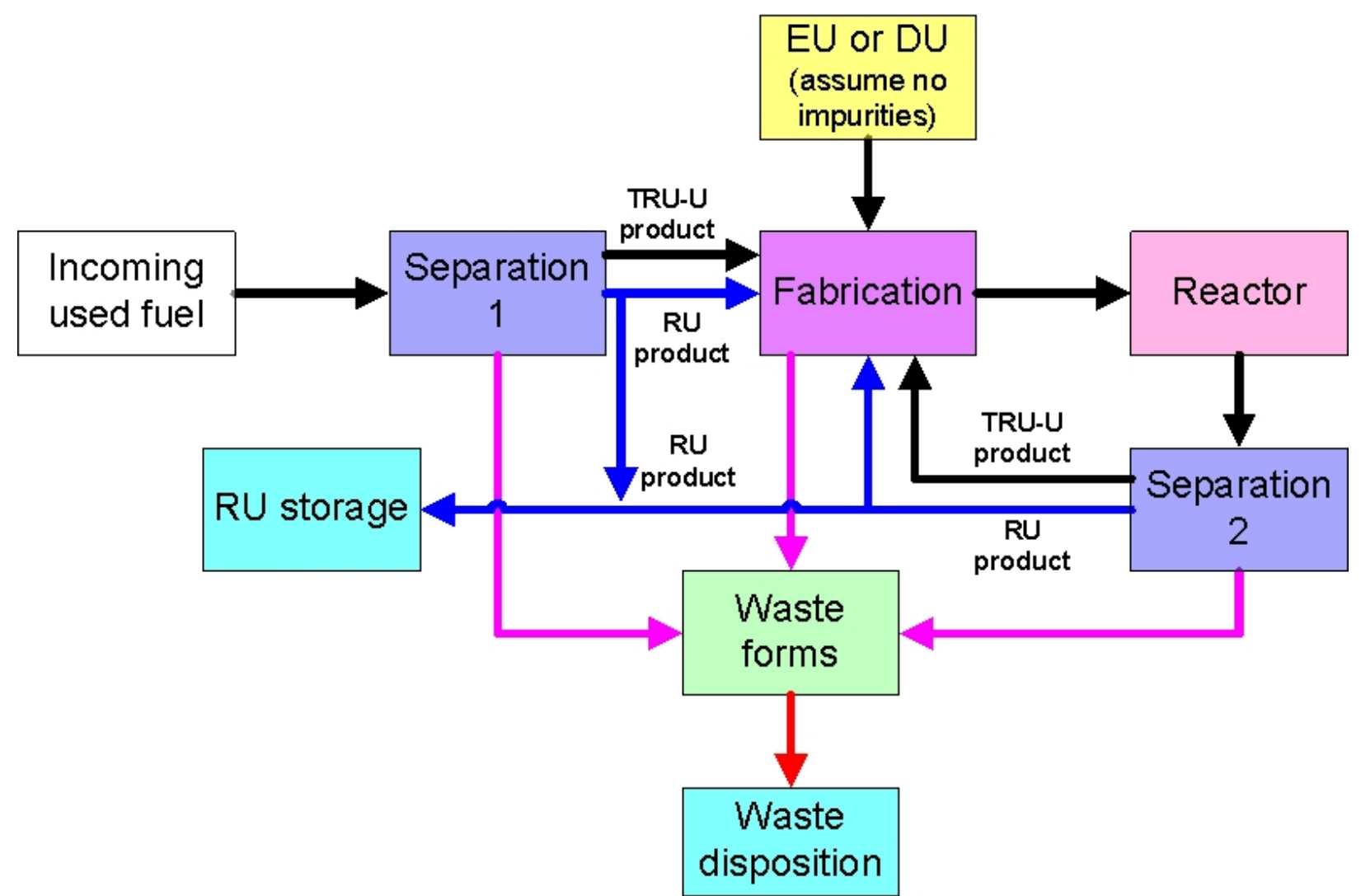

Figure 3-8. Mass flows showing possible feeds into fuel fabrication.

A top-level assumption is that there are only two ways to adjust the reactivity of fuel during a calculation:

- Adjust the TRU:uranium ratio

- Adjust uranium enrichment (not implemented in FIT 1.0).

If a given calculation provides unsatisfactory results, the user can change the separation efficiencies to either reduce the level of impurities or shift uranium from the TRU-U product to uranium products.

Figure 3-8 show not show information feedback loops that can cause iterations in the calculation. These are as follows:

- The impurities in each of the feed streams impacts the reactivity of the product, thereby changing the TRU:uranium ratio and/or required uranium enrichment in the fuel.

- The anticipated delay time between fuel fabrication and use changes the TRU:uranium ratio and/or required uranium enrichment in the fuel. 
- Uranium in the fuel can come from six sources: uranium in the two TRU-U products, uranium in the two RU products, EU, or DU. The isotopic mix among them varies, which in turn changes the TRU:uranium ratio and/or required uranium enrichment in the fuel.

- TRU in the fuel can come from four sources: the two TRU-U products and possibly a small amount in the two RU products.

- The amount of TRU-U that is available plus the TRU:uranium ratio determines how much fuel can be made for the reactor in the recycling loop. This in turn changes the ratio of the amount of incoming fuel to the number of reactors in the recycling loop.

Basically, many parameters must be known to calculate the reactivity of the overall fuel mix, and therefore know the proper TRU:uranium ratio. But, the TRU:uranium ratio must be known to calculate whether the supply of RU-1 or RU-2 is adequate to meet the uranium needs (if the user chooses that option) or the isotopic mix of the blended material.

FIT 1.0 makes the following simplifications, mostly to avoid iteration loops in FIT 1.0.

- Enriched uranium is not an option; it is not needed for any of the use cases described in Section 1.

- Breeder reactors are not considered.

- Thorium fuel cycles are not considered.

- The delay time from fuel fabrication to reactor is not considered; we assume fuel is made only when ready for use.

- There are three options for how RU and DU is used:

1. Use available RU-1 until exhausted, then RU-2, then use DU (At present, this option only works in the simplified form of using RU-1 without regard for how much RU-1 is available. This is not a problem for the cases studied to date because all burner fast reactor cases have more RU-1 than they need. This would be a problem for breeder reactors.

2. Use available RU-2 until exhausted, then RU-1, then use DU (At present, this option only works in the simplified form of using RU-2 without regard for how much RU-2 is available. Like the previous case, this is not a problem for the cases studied to date.

3. Use DU; RU is put into storage.

- The flow rate of incoming fuel is kept constant. Therefore, the number of reactors in the recycling loop that can be supplied from the combination of incoming fuel plus recycling fuel will vary. (If instead the number of recycling reactors is kept constant, then there is a feedback loop between the amount of incoming fuel and the TRU:uranium ratio.)

Even with these simplifications, there are two iteration loops.

The inner iteration loop approximates the appropriate required dilution of TRU-U product by one or more sources of uranium so that the fuel to be made matches user specifications as adjusted for the available feedstock. This involves only the interplay between fabrication, reactor, and the then-estimated feeds into fabrication.

The outer iteration loop is an iteration of the fabrication-reactor-separation loop. Perhaps this gets easier if we begin to consider this a physical iteration, as opposed to only a numerical convergence iteration. Recycle Pass 1 is the initial feedstock through Separation 1, with nothing coming back from Separation 2 (yet). Recycle Pass 2 is the first time there are both feed streams. 
Figure 3-9 shows these iterations in more detail. If impurities accumulate in the fuel, the required TRU:uranium ratio will increase (assuming the reactivity of TRU is higher than that of RU or DU). As long as the TRU reactivity is sufficient to overcome the impurities drag on the system, the model will request RU or DU to dilute the reactivity of the fuel to match that of the initial requested recipe. However, eventually, the required RU/DU could go negative (i.e., the TRU-U streams are no longer adequate to provide fuel reactivity). In this case, the simulation must stop.

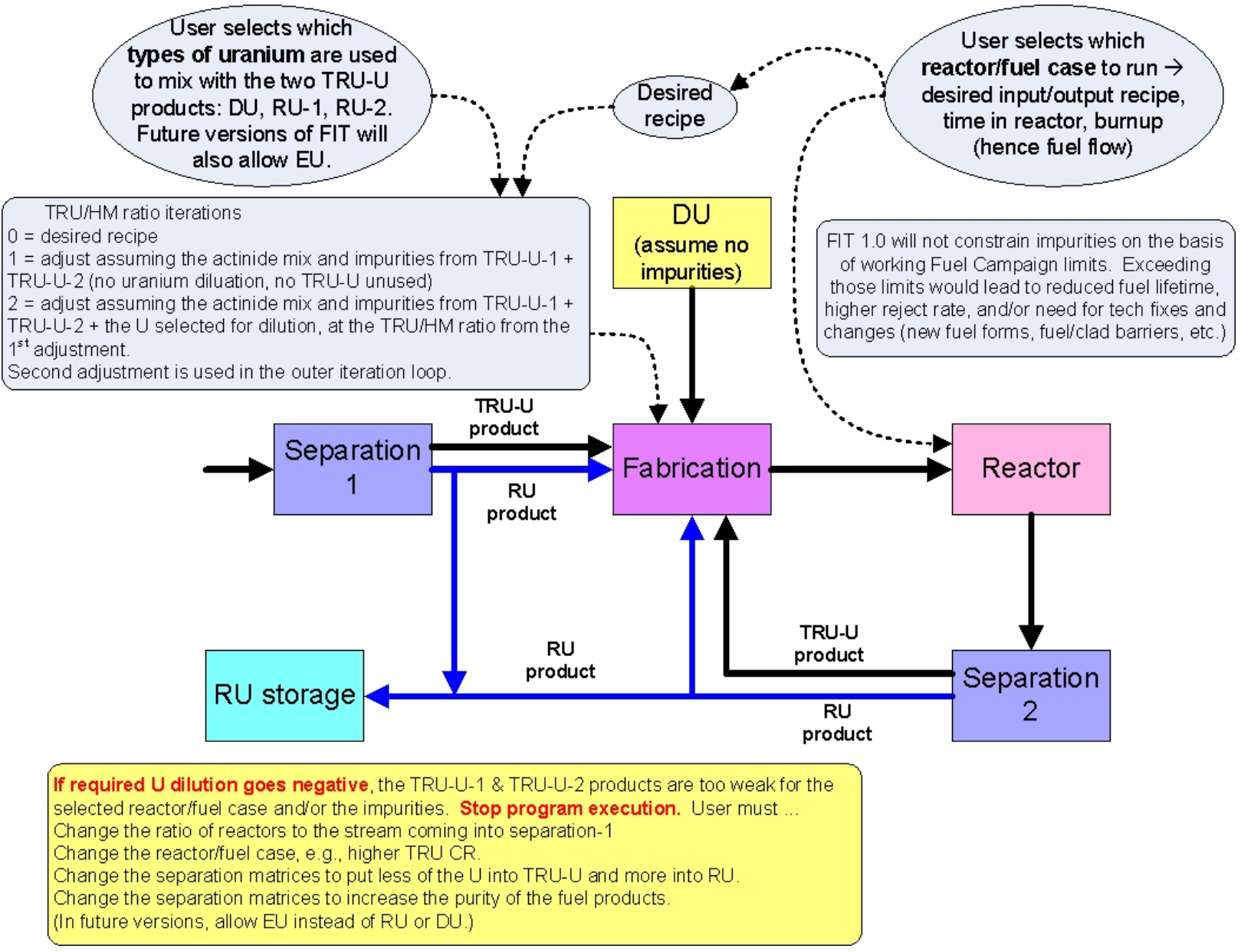

Figure 3-9. Iteration loops

Consider the following example. The fuel coming into Separation 1 is used UOX-51 fuel. The recycling reactor is a fast reactor with transuranic conversion ratio $<1$. Both separation processes only remove fission products; in both cases all the uranium is kept with the TRU. That is, RU-1 and RU-2 are both zero. This case cannot work and simulation would stop at the first attempt to blend feedstocks.

When this problem is reached, the user must:

- Change the reactor/fuel case (i.e., higher transuranic conversion ratio)

- Change the separation matrices to put less of the uranium into the TRU-U product and more into RU product.

- Change the separation matrices to increase the purity of the fuel products (which would not work in the above example) 
- In future FIT versions, allow EU (or higher EU) instead of RU or DU.

Consider the box with "TRU:HM ratio iterations." The first and second adjustments are done with one part of MrTau-Winery, thereby replacing the fixed TRU/heavy metal (HM) parameter in the current "fuel fab" modules in FIT.

For the outer iteration loop (except for the first iteration), we need to know the output composition corresponding to the adjusted (not the desired) input composition. The adjusted output composition is to be assembled as follows. The output actinides = the MrTau-Winery calculating using the actinide mix of TRU-U-1 plus TRU-U-2 plus whatever uranium has been used for dilution. The output impurities $=$ the input impurities + the fission products from the original desired recipe.

Consider the box at the bottom with the phrase "If required U dilution goes negative." This means that the combination of products TRU-U-1, TRU-U-2, and their impurities has become so weak (neutronically) for the current outer loop iteration (recycle pass N), that it is not possible to make fuel for the current outer loop iteration. That is, with the various settings for reactor/fuel case, separation matrices, ratio of "reactor" to incoming stream, we cannot go more than N-1 recycles. Note that each recycle pass (for nonbreeder reactors) the actinide mix gets weaker and the impurities get stronger, so for many sets of input parameters, the system will stop before it gets to equilibrium.

\subsubsection{Reactor Pick List Submodel}

This part of FIT will enable a user to select a reactor-fuel baseline case from among those in the system analysis transmutation data library (Piet 2010). Selection of a case determines the baseline input/output fuel composition mass fractions, fuel residence time (years), burnup (MWth-day/kg-iHM), and thermal efficiency.

\subsubsection{Fuel Composition Adjustment and Blending (Winery) Submodel}

The baseline or unperturbed input/output composition is selected by the user. Virtually all the input/output compositions in the current system analysis transmutation data library are based on no impurities in the input fuel and with relatively short decay time between separation and fuel fabrication prior to insertion into a reactor. As impurities become significant or decay times increase, the value of the fuel material decreases. So, for TRU-based fuels, the TRU:uranium ratio must be increased. For enriched uranium fuels, the U-235 enrichment must be increased. This module will implement the methods described elsewhere (Bays 2009).

The Transmutation Library has dozens of input/output composition recipes (sets of mass fractions) for various cases. Nonetheless, FIT requires two types of adjustments to these fixed recipes in the course of calculations: actinide mix and impurities.

The mix of actinides that are available in recycling strategies does not exactly match the actinide mix in fixed reactor physics calculations unless all the relevant parameters exactly match - reactor design of the source material for recycling, reactor parameters (burnup, fuel residence time, etc.) of the source material, decay time between reactor discharge and separation, separation efficiencies of each of the actinide elements, and decay time between separation and new fuel insertion into recycling reactor. Indeed, the last three of these parameters are designed to be variable within FIT, and therefore a way is required to adjust the required input composition accordingly. That is, FIT changes the available actinide isotope mix as reactor-separation and separation-reactor decay times change as well as the actinide chemical mix as the separation matrices change.

Essentially none of the existing recipes in the Transmutation Library have impurities in the input compositions, whereas all the FIT cases have non-zero impurities. 
In these application areas, there are so many relevant reactor conditions that it is not practical to perform detailed reactor physics calculations for each set of conditions. Instead, we have developed methods to adjust the input and output fuel composition ("recipes") of previous detailed calculations according to the perturbation in question. Results from previous calculations are assembled in the Transmutation Library (Piet 2010).

\section{Assumptions}

- 1 -group cross sections are used.

- Time-dependent parameters such as cross sections and heat are given by the sum of constant coefficients times the inventory of each "tracked" isotope. Appendix C, "Equations for TimeDependent Parameters," gives the basic equations. Appendix D, "Approach to Calculate Cross Sections," explains how the cross sections for mixes of isotopes are calculated. Appendix E, "Justification for Time-Independent Cross Sections," provides the justification for the cross sections being time independent.

Two 1-group adjustment methods were described last year (Bays 2009). The situation in FIT is more complicated than the sum of these, as summarized in Table 3-3.

Table 3-3. 1-group blending and adjustment methods.

\begin{tabular}{|c|c|c|c|}
\hline & What is blended & What is held constant & What can be adjusted? \\
\hline $\begin{array}{l}\text { TRU/Uranium } \\
\text { adjustment } \\
\text { (Bays 2009) }\end{array}$ & $\begin{array}{l}\text { TRU stream } \\
\text { Uranium stream } \\
\text { The isotopic mix of } \\
\text { both streams differs } \\
\text { from that of the initial } \\
\text { targeted recipe. }\end{array}$ & $\begin{array}{l}\text { Uranium enrichment } \\
\text { No impurities in either } \\
\text { TRU or uranium }\end{array}$ & TRU:uranium ratio \\
\hline $\begin{array}{l}\text { Fission } \\
\text { product } \\
\text { impurities } \\
\text { (Bays 2009) }\end{array}$ & $\begin{array}{l}\text { TRU stream } \\
\text { Uranium stream } \\
\text { Impurities }\end{array}$ & $\begin{array}{l}\text { Isotopic mix in TRU and } \\
\text { uranium, respectively }\end{array}$ & TRU:uranium ratio \\
\hline Losses Study & $\begin{array}{l}\text { TRU+U-1 } \\
\text { TRU+U-2 } \\
\text { RU-1 } \\
\text { RU-2 } \\
\text { DU } \\
\text { (In future, EU) } \\
\text { The isotopic mix of } \\
\text { each stream can differ } \\
\text { from that of the initial } \\
\text { target recipe. }\end{array}$ & $\begin{array}{l}\text { Each of these can have } \\
\text { TRU, uranium, and } \\
\text { impurities; those are not } \\
\text { under user control. } \\
\text { The ratio of TRU+U-1 and } \\
\text { TRU+U-2 is determined by } \\
\text { mass flows with the rate of } \\
\text { incoming TRU+U-1 held } \\
\text { constant }\end{array}$ & $\begin{array}{l}\text { TRU:uranium ratio } \\
\text { (In future, uranium } \\
\text { enrichment) } \\
\text { The order of using uranium } \\
\text { sources } \\
1=\text { RU-1, RU-2, then DU } \\
2=\text { RU-2, RU-1, then DU } \\
3=\text { DU }\end{array}$ \\
\hline
\end{tabular}

FIT uses the following method.

The baseline or unperturbed input/output composition is selected by the user. Virtually all the input/output compositions in the current system analysis transmutation data library are based on no impurities in the input fuel and with relatively short decay time between separation and fuel fabrication prior to insertion into a reactor. As impurities become significant or decay times increase, the value of the fuel material decreases. So, for TRU-based fuels, the TRU:uranium ratio must be increased. For enriched 
uranium fuels, the U-235 enrichment must be increased. U-enrichment is not implemented in FIT 1.0 as it was not necessary for the use cases we targeted for analysis.

Next we explain how FIT makes the adjustment of the TRU:U ratio. Start with defining the following four types of compositions.

Initial Composition The input/output composition recipes corresponding to the case being simulated (e.g., uranium oxide at $51 \mathrm{GW}$-day/tonne-HM burnup (UOX-51) or metal fast reactor fuel for TRU conversation ratio $=0.50$ based on 5 -year old feed from UOX-51).

Available Composition The input composition available in the simulation.

Adjusted Composition The input/output composition resulting from the winery adjustment methods described below. During the time period that the adjusted composition is in force, it is used in the simulation as a replacement to the initial composition. Initially, the plan is for the input and output compositions to be adjusted every 5 years, in conjunction with changes to the initial recipes.

The objective is to adjust the "available composition" so that the "adjusted composition" has the same keffective or reactivity worth as an "initial composition" that was calculated by standard reactor physics methods. The adjustment accounts for changes in uranium and/or transuranic isotope mix in the "available composition" relative to the "initial composition" by modifying the TRU:uranium ratio so that the reactivity worth or k-effective of the "adjusted composition" matches the "initial composition."

To derive the relevant equations, define the following parameters:

$A$ is Avagodro's constant $\left(0.6022 \times 10^{24}\right.$ atoms $\left./ \mathrm{mole}\right)$

$F_{F P}$ is the fraction of fission products in the fuel composition

$F_{U}$ is the fraction of uranium in the fuel composition

$F_{T R U}$ is the fraction of transuranic elements in the fuel composition

$\Phi$ is the neutron flux (neutrons/ $\mathrm{cm}_{2}-\mathrm{s}$ )

$k$ is the effective criticality ratio, taken here to refer to fuel itself (actinides plus impurities)

$m_{i}$ is the mass fraction of each isotope (g-isotope/g-total)

$M_{i}$ is the atomic mass $(\mathrm{g} / \mathrm{mole})$

$v$ is the average number of neutrons per fission (neutrons/fission)

$\sigma_{a}$ is the 1-group absorption cross section for a composition $=\sigma_{n, \text { fission }}+\sigma_{n, \gamma}+\sigma_{n, 2 n}+\sigma_{n, \alpha}$

$\sigma_{n, \text { fission }}$ is the 1-group fission cross section for a composition (fissions/neutron $\times 10^{-24} \mathrm{~cm}^{2}$ )

$\sigma_{n, \gamma}$ is the 1-group neutron capture $(\mathrm{n}, \gamma)$ cross section (sometimes called $\sigma_{c}$ ) for a composition

$\sigma_{n, 2 n}$ is the 1-group neutron multiplication (n,2n) cross section for a composition

$\sigma_{n, \alpha}$ is the 1-group (n, $\left.\alpha\right)$ cross section for a composition

We define the mass fractions such that: 
$F_{U}+F_{T R U}+F_{F P}=1$

$\sum_{U \text { isotopes }} m_{U}=1$

$\sum_{\text {TRU isotopes }} m_{\text {TRU }}=1$

$\sum_{F P \text { isotopes }} m_{F P}=1$

The rate of absorption of neutrons is given by:

$0.6022 \sum_{\text {isotopes }} v \sigma_{a} m_{i} \Phi A / M_{i}$ neutrons/second

The production of neutrons is given by:

$0.6022 \sum_{\text {isotopes }}\left(v \sigma_{n, \text { fission }}+\sigma_{n, 2 n}\right) m_{i} \Phi A / M_{i}$ neutrons/second

Eq. 6

Therefore, the value of $\mathrm{k}$ is approximated in 1-group theory by

$$
k=\frac{\sum_{\text {isotopes }} 0.6022\left(v \sigma_{n, \text { fission }}+\sigma_{n, 2 n}\right) m_{i} \Phi A / M_{i}}{\sum_{\text {isotopes }} 0.6022 \sigma_{a} m_{i} \Phi A / M_{i}}=\frac{\sum_{\text {isotopes }}\left(v \sigma_{n, \text { fission }}+\sigma_{n, 2 n}\right) m_{i} / M_{i}}{\sum_{\text {isotopes }} \sigma_{a} m_{i} / M_{i}}
$$

Since $(n, 2 n)$ reactions are a small fraction of the total neutron source and impurities do not fission, we obtain the expression as follows:

$$
k=\frac{F_{U} \sum_{U \text { isotopes }} v \sigma_{n, \text { fission }} \frac{m_{U}}{M_{U}}+F_{T R U} \sum_{\text {TRU isotopes }} v \sigma_{n, \text { fission }} \frac{m_{T R U}}{M_{T R U}}}{F_{U} \sum_{U \text { isotopes }} \sigma_{a} \frac{m_{U}}{M_{U}}+F_{T R U} \sum_{\text {TRU isotopes }} \sigma_{a} \frac{m_{T R U}}{M_{T R U}}+F_{F P} \sum \sum_{F P \text { isotopes }} \frac{m_{F P}}{M_{F P}}}
$$

For the initial recipe, all parameters are known and we can calculate k. That is, use Equation 8 to calculate $\mathrm{k}$ for the initial known recipe. Generally, fraction of fission products (FFP) is zero for known recipes.

For the adjusted recipe, two things can change: the amount of fission products (or other impurities) and/or the mix among actinide isotopes. Instead of zero fission products in initial fuel, we assume some known fission products. Instead of the pre-determined mix among actinides, we have some mix calculated by FIT.

Thus, to determine the composition of the adjusted recipe, we assume neither k nor $\sigma$ change. We know the FFP and the associated mass fractions of fission products. The adjusted mass fractions $\mathrm{m}_{\mathrm{i}}$ among TRU and among uranium are set equal to the available source material, this means we assume there is no change in isotopic mix from available to adjusted recipe-we use what we have. (For cases involving enriched uranium, we can relax this assumption and assume the U-235/U-238 ratio is under our control.)

We are left with two equations, 1 and 8, in two unknowns: FU and FTRU. (If instead uranium enrichment is to be used, we instead solve for $\mathrm{m}_{\mathrm{U}-235}$ and $\mathrm{m}_{\mathrm{U}-238}$.)

Substituting $F_{U}=1-F_{T R U}-F_{F P}$, and a bit of algebra, we obtain: 


$$
F_{T R U}=\frac{\left(1-F_{F P}\right)\left\{\sum_{U \text { isotopes }}\left(-v \sigma_{n, \text { fission }}+k \sigma_{a}\right) \frac{m_{U}}{M_{U}}\right\}+F_{F P} \sum_{F P \text { isotopes }} k \sigma_{a} \frac{m_{F P}}{M_{F P}}}{\left\{\sum_{U \text { isotopes }}\left(-v \sigma_{n, \text { fission }}+k \sigma_{a}\right) \frac{m_{U}}{M_{U}}\right\}+\left\{\sum_{\text {TRU isotopes }}\left(v \sigma_{n, \text { fission }}-k \sigma_{a}\right) \frac{m_{T R U}}{M_{T R U}}\right\}}
$$

This is equivalent to Equation 4-28 of Bays 2009 if $F_{F P}$ is zero. We can instead obtain:

$$
F_{U}=\frac{\left(1-F_{F P}\right)\left\{\sum_{\text {TRU isotopes }}\left(v \sigma_{n, \text { fission }}-k \sigma_{a}\right) \frac{m_{T R U}}{M_{T R U}}\right\}-F_{F P} \sum_{F P \text { isotopes }} k \sigma_{a} \frac{m_{F P}}{M_{F P}}}{\left\{\sum_{U \text { isotopes }}\left(-v \sigma_{n, \text { fission }}+k \sigma_{a}\right) \frac{m_{U}}{M_{U}}\right\}+\left\{\sum_{\text {TRU isotopes }}\left(v \sigma_{n, \text { fission }}-k \sigma_{a}\right) \frac{m_{T R U}}{M_{T R U}}\right\}}
$$

This is equivalent to Equation 4-29 of Bays 2009 if $F_{F P}$ is zero.

Finally, we note that adding Equations 9 and 10, we obtain $1-F_{F P}$ as we should.

So, the procedure is:

Step 1, calculate $k$ for the initial known recipe using Equation 8.

Step 2, calculate $F_{T R U}$ for the adjusted recipe using Equation 9.

Step 3, calculate $F_{U}$ for the adjusted recipe using Equation 1.

\subsubsection{Output Composition Submodel}

Once the input composition has been adjusted, the output composition in FIT 1.0 is assembled from three pieces. In the future, all of these steps will be within MrTau.

- Actinide output is calculated by MrTau (Bays 2009).

- Fission products and impurities in the input fuel are passed into the output fuel composition, unchanged.

- In the current version of MrTau, the mass difference (input - output) represents the mass of fission products created.

\subsubsection{Isotope Decay Submodel}

Storage between process steps (reactor, separations, fuel fabrication, waste treatment, waste disposition) is modeled by calculating decay and in-growth for the desired storage time. The decay calculation is simplified using some assumptions (e.g., assuming nuclides with $>4,000$ year half-life as stable). This simplified version is based on a more elaborate spreadsheet created by S. Piet (Bays 2010).

\subsubsection{Parameter Submodel}

Apart from the estimation of composition change during a few hundred years of storage, to assess fuel cycle options, it is also necessary to calculate various time-dependent parameters out to at least 1,000,000 years. For example, radiotoxicity is a relevant parameter from 1,000 years to at least 1,000,000 years. There is now an isotope decay and parameter spreadsheet that calculates such parameters from 1 to $1 \mathrm{e} 9$ years for a given set of isotopes. This tool has linked with FIT, probably by being used to calculate a table of time-dependent parameters for each chemical grouping for each baseline recipe required for the use cases (Bays 2010). 


\subsection{Waste Treatment and Disposition}

The waste treatment and disposition modules are designed to accomplish the following:

- Receive the separated waste streams from the used fuel separations and fuel fabrication processes

- Convert the waste streams into waste forms for final disposition

- Track all masses of the waste streams and waste forms, and document the properties such as waste loading and density for the waste forms

- (Eventually) document packaging of the waste forms into transportation, storage, and disposal packages, and include transportation, storage (such as for isotope decay), and final disposal

- (Eventually) include estimates of costs and other factors relevant to waste treatment and disposition.

Some limitations currently exist in the model that can be addressed in future versions:

- Front end wastes and wastes from other portions of the fuel cycle such as the reactor are not included in the model. Including these potential waste streams in future versions of the model will provide a more complete picture and better comparison of different fuel cycles that have different ore mining, enrichment, and reactor scenarios.

- Waste disposition costs are not yet rigorously addressed, and they should be in future versions of the model.

- Options for waste disposition vary widely for different objectives, and can change as the Separations and Waste Form Campaign and Used Fuel Disposition Campaign research and development progresses. The beauty of the FIT model is that updates can readily accommodate changes and can be used to evaluate different waste disposition options.

- To some extent, we have included estimates of separations and fuel fabrication facility operations and maintenance wastes, but we have not included operations and maintenance wastes for other portions of a fuel cycle, such as for the reactor(s). Also, these waste streams have been included without detailed and rigorous evaluations. Future versions of the FIT model may be able to address these waste streams better.

- Perhaps the most significant limitation in the current FIT version is that the waste disposition module presently ends with the treatment of the waste streams to convert those streams into waste forms for disposition. The current model version does not include packaging the waste forms into transportation, storage, or disposal containers; nor does it include long-term storage for such purposes as isotopic decay; nor does it include final disposition of waste streams in any of several possible disposal sites or scenarios. At this time, it seemed impractical to address these issues in the development of FIT model that are being more thoroughly and logically addressed in the Used Fuel Disposition Campaign.

Waste treatment includes the treatment and of all the output streams from separations, maintenance, that are not reused, to convert those waste streams into presumed waste forms suitable for disposition. Waste form options in the model at this time are based mainly on the current waste forms for waste streams identified by this year's Waste Form Campaign.

The model includes the capability to process the types of waste streams that evolve for different use cases. Different use cases could eventually include a variety of possible separations and fuel fabrication processes that result in a variety of different waste streams. These waste streams will require treatment consistent with waste treatment technologies and processes used in the past, or included in Separations 
and Waste Form Campaign research and development studies. In some cases, the scope of these waste streams is outside the scope of the focus of the Waste Form Campaign when they include waste streams from new fuel cycle options or when they include waste streams from facility operations and maintenance. In these cases, references used to base waste form selection, waste loading, and other waste form properties, include studies performed under the Integrated Waste Management Strategy, the Engineering Alternative Studies, the Follow-on Engineering Alternative Studies, and the Advanced Fuel Cycle Facility designs. Some specific candidate waste treatment capabilities and variables that should be included in the current or future versions FIT model are listed in the FIT Software Requirements Document in Appendix B, "Software Requirements Document for FIT."

\section{RESULTS}

This section provides the results of FIT analysis of several oxide and metal fuel cases. First, consider Figure 4-1, which shows the basic infrastructure of FIT.

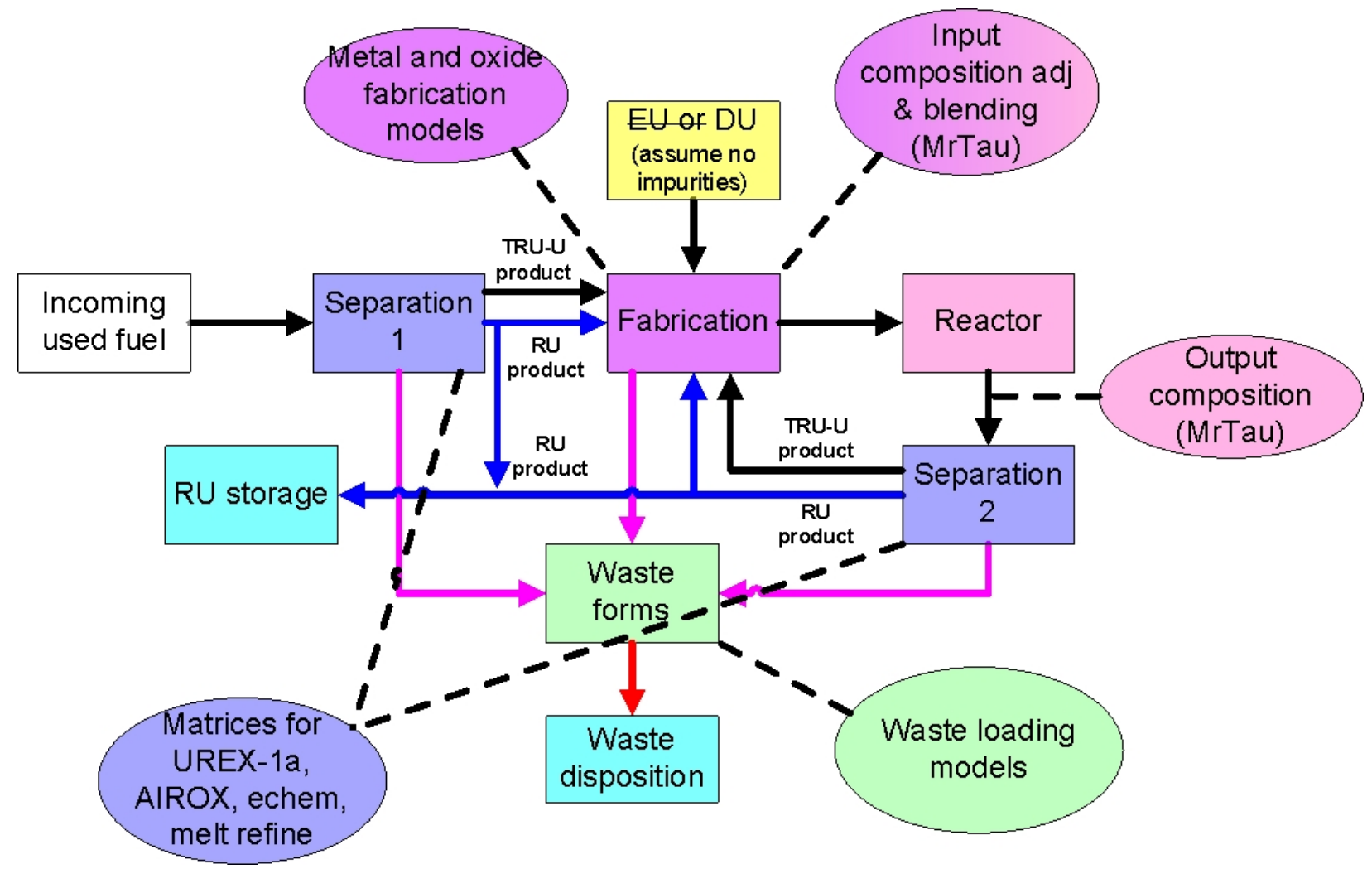

Figure 4-1. FIT infrastructure showing the types of data and calculations involved.

All of the cases have the following characteristics. These are consistent with the cases we knew best, i.e., those we analyzed in FY 2009.

- There is a single incoming fuel, used UOX-51. Isotopic data from the Transmutation Library (Piet2010).

- The recycle reactor is always a fast reactor with transuranic conversion ratio of 0.50 . Isotopic data from the Transmutation Library. (Future version of the model could include other types of recycle reactors.) 
- The recycle fuels are either metal or oxide fuels. FIT does not limit the concentration of impurities in the recycle fuel. The user must compare the output calculated compositions of the recycle fuel to postulated fuel impurity limits to decide acceptability.

- Separation 1 is UREX+1. We also did calculations with AIROX and melt refining as Separation 1 , but neither of these separation techniques are suitable even for a single recycle. The FR fuel requires more fissile content than that provided by the remaining U235 concentration of $0.77 \mathrm{wt} \%$ and the TRU concentration $1.3 \mathrm{wt} \%$ in used UOX-51 fuel. So, to make fuel with TRU content greater than $1.3 \%$, one must either remove uranium from the separated recycle stream, or add fissile material from a separate source, not included in the model at this time. Neither AIROX nor melt refining remove uranium from the separated recycle stream, and are therefore unacceptable Separation 1 options for the model at this time.

- Separation 2 options were varied for different cases. We used electrochemical and melt refining with metal fuel and UREX +1 and AIROX with oxide fuel. Essentially the separation matrix can be anything the user wishes so that any separation option can be considered; the user directly inputs what fraction of which chemical group goes into which type of waste stream.

\subsection{Uranium}

Figure 4-2 shows the fraction of recovered and depleted uranium (RU and DU) that is used in fast reactor recycling at equilibrium for the cases tested thus far. In these cases, the RU is assumed to be used first, and the DU is used only after the RU in making new recycle FR fuel. Another option would be to use DU before RU. Either way, less than about $10 \%$ of the uranium is used until the CR exceeds about 0.9 . When the transuranic conversion ratio exceeds 1.0 (breeder reactors), all the DU and RU is eventually used. In this case, the feed stream to the recycling loop does not have to be used UOX-51 fuel, it can be any source of uranium. However, when the transuranic conversion ratio is less than 1.0 (burner or converter reactors), there is excess DU and RU in the system. That is, at some point in the system, a separation must occur so that excess DU and RU are removed. Of course, DU removal occurs at uranium enrichment. RU removal must occur at either separation 1 or separation 2. For the first recycle, there is no separation 2; the feed is solely from used UOX-51. Thus, separation 1 must be able to separate U from TRU. 


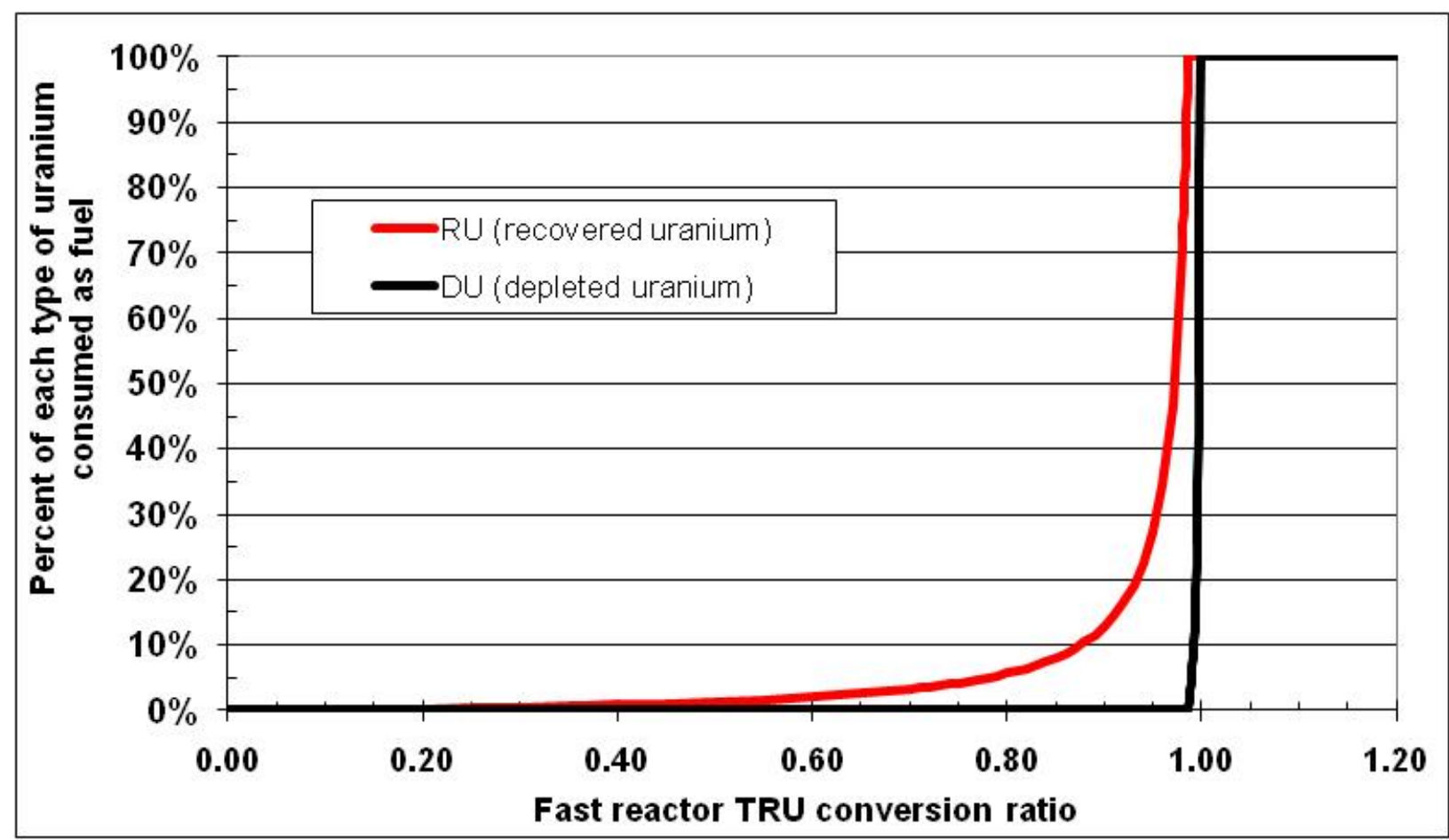

Figure 4-2. Fraction of recovered and depleted uranium used at equilibrium in a system of used UOX-51 feeding recycling fast reactors.

As an example, at $\mathrm{CR}=0.75$, only $4.2 \%$ of the uranium is used. Therefore, separation 1 must be able to remove about $96 \%$ of the uranium from used UOX-51 fuel.

The current version of FIT only allows a single source of uranium to be used for a given recycle iteration. We therefore performed calculations with two bounding uranium sources.

- DU feed means that all RU is put into storage. DU is used to dilute the recycle TRU-U streams to the proper TRU:U ratio.

- RU feed means that no DU is used. RU-1 is used for the first recycle, which is the only option as there is no RU-2. RU-2 is used for the second recycle. This is a simplification because one would likely use a mixture of RU-2 and RU-1.

Finally, recall that U can be in the TRU-U stream, e.g., the U-TRU product stream from electrochemical separations contains about $28 \%$ of the $U$, which is recycled with the separated TRU into new FR fuel. By definition, only impurity levels of TRU are in RU streams. Therefore, the blending ratio of TRU-U product to RU product is not the same as the TRU:U composition.

\subsection{Additional Explanations That Help Clarify Results}

The graphs below show composition as a function of the recycle number. Always recall that recycle 1 uses solely UOX-51 feedstock and therefore the fission product distributions of a thermal reactor, and one dominated by fission of $\mathrm{U}-235$ with some $\mathrm{Pu}-239$. Recycles after the first iteration use a blend of feed from UOX-51 (kept at a constant rate equal to the first recycle) plus whatever TRU has not been consumed by the fast reactor in the previous iteration. Thus, recycles 2 and beyond have a mix of thermal and fast reactor feedstock; the fast reactor feedstock is a mix of several TRU isotope fission yields. 
Therefore, even when the separation efficiencies of separation-1 and separation-2 are identical (as they could be for a UREX $+1 / \mathrm{UREX}+1$ case), the fission product distribution can change with successive recycles, especially from recycle 1 to recycle 2 . At the level of detail of individual chemical elements, a change of yield from thermal/U-235 to fast/TRU can often be noticeable in the graphs. A few examples for the ratio of fission yield of Pu-239 in a FR U-235 in a thermal reactor include:

Mass 95 (key zirconium isotope $)=0.7$

Mass 107 (key palladium isotope $)=22.1$

Mass $113($ key cadmium isotope $)=9.0$

Masses 139 to 148 (first several lanthanides) $=0.7$ to 1.0

Masses 148 to 170 (minor lanthanides) $=1.0$ to 1530 .

The current treatment of two groups of transition metals was found to lead to significant uncertainties for those elements.

The first group is Mo-Ru-Rh-Pd, which is considered a single mass (other than specific radioactive isotopes Ru103 and Pd107). This group exists because these elements constrain the waste loading in glass. These elements are grouped together because they tend to decay into each other so that the mass of individual elements among these four varies more than the total of the four elements together.

Inadvertently, the Transmutation Library grouping lead to much of the FIT model continuing that grouping, instead of dividing molybdenum from Ru-Rh-Pd. Even had that occurred, however, we see in Section 2 that some of the chemical separation factors differ even among ruthenium, rhodium, and palladium. Yes, in the separation matrices, a single value is assigned to all four elements.

For electrochemical separations, the best estimate separation factor for all four elements is the same, 1.5\% retained in the TRU-U product. For UREX+1, the combined value used for retention in TRU-U was $0.875 \%$, but the value for palladium by itself is $14.545 \%$, which was used for the specific isotope Pd107 but not for the fraction of mass of Pd within Mo-Ru-Rh-Pd-stable, which is about $20 \%$ of that mass in fast reactors. The fractions at reactor shutdown of molybdenum, ruthenium, and rhodium are $35 \%, 34 \%$, and $11 \%$ of Mo-Ru-Rh-Pd-stable. Thus, the estimates of composition for these elements must be considered to have relatively high uncertainty, especially for the oxide fuel cases, but even for metal fuel because the incoming TRU feedstock comes from UREX+1.

The second group is all the other transition metals. The dominant ones and their fraction of TM-other at shutdown for fast reactors is $\mathrm{Se}(2.5 \%), \mathrm{Nb}(1.4 \%), \mathrm{Ag}(20 \%), \mathrm{Cd}(13.6 \%), \mathrm{In}(1.0 \%), \mathrm{Sn}(6.4 \%), \mathrm{Sb}$ $(2.1 \%)$, and Te $(52.5 \%)$. Separation data for all of these elements are not available for any of the separations technologies. In fact, we generally lack data for a majority of them.

The retention of these elements in the TRU-U product for electrochemical separations was set at $1.5 \%$ for each of them. The retention of the generic TM-other in UREX +1 was set at $0.099 \%$, but individual elements vary with the outlier being tin $(\mathrm{Sn})$, with $45 \%$ of $\mathrm{Sn}$ retained in recovered uranium and $18 \%$ retained in the TRU-U product. The importance of tine is not known; there is no tin impurity limit for either oxide or metal fuel.

These two sets of transition metal approximations should be re-examined in the future. However, tracking individual elements will require re-examination of the effect of isotopes decaying from one of these elements to another. That is, it would not be easy to go to the next level of chemical specificity.

\subsection{Working Impurity Limits}

The working limits of the Fuels Campaign for oxide and metal fuel were tabulated in last year's report (Shropshire2009). That report explained that the working limits were specified in terms of the required 
purity of TRU feedstock coming into the assumed fast reactor fuel fabrication facility. There were three key assumptions:

- The TRU feed stream was only TRU.

- The uranium blended to make fuel was assumed chemically pure. Thus, the "DU feed" calculations best match the underlying Fuels Campaign assumptions.

- The fast reactor had a TRU conversion ratio near 0.5. The conversion ratio determines the ratio of TRU:U.

Since the uranium was assumed pure, the uranium had the function of diluting the impurities in TRU feedstock. For our analyses, we wanted to consider impurities from other sources including uranium. We therefore "worked backwards" to convert the TRU feedstock limits to fuel impurity limits. For metal fuel at transuranic conversion ratio of 0.50 , the pure fuel (no significant impurities) has $31 \%$ TRU and therefore the fuel impurity limits are taken as $1 / 0.31$ of the TRU feedstock. For oxide fuel at transuranic conversion ratio of 0.50 , the fuel is $33 \%$ TRU, so the fuel impurity limits are taken as $1 / 0.33$ of the TRU feedstock limits.

Many of the TRU feedstock limits pertain to elements that are not fission products and are therefore not included in the current analysis. Working limits that do pertain to one or more fission products are listed in Table 4-1. 
Table 4-1. Working limits for metal and oxide fuel impurities relevant to fission products.

\begin{tabular}{|c|c|c|c|c|}
\hline & \multicolumn{2}{|c|}{$\begin{array}{l}2009 \text { Fuel Campaign working limit for } \\
\text { TRU feedstock converted to FR oxide fuel } \\
\text { limit }\end{array}$} & \multicolumn{2}{|c|}{$\begin{array}{l}2009 \text { Fuel Campaign working limit for TRU } \\
\text { feedstock converted to FR metal fuel limit }\end{array}$} \\
\hline & $\begin{array}{l}\text { Limit } \\
(\mathrm{ppm})\end{array}$ & $\begin{array}{l}\text { Reason per Fuels Campaign } \\
\text { Our notes in italics. }\end{array}$ & $\begin{array}{l}\text { Limit } \\
\text { (ppm }\end{array}$ & $\begin{array}{l}\text { Reason per Fuels Campaign } \\
\text { Our notes in italics. }\end{array}$ \\
\hline $\begin{array}{l}\text { Group } 1 \\
\text { alkali } \\
\text { metals } \\
(\mathrm{Rb}, \mathrm{Cs})\end{array}$ & 462 & $\begin{array}{l}\text { Reactive metals that form } \\
\text { compounds oxides which can } \\
\text { melt or decompose at } \\
\text { temperatures below the fuel } \\
\text { sintering temperature causing } \\
\text { issues in fabrication. This limit is } \\
\text { for Na and K, no limit given for } \\
\mathrm{Rb} \text { and } \mathrm{Cs} \text {. }\end{array}$ & & No limit \\
\hline $\begin{array}{l}\text { Group } 2 \\
\text { alkaline } \\
\text { earth } \\
\text { metals } \\
(\mathrm{Sr}, \mathrm{Ba})\end{array}$ & 330 & $\begin{array}{l}\text { Tramp fission product. Carryover } \\
\text { limited to minimize displacement } \\
\text { of fissile content. This limit is for } \\
\text { Sr. }\end{array}$ & & No limit \\
\hline $\begin{array}{l}\text { Mo and } \\
\text { others }\end{array}$ & & & 465 & $\begin{array}{l}\text { Transition metals form undesirable } \\
\text { intermetallics in the fuel and affect } \\
\text { the total impurities displacing fissile } \\
\text { content. This limit applies to Al, } \\
\mathrm{Cr}, \mathrm{Mn}, \mathrm{Fe}, \mathrm{Ni}, \mathrm{Zn}, \mathrm{Mo} \text {; of these, } \\
\text { only Mo is a fission product. } \\
\text { However, we are aware of the } \\
\text { concept of adding Mo to the fuel } \\
\text { alloy, from which we infer that Mo } \\
\text { may not be limited to this value. }\end{array}$ \\
\hline $\begin{array}{l}\text { Mo, Ag, } \\
\text { and } \\
\text { others }\end{array}$ & 660 & $\begin{array}{l}\text { Transition metals form } \\
\text { undesirable oxides in the fuel and } \\
\text { affect the total impurities } \\
\text { displacing fissile content. } \\
\text { This limit is for } \mathrm{Ti}, \mathrm{V}, \mathrm{Mn}, \mathrm{Co} \text {, } \\
\mathrm{Cu}, \mathrm{Mo}, \mathrm{Ag}, \mathrm{Ta}, \mathrm{W} \text {. Of these, } \\
\text { only Mo and } \mathrm{Ag} \text { are fission } \\
\text { products. }\end{array}$ & & No limit \\
\hline $\mathrm{Ru}$ & 330 & $\begin{array}{l}\text { Tramp fission product. Carryover } \\
\text { limited to minimize displacement } \\
\text { of fissile content. }\end{array}$ & & No limit \\
\hline $\mathrm{Cd}$ & & See below. & 200 & $\begin{array}{l}\text { Limited carryover from } \\
\text { electrochemical separations }\end{array}$ \\
\hline $\begin{array}{l}\mathrm{Cd}, \mathrm{Sn}, \\
\text { and } \\
\text { others }\end{array}$ & 145 & $\begin{array}{l}\text { Low melting point metals that } \\
\text { form oxides which decompose at } \\
\text { temperatures below the fuel } \\
\text { sintering temperature causing } \\
\text { issues in fabrication. This limit is }\end{array}$ & none & See above. \\
\hline
\end{tabular}




\begin{tabular}{|l|l|l|l|l|}
\hline & & $\begin{array}{l}\text { for Zn, Cd, Sn, Pb. Of these, only } \\
\text { Cd and Sn are fission products. }\end{array}$ & & \\
\hline $\begin{array}{l}\text { Group 17 } \\
\text { halogens } \\
\text { (Br, I) }\end{array}$ & 20 & $\begin{array}{l}\text { Halogens are restricted to prevent } \\
\text { fuel cladding corrosion. This } \\
\text { limit is for F and Cl, no limit } \\
\text { given for fission products Br and } \\
\text { I. }\end{array}$ & 93 & $\begin{array}{l}\text { Halogens are restricted to prevent } \\
\text { fuel cladding corrosion }\end{array}$ \\
\hline $\begin{array}{l}\text { Lan- } \\
\text { thanides }\end{array}$ & $\begin{array}{l}\text { 660 ppm - Elements form oxide } \\
\text { hydrates and oxides that make } \\
\text { control of O:M ratio difficult in } \\
\text { pellet sintering. This limit is for } \\
\text { La, Ce, Pr, Nd. } \\
\text { 132 ppm - Restricted as thermal } \\
\text { neutron resonance absorbers } \\
\text { (poisons) This limit is for Sm, Eu, } \\
\text { Gd, Tb, Dy. }\end{array}$ & 775 & $\begin{array}{l}\text { Concentrations of rare earth } \\
\text { elements form low melting eutectics } \\
\text { with fuel cladding. Rare earth } \\
\text { feedstock impurities are more } \\
\text { detrimental to fuel due to their lack } \\
\text { of dispersion. } \\
\text { This limit is given for all } \\
\text { lanthanides. }\end{array}$ \\
\end{tabular}

\subsection{Oxide Fuel Cases}

Table 4-2 shows the oxide fuel cases performed to date. The fuel coming into the recycle loop is always used UOX-51 fuel; the rate of incoming fuel is held constant. The reactor in the recycle loop is always a fast reactor with transuranic conversion ratio of 0.50 .

Table 4-2. Oxide fuel cases.

\begin{tabular}{|l|l|l|l|l|l|}
\hline Case & $\begin{array}{l}\text { Number of } \\
\text { recycles }\end{array}$ & $\begin{array}{l}\text { Source of } \\
\text { uranium for } \\
\text { recycle 1 }\end{array}$ & $\begin{array}{l}\text { Source of uranium } \\
\text { for recycle }>1\end{array}$ & $\begin{array}{l}\text { Separation of used } \\
\text { UOX-51 fuel }\end{array}$ & $\begin{array}{l}\text { Separation of } \\
\text { used FR fuel }\end{array}$ \\
\hline $\begin{array}{l}\text { Pure } \\
\text { feeds }\end{array}$ & 20 & $\begin{array}{l}\text { RU from used } \\
\text { UOX-51 (pure) }\end{array}$ & $\begin{array}{l}\text { RU from used FR } \\
\text { fuel (pure) }\end{array}$ & UREX+1 & UREX+1 \\
\hline DU feed & 20 & DU (pure) & DU (pure) & UREX+1 & UREX+1 \\
\hline RU feed & 20 & $\begin{array}{l}\text { RU from used } \\
\text { UOX-51 }\end{array}$ & $\begin{array}{l}\text { RU from used FR } \\
\text { fuel }\end{array}$ & UREX+1 & UREX+1 \\
\hline AIROX & 3 & $\begin{array}{l}\text { RU from used } \\
\text { UOX-51 }\end{array}$ & $\begin{array}{l}\text { RU from used } \\
\text { UOX-51 }\end{array}$ & UREX+1 & AIROX \\
\hline
\end{tabular}

\subsubsection{Actinides}

Figure 4-3 shows the actinide composition for oxide fuel with pure feedstocks, no impurities. The RU and DU cases have the same behavior as the pure feed stock case. The neptunium fraction slowly decreases as there is a net consumption of $\mathrm{Np} 237$. By the $20^{\text {th }}$ recycle, the chemical composition of the highest actinides, curium, berkelium, and californium, is about at equilibrium, also the isotopic mix (not shown) is still evolving. 


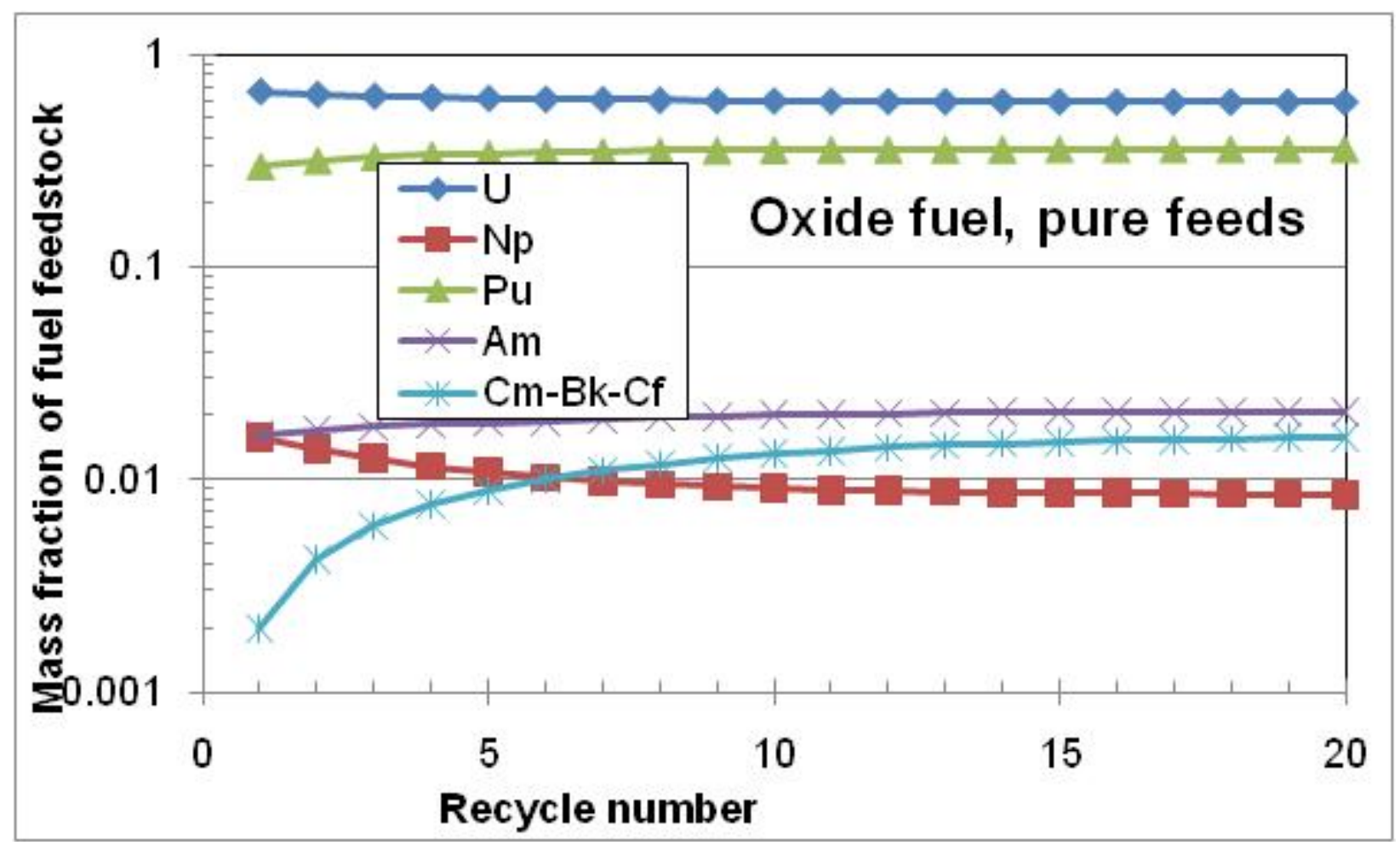

Figure 4-3. Estimated actinide composition in oxide fuels for fast reactor with TRU CR=0.5.

Figure 4-4 shows the actinide and total impurities for the oxide fuel case in which AIROX is used to recycled used FR fuel. Recycle 1 has low impurities since it uses only feed from UREX+1 separation of used UOX-51 fuel. Thereafter the impurities increase substantially as FIT blends used UOX-51 (from UREX+1) with used FR fuel that has been separated with AIROX. The model cannot proceed past 3 recycles because the impurities become too high (13\%) to maintain criticality, even with no uranium dilution from UREX+1, i.e., the model attempts to make recycle-4 using only TRU from UREX+1 treatment of UOX-51 plus AIROX feed from treatment of used FR fuel. 


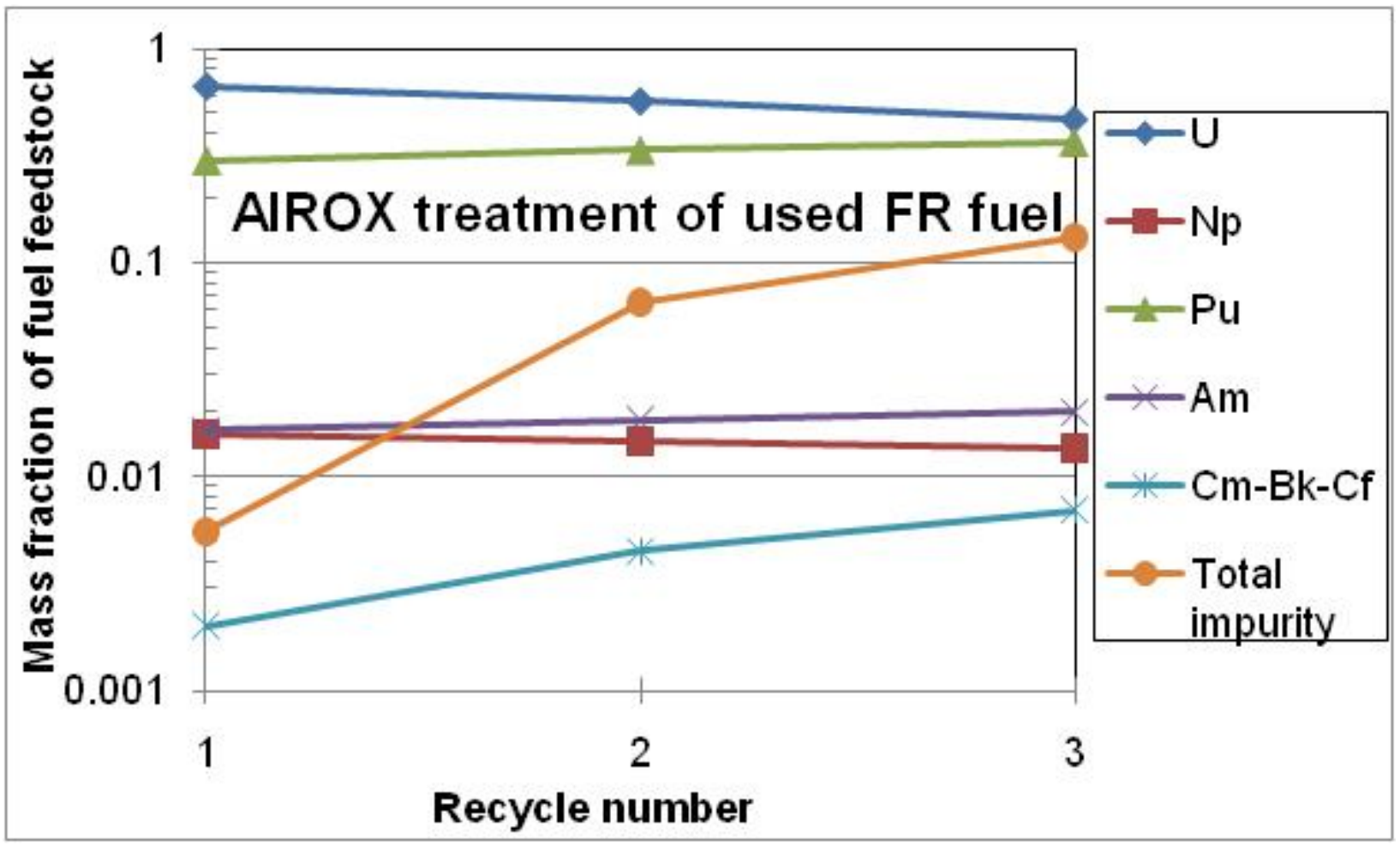

Figure 4-4. Estimated composition of oxide fuels for fast reactor TRU CR $=0.5$ with AIROX treatment of used FR fuel and UREX+1 treatment of used UOX-51 fuel.

\subsubsection{Lanthanides}

Figure $4-5$ shows the estimated lanthanide impurities. In UREX +1 separations, $0.03 \%$ of the lanthanides used fuel go into the TRU-U stream, $0.099 \%$ into the recovered uranium stream, and the rest go to waste. Note therefore that there is more lanthanides in uranium product than the TRU-U product. Of course, DU is considered lanthanide-free. The only AIROX data says that $\sim 100 \%$ is retained, we used $99.9 \%$ but it makes no difference. 


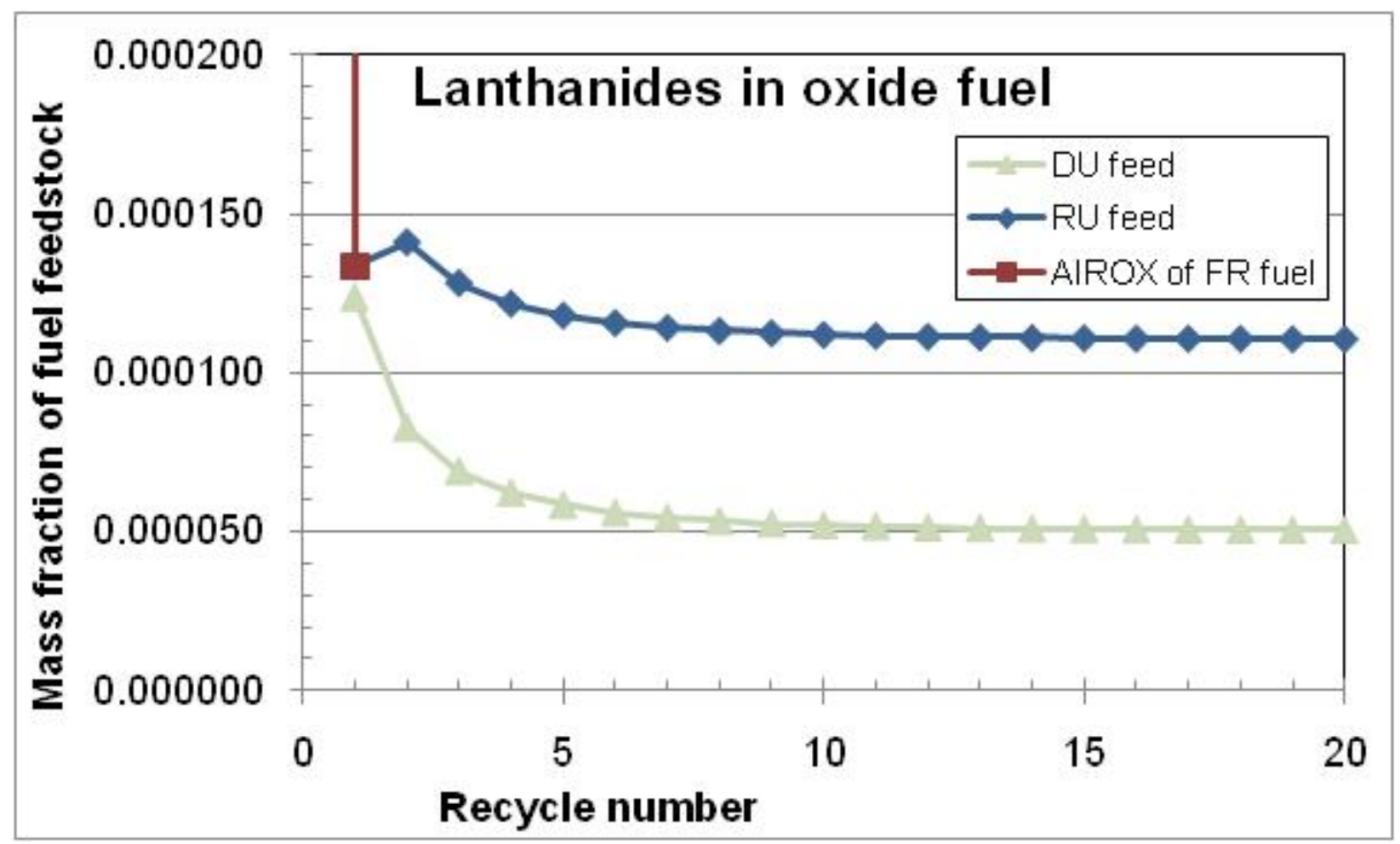

Figure 4-5. Estimated lanthanide impurity in oxide fuels for fast reactor TRU CR=0.5.

FIT cannot provide a direct estimate of individual lanthanide elements to compare with the limits of 660 ppm for lanthanum, cerium, praseodymium, neodymium, and samarium (the first lanthanides minus promethium which does not occur in nature) and $132 \mathrm{ppm}$ for samarium, europium, gadolinium, and dysprosium (some but not all of the rest of the lanthanides). For this reason, the limit for total lanthanides used in the FIT model (792 ppm) is calculated by summing the two limits for the two different lanthanide groupings.

The AIROX case (UREX+1 separation of used UOX, AIROX separation of used FR fuel) obviously has the same value for the first recycle as RU feed (UREX+1 separation of both used UOX and used FR) because AIROX hasn't been used yet. Thereafter, the full retention of lanthanides by AIROX cases the lanthanide content to increase quickly, reaching $7 \%(70,000 \mathrm{ppm})$ at the third recycle.

The DU feed case has less than half the lanthanide impurity as the RU feed case. Both cases result in lanthanide levels in the oxide fuel that are below the total $792 \mathrm{ppm}$ limit.

\subsubsection{Alkali (Group 1) and Alkaline Earth (Group 2) Metals}

Figure 4-6 shows the impurities for Group 1 and Group 2 elements. 


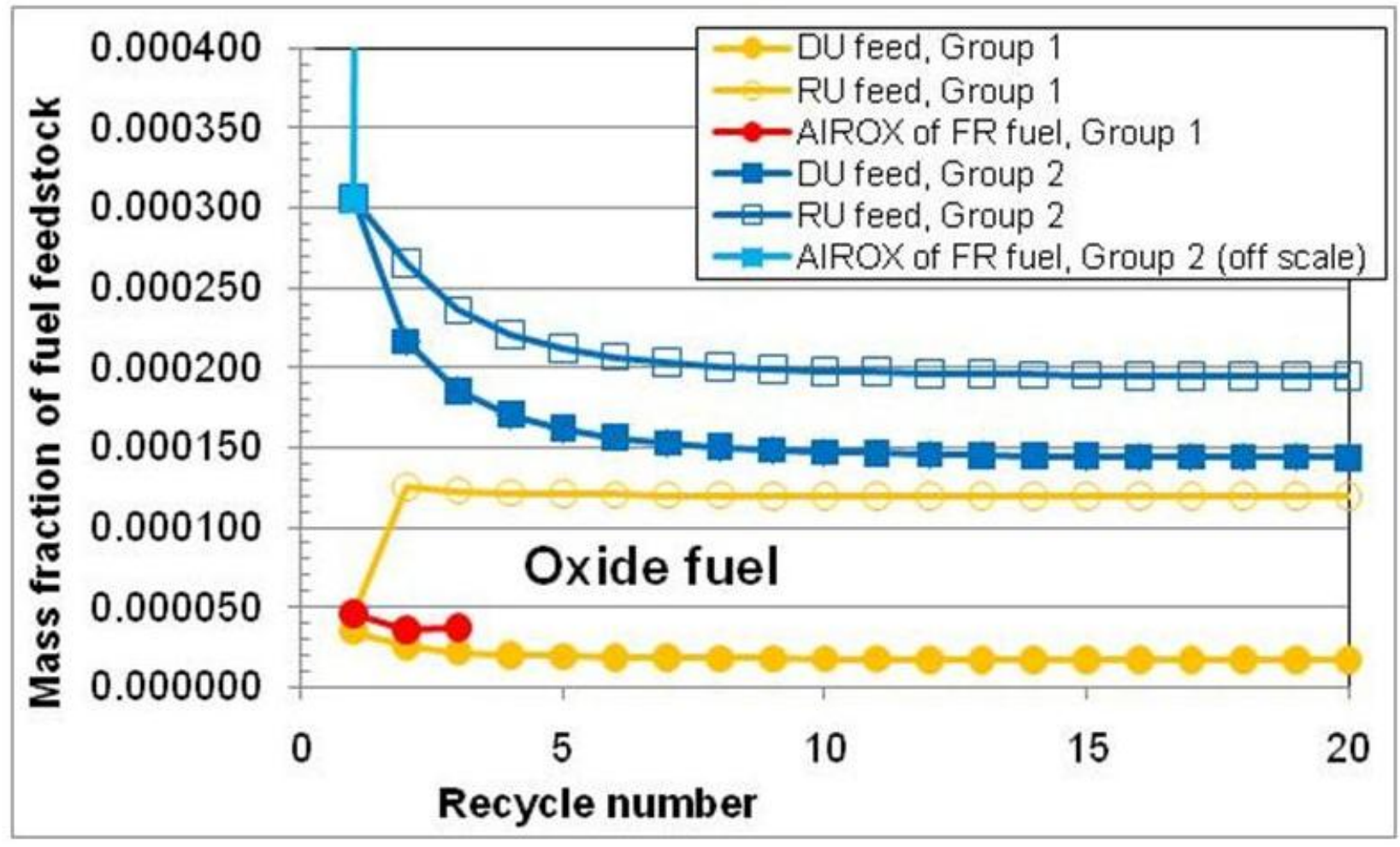

Figure 4-6. Estimated Group 1 and Group 2 impurities in oxide fuels for fast reactor TRU CR=0.5.

AIROX has a high separation efficiency of the Group 1 elements, which are volatilized from the recycled fuel. The existing AIROX separations data refers to the separation as $\sim 100 \%$, we used a default value of $99.9 \%$, leaving only $0.1 \%$ in the fuel. (These default values were used in the model whenever separations data was nonexistent or had insufficient resolution.) In UREX $+1,0.034 \%$ of the Group 1 elements are retained in the TRU-U product but $0.396 \%$ partitions to the RU - so the RU is "dirtier". Thus, there are more recycled Group 1 impurities in the RU feed case than are recycled in the U-TRU recycle stream in either DU or AIROX.

The AIROX separation factors for Group 2 elements default in the model to $99.9 \%$ retained in the recycled fuel, as those elements are not volatile. Because of this, the Group 2 content in the recycled fuel increases to $1.5 \%$ by the third recycle. In UREX +1 separations, $0.193 \%$ of Group 2 elements are retained in the TRU-U product and $0.0495 \%$ into RU product - the UREX+1 recycled TRU is "dirtier". Thus, the RU versus DU penalty for Group 2 is much less than for Group 1.

There is no fuel limit for the Group 1 fission products rubidium and cesium. There is a limit of $462 \mathrm{ppm}$ for sodium and potassium, based on low melting point oxide formation. $\mathrm{Rb}$ and $\mathrm{Cs}$ also form low melting point oxides and would seem appropriate to limit. The estimates show that $\mathrm{Rb}+\mathrm{Cs}$ reach a maximum of about $130 \mathrm{ppm}$. Were these elements to be included in the $462 \mathrm{ppm}$ limit (assuming a total Group 1 limit of $462 \mathrm{ppm}$ ), for the limit for $\mathrm{Na}+\mathrm{K}$ would decrease to $330 \mathrm{ppm}$.

There is a 330 limit for strontium, based on displacement of fissile content. This topic of fissile content displacement and neutron absorption actually applies to all elements to varying degrees. In any case, the figure shows that all of Group 2 stays below $330 \mathrm{ppm}$. 


\subsubsection{Molybdenum and Silver}

The working limit for Ti, V, Mn, Co, Cu, Mo, Ag, Ta, W in fuels is 660 ppm because these transition metals form undesirable oxides in the fuel and because they affect the total impurities displacing fissile content. Of these, Mo and Ag are fission products. The estimated values in Figure 4-7 exceed that limit; however, the estimates must be considered quite uncertain because of the current approximations in FIT involving transition metals.

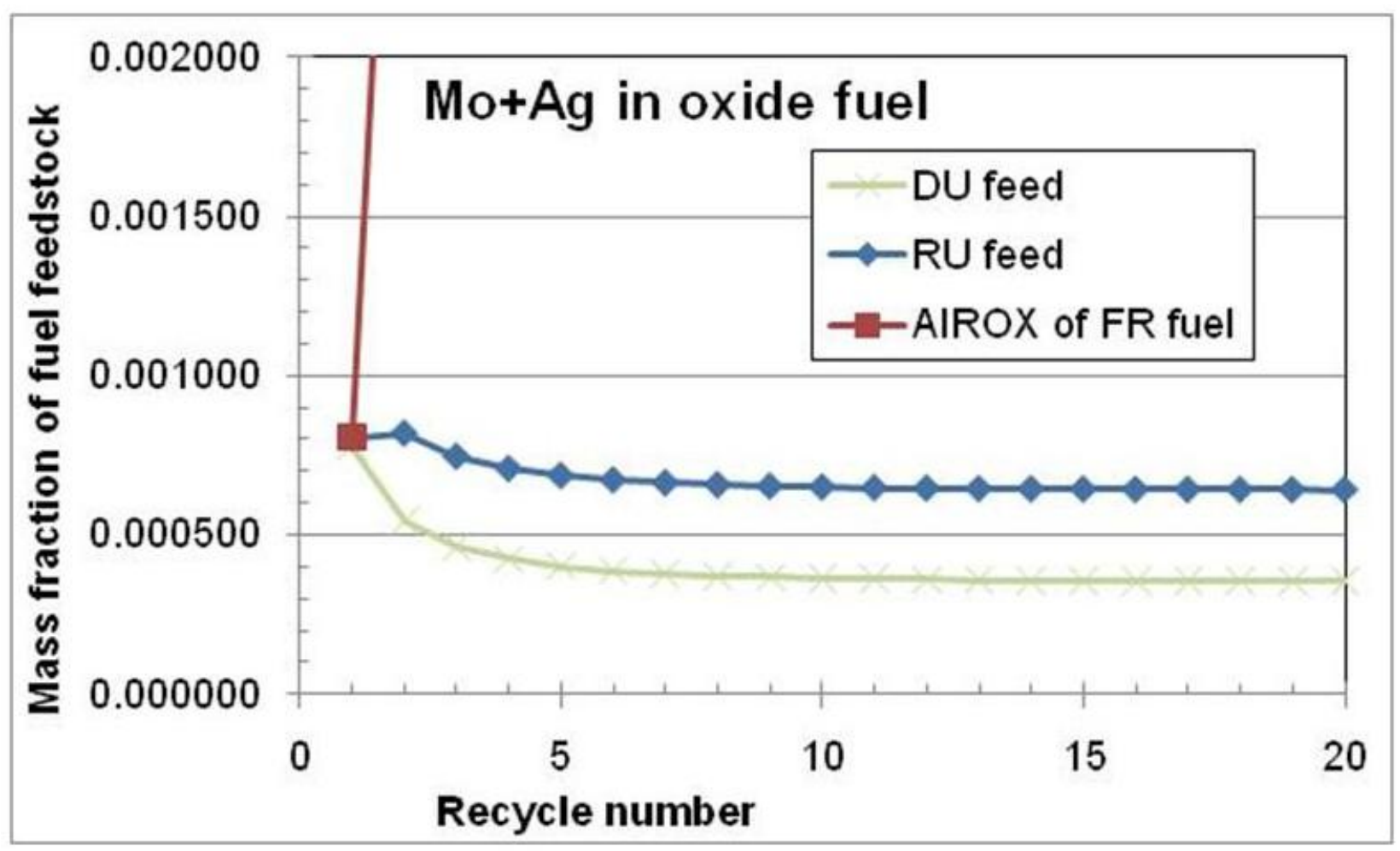

Figure 4-7. Estimated molybdenum and silver in oxide fuels for fast reactor TRU $C R=0.5$; uncertainties are high.

\subsubsection{Ruthenium}

Ruthenium in fuel is limited to $330 \mathrm{ppm}$ because of displacement of fissile content. There is no inherent reason why only one of the transition metals should be limited for this reason and not the others. In any case, Figure 4-8 shows the estimated ruthenium content, which exceeds the $330 \mathrm{ppm}$ limit. 


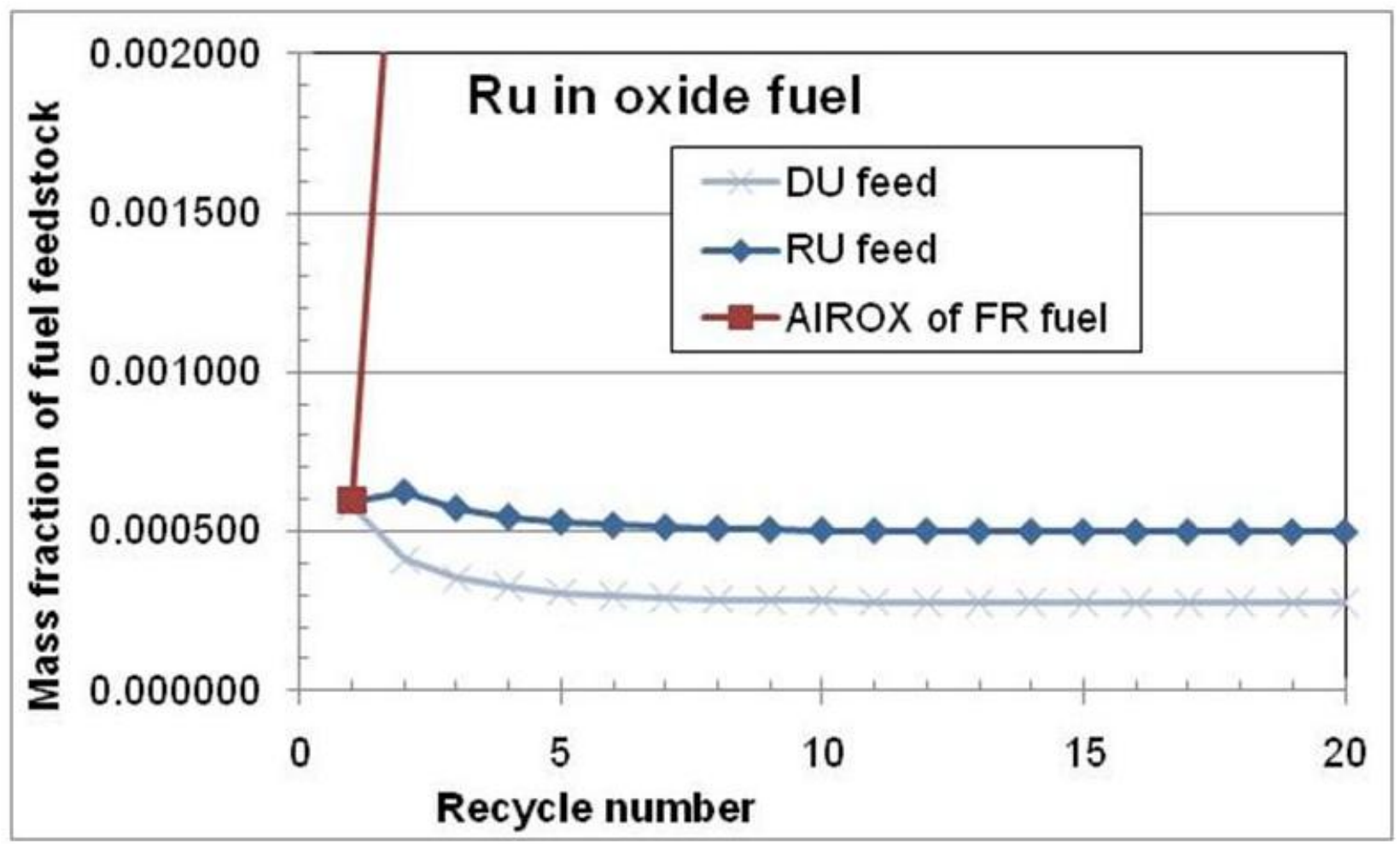

Figure 4-8. Estimated ruthenium in oxide fuels for fast reactor TRU $C R=0.5$; uncertainties are high.

\subsubsection{Cadmium and Tin}

The working limit for zinc, cadmium, tin, and lead is $145 \mathrm{ppm}$ because of low melting point metal behavior and their oxides that decompose at temperatures below fuel sintering temperatures. Of these, cadmium and tin are fission products. The estimated values in Figure 4-9 exceed that limit; however, the estimates must be considered quite uncertain because of the current approximations in FIT involving transition metals. 


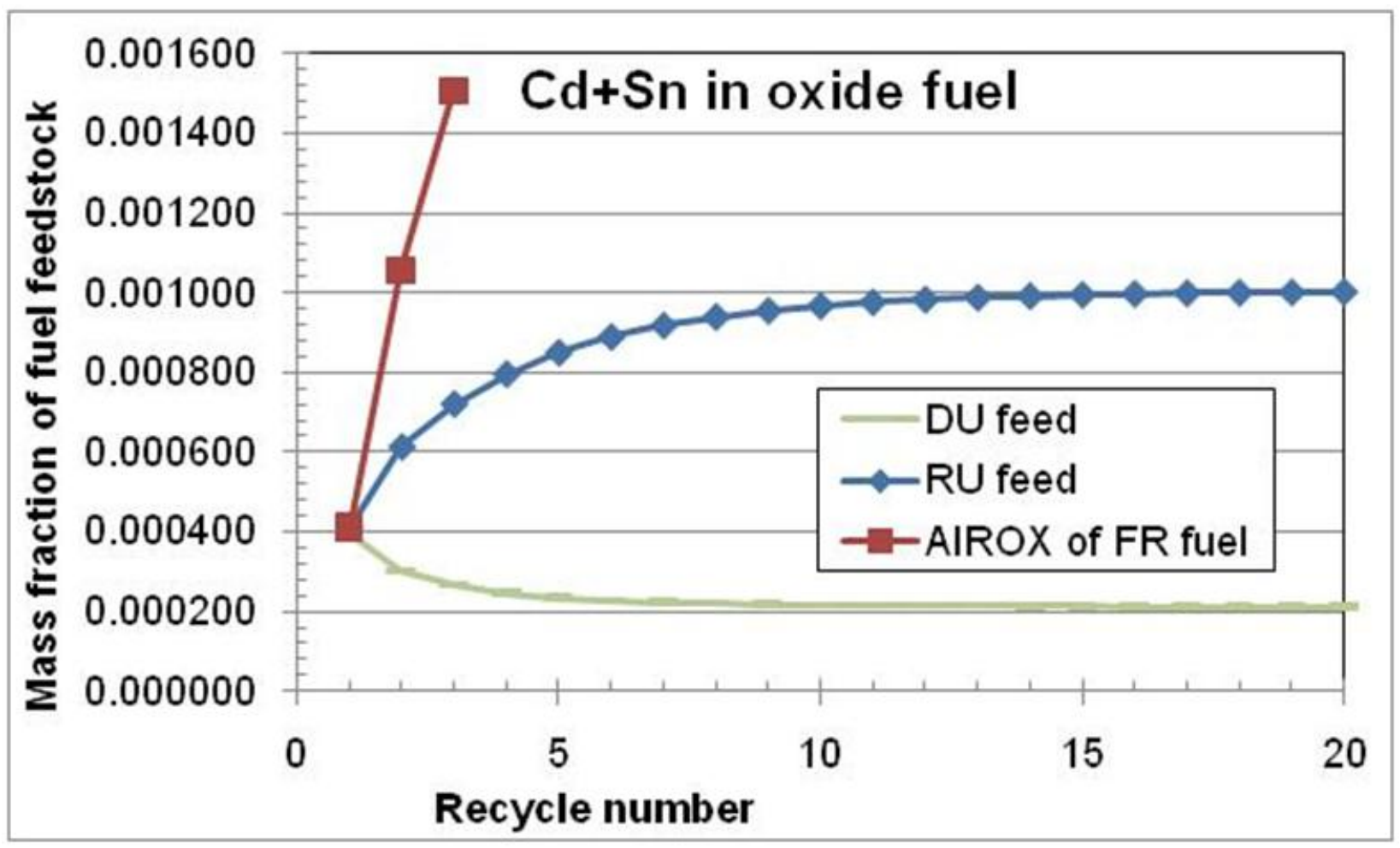

Figure 4-9. Estimated cadmium and tin in oxide fuels for fast reactor TRU CR=0.5; uncertainties are high.

\subsubsection{Halogens}

The working limit in fuels for the halogens (fluorine and chlorine) is $20 \mathrm{ppm}$; we do not know if it also should apply to bromine and iodine. In any case, UREX +1 and electrochemical separations removes nearly complete $(99.999 \%)$ bromine and iodine from the TRU-U and U products. The halogen separations efficiencies for AIROX and melt refining are also high but reported with insufficient resolution, so a default separations efficiency of $99.9 \%$ is assumed. We estimate halogens to be below the 20-ppm limit.

\subsubsection{Elements Not Currently Limited}

Table 4-3 shows the range of estimates for which no oxide fuel limit currently exists. It is important to know if these levels of impurities would be an issue for oxide fuel fabrication and performance.

Table 4-3. Estimates of Fuel Impurities for which no oxide fuel limit exists (UREX+1 separation of both $\mathrm{UOX}$ and $\mathrm{FR}$ at $\mathrm{CR}=0.50$ ).

\begin{tabular}{|l|l|l|l|l|l|l|l|l|l|}
\hline $\begin{array}{l}\text { Estimate in } \\
\text { ppm }\end{array}$ & $\mathrm{Se}$ & $\mathrm{Zr}$ & $\mathrm{Nb}$ & $\mathrm{Tc}$ & $\mathrm{Rh}$ & $\mathrm{Pd}$ & $\mathrm{In}$ & $\mathrm{Sb}$ & $\mathrm{Te}$ \\
\hline Maximum & 30 & 600 & 20 & 200 & 200 & 2000 & 10 & 30 & 500 \\
\hline Minimum & 10 & 200 & 10 & 90 & 90 & 1000 & 1 & 10 & 200 \\
\hline
\end{tabular}




\subsection{Metal Fuel Cases}

Table 4-4 shows the metal fuel cases performed to date. The fuel coming into the recycle loop is always used UOX-51 fuel; the rate of incoming fuel is held constant. The reactor in the recycle loop is always a fast reactor with transuranic conversion ratio of 0.50 .

Table 4-4. Metal fuel cases.

\begin{tabular}{|l|l|l|l|l|l|}
\hline Case & $\begin{array}{l}\text { Number of } \\
\text { recycles }\end{array}$ & $\begin{array}{l}\text { Source of } \\
\text { uranium for } \\
\text { recycle 1 }\end{array}$ & $\begin{array}{l}\text { Source of uranium } \\
\text { for recycle }>1\end{array}$ & $\begin{array}{l}\text { Separation of used } \\
\text { UOX-51 fuel }\end{array}$ & $\begin{array}{l}\text { Separation of } \\
\text { used FR fuel }\end{array}$ \\
\hline $\begin{array}{l}\text { Pure } \\
\text { feeds }\end{array}$ & 20 & $\begin{array}{l}\text { RU from used } \\
\text { UOX-51 (pure) }\end{array}$ & $\begin{array}{l}\text { RU from used FR } \\
\text { fuel (pure) }\end{array}$ & UREX+1 & Electrochemical \\
\hline DU feed & 20 & DU (pure) & DU (pure) & UREX+1 & Electrochemical \\
\hline RU feed & 20 & $\begin{array}{l}\text { RU from used } \\
\text { UOX-51 }\end{array}$ & $\begin{array}{l}\text { RU from used FR } \\
\text { fuel }\end{array}$ & UREX+1 & Electrochemical \\
\hline $\begin{array}{l}\text { Melt } \\
\text { refining }\end{array}$ & 3 & $\begin{array}{l}\text { RU from used } \\
\text { UOX-51 }\end{array}$ & $\begin{array}{l}\text { RU from used } \\
\text { UOX-51 }\end{array}$ & UREX+1 & Melt refining \\
\hline
\end{tabular}

\subsubsection{Actinides}

Figure 4-10 shows the actinide composition for metal fuel with pure feedstocks, no impurities. The RU and DU cases have the same behavior as the pure feed stock case. The neptunium fraction slowly decreases as there is a net consumption of Np237. By the $20^{\text {th }}$ recycle, the chemical composition of the highest actinides, curium, berkelium, and californium, is about at equilibrium, also the isotopic mix (not shown) is still evolving.

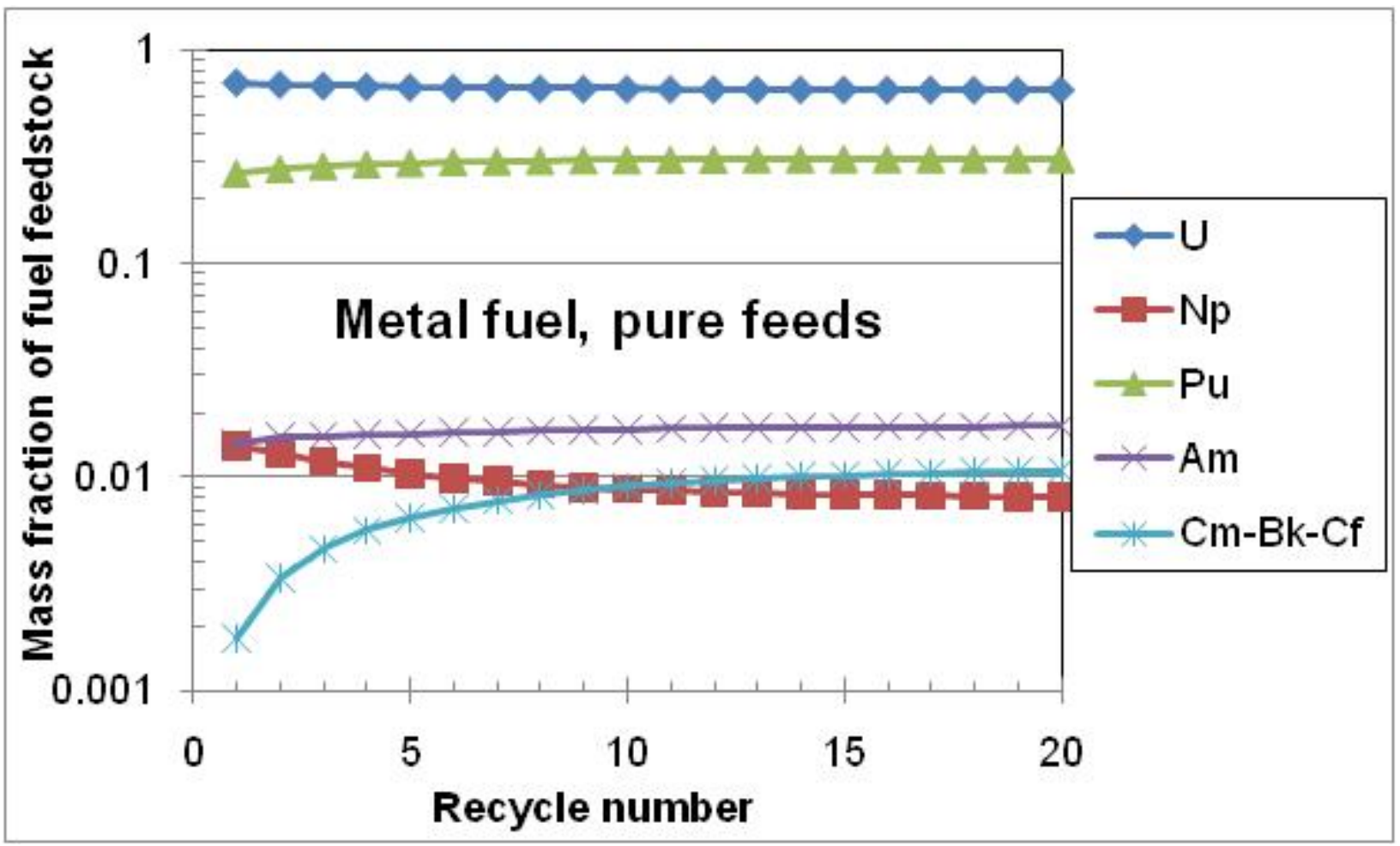


Figure 4-10. Estimated actinides in metal fuels for fast reactor transuranic conversion ratio of 0.5 .

Figure 4-11 shows the actinide and total impurities for the oxide fuel case in which melt refining is used to treat used FR fuel. Recycle 1 has low impurities since it uses only feed from UREX+1 separation of used UOX-51 fuel. Thereafter the impurities increase substantially as FIT blends used UOX-51 (from UREX +1 with used FR that has been treated with melt refining. The model cannot proceed past 3 recycles because the impurities are too high $(8 \%)$ to maintain criticality, even with no uranium dilution from UREX+1, i.e., the model attempts to make recycle- 4 using only TRU from UREX +1 treatment of UOX-51 plus feed from melt refining from treatment of used FR fuel. The result of $8 \%$ is, as expected, somewhat lower than the analogous AIROX result of $13 \%$ as melt refining removes lanthanides whereas AIROX does not.

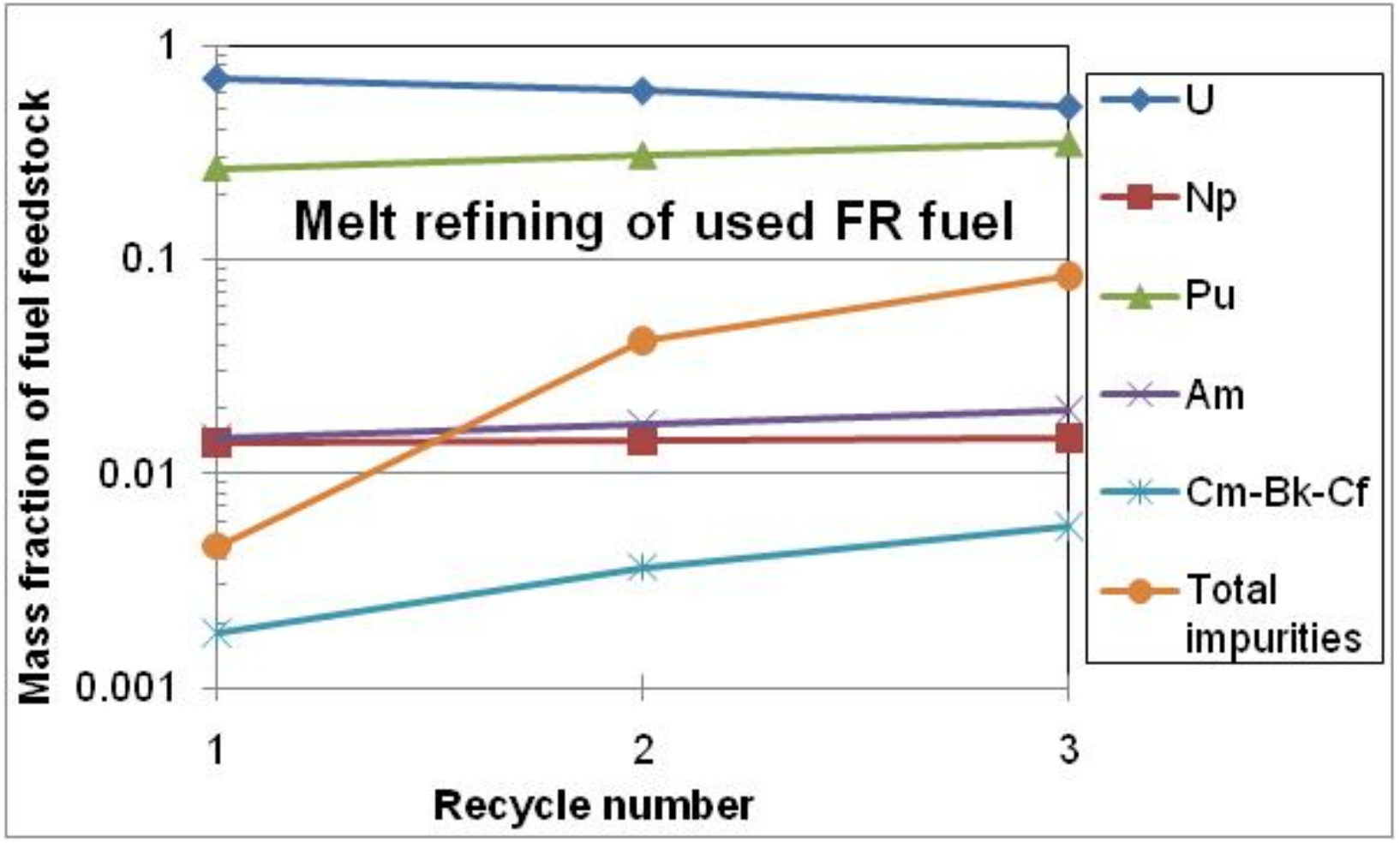

Figure 4-11. Estimated composition of oxide fuels for fast reactor TRU CR $=0.5$ with AIROX treatment of used FR fuel and UREX+1 treatment of used UOX-51 fuel.

\subsubsection{Lanthanides}

Figure 4-12 shows the estimated lanthanide impurities. The first recycle is about the same as for oxide fuel as the feedstock is the same, used UOX-51. (The composition is not exactly the same because the required TRU enrichment for oxide and metal fuels differ slightly.) Because the separation factors for the TRU-U product are still being determined, a conservative $5 \%$ of the lanthanides are assumed to be going into that product. It is assumed that $0.1 \%$ goes into the recovered uranium product, this is a conservative value because the lanthanides in the uranium product are generally below detection limits. These values $(5 \%, 0.1 \%)$ are higher than the analogous UREX +1 values $(0.03 \%, 0.099 \%)$ so that the lanthanide content increases quickly after the first recycle as the blended product shifts from UREX+1 origin material to a blend of electrochemical and UREX +1 . As there is little lanthanide in recovered uranium, there is little difference between the "RU feed and "DU feed" cases. 
The best estimate we have for lanthanide removal via melt refining is $99 \%$. If true, melt refining would have higher lanthanide removal than electrochemical, which is why melt refining is lower in figure. For either "RU feed" or "DU feed", the conservatisms lead to the lanthanide content quickly exceeding the current working limit of 775 ppm assumed for metal fuel.

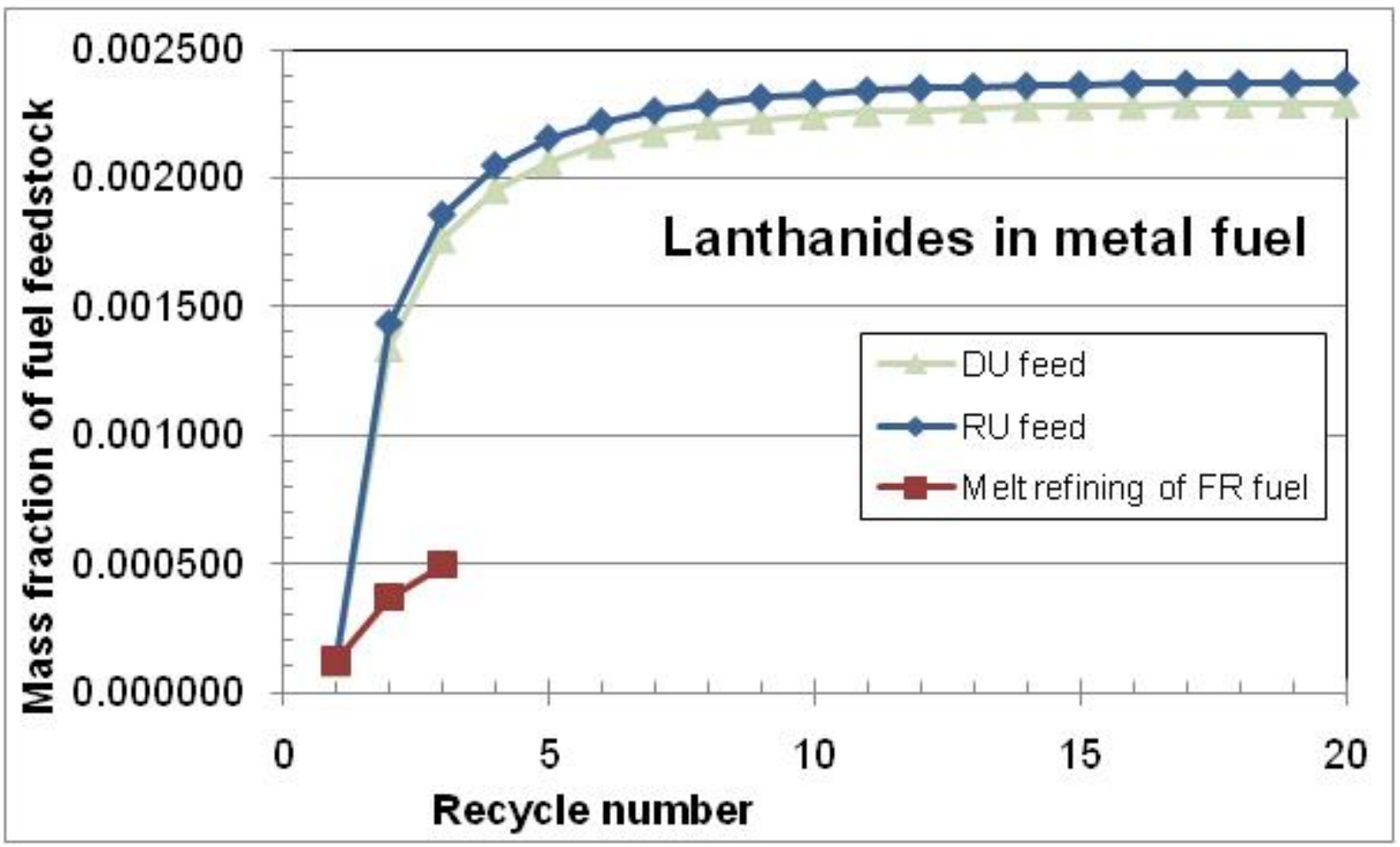

Figure 4-12. Estimated lanthanides in metal fuels for fast reactor transuranic conversion ratio of 0.5.

\subsubsection{Molybdenum}

The working limit for Ti, V, Mn, Co, Cu, Mo, Ag, Ta, W is 465 ppm because these transition metals form form "undesirable intermetallics in the fuel and affect the total impurities displacing fissile content." Yet, we are also aware that there is work exploring use of Mo as a metal fuel alloying agent, presumably meaning that under some circumstances Mo can be advantageous instead of an undesirable impurity.

Except for the first recycle (which is fed from UREX+1), the molybdenum content shown in Figure 4-13 is below the 465 ppm limit, but of course molybdenum is only one of those eleven elements. 


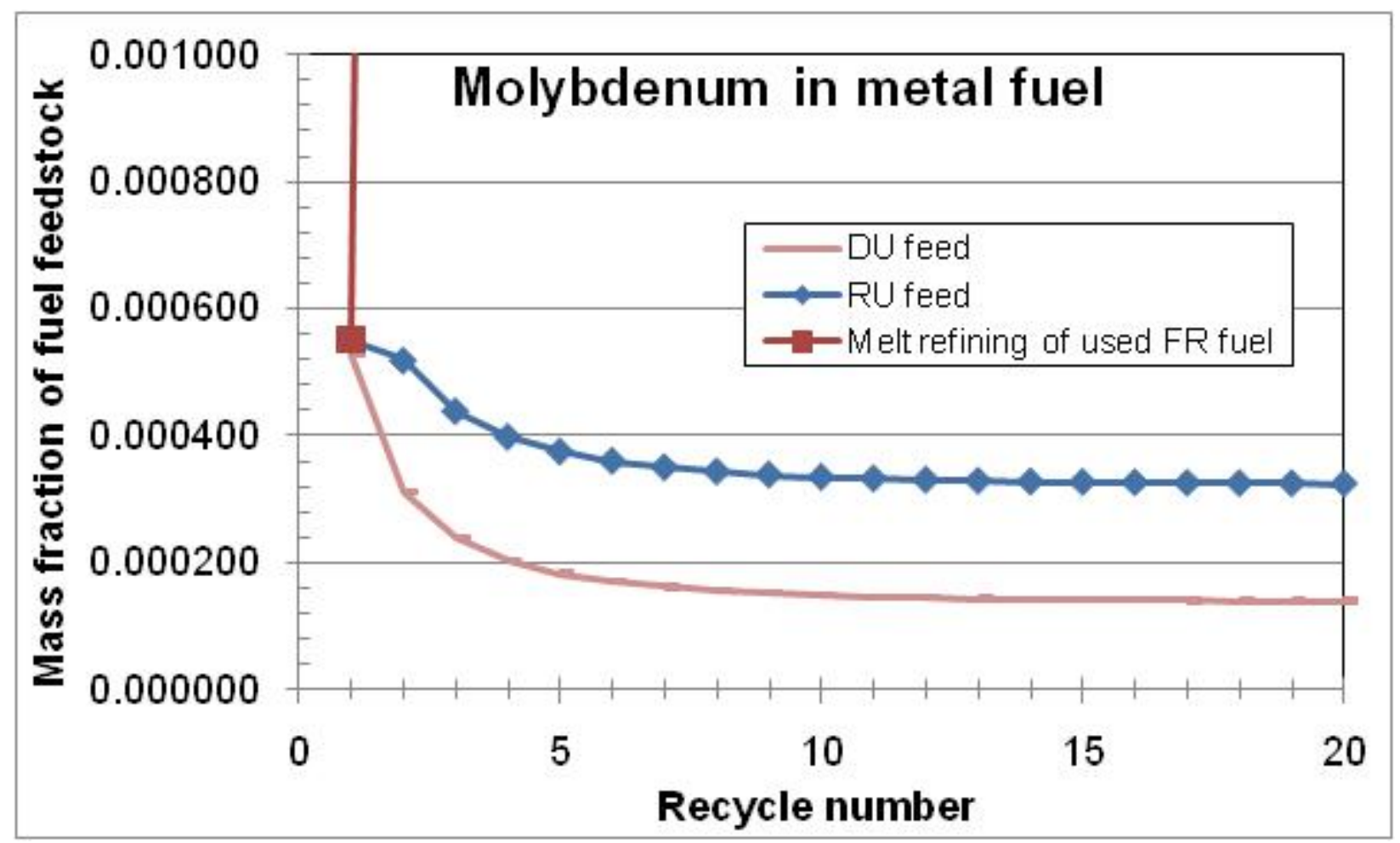

Figure 4-13. Estimated molybdenum in metal fuels for fast reactor transuranic conversion ratio of 0.5 ; uncertainties are high.

\subsubsection{Cadmium}

The working limit for cadmium is $200 \mathrm{ppm}$. Figure 4-14 shows that the electrochemical cases stay below that limit, but melt refining does not. 


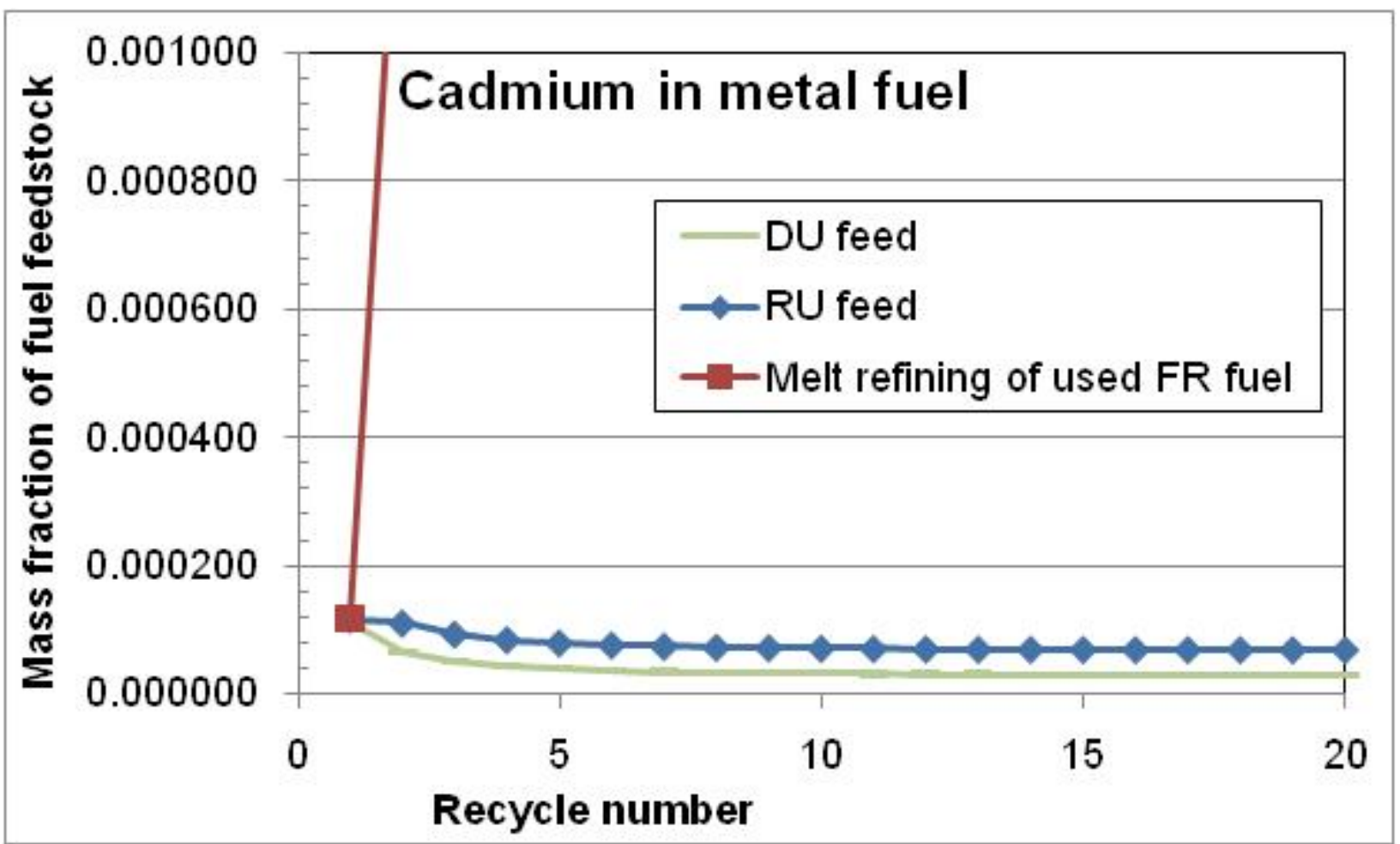

Figure 4-14. Estimated cadmium in metal fuels for fast reactor transuranic conversion ratio of 0.5 ; uncertainties are high.

\subsubsection{Halogens}

The working limit for the halogens $(\mathrm{F}, \mathrm{Cl}, \mathrm{Br}, \mathrm{I})$ is $93 \mathrm{ppm}$. In any case, the UREX+1 data show complete removal of $\mathrm{Br}$ and I from the TRU-U and $\mathrm{U}$ products. We used a value of $0.1 \%$ retention of halogens for electrochemical. The halogen impurity stays below 2 ppm, well below 93 ppm.

\subsubsection{Elements Not Currently Limited}

Table 4-5 shows the range of estimates for which no metal fuel limit currently exists. It is important to know if these levels of impurities would be an issue for metal fuel fabrication and performance.

Table 4-5. Estimates of fuel impurities for which no metal fuel limit exists (UREX +1 separation of UOX and electrochemical separation of $\mathrm{FR}$ at $\mathrm{CR}=0.50$ ).

\begin{tabular}{|l|l|l|l|l|l|l|l|l|l|l|l|l|l|}
\hline $\begin{array}{l}\text { Estimate } \\
\text { in ppm }\end{array}$ & $\begin{array}{c}\text { Group } \\
1\end{array}$ & $\begin{array}{c}\text { Group } \\
2\end{array}$ & $\mathrm{Se}$ & $\mathrm{Nb}$ & $\mathrm{Tc}$ & $\mathrm{Ru}$ & $\mathrm{Rh}$ & $\mathrm{Pd}$ & $\mathrm{Ag}$ & $\mathrm{In}$ & $\mathrm{Sn}$ & $\mathrm{Sb}$ & $\mathrm{Te}$ \\
\hline Maximum & 50 & 300 & 20 & 10 & 200 & 500 & 200 & 1500 & 200 & 10 & 300 & 20 & 500 \\
\hline Minimum & 10 & 70 & 6 & 3 & 50 & 100 & 40 & 400 & 40 & 1 & 60 & 6 & 100 \\
\hline
\end{tabular}

\subsection{Waste Analyses}

The FIT model includes the necessary blocks for tracking waste streams separated from used fuel during recycling and produced during recycle fuel fabrication. Operating and maintenance wastes for 
separations and fuel fabrication are also included; but operating and maintenance wastes from front-end processes, the first (LWR) reactor, and the recycle reactor are not included in the model at this time. If these presently-excluded waste streams are determined through future analyses to be potentially significant in analyzing different fuel cycle options, then they may be included in future versions of FIT.

The model is designed to enable user-selected or modified waste treatment options that are defined to meet user-intended waste dispositions, that could dictate what treatments, and waste forms, and waste loadings are needed. The model does not pre-supposes the application of any specific regulatory or policy requirements on waste forms or and waste dispositions consistent with recent studies of the Integrated Waste Management Strategy (IWMS, Gombert 2008), the Advanced Fuel Cycle Facility (AFCF) design (DOE 2007), and the Waste Form Campaign (Vienna 2010).

Potential waste streams and waste forms are summarized in Table 4-6. The different separations processes do not produce all of these waste streams; zero values are present in the model structure for waste streams that are not produced in that specific separations process. Masses and volumes of the waste forms are calculated based on waste loadings of the waste forms, consistent with models developed by the Waste Form Campaign for glass (Ryan 2009) and the estimations made by the Integrated Waste Management Strategy, the AFCF, and the Waste Form Campaign. Waste packaging, and the impacts on waste volumes and masses introduced by waste packaging, are not yet included in the model structure.

\subsubsection{Handling Waste Streams in FIT}

The amounts of the cladding and waste isotopes are tracked in the various waste streams from each of the separations and fuel fabrication processes. Handling and storage steps for the waste streams include:

- Temporary storage after separations and fuel fabrication, but prior to waste treatment, during which the FIT model calculates isotopic decay for a user-selected time duration. A minimum storage time allows for expected practicalities that would still occur even with planned expeditious waste treatment soon after separations and fuel fabrication. Longer storage times could be used in cases where the waste might be purposefully stored for a number of years for decay prior to waste treatment.

- Treatment to convert the waste stream to the waste form suitable for disposal. Several options are available. For example, Tc or UDS, if separated from other waste streams, could be combined with metal (from cladding and fuel assembly structure material, for example) in a metal waste form, or the Tc could be combined with other fission products into a glass waste form. Waste forms were selected to be generally consistent with the IWMS, AFCF, and Waste Form Campaign.

- In some cases, such as for $\mathrm{Kr} 85$ waste from all separations processes, and for $\mathrm{Cs} / \mathrm{Sr}$ from UREX +1 separations, the strategy in the model allows the option for storage for sufficient time to allow decay and lower-cost disposition. Post-decay free release of $\mathrm{Kr} 85$, and disposal of decayed Cs/Sr waste streams as mixed LLW, are presumed, because these approaches make reasonable practical waste disposition sense even if not specifically supported by current waste policy and regulations.

\subsubsection{Waste Treatment and Waste Forms}

Default waste forms and loadings are used in the model, based on waste management studies in recent years, if the user does not modify the model for other potential waste forms. These default waste forms dictate, or result from, the kinds of waste treatment performed on the waste streams from separations. Several options are available. For example, Tc or UDS, if separated from other waste streams, could be combined with metal (from cladding and fuel assembly structure material, for example) in a metal waste 
form, or the Tc could be combined with other fission products into a glass waste form. Waste forms were selected to be generally consistent with the IWMS, AFCF, and Waste Form Campaign.

Table 4-6. Waste streams and waste forms in the FIT model.

\begin{tabular}{|c|c|c|c|}
\hline $\begin{array}{l}\text { Separated waste } \\
\text { isotope(s) }\end{array}$ & $\begin{array}{c}\text { From these } \\
\text { separations processes }\end{array}$ & Waste form & Comments \\
\hline C14 & All & Grouted carbonate & $\begin{array}{l}\text { Based on longevity and potential } \\
\text { mobility; free release may be allowed } \\
\text { (Waste Form Campaign current } \\
\text { reference case) }\end{array}$ \\
\hline $\begin{array}{l}\text { I129 (and co-collected } \\
\text { halogens) }\end{array}$ & $\begin{array}{l}\text { All except } \\
\text { electrochemical }\end{array}$ & zeolite & $\begin{array}{l}\text { Based on longevity and potential } \\
\text { mobility }\end{array}$ \\
\hline Tc99, UDS & UREX+1 & Metal ingot & $\begin{array}{l}\text { Based on longevity and potential } \\
\text { mobility. Could be combined with } \\
\text { HLW glass. }\end{array}$ \\
\hline $\begin{array}{l}\text { Cladding, UDS, } \\
\text { baskets }\end{array}$ & Electrochemical & Metal ingot & Combined with Tc99 metal \\
\hline Raffinate/residual & All but electrochemical & Glass & $\begin{array}{l}\text { Could include Tc, UDS, Cs/Sr, and } \\
\text { Ln in aqueous separations }\end{array}$ \\
\hline $\begin{array}{l}\text { Raffinate/residual } \\
\text { (salt waste) }\end{array}$ & Electrochemical & $\begin{array}{l}\text { Glass-bonded } \\
\text { zeolite }\end{array}$ & \\
\hline Ln & UREX+1 & Glass & Could be combined with HLW glass \\
\hline Cladding/coatings & Aqueous & Compacted & $\begin{array}{l}\text { Presumes residual TRU } \\
\text { contamination }>10 \mathrm{nCi} / \mathrm{g}\end{array}$ \\
\hline Structure/hardware & All & Compacted & $\begin{array}{l}\text { Presumes combined with } \\
\text { Cladding/coatings }\end{array}$ \\
\hline $\begin{array}{l}\text { Operations and } \\
\text { maintenance wastes }\end{array}$ & All & $\begin{array}{l}\text { Mineralized } \\
\text { monolith }\end{array}$ & $\begin{array}{l}\text { Presumes some wastes contaminated } \\
\text { with TRU }>10 \mathrm{nCi} / \mathrm{g}\end{array}$ \\
\hline Fuel fab wastes & --- & Compact & \\
\hline Tritium & All & $\begin{array}{l}\text { Grouted Tritiated } \\
\text { water }\end{array}$ & $\begin{array}{l}\text { Generally accepted disposition, } \\
\text { although disposition as HLW may } \\
\text { still be required; or free release may } \\
\text { be allowed after sufficient decay } \\
\text { prior to separations }\end{array}$ \\
\hline Spent solvents-liquids & UREX+1 & $\begin{array}{l}\text { Mineralized } \\
\text { monolith }\end{array}$ & $\begin{array}{l}\text { Presumes TRU can be reduced to }>10 \\
\mathrm{nCi} / \mathrm{g}\end{array}$ \\
\hline $\begin{array}{l}\text { Operations and } \\
\text { maintenance wastes }\end{array}$ & All & $\begin{array}{l}\text { Mineralized } \\
\text { monolith }\end{array}$ & $\begin{array}{l}\text { Presumes some wastes with TRU } \\
<10 \mathrm{nCi} / \mathrm{g}\end{array}$ \\
\hline $\begin{array}{l}\mathrm{Kr} 85 \text { (and other } \mathrm{Kr} \\
\text { and Xe isotopes) }\end{array}$ & All & Compressed gas & $\begin{array}{l}\text { Free release after sufficient decay } \\
\text { time }\end{array}$ \\
\hline $\mathrm{Cs} / \mathrm{Sr}$ & UREX+1 & $\begin{array}{l}\text { Mineralized } \\
\text { monolith }\end{array}$ & $\begin{array}{l}\text { Could (or may be required to) be } \\
\text { combined with HLW glass, } \\
\text { depending on waste policy } \\
\text { interpretation or economics }\end{array}$ \\
\hline
\end{tabular}




\section{CONCLUSIONS}

This study aims to understand the broad implications of changes of operating performance and parameters of a fuel cycle component on the entire system. In particular, this report documents the study of the impact of changing the loss of fission products and other impurities into recycled fuel and the loss of actinides into waste.

We have added exploratory analysis of candidates in the modified open fuel cycle category, with "minimum fuel treatment" as opposed to full aqueous or electrochemical separation treatment. This increased complexity in our analysis because equilibrium conditions do not appear sustainable in minimum fuel treatment cases, as was assumed in FY 2009 work. It is no longer reasonable to assume an equilibrium situation exists.

This effort has two types of value. The first are findings regarding the nature of the problem of fitting the fuel cycle together in multi-recycle scenarios, as described in Section 2. These findings both guided and resulted from the attempt to create the FIT model, which is described in Section 3. The FIT model is a new attempt at integrating the fuel cycle at the level of chemical groups. By integration, we mean blending of feed streams, fuel fabrication, reactor, used fuel separation, and waste management. The second are quantitative analyses with the beta version of the FIT model, in Section 4. Table 5-1 summarizes the changes in FY 2010. The increased complexity required the creation of the FIT model. The model was not the task objective, its creation and use has been a tool toward the task's objectives.

Table 5-1. Task complexity change from FY 2009 to FY 2010.

\begin{tabular}{|c|c|c|c|}
\hline Issue & FY 2009 & FY 2010 & Comment \\
\hline $\begin{array}{l}\text { Basic model } \\
\text { structure }\end{array}$ & \multicolumn{2}{|c|}{$\begin{array}{l}\text { An incoming feed stream (e.g., separation product from } \\
\text { used UOX) and a recycling loop (e.g., fast reactor); the } \\
\text { only mass leaving the loop is waste generated by } \\
\text { separation and fabrication. }\end{array}$} & $\begin{array}{l}\text { Simplest possible substructure of } \\
\text { potentially complex scenarios. }\end{array}$ \\
\hline $\begin{array}{l}\text { Reactor and fuel } \\
\text { types }\end{array}$ & \multicolumn{2}{|c|}{$\begin{array}{l}\text { Fast reactor with transuranic conversion ratio of } 0.50 \\
\text { (metal or oxide fuel) }\end{array}$} & $\begin{array}{l}\text { This is the case we know most } \\
\text { about and therefore have the best } \\
\text { chance to model with any } \\
\text { confidence. }\end{array}$ \\
\hline Separation types & Aqueous, electrochemical & $\begin{array}{l}\text { Aqueous, } \\
\text { electrochemical, air } \\
\text { oxidation (AIROX), } \\
\text { melt-refining }\end{array}$ & $\begin{array}{l}\text { AIROX and melt refining added } \\
\text { as candidate "minimum fuel } \\
\text { treatment" options. }\end{array}$ \\
\hline $\begin{array}{l}\text { Impurities in } \\
\text { incoming feed } \\
\text { stream }\end{array}$ & No & Yes & $\begin{array}{l}\text { This completes the scenarios we } \\
\text { started in FY } 2009 .\end{array}$ \\
\hline $\begin{array}{l}\text { Impurities in } \\
\text { recycling stream }\end{array}$ & \multicolumn{2}{|l|}{ Yes } & \\
\hline Chemical groups & 2 (actinides, lanthanides) & 15 & $\begin{array}{l}\text { Required to do meaningful } \\
\text { assessments of waste streams } \\
\text { (e.g., gases, metals, ceramics) }\end{array}$ \\
\hline Blending & Fixed ratio & $\begin{array}{l}\text { Blend among: } \\
\text { TRU-U-1 incoming } \\
\text { TRU-U-2 recycling } \\
\text { RU-1 incoming } \\
\text { RU-2 recycling } \\
\text { DU }\end{array}$ & \\
\hline State of system & Equilibrium & Recycle by recycle & \\
\hline
\end{tabular}


Figure 5-1 illustrates the central challenge of the discharge side of nuclear fuel cycles-how can active radioactive materials "in service" be dispositioned? ${ }^{\mathrm{m}}$ All mass must eventually leave active status, to either be readied for recycling or permanently disposed. These questions arise: what options exist for individual technologies, how should such options integrate to make a system, and when and for how long can materials be recycled? In short, what are the sagacious disposition options? This recycle losses study aims at answering those questions via time-independent, equilibrium analyses. Until candidate materials are treated to achieve impurity limits, active materials cannot be re-used as new fuel, stored as recovered uranium (RU), stored as depleted uranium (DU), re-used zirconium, re-used graphite, used for non-energy applications, ${ }^{n}$ etc. As this list shows, there are more materials to be considered than simply transuranic (TRU) elements. Impurity limits are based on fuel fabrication, service conditions, and performance estimations. Until candidate materials are treated to achieve waste acceptance criteria (WAC), active materials cannot be disposed as high-level waste (HLW), low-level waste (LLW) qualifying for nearsurface burial, or intermediate categories. WAC are established by the waste receiver. Thus, separation produces two sets of products that must meet criteria: recycled materials and wastes. Loss of useful materials into wastes impact meeting WACs, and loss of non-useful materials into recycle fuel streams impact impurity limits; hence, of these issues are linked.

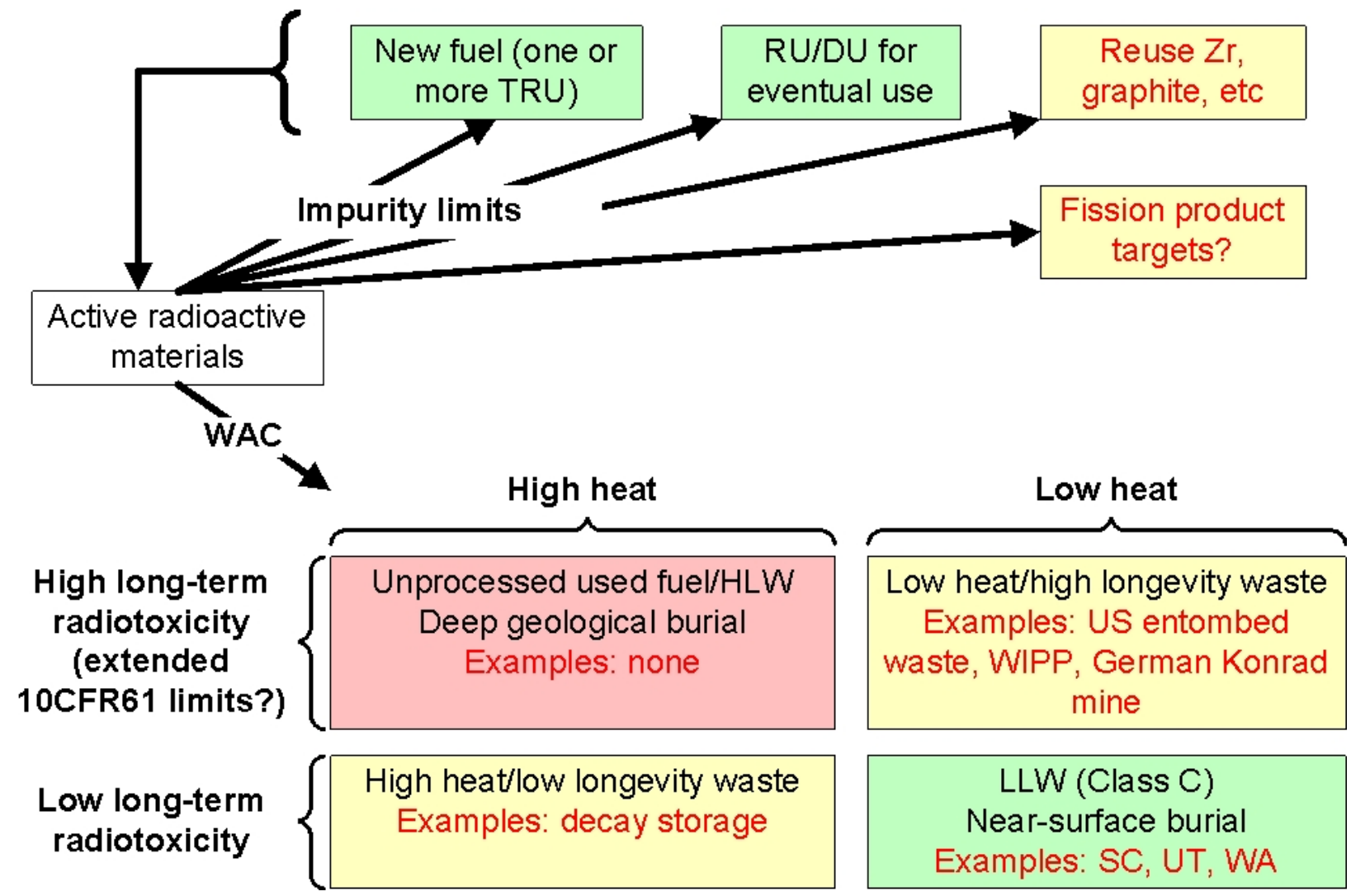

Figure 5-1. Central challenge of the downstream side of nuclear fuel cycles

m. The central challenge of the upstream side of nuclear fuel cycles is obtaining materials that must be put into radioactive service.

n. Although outside of our scope, we note that there is a wide range of potential non-fuel uses of material removed from a reactor materials to be reinserted into a reactor (cladding, fuel matrix materials such as zirconium in Zr-U-TRU fuels, graphite moderator), isotopes for non-energy nuclear applications such as medicine and detectors, and possibly nonradioactive service for lanthanides that do not have long-lived radioactive isotopes. Imagine nuclear-enhanced wind energy by using recovered neodymium, a main component of permanent magnets in wind turbines. The longest-lived artificial neodymium isotope is $\mathrm{Nd}-147$ (10.98-day halflife). 
The recycle losses study started in FY 2009 articulating the losses of undesired materials into recycle streams and losses of desirable materials into waste streams. Our exploratory FY 2009 analyses were done piece-meal with sets of spreadsheets, expert judgments, and a Decision Programming Language mini-model (Shropshire 2009). We have realized that it is time to make a FIT model to automate our analyses and to harvest expert judgment in a more systematic way as we analyze different aspects of material management within the fuel cycle and step back to evaluate the impacts of higher level issues and drivers (e.g., fuel cycle selection that minimizes the generation of TRU, simplifies treatment for closure, minimizes or eliminates recycle, minimizes proliferation risk, etc.).

This study identifies a few operating assumptions and constraints. Our analyses are limited to:

1. Commercial nuclear energy fuel cycles.

2. Currently, light water reactors and sodium-cooled fast reactors; we readily acknowledge that there are a wide range of alternatives to be studied in the future.

3. Four used fuel treatment options: aqueous and electrochemical are taken as examples of traditional, full separation techniques and AIROX and melt-refining are taken as examples of limited separation, also known as minimum fuel treatment (MFT). There is a wide range of variations and alternatives to be studied in the future.

We identified appropriate "use cases" to analyze, qualitatively coherent related issues, developed a modeling approach, created the model architecture, and created some of the submodels. The most difficult challenges will be analysis of "minimum fuel treatment" options such as AIROX or melt refining and trying to quantify cost sensitivities as the facility size, processing parameters, and waste treatment systems change. Table 5-2 summarizes the identified use cases. 
Table 5-2. Use cases identified by FIT team.

\begin{tabular}{|l|l|l|}
\hline $\begin{array}{l}\text { Lead-in Step } \\
\text { (source of feed material } \\
\text { for the recirculation part } \\
\text { of system) }\end{array}$ & \multicolumn{1}{|c|}{ Recirculation Steps } & \multicolumn{1}{|c|}{ Comment } \\
\hline $\begin{array}{l}\text { None } \\
\text { Metal/fast reactor/echem } \\
\text { Oxide/fast reactor/UREX+1 }\end{array}$ & FY 2009 analysis \\
\hline UOX/UREX+1 & Both & Complete 1-tier, completed \\
\hline UOX/AIROX & $\begin{array}{l}\text { Metal/ fast reactor/melt refine fast reactor/UREX+1 } \\
\text { Oxide/ fast reactor/echem }\end{array}$ & $\begin{array}{l}\text { Minimum fuel treatment, completed } \\
\text { fabrication and fuel separation (metal } \\
\text { fuel with UREX+1 and oxide fuel with } \\
\text { echem). We lacked the resources to } \\
\text { model the required oxidation and } \\
\text { reduction steps this year. }\end{array}$ \\
\hline $\begin{array}{l}\text { UOX/UREX+1 } \\
\text { FIT 1.0 could analyze this case. }\end{array}$ \\
\hline MOX/UREX+1 & Both & FIT 1.0 could analyze this case. \\
\hline $\begin{array}{l}\text { UOX/UREX+1 } \\
\text { With long interim storage }\end{array}$ & Both & FIT 1.0 could analyze this case. \\
\hline $\begin{array}{l}\text { UOX/UREX+1 } \\
\text { Without CsSr removal }\end{array}$ & Both & Requires separation matrix for NUEX. \\
\hline UOX/NUEX & Both & Requires separation matrix for COEX. \\
\hline UOX/COEX & Both & $\begin{array}{l}\text { Requires adding EU as a uranium } \\
\text { blending option }\end{array}$ \\
\hline $\begin{array}{l}\text { Options using enriched uranium in the recycle loop } \\
\text { Requires adding NU as a uranium } \\
\text { blending option }\end{array}$ & Requires new fuel modules \\
\hline $\begin{array}{l}\text { Breeder reactors in the recycle loop } \\
\text { Fuels other than oxide or metal in the recycle loop, e.g., } \\
\text { TRISO fuel for HTGRs }\end{array}$ & $\begin{array}{l}\text { May only require appropriate physics } \\
\text { data for that reactor and fuel }\end{array}$ \\
\hline $\begin{array}{l}\text { Reactors other than FR in the recycle loop, e.g., CANDU } \\
\text { Thorium fuels }\end{array}$ & Well beyond FIT 1.0 \\
\hline Melt refining and AIROX are considered potential minimum fuel treatment examples. \\
\hline
\end{tabular}

Our observations in FY 2010 on issues related to commercial used fuel cycles include the following:

1. The experimental basis for quantifying the degree of separation of the lanthanides from actinides ranges from having data for several lanthanides from UREX tests to relatively weak or remains to be developed. Often, the behaviors of the lanthanides are extrapolated from data for only a few of them; yet, as is the case with transition metals and actinides that have multiple possible oxidation states, the behavior of individual lanthanide elements may vary.

2. The reasons for working limits on impurities in oxide and metal fuel feedstock include fabrication difficulties, formation of oxides/intermetallics, attack on fuel cladding, displacement of fissile content, and neutron absorption. If the program is to consider minimum fuel treatment options, solutions will have to be considered for many of these issues for particular combinations of fuels, fabrication technology, and separation technology. 
3. Currently, there are not working limits for impurities in oxide and metal fuel feedstock for many chemical elements. Non-limited elements may need to be reconsidered if the program is to consider minimum fuel treatment options. For example, the only limits on noble metalsruthenium, rhodium, palladium, silver, rhenium, osmium, iridium, platinum, gold - are for oxide fuels, specifically ruthenium for fissile displacement, and silver for undesirable oxides and fissile displacement. Minimum fuel treatment options typically do not remove noble metals. Thus, the question arises: would minimum fuel treatment approaches put so much noble metal content in oxide or metal fuels as to cause a problem? Or, would other hard-to-separate materials continue to be the limiting elements?

4. Most fuel fabrication methods include a feed conditioning step that involves dissolution or melting of the feedstock. This has to be considered in the proliferation risk assessments and the definition of minimum fuel treatment. It also motivates integration of separation and fuel fabrication.

5. Adoption of "minimum fuel treatment" options would drive new approaches for fuels and fuel fabrication because the impurity levels would be significantly higher.

6. More fully quantifying the chemistry for different separation techniques has several potential benefits. First, it may provide a basis for initial estimation of separation of elements for which there currently are no data. Second, a better definition of the relative importance of different elements among the full range of issues (fuel fabrication difficulties, cladding attack, etc.) provides a solid foundation for potentially modifying and combining parts of separation approaches (e.g., voloxidation with melt-refining). Third, proliferation risk assessments must not only consider a facility as designed, but also how a facility may be modified. That is, from chemical principles, a given approach such as volatility can separate some elements but not others. A facility designed to use a gas-phase process may not be particularly suited to for liquid separations that may be required for certain elemental separations. However, a facility designed to use volatility as one step in a series of separations may be changed to operate under conditions that differ from those for which it was initially designed. These matters are likely to become more important as the program considers minimum fuel treatment possibilities.

7. The definition and assessment of "minimum fuel treatment" must reflect both separation and subsequent fuel fabrication. For example, current TRISO fuel fabrication involves a dissolution step, apart from whether or not separation of used fuel is the source of the feed material.

8. All fuel treatment methods (even minimum fuel treatment) have some chemistry associated with them (i.e., variable volatility among different chemical species in AIROX).

9. The fate of non-fission product impurities is often inadequately understood (e.g., C-14, Cl-36, and some elements identified as limited for fuel fabrication).

10. Because separation techniques use different chemical characteristics (volatility, selective oxidation, complexation in nitric acid, etc.) one cannot assume that elements of the same chemical grouping (as we have defined them) behave the same in two different separation techniques.

11. Because fuel fabrication and performance are based on different chemical characteristics for oxide versus metal fuels, one cannot assume that elements of the same chemical group face comparable limitations in two different fuel types.

o. AIROX does not remove the lanthanides but does remove $100 \%$ of the silver, so it might be expected that noble metals would not be limiting in such an approach. Melt refining (with an oxidizing crucible) does remove $\sim 95 \%$ of the lanthanides, so noble metals might be found to be limiting. 
12. Build understanding and analysis in stages.

13. Consider uncertainty ranges.

14. A key issue is how each subsystem or full system responds to perturbations, but that is beyond what we currently intend to study with the steady-state FIT model; it will await future VISION analyses.

We have also identified these questions, which are intended to be answered during FY 2011.

1. Proliferation resistance and physical protection - does "minimum fuel treatment" have benefits versus aqueous or electrochemical?

2. Reactor-quantify the increased TRU:uranium ratio or uranium enrichment as TRU degrades (from increased storage time) or impurities increase.

3. Separation

- Which fuels and fuel cycle management options are the most user-friendly (i.e., treatment is simplified or minimized)?

- What are the losses into each waste and fuel stream?

- How does separation performance change as the quantity of recycling impurities increases?

- How does cost vary as losses change?

- How does cost vary with gamma/neutron dose?

4. Fabrication

- What happens to fuel fabrication and reactor performance if impurities in the feed stream are significantly higher than the working impurity targets?

- How does cost vary as impurities in the feed steam increase?

- How does cost vary with gamma/neutron dose?

○ What dissolution or melting steps occur during fabrication (e.g., dissolution step in current TRISO fabrication)?

- What are the losses into each waste stream and fuel stream?

5. Waste form - what can we get out of the heat-per-container trap?

6. Waste disposition - if waste classification is changed from source-based to characteristic-based, what benefits (and costs) arise?

Many of the above pertain to minimum fuel treatment options. Tables 5-3 and 5-4 summarize initial qualitative analyses. Fundamentally, high-impurities are analogous to extra long-life (extreme burnup) in that more non-fuel material accumulates in in-service fuel. So, research and development (R\&D) thrusts like impurity-tolerant fuel matrices and clad coatings that protect against impurities may enable minimum fuel treatment and/or extreme burnup. Note that the Fuels Campaign already has a question about how impurities generated during irradiation behave versus how impurities residual after separations behave. The example in the FY 2009 report was that the working impurity limit for lanthanides was 4000 ppm, but $40,000 \mathrm{ppm}$ generated during irradiation. These are viewed as consistent because the $4000 \mathrm{ppm}$ is viewed as more mobile and likely to attack cladding, whereas the $40,000 \mathrm{ppm}$ is viewed as relatively immobile - not all impurities behave the same. Instead, if we have impurities after minimum fuel treatment (such as AIROX-treated particles) is used to treat used fuel, are they more like the low-mobility $40,000 \mathrm{ppm}$ created during fuel irradiation (because their original matrix was not as disturbed) or more like the high-mobility 4,000 ppm impurity limit assumed to apply to feedstock. 
Table 5-3. Qualitative potential implications of "minimum fuel treatment" on fuel cycle components

\begin{tabular}{|l|l|l|}
\hline Reactor & $\begin{array}{l}|c| \\
\text { Some recycled impurities could serve as } \\
\text { burnable poisons }^{\text {p }}\end{array}$ & $\begin{array}{l}\text { Nigher impurities absorb more } \\
\text { neutrons, slight increase in TRU/U or } \\
\text { U-235/U enrichment required }\end{array}$ \\
\hline $\begin{array}{l}\text { Fuel } \\
\text { Fabrication }\end{array}$ & $\begin{array}{l}\text { High impurities, but for same net burnup, } \\
\text { less gas generation and less radiation } \\
\text { damage to clad/coating }\end{array}$ & $\begin{array}{l}\text { Impurity accumulation in fuel } \\
\text { Impurity attack on cladding/coating } \\
\text { Impacts during fuel fabrication: remote } \\
\text { operations, radiation damage to } \\
\text { fabrication equipment, control of heat } \\
\text { generation }\end{array}$ \\
\hline Separations & $\begin{array}{l}\text { Fewer, easier separations } \\
\text { Possibly no liquids (e.g., AIROX) }\end{array}$ & $\begin{array}{l}\text { Gasification or entrainment of } \\
\text { radioactive materials that necessitate } \\
\text { efficient capture from gas streams }\end{array}$ \\
\hline Waste forms & $\begin{array}{l}\text { Potential for fewer or different types of } \\
\text { waste forms due to different separation } \\
\text { principles, that may enable purer waste } \\
\text { forms (fewer chemical species in a given } \\
\text { stream) in some cases }\end{array}$ & Limited current data and analyses \\
\hline $\begin{array}{l}\text { Waste } \\
\text { disposal }\end{array}$ & \begin{tabular}{l} 
Potentially less TRU in some waste streams \\
\hline
\end{tabular} & \multicolumn{2}{|l}{} \\
\hline
\end{tabular}

Table 5-4. Qualitative potential implications of "minimum fuel treatment" on fuel cycle objectives.

\begin{tabular}{|c|c|c|c|}
\hline & Positive & Negative & Questions \\
\hline $\begin{array}{l}\text { Waste } \\
\text { management }\end{array}$ & $\begin{array}{l}\text { Potentially less TRU in } \\
\text { waste streams for some MFT } \\
\text { conditions may enable less } \\
\text { HLW if some waste can } \\
\text { meet LLW limits } \\
\text { Repeated recycle of long- } \\
\text { lived fission products may } \\
\text { consume some }\end{array}$ & $\begin{array}{l}\text { If MFT processes } \\
\text { enable repeated recycle, } \\
\text { recycle of impurities } \\
\text { may lead to more } \\
\text { activation and } \\
\text { accumulation of long- } \\
\text { lived fission products }\end{array}$ & $\begin{array}{l}\text { Next step is FY } 2010 \\
\text { calculations that examine } \\
\text { impact of long } \\
\text { irradiation on impurities } \\
\text { to determine which long- } \\
\text { lived FP decrease and } \\
\text { which increase } \\
\text { Several unresolved areas } \\
\text { need more R\&D, such as } \\
\text { improved completeness } \\
\text { and quality of } \\
\text { separations data, and } \\
\text { characteristics of the } \\
\text { separated waste streams }\end{array}$ \\
\hline Proliferation and & Some MFT may be very & Safeguard & What do metrics and \\
\hline
\end{tabular}

p. Some fission products can serve as the stabilizing isotope for the matrix itself (as opposed to residing in the dispersion kernel). For example, much of the lanthanides are neodymium isotopes (some are neutron poisons of course). Coincidently, this element may prove to make a more stable damage resistant inert matrix. Case in point (neodymium zirconate, $\mathrm{Nd}_{2} \mathrm{Zr}_{2} \mathrm{O}_{7}$ ) which is a pyrochlore compound of interest in the inert matrix community (ongoing research mainly at University of Florida). Also, lanthanides are likely to form oxide phases in oxide fuel (mobility and restructuring to be addressed). In metal fuels, lanthanides pose a fuel-cladding problem as they tend to try to trade places with iron in the cladding. 


\begin{tabular}{|l|l|l|l|}
\hline $\begin{array}{l}\text { physical } \\
\text { protection }\end{array}$ & $\begin{array}{l}\text { difficult to alter to provide } \\
\text { high-grade weapon usable } \\
\text { material } \\
\text { Higher radiation fields in } \\
\text { recycled material }\end{array}$ & $\begin{array}{l}\text { measurements may be } \\
\text { more difficult }\end{array}$ & methodologies say? \\
\hline $\begin{array}{l}\text { Uranium } \\
\text { utilization }\end{array}$ & Lower separation cost & $\begin{array}{l}\text { More neutron } \\
\text { absorption by } \\
\text { impurities will slightly } \\
\text { decrease uranium } \\
\text { utilization }\end{array}$ & $\begin{array}{l}\text { Higher fuel fabrication } \\
\text { cost } \\
\text { treatment" to maximize } \\
\text { nemonal absorber } \\
\text { cost }\end{array}$ \\
\hline Economics & $\begin{array}{l}\text { More detailed economic } \\
\text { studies are needed for } \\
\text { specific illustrative } \\
\text { examples }\end{array}$ \\
\hline Safety & $\begin{array}{l}\text { In some MFT versions, no } \\
\text { handling or spills of } \\
\text { reparations }\end{array}$ & $\begin{array}{l}\text { Potential for higher risk } \\
\text { of environmental } \\
\text { release compared to } \\
\text { processes that do not } \\
\text { rely on gasification }\end{array}$ & $\begin{array}{l}\text { Need to better assess } \\
\text { how to capture and } \\
\text { handle the separated } \\
\text { streams }\end{array}$ \\
\hline
\end{tabular}

Finally, we can identify broad R\&D needs, summarized in Table 5-5. As an example, consider the second R\&D need to obtain separation factor details for a wider range of elements. Compare which elements are limited as impurities in the TRU feed stream for fuel fabrication (Section 2.3) versus which elements' separation factors are known for separation methods (Section 2.4). Even for conventional separation methods, there are impurity-limited elements for which we lack separation factors; perhaps these elements are indeed unimportant but it seems unusual that an element is limited in the separation product (fuel impurity) without knowing how that element behaves in the separation process. In addition, if the program now emphases minimum fuel treatment options, they would result in higher impurities of more elements in fuels so that more separation factors will be need to be studied.

Table 5-5. High-leverage R\&D needs motivated by analyses to date.

\begin{tabular}{|l|l|}
\hline \multicolumn{1}{|c|}{ High-leverage common R\&D need } & \multicolumn{1}{c|}{ Explanation } \\
\hline $\begin{array}{l}\text { Recycle fuels and reactor designs that } \\
\text { tolerate high levels of fission product } \\
\text { and other impurities in the recycled } \\
\text { feedstock. }\end{array}$ & $\begin{array}{l}\text { Either "minimum fuel treatment" approaches or ultra-high } \\
\text { fuel residence time (extreme burnup or battery reactors) } \\
\text { increase non-fuel material accumulation in in-service fuel. } \\
\text { So, R\&D thrusts like impurity-tolerant fuel matrices and clad } \\
\text { coatings that protect against impurities may enable minimum } \\
\text { fuel treatment and/or extreme burnup. }\end{array}$ \\
\hline $\begin{array}{l}\text { Fuel fabrication R\&D to better define } \\
\text { fuel impurity limits for relevant fuel } \\
\text { type options for a wider range of } \\
\text { chemical elements. }\end{array}$ & $\begin{array}{l}\text { The tolerable level of impurities are not always known for } \\
\text { elements that can be reasonably expected to be present in } \\
\text { recycle materials, especially if minimum fuel treatment } \\
\text { approaches are used. This inhibits a comprehensive system }\end{array}$ \\
\hline
\end{tabular}

q. Example questions for oxide fuels: Are the two different sets of separation transition metal limits (titanium, vanadium, manganese, cobalt, copper, molybdenum, silver, tantalum, tungsten $=2000 \mathrm{ppm}$ and chromium, iron, nickel $=1500 \mathrm{ppm}$ ) required to be different? What is the lithium limit? Are there limits for rubidium, cesium, and strontium as there are for other Group 1 and Group 2 elements? As the noble metals limited; minimum fuel treatment options tend not to remove them. Since zinc, cadmium, tin, and lead are limited, what about indium, which lies in-between? It would be easier if there was a 


\begin{tabular}{|c|c|}
\hline & analysis. \\
\hline $\begin{array}{l}\text { Separations R\&D to better define and } \\
\text { improve separations factors for } \\
\text { relevant options for a wider range of } \\
\text { chemical elements. }\end{array}$ & $\begin{array}{l}\text { The separation factors are not always known for elements } \\
\text { that are constrained in TRU product (impurity limits) or } \\
\text { waste forms (e.g., constraining the waste loading in glass). } \\
\text { This inhibits a comprehensive system analysis. }\end{array}$ \\
\hline $\begin{array}{l}\text { Waste management options designed } \\
\text { to lower waste disposal cost, reduce } \\
\text { waste radiotoxicity and dose, increase } \\
\text { waste form and disposal site integrity } \\
\text { (reduce heat), and better re-use } \\
\text { valuable fertile and fissile materials. }\end{array}$ & $\begin{array}{l}\text { Truly taking advantage of recycling to reduce waste } \\
\text { management burdens and costs requires moving from a } \\
\text { prescriptive source-based definition of HLW to one based on } \\
\text { waste characteristics. If so, in the bounding case of several } \\
\text { separation steps and intermediate waste classification, } \\
\text { creation of HLW can be eliminated. }\end{array}$ \\
\hline $\begin{array}{l}\text { Analysis tools and methods that allow } \\
\text { comprehensive and systematic } \\
\text { examination of the disposition options } \\
\text { of all radioactive materials (recycle, } \\
\text { waste, etc.). }{ }^{\mathrm{s}}\end{array}$ & $\begin{array}{l}\text { The central challenge of the discharge side of nuclear fuel } \\
\text { cycles: how can active radioactive materials "in service" be } \\
\text { dispositioned, what options exist for the system and the } \\
\text { individual technologies, how should those options integrate } \\
\text { with each other, when and for how long can materials be } \\
\text { recycled, what fraction of material should be disposed while } \\
\text { recycling occurs (i.e., what are the best disposition options)? }\end{array}$ \\
\hline
\end{tabular}

Finally, we note that FIT may eventually "set the standard" for data from separations as the Transmutation Library's common format is setting the standard for transmutation analyses (i.e., all analyses need to provide a minimum set of data in a common format). The intent will be that separation experts provide (at minimum) a basis for knowing the separation performance for each chemical grouping, how much of each chemical grouping ends up in each separation stream. Similarly, the intent will be that fabrication experts provide (at minimum) a basis for the maximum impurity limit for each chemical grouping.

single limit covering all the lanthanides, would this fit the data? Example questions for metal fuels: Some transition metals are limited, what about the others? Are the noble and other metals limited? Metalloids?

r. It is important to have better aqueous and non-aqueous process separation factor data on the impurities that impact fuels recycle and waste management. Other than uranium, plutonium, neptunium, from FP, lanthanides and actinides (together), all well-known separation factors from actual PUREX production scale processing, and all our other data comes from laboratory batch or very small scale process experiments. The FIT model will need to be validated with data from pilot processing experiments before it is able to reliably discriminate between alternatives. Pilot scale experiments on each new fuel cycle process are thus required.

s. Higher-level questions include: minimizing the amount of separations that may be needed (e.g., fuel cycles that need little or no separation [i.e. minimum fuel treatment]) and a simplified processing flow sheet is better than a very complex one that may require multiple separations. Lower-level questions include: development of near real-time sampling and analytical results to support process control and accountability; improvements in integrated process control systems relative to things like security, automated corrective action responses, preventive maintenance alerts, etc. 
Questions have been posed to the Used Fuel Disposition Campaign regarding their calculations for Generic Disposal System Environments (GDSE) for tuff and salt. Via Bill Halsey, input has been provided to the Disposal Systems Evaluation Framework (DSEF). 
Losses Study

September 15, 2010

This page intentionally left blank. 


\section{REFERENCES}

10 CFR $60 \quad$ Nuclear Regulatory Commission, "Disposal of High-Level Radioactive Wastes in Geologic Repositories," Title 10, Part 60 of the Code of Federal Regulations, revised as of 2002 .

10 CFR $61 \quad$ Nuclear Regulatory Commission, "Licensing Requirements for Land Disposal of Radioactive Waste," Title 10, Part 61 of the Code of Federal Regulations, revised as of 2002.

10 CFR 63 Nuclear Regulatory Commission, "Disposal of High-Level Radioactive Wastes in a Geologic Repository at Yucca Mountain, Nevada," Title 10, Part 63 of the Code of Federal Regulations, revised as of 2002.

40 CFR 191 Environmental Protection Agency, "Environmental Radiation Protection Standards for Management and Disposal of Spent Nuclear Fuel, High-Level and Transuranic Radioactive Wastes," Title 40, Part 191 of the Code of Federal Regulations, revised as of 2002 .

Ackerman 1991 John P. Ackerman, "Chemical Basis for Pyrochemical Reprocessing of Nuclear Fuel,” Industrial and Engineering Chemistry Reseach, 30(1), 1991, pp. 141-145.

Bays 2009 S. E. Bays, S. J. Piet, M. Pope, G. Youinou, G. Dumontier, D. Hawn, Transmutation Dynamics: Impacts of Multi-Recycling on Fuel Cycle Performances, INL/EXT-09-16857, AFCI-SYSA-PMO-MI-DV-2009000185 , September 2009.

Bays $2010 \quad$ Samuel E. Bays, Steven J. Piet, Kurt G. Vedros, Alex C. Chambers, "INL FY 2010 Transmutation Studies,” FCR\&D-SYSA-2010-000103, July 21, 2010.

Christian 1999 Jerry D. Christian, James W. Sterbentz, David G. Abbott, Dieter A. Knecht, Ivan R. Thomas, Norman E. Stanley, Chris S. Staley, Michael L. Croson, Richard J. Cacciapouti, G. M. Solan, M. C. Beganski, A. P. Fyfe, Herbert Feinroth, Bernard Hao, Kenneth R. Czerwinski, M. P. Reynard, Kevin P. Carney, "Dry Recycle of Spent Nuclear Fuel," LDRD Project 99-292, December 1999.

Dixon 2008 Brent Dixon, Bill Halsey, Sonny Kim, Gretchen Matthern, Steven Piet, David Shropshire, "Dynamic Systems Analysis Report for Nuclear Fuel Recycle," INL/EXT8-15201, Revision 1, December 2008.

DOE 2007 DOE, "Product Solidification, Waste Solidification, and Off-Gas Unit Operations Mass Balance Basis, Advanced Fuel Cycle Facility Project," GNEP-AFCF-WAST-PC-RT2007-000332, Rev Draft A, September 27, 2007

DOE-STD-3013 “Stabilization, Packaging, and Storage of Plutonium-Bearing Materials," U.S. Department of Energy, April 2004.

Gombert 2008 Gombert, Dirk II, et al, "Global Nuclear Energy Partnership Integrated Waste Management Strategy,” GNEP-WAST-WAST-AI-RT-2008-000214, May 2008.

Hesson 1963 J. C. Hesson, M. J. Feldman, and L. Burris, "Description and Proposed Operation of the Fuel Cycle Facility for the Second Experimental Breeder Reactor (EBR-II)," ANL6605, April 1963. 
Jacobson 2010 J. J. Jacobson, A. M. Yacout, G. E. Matthern, S. J. Piet, D. E. Shropshire, R. F. Jeffers, T. Schweitzer, "Verifiable Fuel Cycle Simulation Model (VISION): A Tool for Analyzing Nuclear Fuel Cycle Futures," (accepted by Nuclear Technology).

Jacobson 2009 J. J. Jacobson, A. M. Yacout, G. E. Matthern, S. J. Piet, D. E. Shropshire, "Verifiable Fuel Cycle Simulation (VISION) Model," paper 9312, Global 2009, Paris, France, September, 2009.

NRC 1987 Nuclear Regulatory Commission, Definition of "High-Level Radioactive Waste, Advanced Notice of Proposed Rulemaking," Federal Register, Volume 52, No. 39, February 27, 1987.

NWPA 1982 Nuclear Waste Policy Act of 1982, 96 Statutes at large 2201, 42 U.S. Code 10101 et seq. Amendments of 1987.

Piet 2009b Steven J. Piet, David E. Shropshire, Nick Soelberg (INL), "Must Advanced Fuel Cycles Produce High-Level Waste?," Integrated Radioactive Waste Management in Future Fuel Cycles, November 8-12, 2009, Charleston, South Carolina.

Piet 2009a S. J. Piet, Selection of Isotopes and Elements for Fuel Cycle Analysis, "Advances In Nuclear Fuel Management IV (ANFM IV),” April 12-15, 2009, INL/CON-08-15050.

Piet 2010 Steven J. Piet, Samuel E. Bays, Edward A. Hoffman, "Description of Transmutation Library for Fuel Cycle System Analyses," FCRD-SYSA-2010-000116, INL/EXT-1019545, August 4, 2010.

Ryan $2009 \quad$ Joseph Ryan, "Complete Model for Glass Waste Form Volume vs. Key Process Parameters," Pacific Northwest National Laboratory, September 4, 2009.

Shropshire 2009 D. E. Shropshire, S. J. Piet, N. Soelberg, R. Cherry, R. Henry, D. Meikrantz, G. Teske, C. Pereira, E. Shaber, "System Losses and Assessment Trade Study," AFCI-SYSAPMO-MI-DV-2009-000203, INL/EXT-09-16891, September 30, 2009.

Soelberg 2010 N. R. Soelberg, S. J. Piet, S. E. Bays, R. N. Henry, D. H. Meikrantz, T. A. Taiwo, T. K. Kim, D. Yun, J. Gehin, L. Qualls, K. Williams, W. Halsey, "Status Report - Waste Stream Analysis for Nuclear Fuel Cycles," April 15, 2010.

Vienna 2010 John Vienna, personal communication to Denia Djokić, July 29, 2010. 



\section{Appendix A}

\section{FIT Modeling Details}


This page intentionally left blank 


\section{A-1. FIT Model Details}

The basic flow of the FIT model is shown in Figure A-1. The model starts with a UOX-51uranium oxide spent fuel inventory (decayed to a user specified number of years, default is 15 years) in grams per metric ton initial heavy metal as shown in Table A-1. The inventory was summarized into the radionuclides/groups used in the FIT model. The basis for this spent fuel input is $1 \mathrm{GWe}$ power, 33\% efficiency, $90 \%$ capacity factor, and $51 \mathrm{MWth}$-day/kg burnup. This equates to $19,532 \mathrm{~kg}$ initial heavy metal per year. Using this basis, the grams per metric ton initial heavy metal inventory is converted to $\mathrm{kg} / \mathrm{yr}$ for the rest of the model.
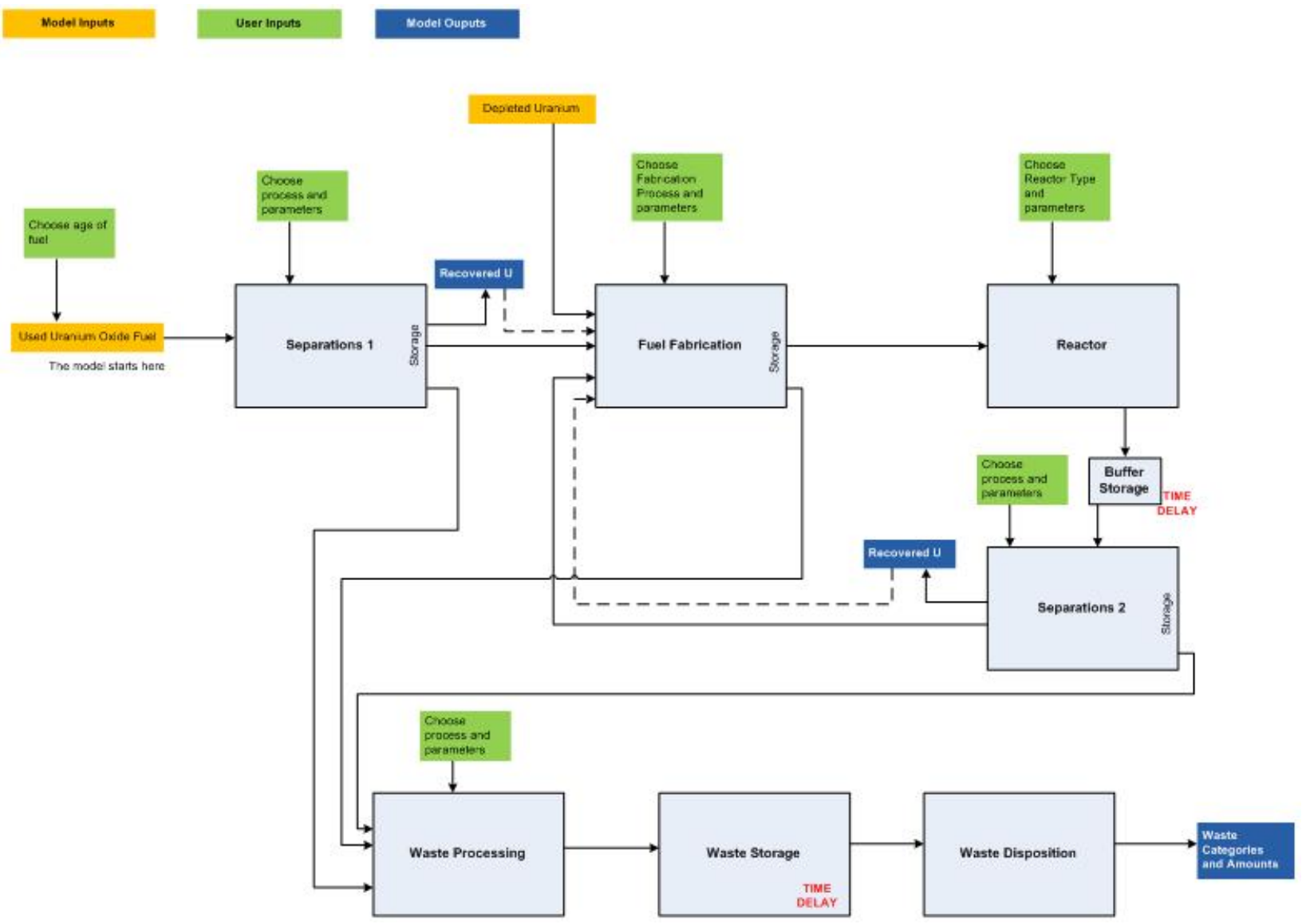

Figure A-1. Flow of FIT model. 
Table A-1. Uranium-oxide spent fuel inventory used in FIT model.

\begin{tabular}{|c|c|c|c|c|c|c|c|}
\hline \multirow{6}{*}{$\begin{array}{l}\text { Insemons } \\
\text { Humber }\end{array}$} & & & & \multirow[t]{2}{*}{$\begin{array}{l}\text { Imventony } \\
\text { Number }\end{array}$} & \multicolumn{2}{|c|}{ Actinides andDecayChain } & \multirow[t]{2}{*}{$\begin{array}{l}\text { Irventory } \\
\text { (gMTHM) }\end{array}$} \\
\hline & & & & & \multicolumn{2}{|c|}{ Fission Products } & \\
\hline & & & & \multirow{6}{*}{$\begin{array}{l}44 \\
45 \\
48 \\
47 \\
48 \\
49\end{array}$} & \multirow{3}{*}{\begin{tabular}{|l|l|}
$\mathrm{H3}$ \\
$\mathrm{C} 14$ \\
6
\end{tabular}} & \multirow[b]{3}{*}{ Other gases } & $3.699 \mathrm{E}-02$ \\
\hline & \multirow{3}{*}{\multicolumn{2}{|c|}{ Actirides and Decay Chain }} & & & & & $4050 \mathrm{E}-05$ \\
\hline & & & nuentr; & & & & $0.000 E+\infty$ \\
\hline & & & (g/MTHM) & & $\mathrm{Kr81}$ & \multirow{3}{*}{$\begin{array}{l}\text { Irert gases } \\
\text { (Group } 0)\end{array}$} & 4217E-06 \\
\hline & Hes (athb) & & $29471-\infty$ & & Kr85 & & 1.306E+01 \\
\hline 2 & $\frac{124(s \tan )}{102006}$ & \multirow[b]{5}{*}{ Tramaitionmetak } & $4,048 \mathrm{E}-10$ & & \multirow{2}{*}{$\begin{array}{l}\text { 9o Inert gas other }(\mathrm{Kr}, \mathrm{Xe}) \\
50 \text { Fb }\end{array}$} & & $8.565 \mathrm{E}+03$ \\
\hline & poran & & $6844 \mathrm{E}-08$ & 50 & & \multirow[b]{3}{*}{ Group $1 \mathrm{~A} / 2 \mathrm{~A}$} & $5.370 \mathrm{E}+02$ \\
\hline & $\mathrm{P} 6208$ & & $1.150 \mathrm{E}-04$ & 51 & $1 \longdiv { \text { Sr } 9 0 \text { w/Y90 decay } }$ & & $5.515 \mathrm{E}+02$ \\
\hline & 10210 & & $2.3945-6$ & 52 & Sr-other & & $5.274 E+02$ \\
\hline 6 & Bimog & & $4354 E_{-10}$ & 53 & 3783 whb93m decay & \multirow{4}{*}{ Zirconium } & $1.086 \mathrm{E}+03$ \\
\hline & R.206 & \multirow[b]{2}{*}{$\operatorname{tran} 28$} & $9 \leq 31 \mathrm{k}-0 \mathrm{~T}$ & & \multirow{2}{*}{4795 who 155 m decay } & & $1.121 \mathrm{E}-24$ \\
\hline & Ro208 & & $T-347 \mathrm{~T}-12$ & $\begin{array}{l}54 \\
55\end{array}$ & & & $\frac{1.1215-24}{4501 E+03}$ \\
\hline & 40227 & \multirow[b]{6}{*}{ Autiniles } & $2.641 \mathrm{E}-0 \mathrm{~T}$ & 55 & & & $4.501 \mathrm{E}+\mathrm{LS}$ \\
\hline 10 & $\operatorname{Th} 208$ & & $2,404 \mathrm{E}^{-\infty} \mathrm{S}$ & 56 & $\mathrm{Tc} 99$ & \multirow[b]{2}{*}{ Technetium } & $1.145 E+0 B$ \\
\hline 11 & $\operatorname{Tn} 200$ & & $2.569 \mathrm{E}-06$ & 57 & Tc-other & & $1,085 \mathrm{E}-02$ \\
\hline 12 & $\operatorname{Tn} 200$ & & $10 \mathrm{OSSE}-02$ & 58 & Bu106 w/Rh106 decay & Transition metals that & 7 001E-03 \\
\hline 12 & $\operatorname{Th} 232$ & & $2509 \mathrm{E}-0 \mathrm{a}$ & 59 & Pd10? & constraing lass uaste & $3.596 \mathrm{E}+02$ \\
\hline 14 & $\mathrm{~N}_{2} 231$ & & $1039 \mathrm{E}-03$ & & Mo-Bu-Bh-Pdother & forms & $1120 E+04$ \\
\hline 15 & 10,32 & & $8993 \mathrm{E}-04$ & 60 & $\frac{\text { WD-Kul-Kh-Pd-other }}{\mathrm{Se} 70}$ & & 1.12 UE + +U4 \\
\hline 16 & 1023 & & $\$ 243 \mathrm{E}-03$ & 61 & 1 Se79 & & $8.962 E+\infty$ \\
\hline 17 & $\underline{L 234}$ & & $2.0696-02$ & 62 & Cd113m & & $2.176 \mathrm{E}-01$ \\
\hline 18 & ID235 & & $T 6616-03$ & 63 & Sn125 w/Sb126miSb126 & & $4.277 \mathrm{E}+01$ \\
\hline 18 & $\operatorname{Ln} 236$ & & S.T11E-03 & 64 & $4 \longdiv { \mathrm { Sb } 1 2 5 \text { w Te125m decay } }$ & & $4480 \mathrm{E}-01$ \\
\hline 20 & ID23 & Uranim & $92005-06$ & & TMether $(\mathrm{Co} \mathrm{Se} \mathrm{Hh}$ \&g & & $7.4000-01$ \\
\hline 21 & $\$ \mathrm{p} 237$ & Nepurim & $632365+02$ & & 1W-other(Co-se, Na, $\mathrm{gg}-$ & & \\
\hline 22 & $\ln 23$ & & $2834[-02$ & 65 & $\mathrm{Te}$ & Other transition metals & $1.273 E+03$ \\
\hline 22 & $\operatorname{lin}_{20}$ & & $6.15215-0.03$ & 68 & 1129 & Halogens & $2.748 E+02$ \\
\hline 24 & $P(1040$ & & $29385-03$ & 67 & Halogen-other $(\mathrm{Br}, \mathrm{I})$ & (Group 7) & 1.168E+02 \\
\hline 25 & anats & & $8 \leq 40 \mathrm{E}-02$ & 68 & $\mathrm{Cs} 134$ & & $1.486 \mathrm{E}+\infty$ \\
\hline 26 & Pine42 & & $8.6396-02$ & 69 & $\mathrm{Cs} 135$ & & $6.604 E+02$ \\
\hline 27 & Pus 44 & Phtánim & $285 \mathrm{SE}-02$ & & $\mathrm{Cs} 137$ wa137m decaw & & $1285 \mathrm{E}+\infty$ \\
\hline 28 & $\sin 241$ & & 9S495-02 & 70 & CS13r WBal sim decay & & $1.285 \mathrm{E}+0 \mathrm{~B}$ \\
\hline 28 & $6 m, 243 m$ & & TSTOE-01 & 71 & 1 Cs-other & & $1.628 \mathrm{E}+\infty 8$ \\
\hline 30 & $\sin 243$ & Ammaricim & $19836-02$ & 72 & $\mathrm{Ba}$ & Groun $1 \mathrm{~A} / 2 \mathrm{~A}$ & $2.972 \mathrm{E}+0 \mathrm{~B}$ \\
\hline 31 & $\operatorname{com} 242$ & & $1932 \mathrm{E}-03$ & & Ce144 wPr144mPr144 & & \\
\hline 32 & $0 \mathrm{~m}, 243$ & & $\$ 3 \leqslant 4 \mathrm{E}-01$ & 73 & decay & & 5.984E-04 \\
\hline 33 & $\operatorname{lom} 244$ & & $483212-01$ & & Prm147 & & $2.923 \mathrm{E}+\infty$ \\
\hline 34 & $\operatorname{com} 245$ & & S.TLEF & 75 & $5 \mathrm{Sm} 146$ & & $1383 \mathrm{E}-\mathrm{0R}$ \\
\hline 35 & $0 \mathrm{~m} 246$ & & $T 280 \mathrm{E}-01$ & 75 & $\frac{1140}{5 m 14 ?}$ & & $1,38 \mathrm{sE}-\mathrm{UL}$ \\
\hline 36 & $\operatorname{com} 247$ & & $9972 E-03$ & 76 & Sm147 & & $2.452 \mathrm{E}+02$ \\
\hline 37 & $\ln 248$ & & T.69TE-04 & $\pi$ & Sm151 & & $2.043 E+01$ \\
\hline 38 & $10 \mathrm{~m} 250$ & Camim. & $4,410 \mathrm{k}-12$ & 78 & Eul 54 & & $1.970 E+01$ \\
\hline 39 & Brat9 & Berbolim & $6,433 \mathrm{k}-11$ & 79 & Eu155 & & $3.165 \mathrm{E}+\infty$ \\
\hline 40 & 06249 & & $1.082 \mathrm{E}-\infty \mathrm{s}$ & & $\mathrm{Ho} 166 \mathrm{~m}$ & & 3482 E. 09 \\
\hline 41 & $\cos 200$ & & $9.271 \mathrm{E}-0 \mathrm{~T}$ & 80 & 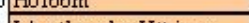 & & $3.40 \angle 5-103$ \\
\hline 42 & 00251 & & 9.TS3E- $-0 T$ & 81 & 1 LA-other plus Y thrium & Lanthanides (plus $Y$ ) & $1.491 \mathrm{E}+04$ \\
\hline 43 & $\longdiv { C f 2 5 2 }$ & |Calímim & $1.278 \mathrm{E}-08$ & 82 & $\mathrm{Cl}-36$ & & $4.135 \mathrm{E}-01$ \\
\hline
\end{tabular}

The used fuel inventory then feeds into the first separations module. This module then splits the inventory into the 14 streams based on the separation factors for the selected separations technology. Separation factors for one of several different intended separations options (UREX+1a) are shown in Table A-2. 
Table A-2. Separations factors for UREX+1a.

\begin{tabular}{|c|c|c|c|c|c|c|c|c|c|c|c|c|c|}
\hline & & UREX+1A & & & & & & & & & & & \\
\hline & & \begin{tabular}{|l|} 
Recovered U \\
\end{tabular} & U-TRU Product 1 & U-TRU Product 2 & Captured Gases & 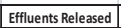 & |Cladding/Coating & Technetium & Cs-Sr & Lanthinides & UDS & \begin{tabular}{|l|} 
Raffinate/Residual \\
\end{tabular} & al Struct \\
\hline Het (stable) & & & & & & $100 \%$ & & & & & & & \\
\hline Pb206 & & $0.0990 \%$ & $0.099 \%$ & & & & & & $0.099 \%$ & $0.0001 \%$ & $1.00 \%$ & $98.703 \%$ & \\
\hline Pb207 & & $0.0990 \%$ & $0.099 \%$ & & & & & & $0.099 \%$ & $0.0001 \%$ & $1.00 \%$ & $98.703 \%$ & \\
\hline PB208 & & $0.0990 \%$ & $0.099 \%$ & & & & & & $0.099 \%$ & $0.0001 \%$ & $1.00 \%$ & $98.703 \%$ & \\
\hline Pb210 & & $0.0990 \%$ & $0.099 \%$ & & & & & & $0.099 \%$ & $0.0001 \%$ & $1.00 \%$ & $98.703 \%$ & \\
\hline Bi209 & Transition metals & $0.0990 \%$ & $0.099 \%$ & & & & & & $0.099 \%$ & $0.0001 \%$ & $1.00 \%$ & $98.703 \%$ & \\
\hline Ra226 & & $0.0495 \%$ & $0.193 \%$ & & & & & & $98.555 \%$ & $0.2028 \%$ & $1.00 \%$ & $0.000 \%$ & \\
\hline Ra228 & Group 2A & $0.0495 \%$ & $0.193 \%$ & & & & & & $98.555 \%$ & $0.2028 \%$ & $1.00 \%$ & $0.000 \%$ & \\
\hline Ac227 & & $0.0792 \%$ & $98.885 \%$ & & & & & & $0.030 \%$ & $0.0020 \%$ & $1.00 \%$ & $0.004 \%$ & \\
\hline Th228 & & $0.0792 \%$ & $98.885 \%$ & & & & & & $0.030 \%$ & $0.002 \%$ & $1.00 \%$ & $0.004 \%$ & \\
\hline Th229 & & $0.0792 \%$ & $98.885 \%$ & & & & & & $0.030 \%$ & $0.0020 \%$ & $1.00 \%$ & $0.004 \%$ & \\
\hline Th230 & & $0.0792 \%$ & $98.885 \%$ & & & & & & $0.030 \%$ & $0.0020 \%$ & $1.00 \%$ & $0.004 \%$ & \\
\hline Th232 & & $0.0792 \%$ & $98.885 \%$ & & & & & & $0.030 \%$ & $0.0020 \%$ & $1.00 \%$ & $0.004 \%$ & \\
\hline Pa231 & Actinids & $0.0792 \%$ & $98.885 \%$ & & & & & & $0.030 \%$ & $0.0020 \%$ & $1.00 \%$ & $0.004 \%$ & \\
\hline 0232 & & $98.9970 \%$ & $0.000 \%$ & & & & & & $0.003 \%$ & $0.0000 \%$ & $1.00 \%$ & $0.00 \%$ & \\
\hline 0233 & & $98.9970 \%$ & $0.000 \%$ & & & & & & $0.003 \%$ & $0.0000 \%$ & $1.00 \%$ & $0.000 \%$ & \\
\hline 0234 & & $98.9970 \%$ & $0.00 \%$ & & & & & & $0.003 \%$ & $0.0000 \%$ & $1.00 \%$ & $0.000 \%$ & \\
\hline 0235 & & $98.9970 \%$ & $0.000 \%$ & & & & & & $0.003 \%$ & $0.0000 \%$ & $1.00 \%$ & $0.000 \%$ & \\
\hline $\mathrm{U} 236$ & & $98.9970 \%$ & $0.000 \%$ & & & & & & $0.003 \%$ & $0.0000 \%$ & $1.00 \%$ & $0.000 \%$ & \\
\hline 0238 & Uranium & $98.9970 \%$ & $0.000 \%$ & & & & & & $0.003 \%$ & $0.0000 \%$ & $1.00 \%$ & $0.000 \%$ & \\
\hline Np237 & Neptunium & $1.7820 \%$ & $97.193 \%$ & & & & & & $0.019 \%$ & $0.0008 \%$ & $1.00 \%$ & $0.005 \%$ & \\
\hline Pu238 & & $0.0003 \%$ & $98.963 \%$ & & & & & & $0.030 \%$ & $0.0020 \%$ & $1.00 \%$ & $0.005 \%$ & \\
\hline Pu239 & & $0.0003 \%$ & $98.963 \%$ & & & & & & $0.030 \%$ & $0.0020 \%$ & $1.00 \%$ & $0.005 \%$ & \\
\hline Pu240 & & $0.0003 \%$ & $98.963 \%$ & & & & & & $0.030 \%$ & $0.0020 \%$ & $1.00 \%$ & $0.005 \%$ & \\
\hline \begin{tabular}{|l|l|} 
Pu241 \\
\end{tabular} & & $0.0003 \%$ & $98.963 \%$ & & & & & & $0.030 \%$ & $0.0020 \%$ & $1.00 \%$ & $0.005 \%$ & \\
\hline Pu242 & & $0.0003 \%$ & $98.963 \%$ & & & & & & $0.030 \%$ & $0.0020 \%$ & $1.00 \%$ & $0.005 \%$ & \\
\hline Pu244 & Plutonium & $0.0003 \%$ & $98.963 \%$ & & & & & & $0.030 \%$ & $0.0020 \%$ & $1.00 \%$ & $0.005 \%$ & \\
\hline \begin{tabular}{|l|l|} 
Am241 & \\
\end{tabular} & & $0.0792 \%$ & $98.885 \%$ & & & & & & $0.030 \%$ & $0.0020 \%$ & $1.00 \%$ & $0.004 \%$ & \\
\hline$\overline{A m 242 m}$ & & $0.0792 \%$ & $98.885 \%$ & & & & & & $0.030 \%$ & $0.0020 \%$ & $1.00 \%$ & $0.004 \%$ & \\
\hline \begin{tabular}{|l|l|l}
$\mathrm{Am} 243$ \\
\end{tabular} & Americium & $0.0792 \%$ & $98.885 \%$ & & & & & & $0.030 \%$ & $0.0020 \%$ & $1.00 \%$ & $0.004 \%$ & \\
\hline $\mathrm{Cm}^{242}$ & & $0.0792 \%$ & $98.885 \%$ & & & & & & $0.030 \%$ & $0.0020 \%$ & $1.00 \%$ & $0.004 \%$ & \\
\hline $\mathrm{Cm} 243$ & & $0.0792 \%$ & $98.885 \%$ & & & & & & $0.030 \%$ & $0.0020 \%$ & $1.00 \%$ & $0.004 \%$ & \\
\hline $\mathrm{cm} 244$ & & $0.0792 \%$ & $98.885 \%$ & & & & & & $0.030 \%$ & $0.0020 \%$ & $1.00 \%$ & $0.004 \%$ & \\
\hline$\overline{\mathrm{cm} 245}$ & & $0.0792 \%$ & $98.885 \%$ & & & & & & $0.030 \%$ & $0.0020 \%$ & $1.00 \%$ & $0.004 \%$ & \\
\hline $\mathrm{Cm}^{2} 46$ & & $0.0792 \%$ & $98.885 \%$ & & & & & & $0.030 \%$ & $0.0020 \%$ & $1.00 \%$ & $0.004 \%$ & \\
\hline$\overline{\mathrm{Cm} 247}$ & & $0.0792 \%$ & $98.885 \%$ & & & & & & $0.030 \%$ & $0.0020 \%$ & $1.00 \%$ & $0.004 \%$ & \\
\hline $\mathrm{cm} 248$ & & $0.0792 \%$ & $98.885 \%$ & & & & & & $0.030 \%$ & $0.0020 \%$ & $1.00 \%$ & $0.004 \%$ & \\
\hline $\mathrm{cm} 250$ & Curium & $0.0792 \%$ & $98.885 \%$ & & & & & & $0.030 \%$ & $0.0020 \%$ & $1.00 \%$ & $0.004 \%$ & \\
\hline 8 Bk249 & Berkelium & $0.0792 \%$ & $98.885 \%$ & & & & & & $0.030 \%$ & $0.0020 \%$ & $1.00 \%$ & $0.004 \%$ & \\
\hline C2249 & & $0.0792 \%$ & $98.885 \%$ & & & & & & $0.030 \%$ & $0.0020 \%$ & $1.00 \%$ & $0.004 \%$ & \\
\hline$\overline{C 250}$ & & $0.0792 \%$ & $98.885 \%$ & & & & & & $0.030 \%$ & $0.0020 \%$ & $1.00 \%$ & $0.004 \%$ & \\
\hline C2251 & & $0.0792 \%$ & $98.885 \%$ & & & & & & $0.030 \%$ & $0.0020 \%$ & $1.00 \%$ & $0.004 \%$ & \\
\hline \begin{tabular}{|c|}
$\mathrm{C} 252$ \\
\end{tabular} & Calffomium & $0.0792 \%$ & $98.885 \%$ & & & & & & $0.030 \%$ & $0.0020 \%$ & $1.00 \%$ & $0.004 \%$ & \\
\hline $\mathrm{H3}$ & & & & & $99.00 \%$ & $1.00 \%$ & & & & & & & \\
\hline $\mathrm{Cl} 4$ & & & & & $90.00 \%$ & $10.00 \%$ & & & & & & & \\
\hline C.other & Oother gases & & & & $90.00 \%$ & $10.00 \%$ & & & & & & & \\
\hline Krol & Inert gsses & & & & $99.00 \%$ & $1.00 \%$ & & & & & & & \\
\hline Kr85 & (Group 0) & & & & $99.00 \%$ & $1.00 \%$ & & & & & & & \\
\hline Inert gss other $\left(\mathrm{Kr}_{\mathrm{r}} \mathrm{Xe}\right)$ & & & & & $99.00 \%$ & $1.00 \%$ & & & & & & & \\
\hline $\mathrm{Rb}$ & & $0.0990 \%$ & $0.000 \%$ & & & & & & $98.802 \%$ & $0.000 \%$ & $1.00 \%$ & $0.099 \%$ & \\
\hline \begin{tabular}{|l|}
5900 w $Y 900$ decay \\
\end{tabular} & & $0.3960 \%$ & $0.547 \%$ & & & & & & $97.756 \%$ & $0.232 \%$ & $1.00 \%$ & $0.069 \%$ & \\
\hline $\begin{array}{l}\text { Sroother } \\
\end{array}$ & Group IARA & $0.3960 \%$ & $0.547 \%$ & & & & & & $97.756 \%$ & $0.232 \%$ & $1.00 \%$ & $0.069 \%$ & \\
\hline 2793 wNb63m deay & & $0.3960 \%$ & $0.390 \%$ & & & & & & $1.006 \%$ & $0.000 \%$ & $100 \%$ & $97.208 \%$ & \\
\hline 2709 wNb95m doxay & & $0.3960 \%$ & $0.390 \%$ & & & & & & $1.006 \%$ & $0.000 \%$ & $1.00 \%$ & $97.208 \%$ & \\
\hline Zr-other & Zironium & $0.3960 \%$ & $0.390 \%$ & & & & & & $1.006 \%$ & $0.000 \%$ & $1.00 \%$ & $97.208 \%$ & \\
\hline T1999 & & & $0.703 \%$ & & & & & $94.545 \%$ & $0.218 \%$ & $0.001 \%$ & $1.00 \%$ & $3.533 \%$ & \\
\hline Teother & Technetium & & $0.703 \%$ & & & & & $94.545 \%$ & $0.218 \%$ & $0.001 \%$ & $1.00 \%$ & $3.533 \%$ & \\
\hline Rul06 wRhl06 decay & & $2.0790 \%$ & $4.894 \%$ & & & & & & $6.203 \%$ & $0.005 \%$ & $1.00 \%$ & $85.819 \%$ & \\
\hline Pd107 & $\begin{array}{l}\text { Trassition metats that } \\
\text { constrin gass waste }\end{array}$ & $5.3460 \%$ & $14.545 \%$ & & & & & & $14.797 \%$ & $3.434 \%$ & $1.00 \%$ & $60.877 \%$ & \\
\hline Mo-Ru-Rh-Pd-other & forms & $1.5840 \%$ & $0.875 \%$ & & & & & & $54.719 \%$ & $0.192 \%$ & $1.00 \%$ & $41.630 \%$ & \\
\hline Se79 & & $0.0990 \%$ & $0.099 \%$ & & & & & & $0.099 \%$ & $0.000 \%$ & $1.00 \%$ & $98.703 \%$ & \\
\hline Cd113m & & $0.0990 \%$ & $0.089 \%$ & & & & & & $9.791 \%$ & $0.000 \%$ & $1.00 \%$ & $89.021 \%$ & \\
\hline Snl126 wSbl126m Sbl26 & & $45.4410 \%$ & $18.441 \%$ & & & & & & $0.054 \%$ & $0.018 \%$ & $1.00 \%$ & $35.046 \%$ & \\
\hline Sbl25 wTel25m decay & & $7.6230 \%$ & $3.127 \%$ & & & & & & $76.848 \%$ & $3.294 \%$ & $1.00 \%$ & $8.107 \%$ & \\
\hline TM-other (CO-Se, Nb, AGTe) & Other transition metals & $0.0990 \%$ & $0.099 \%$ & & . & & & & $0.099 \%$ & $0.000 \%$ & $1.00 \%$ & $98.703 \%$ & \\
\hline 11129 & 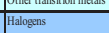 & & & & $99.999 \%$ & $0.0010 \%$ & & & & $.000 \%$ & & & \\
\hline Halogegn-other $(\mathrm{Br}, \mathrm{I})$ & (Group 7$)$ & & & & $99.999 \%$ & $0.0010 \%$ & & & & & & & \\
\hline Cs 34 & & $0.3960 \%$ & $0.034 \%$ & & & & & & $98.456 \%$ & $0.000 \%$ & $1.00 \%$ & $0.114 \%$ & \\
\hline Csl35 & & $0.3960 \%$ & $0.034 \%$ & & & & & & $98.456 \%$ & $0.000 \%$ & $1.00 \%$ & $0.114 \%$ & \\
\hline 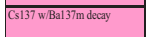 & & $0.3960 \%$ & $0.034 \%$ & & & & & & $98.456 \%$ & $0.000 \%$ & $1.00 \%$ & $0.114 \%$ & \\
\hline Cs-other & & $0.3960 \%$ & $0.034 \%$ & & & & & & $98.456 \%$ & $0.000 \%$ & $1.00 \%$ & $0.114 \%$ & \\
\hline Ba & Group 1A2A & $0.0495 \%$ & $0.193 \%$ & & & & & & $98.555 \%$ & $0.203 \%$ & $1.00 \%$ & $0.000 \%$ & \\
\hline 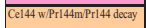 & & & & & & & & & & & & & \\
\hline & & $0.0990 \%$ & $0.030 \%$ & & & & & & $0.069 \%$ & $98.713 \%$ & $1.00 \%$ & $0.089 \%$ & \\
\hline Pml47 & & $0.0990 \%$ & $0.030 \%$ & & & & & & $0.069 \%$ & $98.713 \%$ & $1.00 \%$ & $0.089 \%$ & \\
\hline Sml46 & & $0.0990 \%$ & $0.030 \%$ & & & & & & $0.069 \%$ & $98.713 \%$ & $1.00 \%$ & $0.089 \%$ & \\
\hline$\overline{S m 147}$ & & $0.0990 \%$ & $0.030 \%$ & & & & & & $0.069 \%$ & $98.713 \%$ & $1.00 \%$ & $0.089 \%$ & \\
\hline Sml51 & & $0.0990 \%$ & $0.030 \%$ & & & & & & $0.069 \%$ & $98.713 \%$ & $1.00 \%$ & $0.089 \%$ & \\
\hline Eul154 & & $0.0990 \%$ & $0.030 \%$ & & & & & & $0.069 \%$ & $98.713 \%$ & $1.00 \%$ & $0.089 \%$ & \\
\hline Eul155 & & $0.0990 \%$ & $0.030 \%$ & & & & & & $0.069 \%$ & $98.713 \%$ & $1.00 \%$ & $0.089 \%$ & \\
\hline Hol $6 \mathrm{gm}$ & & $0.0990 \%$ & $0.030 \%$ & & & & & & $0.069 \%$ & $98.713 \%$ & $1.00 \%$ & $0.089 \%$ & \\
\hline LA-other plus Ytrtrium & Lanthanides (plus Y) & $0.0990 \%$ & $0.030 \%$ & & & & & & $0.069 \%$ & $98.713 \%$ & $1.00 \%$ & $0.089 \%$ & \\
\hline $\mathrm{Cl}-36$ & & & & & $99.9 \%$ & $0.10 \%$ & & & & & & & \\
\hline
\end{tabular}


Next, the U-TRU stream (along with its impurities) is transferred to another spreadsheet application (MrTau) which adjusts the U-TRU ratios (using depleted uranium or recovered uranium) to keep keffective constant given the impurities present. This adjusted inventory then goes to the fuel fabrication module. The fuel fabrication module fabricates a metal or oxide fuel depending on the case selected by the user. As an example, the summary sheet from the fuel fabrication module for producing a metal fuel is shown in Figure A-2.
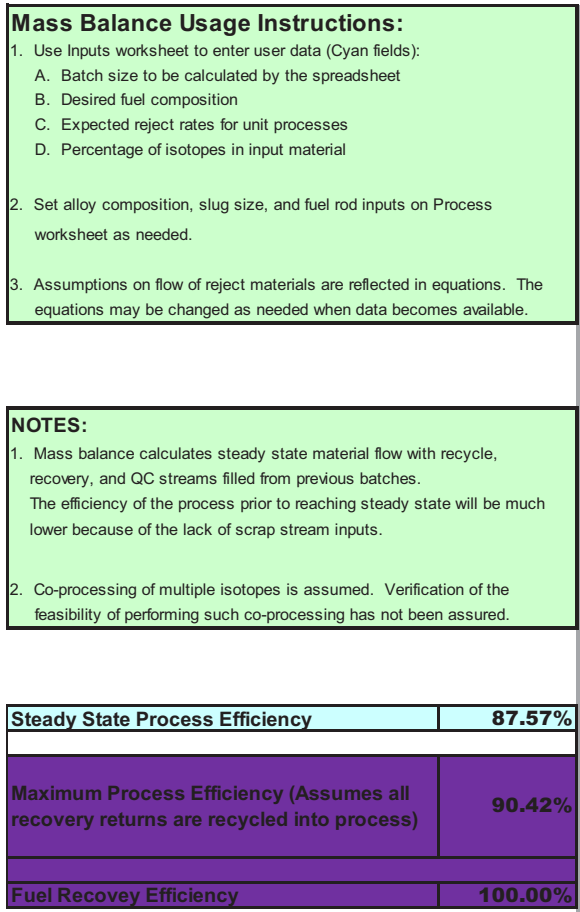

Figure A-2. Fuel fabrication module summary sheet.
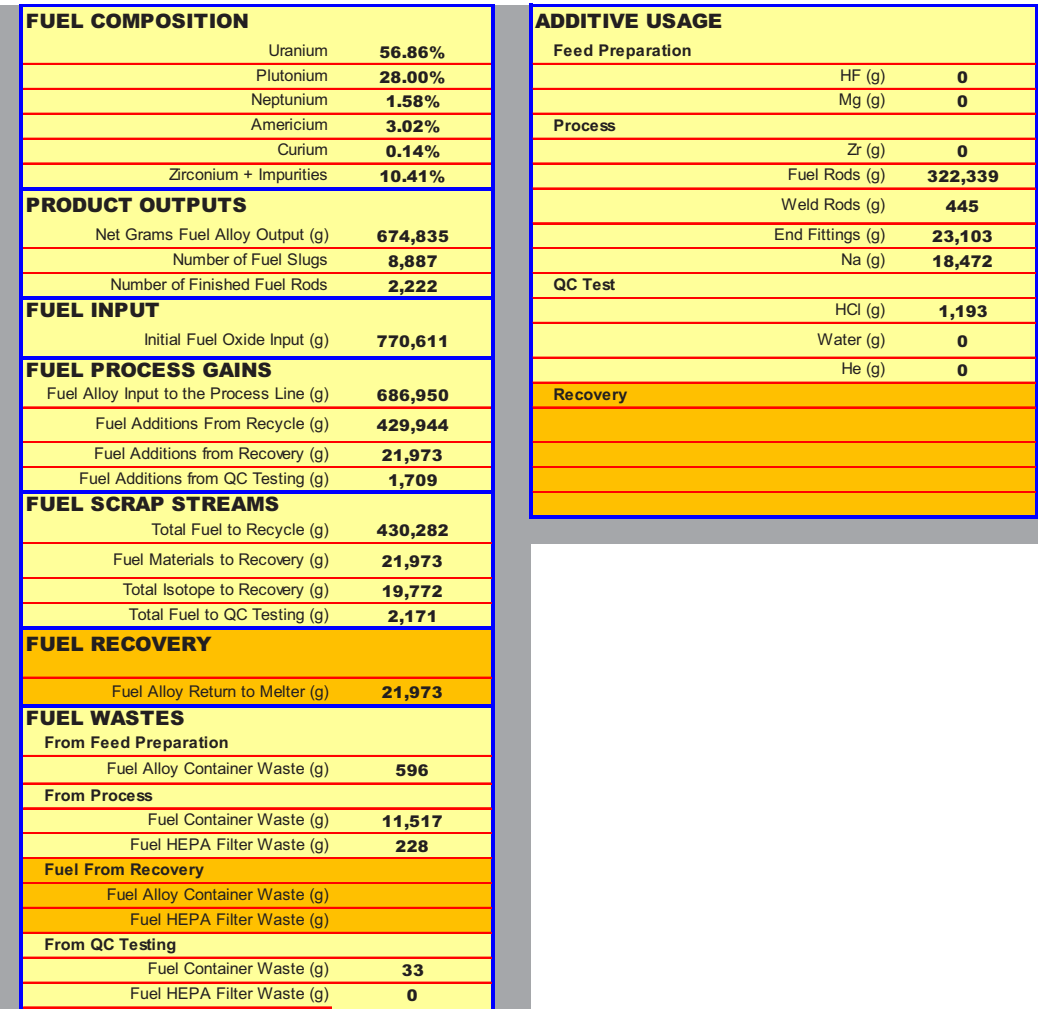

Next, the material from fuel fabrication is sent to the MrTau application to calculated depletion in the reactor according to the user specified case. The results are then passed back to the FIT model and stored in reactor storage. This inventory then goes to the second separations module and connects back to the input to fuel fabrication, thus making a calculation loop. 
Waste streams from separations and fuel fabrication are fed into the waste processing module. Inside this module decisions must be made about how each of the streams will be processed. For example, most high-level waste streams could be processed into a glass waste form. This is accomplished by implementing a glass waste loading model within the waste processing module. Some waste streams can go through extended storage to decay isotopes with relatively short half-lives. Heat, gamma, neutron, and radiotoxicity factors are applied to waste inventories to Figure A-3 shows an example of outputs from the waste disposition module. Table A-3 shows an example of similar outputs in tabular form for High-Level Waste.
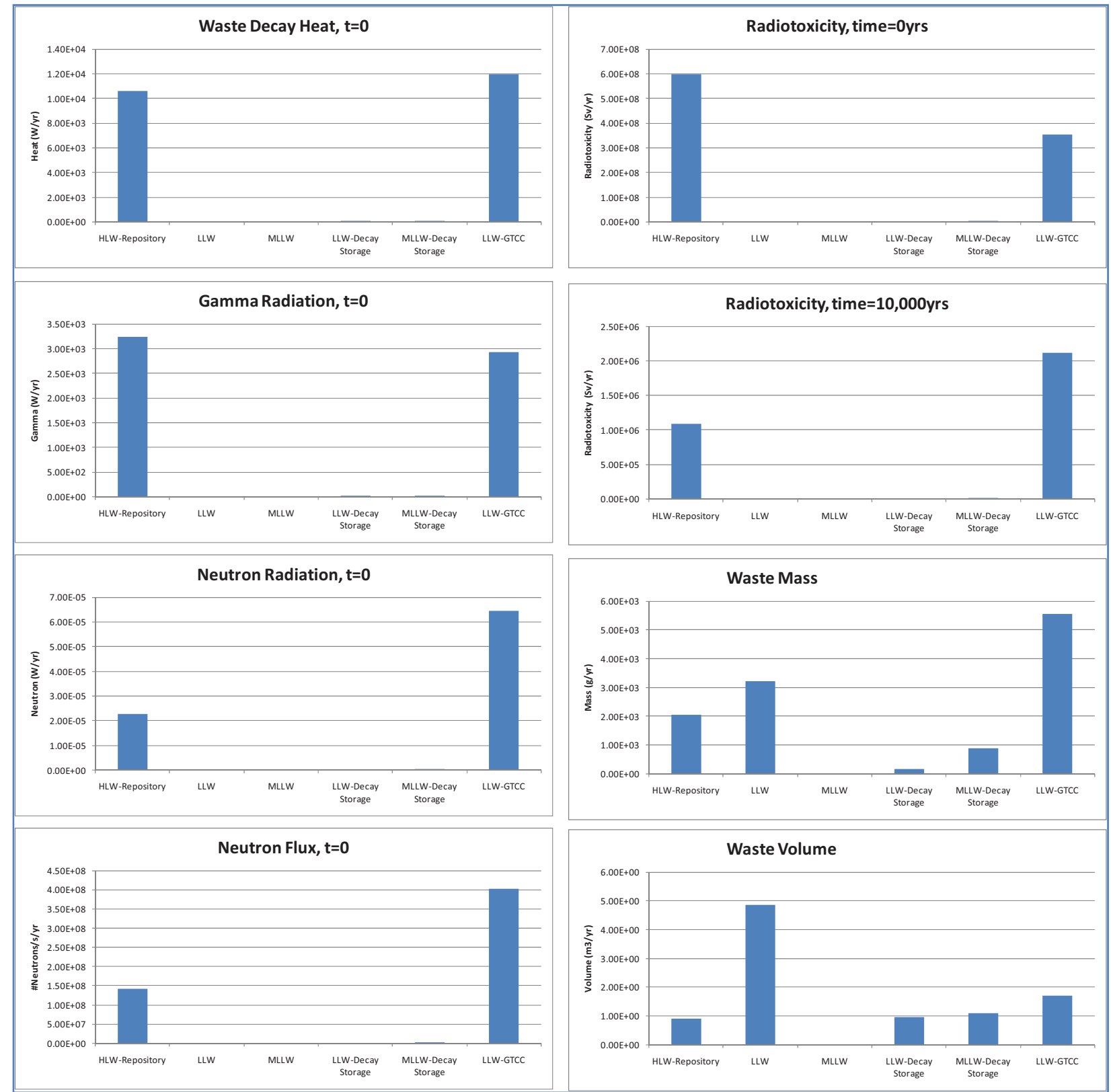

Figure A-3. Example waste disposition module outputs. 
Waste streams from separations and fuel fabrication are fed into the waste processing module. Inside this module decisions must be made about how each of the streams will be processed. For example, most high-level waste streams could be processed into a glass waste form. This is accomplished by implementing a glass waste loading model within the waste processing module. Figure A-2 shows an example of outputs from the glass waste loading model.

Table A-3. Example HLW output from FIT model.

\begin{tabular}{|c|c|c|c|c|c|c|c|c|}
\hline \multirow[b]{2}{*}{ HLW-Repository } & \multicolumn{8}{|c|}{ HLW Repository Disposal } \\
\hline & Heat $(W / y r)$ & $\begin{array}{l}\text { Gamma } \\
\text { (W/yr) }\end{array}$ & $\begin{array}{l}\text { Neutron } \\
\text { (W/yr) }\end{array}$ & $\begin{array}{l}\text { Neutron } \\
(\# / s / y r)\end{array}$ & $\begin{array}{l}\text { Radiotoxicity } \\
\text { (Sv/yr) at t=0 }\end{array}$ & $\begin{array}{l}\text { Radiotoxicity } \\
\text { (Sv/yr) at } \\
\mathrm{t}=10,000 \mathrm{yr}\end{array}$ & $\begin{array}{l}\text { Mass } \\
(\mathrm{kg} / \mathrm{yr})\end{array}$ & $\begin{array}{l}\text { Volume } \\
(\mathrm{m} 3 / \mathrm{yr})\end{array}$ \\
\hline TOTAL: & $1.06 \mathrm{E}+04$ & $3.23 E+03$ & 2.27E-05 & $1.42 \mathrm{E}+08$ & $5.99 \mathrm{E}+08$ & $1.09 \mathrm{E}+06$ & $2.04 E+03$ & $9.10 \mathrm{E}-01$ \\
\hline Zeolite & $4.38 \mathrm{E}-04$ & 1.41E-04 & $0.00 E+00$ & $0.00 E+00$ & $3.85 \mathrm{E}+03$ & $3.85 \mathrm{E}+03$ & $3.02 \mathrm{E}+02$ & $1.68 \mathrm{E}-01$ \\
\hline $\mathrm{Kr}-\mathrm{Xe}$ & $0.00 E+00$ & $0.00 E+00$ & $0.00 E+00$ & $0.00 E+00$ & $0.00 E+00$ & $0.00 \mathrm{E}+00$ & $0.00 E+00$ & $0.00 E+0 C$ \\
\hline Cs-Sr & $0.00 E+00$ & $0.00 \mathrm{E}+00$ & $0.00 E+00$ & $0.00 E+00$ & $0.00 \mathrm{E}+00$ & $0.00 E+00$ & $0.00 E+00$ & $0.00 E+0 C$ \\
\hline Metal Alloy Ingot & $3.04 E+02$ & $9.18 \mathrm{E}+01$ & $1.72 \mathrm{E}-05$ & $1.07 \mathrm{E}+08$ & $4.73 \mathrm{E}+07$ & $9.99 E+05$ & 4.23E+02 & $5.00 \mathrm{E}-02$ \\
\hline Remainder Metal & $0.00 E+00$ & $0.00 E+00$ & $0.00 E+00$ & $0.00 E+00$ & $0.00 E+00$ & $0.00 E+00$ & $0.00 E+00$ & $0.00 E+0 C$ \\
\hline HTO Grout & $0.00 E+00$ & $0.00 \mathrm{E}+00$ & $0.00 E+00$ & $0.00 E+00$ & $0.00 E+00$ & $0.00 E+00$ & $0.00 E+00$ & $0.00 E+0 C$ \\
\hline C14 Grout & 9.30E-07 & 8.79E-09 & $0.00 E+00$ & $0.00 E+00$ & $6.81 \mathrm{E}-02$ & 2.03E-02 & $0.00 E+00$ & $0.00 E+0 C$ \\
\hline LLW Mineralized Monolith & $0.00 E+00$ & $0.00 E+00$ & $0.00 E+00$ & $0.00 E+00$ & $0.00 E+00$ & $0.00 E+00$ & $0.00 E+00$ & $0.00 E+0 C$ \\
\hline TRU Mineralized Monolith & $0.00 E+00$ & $0.00 E+00$ & $0.00 E+00$ & $0.00 E+00$ & $0.00 E+00$ & $0.00 E+00$ & $0.00 E+00$ & $0.00 E+0 C$ \\
\hline Glass & $2.82 E+01$ & $1.28 \mathrm{E}+01$ & $6.82 \mathrm{E}-08$ & $4.26 \mathrm{E}+05$ & $3.21 E+06$ & $1.01 \mathrm{E}+04$ & $2.28 \mathrm{E}+02$ & $8.71 \mathrm{E}-02$ \\
\hline Glass Bonded Zeolite & $1.03 E+04$ & $3.13 E+03$ & $5.46 \mathrm{E}-06$ & $3.41 E+07$ & $5.49 \mathrm{E}+08$ & $7.76 \mathrm{E}+04$ & $1.09 \mathrm{E}+03$ & $6.05 \mathrm{E}-01$ \\
\hline Fuel Fab Waste & $0.00 E+00$ & $0.00 \mathrm{E}+00$ & $0.00 \mathrm{E}+00$ & $0.00 E+00$ & $0.00 E+00$ & $0.00 E+00$ & $0.00 E+00$ & $0.00 E+0 C$ \\
\hline Operational Waste & $0.00 E+00$ & $0.00 E+00$ & $0.00 E+00$ & $0.00 E+00$ & $0.00 E+00$ & $0.00 E+00$ & $0.00 E+00$ & $0.00 E+0 C$ \\
\hline Operational Waste (TRU) & $0.00 E+00$ & $0.00 \mathrm{E}+00$ & $0.00 \mathrm{E}+00$ & $0.00 E+00$ & $0.00 E+00$ & $0.00 E+00$ & $0.00 E+00$ & $0.00 E+0 C$ \\
\hline
\end{tabular}


Appendix B Software Requirements Document for FIT 
This page intentionally left blank 
May 12, 1010

Revision 2.0

\section{B-1. Introduction}

The purpose of this Software Requirements Document (SRD) is to define the top-level requirements for the Fuel Cycle Integration and Trade-offs Model (FIT). This modeling tool has evolved from initial efforts to evaluate fuel cycle system losses (the Losses Study) started in Fiscal Year 2009 (Shropshire 2009). The initial Losses Study focused on impacts to the fuel cycle due to "losses" that occur during used fuel recycling due to separation inefficiencies; namely (a) losses of a portion of re-usable fuel components (specifically $\mathrm{U}, \mathrm{Pu}$, and other actinides), that cannot be $100 \%$ recovered and so are no longer available for recycle and also contaminate separated waste streams, and (b) losses of a portion of fission products and inert materials that are not possible to separate with $100 \%$ efficiency, and so contaminate recycled fuel streams. These recycle and waste losses become important when (a) contamination of the recycled fuel impacts how the recycled fuel is made, and how the recycled fuel behaves in recycle reactors, and (b) contamination of waste streams affects how those waste streams can be handled and ultimately disposed. These losses increase in multiple-recycle strategies. The losses of valuable actinides (to waste) that could otherwise be recycled into new fuel can affect uranium (and thorium when used) resource utilization efficiency.

The FIT model is intended to evolve beyond the initial focus on losses and serve as a broad systems analysis and study tool for performing analyses conducted by the Systems Analysis Campaign in conjunction with the Transmutation Fuels Campaign and the combined Separations and Waste Form Campaigns. It is intended to be used to identify and evaluate high level discriminating issues that could be used by the Department of Energy (DOE) to evaluate and down-select different fuel cycle options, and to be used when considering where to focus future nuclear fuel cycle research and development.

This is a "living document" that can be modified as needed over the course of the execution of this work element, but with configuration control by the INL work package manager for the Losses Study.

\section{B-2. Need, Scope and Purpose of the FIT Model}

\section{B-2.1. Need for the FIT Model}

Various modeling tools have been developed or are under development for nuclear fuel cycle research and development. Figure B-1 shows how fundamental science and data provide a foundation for modeling tools such as AMUSE and ORIGEN. These models are used to study various fuel cycle components. For example, ORIGEN is used to study the fission of nuclear fuel in nuclear reactors to estimate the composition of used fuel. AMUSE is used to study aqueous separations processes.

The Verifiable Fuel Cycle Simulation (VISION) model has been developed to perform high-level dynamic simulations over time for an entire fuel cycle. Because it is dynamic and high level, it excludes detail needed to readily evaluate fuel cycle options at a more detailed level.

An initial scoping of candidate Systems Analysis Campaign models was included in the Losses Study in FY-09 (Shropshire 2009). The FY-2009 effort resulted in the recommendation that the FIT model is needed to bridge the system analysis gap between component-specific science and models such as AMUSE and ORIGEN, and the higher-level, dynamic VISION model. 


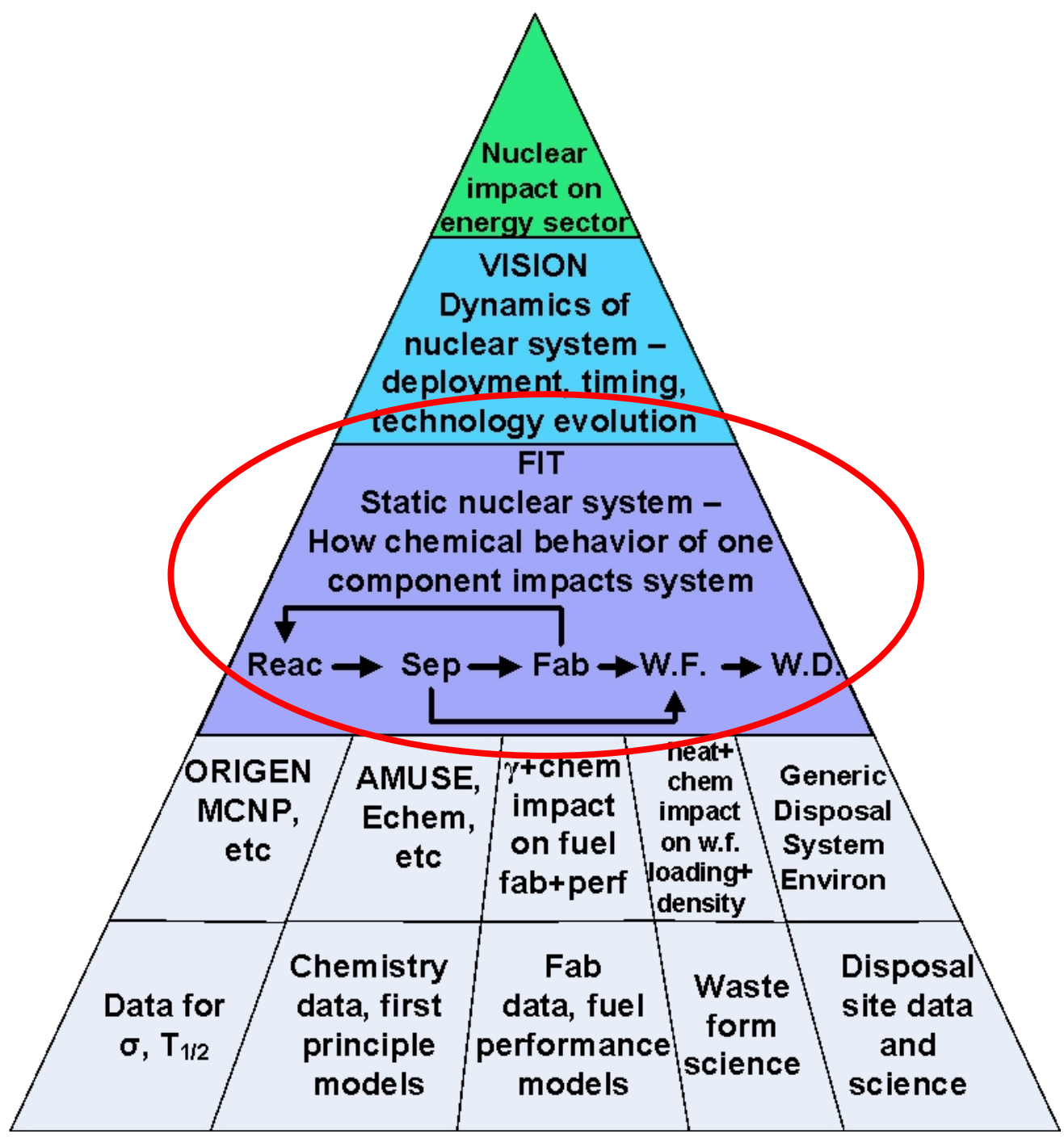

Figure B-1. Modeling pyramid diagram showing relative hierarchy of models.

\section{B-2.2. Scope of the FIT Model}

The initial versions of the FIT model will simulate the fuel cycle functions as nuclear fuel leaves the initial reactor and is either disposed of (in once-through strategies) or is otherwise processed to separate recyclable components from waste components that are discarded (in modified open or full recycle strategies). The model is intended to be able to include fuel cycle functions upstream of the initial reactor, such as mining, enrichment, and initial fuel fabrication, but not in the initial development stage.

Figure B-2 shows that the initial scope of model will include post-reactor fuel storage, separations, recycled product storage, fuel fabrication, recycle reactor(s), waste conditioning, long-term waste storage, and final disposition. The model will provide the capability to evaluate a wide range of systems including thermal and fast transmutation systems, various types of fuels (oxide, metal, others), different fuel origins (commercial or defense), fuel separation technologies (such as aqueous and electrochemical [EChem]), waste forms, and waste disposition strategies. The FIT modeling domain interfaces with other the Fuel Cycle Technology (FCT) research and development efforts in fuel fabrication, reactors, separations, waste forms, and waste disposition. The color coding on the diagram illustrates the various focus areas of those efforts, where the FIT model integrates the results of those efforts into a composite modeling structure. 


\section{FIT model domain and interface with FCT campaigns}

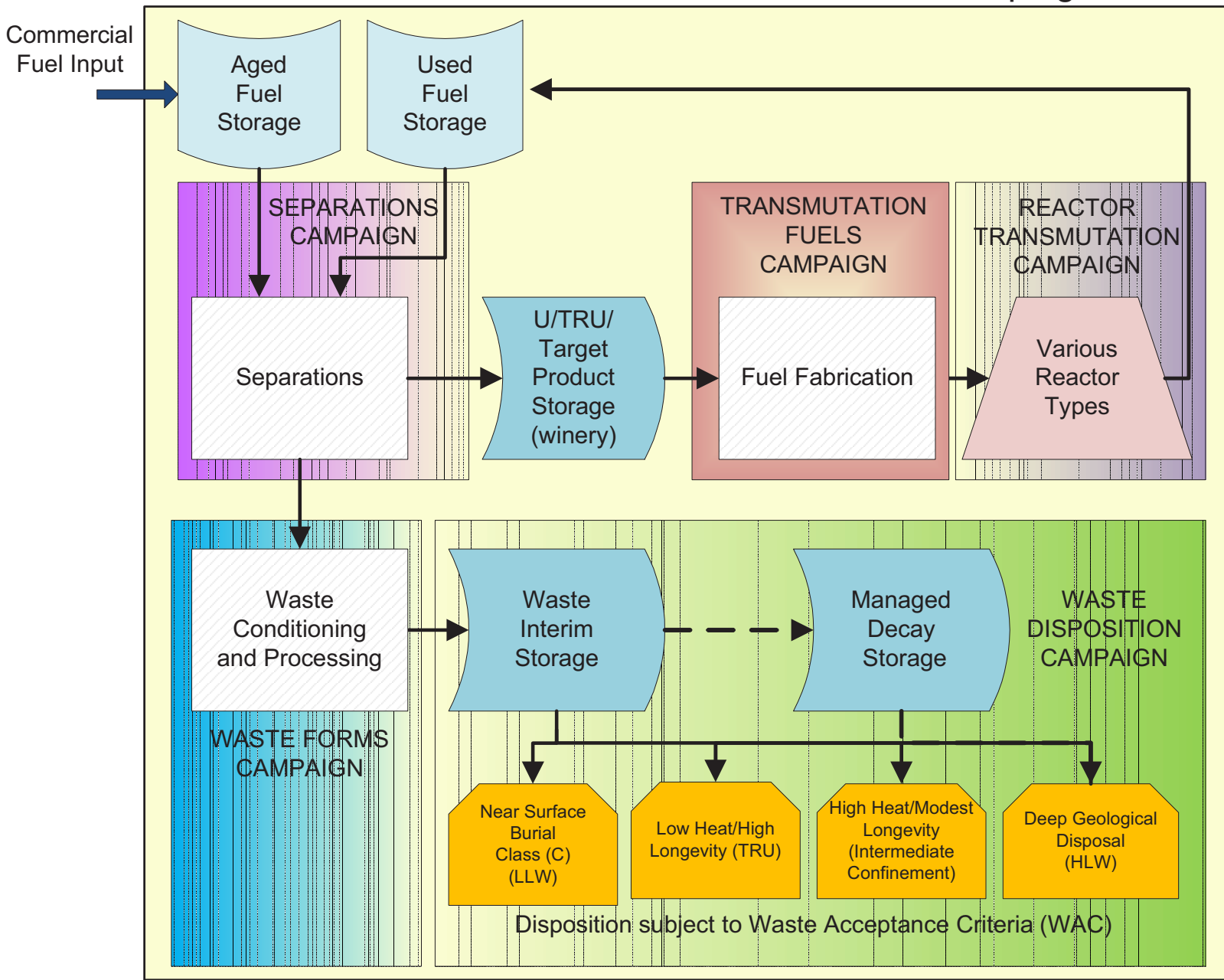

Figure B-2. The FIT modeling domain.

\section{B-2.3. Purpose of the FIT Model}

The primary objective of the model is to provide an overall system understanding of the tradeoffs between separations, transmutation fuel fabrication, waste forms, waste disposition, and reactor performance features of potential nuclear fuel cycle options. The use of the model will result in useful insights in system performance that DOE can use to make decisions regarding different fuel cycle options, provide information about how waste can be safely and cost effectively managed, and provide information for guiding the focus of future fuel cycle research and development.

\section{B-3. Users of the FIT Model}

The model is being designed for two major anticipated user groups. The user group will have a direct bearing on the implementation and timing of the requirements. The model is not intended for use by people unfamiliar with advanced fuel cycles, their issues, terminology, and basic interrelationships.

Group 1 is the Losses Study Team participants and software developers who will be creating the overall code and integrating the results from the lower-level detailed models and science into the model. These 
users will be responsible for developing the model, conducting theoretical "what-if" scenarios to test assumptions and further refine alternatives, assessing the reliability and robustness of model results, performing overall model verification and validation $(\mathrm{V} \& \mathrm{~V})$, and making suggested changes to the model. In general this class of users will have access to internal versions of the model for testing, analysis and experimentation and will also be responsible to resolve quality assurance (QA) issues.

Group 2 includes other various FCT researchers and potentially Department of Energy employees external to the Losses Study Team. This group will use a compiled or "locked" version of the model to conduct analysis and "what-if" scenarios within the published functionality of the model. These users will operate the model through an interface that restricts access to the underlying data and algorithms. These users will have access to approved and published versions of the software that have been through an established quality assurance process that verifies and validates the model.

\section{B-4. High Level Functionality}

The model will be used to assist in evaluating and improving major fuel cycle options based on cost and risk trade-off issues e.g., waste management, proliferation resistance, energy recovery, and systematic fuel management (economics, safety, at-reactor storage) objectives.

The model is NOT intended to actually manage the fuel cycle. For example, there is no intent to track each fuel assembly from each reactor, as might be required for actual fuel management. The model is not intended to address transportation issues.

The model could utilize data, structures, and functionality developed by other FCT efforts. Results from other models such as VISION, VISION.ECON, ORIGEN, AMUSE, Aspen, or spreadsheets may be used. The FIT model could utilize (a) isotopic flow control and decay, (b) recipes for transmutation analyses, (c) simplified models for fuel separation and fabrication, (d) fuel cycle cost calculations, and (e) flexibility to analyze various combinations and transitions of fuel cycle technologies.

The FIT model could be used to:

- Quickly assess and evaluate, with reasonable accuracy, relative economic trade-offs between a wide-range of fuel cycle and transmutation strategies.

- Provide an understanding of system sensitivities and areas of greatest uncertainty.

- Simulate feedback impacts from multiple recycling of fuels; for example, the system implications of multiple recycles of the fuel and build up of impurities.

- Conduct qualitative and quantitative comparisons of alternative fuel cycles with respect to:

○ reactor types (e.g., fast, thermal)

○ reactor fuel meat (e.g., oxide, metal, ceramic)

$\circ$ sequencing and timing of recycling

○ fuel make-up requirements (due to build up of system poisons)

$\circ$ energy recovery

$\circ$ proliferation resistance

○ used fuel management (open, modified open, closed)

○ processing options ( aqueous, electrochemical, AIROX, etc)

- separations - simple versus complex with multiple product and waste streams

○ waste stream characteristics 
○ waste form characteristics

○ potential waste disposition pathways

$\circ$ cost.

Typical, but by no means all, of the questions that may be answered using the model include:

- What strategies can minimize the production of HLW?

- How can separation and fuel fabrication losses and costs be minimized?

- What reactor concepts can minimize the Pu inventory and/or the production of $\mathrm{Pu}$ ?

- How do different fuel cycle options compare to each other?

Fuel cycle processes are defined fairly generically in the model to allow for a maximum of modeling flexibility to evaluate a wide range of system configurations. Figure B-3 shows the fuel cycle process blocks that are to be included in the initial model development of FY-10. These process blocks are presently limited to the "back end" of a fuel cycle, after used fuel is removed from an initial power reactor. The current scope of the model was restricted to the fuel cycle back-end processes to enable a focus on recycling used fuel. Continued development beyond FY-10 may expand the scope of the model to include front-end processes including ore mining, enrichment, initial fuel fabrication, and initial reactor. 


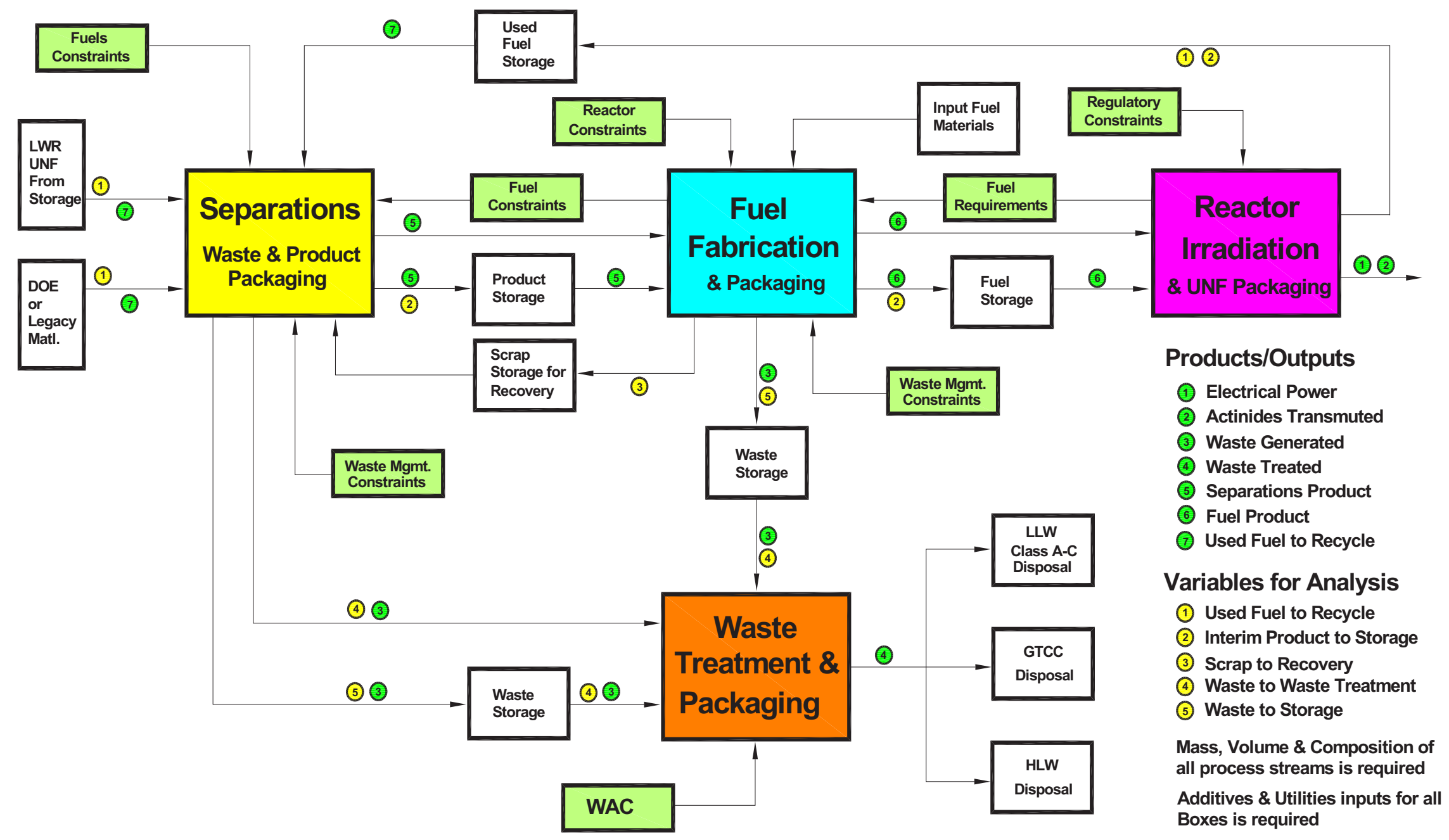

Figure B-3. Proposed FIT variables and products/outputs. 
The processes in Figure B-3 are briefly described in the following subsections.

\section{B-4.1. Used Fuel Storage}

The model allows for storage of used fuels that have been transmuted in commercial light water reactors (LWRs) or other types of reactors (research, etc.). These fuels may have been stored for decades in wet or dry storage, or may be recently removed from a reactor. The types of storage processes may include:

- Wet monitored and retrievable storage (water or liquid metal)

- Dry monitored and retrievable storage (air or inert gas)

- Combinations of the above

Key variables for used fuel storage include:

- Used fuel properties (fuel type, initial enrichments, burn-up, estimated composition at time of reactor discharge)

- Storage duration (1 yr to 400 or $500 \mathrm{yrs}$ ).

- $\quad$ Storage capacity

- $\quad \mathrm{ES} \& H$ and S\&S requirements

- Used fuel inspection/isolation requirements

- Different used fuel storage blocks are shown in the figure to enable used fuel from different sources - commercial power reactors, DOE used fuel inventories, and used fuel recycled from a recycle reactor used in this model.

\section{B-4.2. Separations}

Separation of used fuels could be performed using various technologies and could result in a few products $(\mathrm{U} / \mathrm{Pu}, \mathrm{HLW})$ or multiple streams depending upon the selected flowsheet and desired ends states. Interim storage of products that will be re-fabricated into new fuel is also included. Examples of types of separation processes include:

1. Aqueous or organic solution

- Solvent extraction

- Ion exchange

- Precipitation

2. Non-aqueous

- Ionic Liquids / Electrochemical

- Distillation

- Gaseous

- Supercritical Fluids

- Plasma

- Laser

- Thermomechanical 
3. Other

- Oxidation

- Reduction

- Zone freeze refining

Key variables for separations and product storage include:

- Flowsheet selection

- Storage time

- Maintenance concepts and annual processing rates

- Separation and process equipment efficiency

- Tolerable/acceptable contamination limits in fuel products and waste streams

\section{B-4.3. Product and Waste Storage}

The separations, fuel fabrication, waste treatment, and reactor irradiation blocks will include, as necessary, appropriate temporary surge storage needed for efficient processing. Beyond that amount of storage, additional decoupling storage is allowed for product and waste streams that exit one block and enter another. Temporary storage modules are provided for (a) reusable product materials that exit separations on the way to fuel fabrication, (b) waste streams that exit separations and fuel fabrication blocks on the way to waste treatment and packaging, (c) fuel and targets that exit fuel fabrication on the way to reactor irradiation, and (d) waste packages prepared for decay storage or for disposal.

These storage modules are important because unless the used fuel has been aged for several hundred years, the isotopic composition, heat generation, radioactivity, radiation levels, and radiotoxicity can change significantly as the product and waste materials decay during this temporary storage. This temporary storage could be key components of some fuel cycle options. The temporary storage features must include the capability to tolerate, control, and contain levels of heat generation and radiation expected for those process materials in each model evaluation.

\section{B-4.4. Transmutation Fuel Fabrication}

Transmutation fuel fabrication could be performed using various technologies. The types of fuel fabrication processes may include the capabilities to produce fuels (or targets) containing these types of recycled materials:

- Uranium

- Uranium-TRU (oxide and metal alloys)

- TRU only

- Mixed fuels, e.g. heterogeneous assemblies have both UOX and TRU-oxide fuels

- Minor actinide targets (Np, Am, and/or Cm-Bk-Cf)

- Fission product targets (e.g. technetium or iodine).

Key variables for fuel fabrication include: 
- Fuel material isotopic content that drives needs for new or unique fuel fabrication requirements, such as inert atmospheres and remote operations/maintenance, and time dependent processing rates to minimize buildup of decay daughters (e.g. U-232 decay chain)

- Fuel fabrication technology

- Fuel cladding/coating

- Requirements imposed by the reactor.

\section{B-4.5. Waste Treatment and Packaging}

Waste treatment and packaging includes the treatment and packing for disposition of all the non-product streams produced by the separations, maintenance, and other processes in the model. The types of waste treatment processes can include various waste stabilization technologies that produce waste forms suitable for packaging, transportation, storage, and final disposal, such as:

- Packaging (when no other treatment is needed, or after treatment is complete)

- Compaction

- Encapsulation (micro or macro)

- Grouting and other cementing processes

- Evaporation

- Calcination (under oxidizing or reducing [steam reforming] stoichiometry)

- Mineralization

- Vitrification

- Incineration

- Ion exchange

- Filtration

Key variables for waste treatment include:

- Input waste stream properties, especially amounts of TRU losses to waste, and other constituents of the waste streams (water, acids, organics, salts, etc.) besides the waste components separated from the used fuel

- Waste form requirements imposed by downstream waste storage or disposal processes (WAC)

- Waste treatment technologies

- Characteristics/limits of the waste forms such as waste loading limits imposed based on durability and temperature limits.

\section{B-4.6. Waste Storage and Final Disposition}

This includes interim waste storage of treated and packaged waste streams prior to disposal. Waste streams may be additionally held in managed decay storage prior to disposal. Final waste disposition will include the final disposal technologies in accordance with current legal waste definitions (10 CFR 61) and classifications based on waste characteristics (heat, radiotoxicity).

Key variables for waste storage and final disposition include: 
- Waste storage duration

- Waste limits on transuranics and technetium impurities in waste

- Class A/B/C/GTCC disposal waste acceptance criteria (WAC)

- HLW disposal repository characteristics/WAC

- Transportation limitations

- Heat generation, $\mathrm{W} / \mathrm{kg}$

- Gamma field, $\mathrm{Gy} / \mathrm{kg}$ ( $\mathrm{Sv}=$ sievert, $\mathrm{Gy}=$ gray)

- Neutron field, $\mathrm{n} / \mathrm{kg}$-second or Gy/kg

- Alpha field

- Assumed date for disposal of waste traditionally considered high level waste or spent nuclear fuel in a geologic repository

\section{B-4.7. Transmutation}

Transmutation may include a broad range of reactor or accelerator technologies (fast, thermal, or epithermal) using various configurations of cores and blankets. Strategies to recycle fuel from one rector type to another to maximize transmutation effects may also be implemented to optimize fuel utilization and transmutation effects. The types of reactors may include:

- Light water reactors

- Heavy water reactors

- Supercritical water reactors

- Gas cooled (thermal) reactors

- Gas cooled (fast) reactors

- Molten salt cooled reactors (salt is coolant only, fuel is solid)

- Molten salt fueled reactors (salt is both coolant and fuel)

- Sodium cooled (fast) reactors

- Lead cooled (fast) reactors

- Accelerator driven

- Fusion-driven, i.e., fusion-fission hybrid

Key variables for reactor transmutation include:

- Types and quantities of fuel impurities (Ln)

- Fuel composition adjustments

- Type of fuel meat and or combinations - HEU, Pu, Th, etc.

- Fuel cladding adjustments

- Fuel burn-up

- Fuel life 
- Target location in core

- Power level produced by reactors

- Average age of reactors in service

\section{B-5. Modeling Assumptions, Requirements, Structure, and Constraints}

The FIT model will be structured (Figure B-4) to show how system outputs or products are affected by modification of a given set of independent (input) variables (black box inputs/outputs) while controlling the other variables with mathematical relationships. The inputs/outputs within the system will have a characteristic mass, form and composition. Specific constraints (requirement limits) are involved for each of the black boxes that set the boundaries within which the process functions. These constraints can be modified as independent variables for the model to evaluate. The model will be used to evaluate impacts at a sub-system level (e.g., fabrication) and at a total system level. 


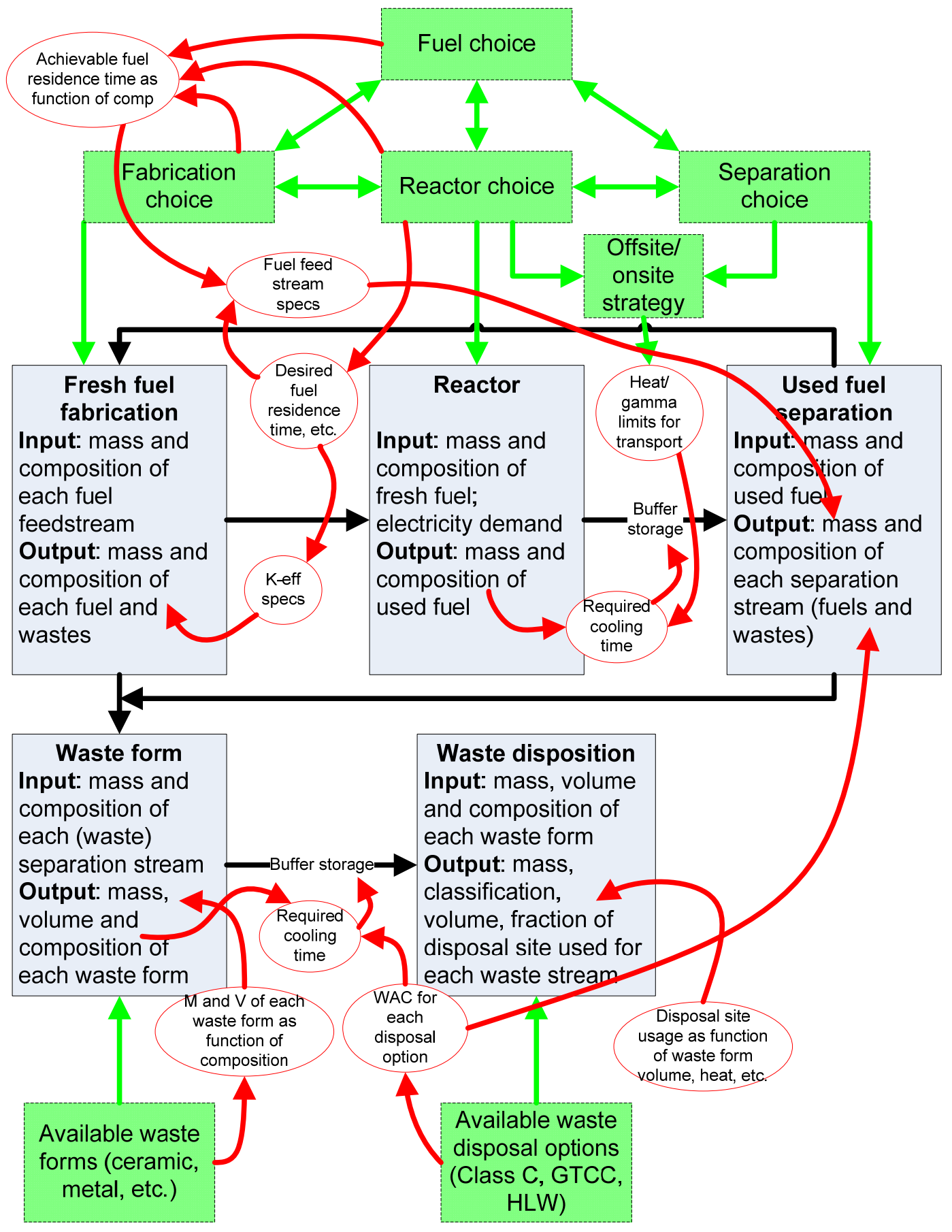

Figure B-4. FIT model mass and information flow.

The model will be designed to assess one fuel cycle condition at a time. Results of multiple runs of the model, using different fuel cycle options, will be used to compare different fuel cycle options.

The modeling structure has to allow us to estimate the mass (e.g. chemical element, key isotopes) of each mass flow from one box to another. For some boxes, there are other parameters that must be calculated based on the composition - such as heat, gamma dose, neutron emission, k-effective.

The model must be able to handle appropriate combinations of: 
- Fuel material - Th, U, Np, Pu, Am, Cm-Bk-Cf and combinations thereof

- Fuel matrix materials, e.g., oxide matrix for UOX/MOX fuels, metal alloy for fast reactor Zr-UTRU fuels, oxide or oxycarbide for TRISO

- Clad/coat materials, e.g., Zr-alloy, steel clad C/SiC coating.

Other assumptions, requirements, structure, and constraints include:

- System level cases will be used to test the model after the model structure is created

- Existing models and commercial off the shelf software will be used to the extent possible

- The model will be developed in FY-10 in support of System Losses trade off studies, for use by Group 1 users

- The model will be distributed and used beyond the INL

- The model will be designed to be available for use by other Fuel Cycle Technology users

- The model will be of sufficient quality to pass independent review.

\section{B-6. Treatment of Modeling Uncertainties and Global Optimization}

The model can be run based on discrete data to produce deterministic outputs. Additionally, key variables (performance, cost) can be described as an uncertainty range or distribution. The model will consist of multiple features or capabilities:

- The base level includes the deterministic calculations for all the mass flows in the system

- Information and mass flows from subsystems (e.g. separations) to/from the full system must be carefully considered and linked

- Understanding and analysis will be built step-wise

- Uncertainty ranges need to be considered and allowed where necessary to bound uncertain values

- Attempting to model new ideas is itself an issue identifier. For example, evaluations of "minimum fuel treatment" variations indicate that even minimal fuel treatment involves physical or chemical changes to the used fuel, that result in changes to chemical composition. Evaluations of "minimum fuel treatment" separations options must reflect impacts to separations and downstream fuel fabrication, reactor, and waste treatment steps.

\section{B-7. Metrics}

The metrics used to support the FY-2010 Use Cases would include:

- Mass flows through the system. Outputs from each functional unit of the model (i.e., black box) will be derived based on the input streams to, and the features in, that functional unit. These relationships will be based on the more detailed codes (AMUSE, Aspen, Spreadsheet program or other means) to compute the changes within the black boxes.

- Economics. The primary cost unit will be $\$ / \mathrm{kg}-\mathrm{HM}, \$ / \mathrm{MW}$ th energy produced, $\$ / \mathrm{MWe}$ energy produced, or other cost measure which encompasses the capital and operating costs of fuel cycle processes and storage. The model must contain algorithms that can convert changes in mass, form, and composition from the black boxes to changes in cost. The model must be able to answer questions such as, "How does fabrication or separation costs vary with the heat/gamma/neutron emission of the mass flowing into the process?" 


\section{B-8. Candidate Modeling Cases}

Table B-1 shows candidate cases that could be used to help mature the model. This selection of cases will be used to illustrate, step-wise, how the model can be used. We do not expect to be able to run all of these possible cases this fiscal year. Results of initial modeling will be used to determine the sequence of additional use cases to best build the model capabilities and also begin to show model results in a stepwise fashion.

Most important will be (a) development of the ability to consider and use information and mass flows between different blocks of the model, (b) development of the ability to compare different fuel cycle options and perform sensitivity studies with individual options; and (c) documentation of results tied to input assumptions and information.

Table B-1. Desired use cases.

\begin{tabular}{|c|c|c|c|c|c|}
\hline & $\begin{array}{l}\text { Feed } \\
\text { Fuel }\end{array}$ & $\begin{array}{l}\text { First } \\
\text { Separation }\end{array}$ & Recycle Fuel & $\begin{array}{l}\text { Recycle } \\
\text { Separation }\end{array}$ & Comment \\
\hline $1 p$ & & & FR-oxide at $\mathrm{CR}=0.50$ & UREX+1 & \multirow[t]{2}{*}{ FY 2009 cases } \\
\hline $2 \mathrm{p}$ & & & FR-metal at $\mathrm{CR}=0.50$ & Echem & \\
\hline 1 & UOX & UREX+1a & FR-oxide at $\mathrm{CR}=0.50$ & UREX+1 & \multirow{2}{*}{$\begin{array}{l}\text { Completes DSARR 1-tier } \\
\text { scenarios, forces allocation of } \\
\text { tolerable impurities between two } \\
\text { streams }\end{array}$} \\
\hline 2 & UOX & UREX+1a & FR-metal at $\mathrm{CR}=0.50$ & Echem & \\
\hline $1 \mathrm{c}$ & UOX & UREX+1a & FR-oxide at $\mathrm{CR}=0.50$ & Echem & \multirow{2}{*}{$\begin{array}{l}\text { Cross compare fuel-separation, } \\
\text { putting echem with oxide fuel or } \\
\text { UREX with metal fuel adds } \\
\text { oxidation and reduction steps }\end{array}$} \\
\hline $2 \mathrm{c}$ & UOX & UREX+1a & FR-metal at $\mathrm{CR}=0.50$ & UREX+1 & \\
\hline $1 \mathrm{~m}$ & UOX & AIROX & FR-oxide at $\mathrm{CR}=0.50$ & AIROX & \multirow[t]{2}{*}{ "Minimal fuel treatment" variants } \\
\hline $2 \mathrm{~m}$ & UOX & AIROX & FR-metal at $\mathrm{CR}=0.50$ & Melt refine & \\
\hline $1 \mathrm{t}$ & MOX & UREX+1a & FR-oxide at $\mathrm{CR}=0.50$ & UREX+1 & \multirow[t]{2}{*}{ DSARR 2-tier scenarios } \\
\hline $2 \mathrm{t}$ & MOX & $\mathrm{UREX}+1 \mathrm{a}$ & FR-metal at $\mathrm{CR}=0.50$ & Echem & \\
\hline $1 \mathrm{~h}$ & UOX & $\begin{array}{l}\text { UREX+1a } \\
\text { without } \mathrm{CsSr} \\
\text { removal }\end{array}$ & FR-oxide at $\mathrm{CR}=0.50$ & $\begin{array}{l}\text { UREX+1 } \\
\text { without } \mathrm{CsSr} \\
\text { removal }\end{array}$ & \multirow[t]{2}{*}{$\begin{array}{l}\text { Same as } 1 / 2 \text { except no } \mathrm{CsSr} \\
\text { removal }\end{array}$} \\
\hline $2 \mathrm{~h}$ & UOX & $\begin{array}{l}\mathrm{UREX}+1 \mathrm{a} \\
\text { without } \mathrm{CsSr} \\
\text { removal }\end{array}$ & FR-metal at $\mathrm{CR}=0.50$ & $\begin{array}{l}\text { Echem } \\
\text { without } \mathrm{CsSr} \\
\text { removal }\end{array}$ & \\
\hline $1 \mathrm{~s}$ & UOX & UREX+1a & FR-oxide at $\mathrm{CR}=0.50$ & UREX+1 & \multirow{2}{*}{$\begin{array}{l}\text { Same as above, but with longer } \\
\text { interim storage times }\end{array}$} \\
\hline $2 \mathrm{~s}$ & UOX & UREX+1a & FR-metal at $\mathrm{CR}=0.50$ & Echem & \\
\hline $1 \mathrm{a}$ & UOX & COEX & FR-oxide at $\mathrm{CR}=0.50$ & UREX+1 & \multirow[b]{2}{*}{$\begin{array}{l}\text { Enables evaluation of a first } \\
\text { separation case where other TRU } \\
\text { elements besides Pu are not } \\
\text { recovered for recycle, but sent to a } \\
\text { single borosilicate glass (BSG) } \\
\text { waste form along with technetium, } \\
\text { lanthanides, undissolved solids } \\
\text { (UDS), other fission products. }\end{array}$} \\
\hline $2 \mathrm{a}$ & UOX & COEX & FR-metal at $\mathrm{CR}=0.50$ & Echem & \\
\hline $1 \mathrm{n}$ & UOX & NUEX & FR-oxide at $\mathrm{CR}=0.50$ & UREX+1 & Enables evaluation of a first \\
\hline
\end{tabular}




\begin{tabular}{|l|l|l|l|l|}
\hline $2 \mathrm{n}$ & UOX & NUEX & FR-metal at CR=0.50 Echem & $\begin{array}{l}\text { separation case where all TRU } \\
\text { elements are recovered for recycle, } \\
\text { and a single BSG waste form } \\
\text { contains technetium, lanthanides, } \\
\text { UDS, other fission products (FP). }\end{array}$ \\
\hline $\begin{array}{l}\text { Use cases that include other advanced waste forms besides BSG (that can tolerate higher waste loadings, } \\
\text { high heat generation, etc.) are also interesting, but should probably not be included in this year's analyses, } \\
\text { until after the waste form experts makes more progress in this area. }\end{array}$ \\
$\begin{array}{l}\text { (no identifier) = the full 1-tier DSARR scenarios } \\
\mathrm{a}=\text { COEX (did not come up with a descriptive letter) } \\
\mathrm{c}=\text { cross compare (use echem on oxide fuel, use UREX on metal fuel) } \\
\mathrm{h}=\text { hot (no CsSr removal) } \\
\mathrm{m}=\text { minimum fuel treatment } \\
\mathrm{n}=\text { NUEX } \\
\mathrm{p}=\text { partial in the sense that in FY 2009 we didn't do a complete fuel cycle, only the fast reactor portion of 1-tier DSARR scenario } \\
\mathrm{s}=\text { storage (more storage time than the 1-tier DSARR scenario) } \\
\mathrm{t}=\text { two-tier DSARR scenario (LWR-UOX to LWR-MOX to fast reactor) }\end{array}$ \\
\end{tabular}

\section{B-9. Products and Outputs}

There are many ways to represent tradeoffs between system parameters and various software programs that could be used to produce the output. Output could be produced using Excel to produce simple 2 or 3dimensional outputs. Enhanced outputs (e.g., trade-off surfaces) could be produced by more sophisticated mathematical software (Maple, MATLAB®).

The following example figures illustrate the types of graphic outputs from the model. In Figure B-5 the cost performance is shown as a function of time that spent fuel spends in interim storage before being recycled. Figure B-6 shows the inventory of different types of waste as a function of losses to waste.

Several standard outputs could be automatically generated by the model to enable quick analysis of system tradeoffs. The outputs would be designed with the flexibility to show inflection points on surfaces, or show surfaces that evolve with time. A range of system performance measures can be explored, such as repository performance, fuel performance, and electricity generation, all as a function of system parameters. Scenario analysis should allow quick comparisons between different technologies utilizing the same parameter space. 


\section{Cost based on storage time of spent fuel before recycle}

N.B.: Values for demonstration purposes only. They do not reflect actual data.

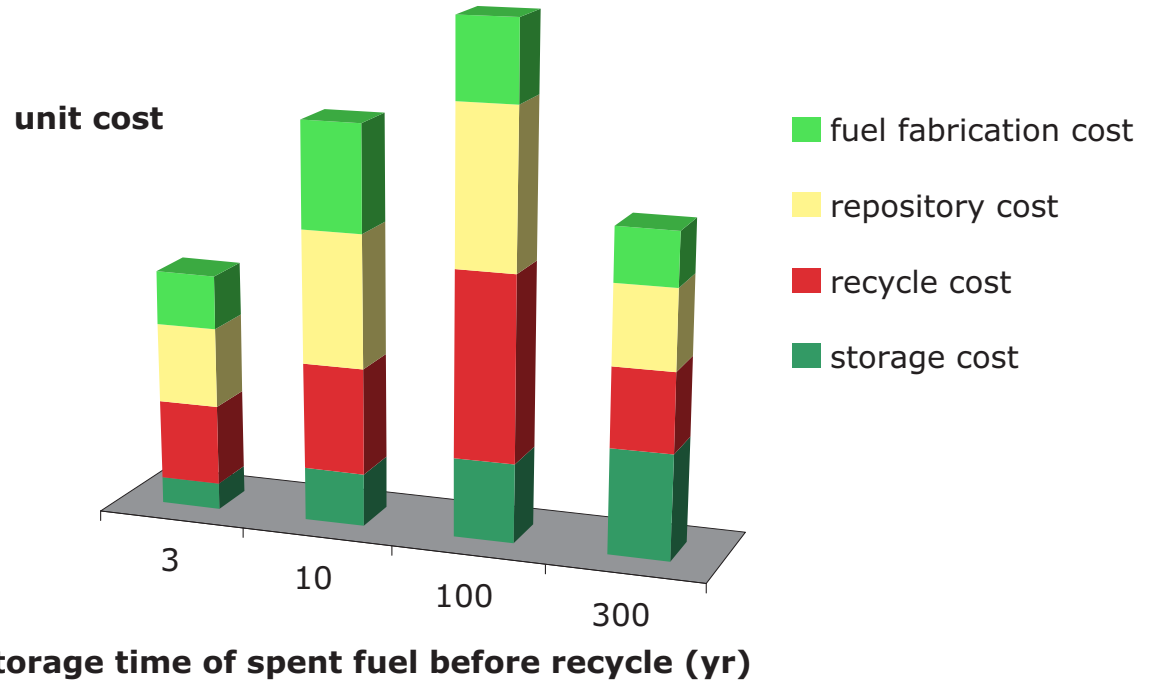

Figure B-5. Cost based on interim storage time of spent fuel before recycle.

Inventory of different types of wastes based on losses to HLW

N.B.: Values for demonstration purposes only. They do not reflect actual data. composition of waste types

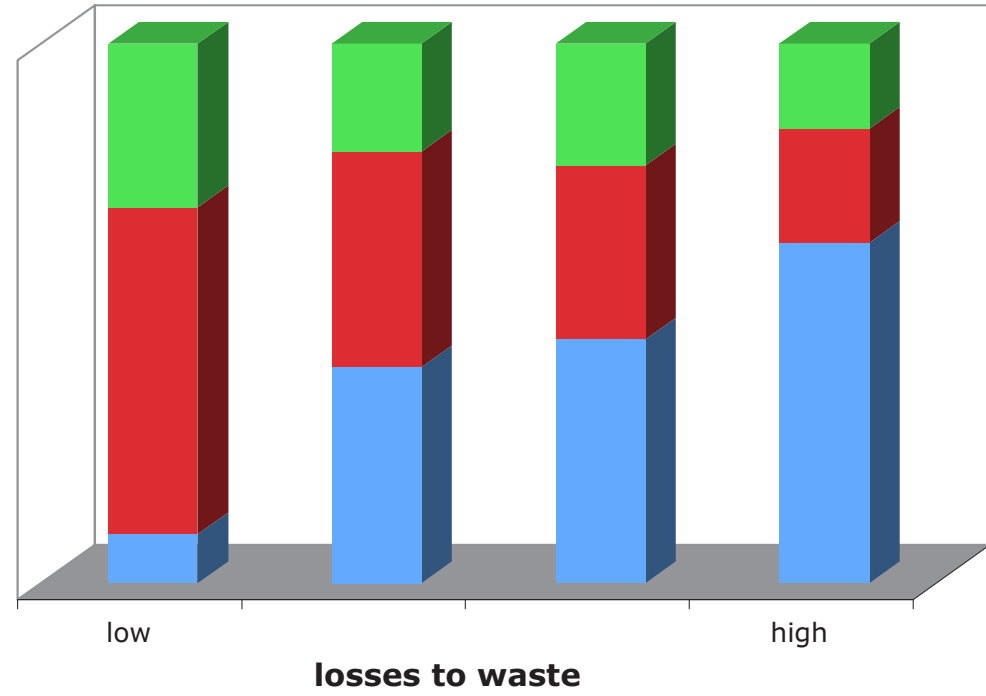

$\mathrm{Cs} / \mathrm{Sr}$

TRU

HLW

waste

Figure B-6. Waste inventory based on losses to HLW. 


\section{B-10. Software Quality}

The model will be evaluated in accordance with the Software Management procedures of the INL (MCP2022). The determination of quality level will be made using the quality level determination (QLD) documentation. We anticipate that the evaluation of FIT model will result in a designation as "Custom Developed" non-safety software with a quality level classification of QL-3. The application would not be required to meet the criteria specified for a higher classification level. Data in the deferrable class, if lost, can affect individual performance, but would not affect INL mission success. Applications in this class have no requirement to be back on-line within a specified period of time.

Documentation will be prepared as needed and specified by the Software Quality Assurance procedure (LWP-13620) which may include the following:

a. Software Management Plan (SMP), which will include:

- Software Quality Assurance Plan (SQAP)

- Software Configuration Management Plan (SCMP)

b. Software Requirements Document (SRS)

c. Software Platform Evaluation

d. Planning and Design Basis (sometimes called a Design description for software or DDS)

e. User documentation

Optional software application documentation that may include a requirements traceability matrix (RTM).

\section{B-11. PERFORMANCE TESTING}

Performance testing will be done according to the software quality assurance plan and the software test plan. Presentations and publications for external communication using data or results from the model will require peer review before submittal.

Verification and validation refers to the process of determining if the requirements for a system or component are complete and correct, the products of each development phase fulfill the requirements or conditions imposed by the previous phase, and the final system or component complies with specified requirements. Verification evaluates the system or component to determine if it satisfies specified requirements. Validation evaluates the system or component for proof of correctness. V\&V requirements will be met based on a review of the model performance based on acceptance criteria that is established for each key modeling requirement. 
This page intentionally left blank. 


\section{Appendix C}

\section{Equations for Time-Dependent Parameters}


This page intentionally left blank 
Define the following basic parameters:

$$
\begin{aligned}
& \sigma_{i}=\text { cross section of } \mathrm{i}^{\text {th }} \text { isotope in units of neutron interactions per target atom per incoming neutron } \\
& \qquad \times 10^{-24} \mathrm{~cm}^{2} \\
& m_{i}=\text { mass of } \mathrm{i}^{\text {th }} \text { isotope (grams) } \\
& q_{i}=\text { heat coefficient of } \mathrm{i}^{\text {th }} \text { isotope (watts/gram) } \\
& M_{i}=\text { atomic mass of } \mathrm{i}^{\text {th }} \text { isotope (grams per mole) } \\
& x_{i}=\text { generic parameter of } \mathrm{i}^{\text {th }} \text { isotope (tbd/gram). }
\end{aligned}
$$

For any generic time-dependent parameter, the total value of the parameter is given by:

$$
X(t)=\sum_{i} x_{i} m_{i}(t)
$$

The problem is that there can be a large number of isotopes involved. The Isotope Parameter and Decay Tool's decay engine has a list of 1637 isotopes and typical ANL output files have 952 isotopes.

Fortunately, most of those isotopes are either:

1. Short-lived, so that their contribution to the sum in Equation $\mathrm{C}-1$ can be ignored.

2. Small parameter value, so that their contribution to the sum in Equation C-1 can be ignored.

The second exclusion occurs for most nuclear-related parameters for all the stable isotopes (i.e., the heat), gamma, neutron emission from stable isotopes is zero and they are ignored in calculating the sum in Equation C-1.

To calculate various parameters of interest as simply as possible, we want to find the least number of isotopes so that Equation C-1 can be approximated by Equation C-2.

$$
X(t)=\sum_{\text {tracked }} x_{i} m_{i}(t)+x_{\text {lump }} m_{\text {lump }}
$$

This formulation puts the time dependence in a limited set of "tracked" isotopes, those whose decay we calculate. The second term is taken as time independent constant. For example, the heat from the Group $1 /$ Group 2 isotopes can be approximated within $\sim 1 \%$ as follows over the range of 1 to $1,000,000$ years, which is adequate for our purposes (Piet 2009).

$$
Q(t)=q_{S r 90} m_{S r 90}(t)+q_{C s 134} m_{C s 134}(t)+q_{C s 135} m_{C s 135}(t)+q_{C s 137} m_{C s 137}(t)
$$

In other words, we merely have to track four isotopes. Note that in Equation C-3, the "lump" term is zero. Recall that "lump" includes the stable isotopes, whose heat emission is zero, and the short-lived isotopes, whose heat is often high but which decay before the fuel cycle management time scale (taken as a minimum of 1 year after reactor discharge).

Similarly, the mass of Group 1 and Group 2 can be approximated by:

$$
m(t)=m_{R b}+m_{S r 90}(t)+m_{S r-o t h e r}+m_{C s 134}(t)+m_{C s 135}(t)+m_{C S 137}(t)+m_{C s-o t h e r}+m_{B a}
$$

(Equation C-3 is somewhat incorrect for reasons stated below.) Only four of the terms in Equation C-2 are time dependent, the other four terms are time independent. Work in 2009 [Piet2009] established that the radioactive isotopes in the "List of 81 " are adequate for heat, gamma, neutron, radiotoxicity, and mass from a few years to $1,000,000$ years. There are two caveats or cautions. 
First, when there is a short-lived progeny of a tracked isotope, we have to add its parameter $q$ to that of the parent $q$. As an example, most of the heat emitted by Sr-90 and Cs-137 actually comes the decay of their short-lived progeny Y-90 and Ba-137m respectively. Y-90 half-life is 2.67 days; Ba- $137 \mathrm{~m}$ half-life is 2.552 minutes. In such cases, the amount of mass of these isotopes at any one moment is negligible. So, we simply add the heat emitted by the progeny to the parent, and the heat emission calculation is correct for our purposes. This is done outside of FIT and VISION by adding the appropriate parameters for progeny to that of parents.

Second, to get the mass right, the mass of an isotope that is tracked must be moved to its stable progeny as it decays. For Sr-90 and Cs-137 those are Zr-90 and Ba-137. Thus, as Sr-90 decays, the total mass of Group 1+2 decreases slightly and the mass of zirconium increases. Because cesium and barium are in Group 1 and 2 respectively, the decay of Cs-137 does not change the mass of Group 1+2; but, if the mass of Group 1 and 2 must be differentiated, then Cs-137 decay shifts mass from Group 1 to Group 2. Said another way, if Group 1 and 2 are considered together, the total Group 1+2 mass is given by:

$$
m_{\text {Group } 1+2}(t)=m_{R b}+m_{S r 90}(t)+m_{S r-\text { other }}+m_{C s 134}(0)+m_{C s 135}(0)+m_{C s 137}(0)+m_{C s-\text { other }}+m_{B a} \quad \text { Eq. C-5 }
$$

Because all three Cs isotopes decay into barium, their decay does not change the total Group 1+2 mass and therefore the total Group 1+2 mass is constant except for the decay of Sr-90 to Zr-90. Equation C-5 is the corrected version of equation 4.

If, however, we want to keep track of the mass of Group 1 and Group 2 separately, the situation becomes more complicated. The mass of Group 1 is still relatively straightforward; it is given by:

$$
m_{\text {Group } 1}(t)=m_{R b}+m_{C s 134}(t)+m_{C s 135}(t)+m_{C s 137}(t)+m_{C s-o t h e r}
$$

The mass of Group 2, however, has the complication that Cs-134, Cs-135, and Cs-137 decay into Ba-134, Ba-135, and Ba-137.

$$
\begin{gathered}
m_{\text {Group } 2}(t)=m_{S r 90}(t)+m_{S r-\text { other }}+\left[m_{C s 134}(0)-m_{C s 134}(t)\right]+\left[m_{C s 134}(0)-m_{C s 135}(t)\right]+ \\
{\left[m_{C s 137}(0)-m_{C s 137}(t)\right]+m_{B a}}
\end{gathered}
$$

When one adds Equations C-6 and C-7 together, the time-dependent terms for Cs-134, Cs-135, and Cs137 cancel and one recovers Equation C-5. Often, the decay chains for tracked isotopes are sufficiently simple that the terms in square brackets have a simple analytical expression.

We now have two sets of new issues requiring new analysis.

First, we need to analyze cross sections. The two cross sections we are concerned about are:

$\sigma_{\text {fission }}=$ fission cross section

$\sigma_{\text {capture }}=\sigma_{\text {absorption }}-\sigma_{\text {fission }}=\sigma_{(\mathrm{n}, \gamma)}+\sigma_{(\mathrm{n}, 2 \mathrm{n})}+\sigma_{(\mathrm{n}, \alpha)}+\sigma_{(\mathrm{n}, \mathrm{p})}+$ other more exotic terms

Generally, the waste of neutrons $\left(\sigma_{\text {capture }}\right)$ is well approximated by radiation capture, $(n, \gamma)$, but there are exceptions such as boron, where the absorption of neutrons is dominated by $(n, \alpha)$. Since ORIGEN-2.2 provides cross sections for (n,fission), $(n, \gamma),(n, 2 n),(n, \alpha)$, and $(n, p)$, I'll use all of them in calculating $\sigma_{\text {capture. }}$ Thus, we need to know $\sigma_{\text {fission }}$ and $\sigma_{\text {capture }}$ for each chemical grouping (e.g., Group 1, Group 2, halogens, etc.). So, I must test whether these two parameters can be approximated by the following expression that weights cross sections by the number density (hence $m / M$ ): 


$$
\sigma(t)=\frac{\sum_{\text {tracked }} \sigma_{i} m_{i}(t) / M_{i}+\sigma_{\text {lump }} m_{\text {lump }} / M_{\text {lump }}}{\sum_{\text {tracked }} m_{i}(t) / M_{i}+m_{\text {lump }} / M_{\text {lump }}}
$$

In both Equation C-2 and Equation C-10, the idea is that the time dependence is to be adequately calculated by the time dependence of the tracked isotopes. If not, we will either have to track more individual isotopes or provide a look-up table of cross sections as function of time.

The good news is that the first time I looked at cross sections in detail for the losses study in 2009 I observed that at the top-level, total fission product cross sections are dominated by those of stable isotopes. This is logical since fission products are typically radioactive if they are too neutron-rich; absorption another neutron only makes them more neutron-rich and this is unlikely to have a high cross section. So, I expect that more cross sections for Group 1, Group 2, etc., will be dominated by stable isotopes. The trick, however, will be whether a dominant stable isotope is increasing significantly because something decays into it. For example, consider gadolinium. It has three isotopes with high cross sections (over 1000 barns).

1. Gd-155 is stable, it is a progeny of Eu-155, which is a tracked isotope

2. Gd-157 is stable, it is a progeny only of very short-lived isotopes

3. Gd-161 is short-lived (1.61 minutes) and can certainly be ignored.

So, the absorption potential of gadolinium fission products will increase with time, first from several very short-lived isotopes decaying into Gd-157 and then as Eu-155 decaying into Gd-155. If neither of these is significant, then $\sigma_{\mathrm{Gd} 157} m_{\mathrm{Gd} 157}(\mathrm{t})$ can be approximated $\sigma_{\mathrm{Gd} 157} m_{\mathrm{Gd} 157}(0)$, which is time independent. For UOX-51, the decay of short-lived isotope into Gd- 157 increases $m_{\mathrm{Gd} 157}(0)$ by $13 \%$ by 0.01 years. As this is only one of three key gadolinium isotopes, it is unlikely that the net increase of absorption by gadolinium (or by lanthanides as a whole) is significantly impacted by this, but I have to check. (And even if so, the easiest fix would be to simply group the appropriate isotopes with gadolinium instead of their initial element.) However, the decay of Eu-155 into Gd-155 increases $m_{\mathrm{Gd} 155}(0)$ by a factor of 90 by $\mathrm{t}=10$ years. This is far more likely to be an issue. If so, the $\sigma_{\mathrm{Gd} 155} m_{\mathrm{Gd} 155}(\mathrm{t})$ will have to be approximated by:

$\sigma_{\mathrm{Gd} 155}\left[m_{\mathrm{Gd} 155}(0)+\left\{m_{\mathrm{Eu} 155}(0)-m_{\mathrm{Eu} 155}(\mathrm{t})\right\}\right]$

rather than

$\sigma_{\mathrm{Gd} 155} m_{\mathrm{Gd} 155}(0)$.

Remember, the analogous problem does not occur for heat, gamma, neutron, radiotoxicity because such stable progeny isotopes (such as Gd-155) are irrelevant. Instead, here, it is the stable isotopes that typically dominate absorption cross sections, the exact opposite of the parameters I previously studied.

Second, I need to (eventually) recheck the 2009 analyses for the new chemical groupings. I have taken the first step, which is to split stable masses accordingly (e.g., we have split the old TM-other into transition metals, other-metals, metalloids, and non-metals). In 2009, I convinced myself that TM-other and LNother (and so forth) were adequate approximations (i.e., that Equation C-2 provided an adequate approximation of heat, mass, gamma, neutron, radiotoxicity with "lump" = TM-other, LA-other, halogenother, inert-gas-other, and Mo-Ru-Rh-Pd-other). Those "lumps" (at $\mathrm{t}=0$ ) have been split into the appropriate new, smaller lumps (e.g., $m_{\mathrm{Mo}-\mathrm{Ru}-\mathrm{Rh} \text {-Pd-other }}$ into $m_{\mathrm{Mo}}+m_{\mathrm{Ru}-\mathrm{Rh}-\mathrm{Pd}-\mathrm{other})}$. Thus, the mass of molybdenum would be given by: 
$m_{\mathrm{Mo}}(\mathrm{t})=m_{\mathrm{Mo}}+\left[m_{\mathrm{Zr} 95}(0)-m_{\mathrm{Zr} 95}(\mathrm{t})\right]$

which is time-independent; there are no tracked Mo isotopes but Zr-95 does decay to Mo-95. The question is now whether that approximation is adequate. For Ru-Rh-Pd there are two tracked isotopes. $\mathrm{Ru}-106$ decays into Pd-106, so there is no net change in mass for Ru-Rh-Pd. Pd-107 decays into Ag-107, which moves mass from noble metals to transition metals. However, we already know that the Pd-107Ag-107 mass is extremely small, so this mass change can be ignored in this example. 


\section{Appendix D}

\section{Approach to Calculate Cross Sections}


As describe in the main body of the report, FIT does not simulate hundreds of isotopes. Instead, the nonradioactive isotopes are presented via lumped parameters, such as lanthanide-other. We therefore had to estimate the cross sections for these lumped masses. This appendix explains the approach.

Note that (n,2n) and (n,fission) reactions are both sink and source of neutrons. However, our analysis is simplified to ignore $(\mathrm{n}, 2 \mathrm{n})$ sources of neutrons.

Define the following basic parameters:

$6.022 \times 10^{23}$ atoms $/$ mole $=$ Avogadro's constant

$\Phi=$ neutron flux (neutrons $/ \mathrm{cm}^{2}-\mathrm{s}$ )

$\sigma_{i}=$ absorption cross section of $\mathrm{i}^{\text {th }}$ isotope (capture $+\mathrm{n}, 2 \mathrm{n}+\mathrm{n}, \alpha+$ fission) in units of absorptions per target atom per incoming neutron $\times 10^{-24} \mathrm{~cm}^{2}$

$m_{i}=$ mass of $i^{\text {th }}$ isotope (grams)

$M_{i}=$ atomic mass of $\mathrm{i}^{\text {th }}$ isotope (grams per mole).

Define the following derived parameters for total or lumped parameters:

$$
\begin{aligned}
& m_{\text {Total }}=\sum_{i} m_{i} \\
& n_{\text {Total }}=\sum_{i} n_{i} \\
& \sigma_{\text {lump }} \equiv \frac{\sum_{i} \sigma_{i} n_{i}}{\sum_{i} n_{i}}=\frac{\sum_{i} \sigma_{i} n_{i}}{n_{\text {Total }}} \\
& M_{\text {lump }} \equiv \frac{\sum_{i} M_{i} n_{i}}{\sum_{i} n_{i}}=\frac{\sum_{i} M_{i} n_{i}}{n_{\text {Total }}}
\end{aligned}
$$

The fundamental equation for absorption of neutrons is given by:

$$
\text { Absorptions } / \mathrm{s}=\Phi\left(\mathrm{n} / \mathrm{cm}^{2} \mathrm{~s}\right) \sum_{i} \frac{\sigma_{i}\left(\text { absorptions } 10^{-24} \mathrm{~cm}^{2} / \text { atom }-n\right) m_{i}(\mathrm{~g})\left(6.022 \times 10^{23} \text { atoms } / \text { mole }\right)}{M_{i}(\mathrm{~g} / \mathrm{mole})}
$$

which can be rewritten after canceling units:

$$
\text { Absorptions } / s=\Phi \sum_{i} \frac{\sigma_{i} m_{i}}{M_{i}}(0.6022) \text { absorptions } / s
$$


The fundamental relationship among $\mathrm{n}, \mathrm{m}$, and $\mathrm{M}$ is given by:

$n_{i}($ atoms $) \equiv \frac{m_{i}(g)\left(6.022 \times 10^{23} \text { atoms } / \text { mole }\right)}{M_{i}(\mathrm{~g} / \text { mole })}=\frac{m_{i}}{M_{i}}\left(6.022 \times 10^{23}\right.$ atoms $/$ mole $)$

Therefore combining Equations D-2 and D-7, we obtain:

Eq. D-7

$n_{\text {Total }} \equiv \sum_{i} n_{i}($ atoms $)=\sum_{i} \frac{m_{i}}{M_{i}}\left(6.022 \times 10^{23}\right.$ atoms $/$ mole $)$

Eq. D-8

And using Equations D-3 and D-7, we obtain:

$$
m_{\text {Total }} \equiv \sum_{i} m_{i}(\text { atoms })=\frac{\sum_{i} M_{i} n_{i}}{\left(6.022 \times 10^{23} \text { atoms } / \text { mole }\right)}
$$

By using Equations D-7 and D-8, I can rewrite Equation D-6 as follows:

Absorptions $/ s=\Phi \frac{\sum_{i} \sigma_{i} n_{i}}{\sum_{i} n_{i}} \frac{(0.6022)}{\left(6.022 \times 10^{23} \text { atoms / mole }\right)} \frac{\sum_{i} n_{i}}{\sum_{i} M_{i} n_{i}} \sum_{i} M_{i} n_{i}$

Absorptions $/ s=\Phi \frac{\sigma_{\text {lump }}}{M_{\text {lump }}} \frac{(0.6022)}{\left(6.022 \times 10^{23} \text { atoms / mole }\right)} \sum_{i} M_{i} n_{i}$

Eq. D-10

Absorptions $/ s=\Phi \frac{\sigma_{\text {lump }} m_{\text {Total }}}{M_{\text {lump }}}(0.6022)$ absorptions $/ s$

Eq. D-11

Eq. D-12

Equation D-12 is simply equation D-6 with three lumped or total parameters replacing the individual isotope parameters.

An alternative expression for $\sigma_{\text {lump }}$ can be derived as follows:

$$
\sigma_{\text {lump }} \equiv \frac{\sum_{i} \sigma_{i} n_{i}}{\sum_{i} n_{i}}=\frac{\sum_{i} \sigma_{i} n_{i}}{n_{\text {Total }}}=6.022 \times 10^{23} \frac{\sum_{i} \frac{\sigma_{i} m_{i}}{M_{i}}}{n_{\text {Total }}}=\frac{6.022 \times 10^{23} \sum_{i} \frac{\sigma_{i} m_{i}}{M_{i}}}{6.022 \times 10^{23} \sum_{i} \frac{m_{i}}{M_{i}}}=\frac{\sum_{i} \frac{\sigma_{i} m_{i}}{M_{i}}}{\sum_{i} \frac{m_{i}}{M_{i}}}
$$

So that $\sigma_{\text {lump }}$ is seen as the weighted sum of $\sigma_{i}$ with the weights being either the number density $(n)$ via Equation D-3 or equivalently $(m / M)$ via Equation D-12.

An alternative expression for $M_{\text {lump }}$ can be derived as follows using Equation D-9:

$$
M_{\text {lump }} \equiv \frac{\sum_{i} M_{i} n_{i}}{\sum_{i} n_{i}}=\frac{m_{\text {Total }}}{\sum_{i} n_{i}}\left(6.022 \times 10^{23} \text { atoms } / \text { mole }\right)=\frac{m_{\text {Total }}}{n_{\text {Total }}}\left(6.022 \times 10^{23} \text { atoms } / \text { mole }\right)
$$

Eq. D-14

Or, 


$$
M_{\text {lump }} \equiv \frac{\sum_{i} m_{i}}{\sum_{i} \frac{m_{i}}{M_{i}}}=\frac{m_{\text {Total }}}{\sum_{i} \frac{m_{i}}{M_{i}}}
$$

Our approach holds $\sum_{i} \frac{m_{i}}{M_{i}}$ constant. Examination of equations D-13 and D-15 show that it does not because this term disappears when one takes $\sigma_{\text {lump }} / M_{\text {lump }}$. 


\section{Appendix E}

\section{Justification for Time-Independent Cross Sections}


This page intentionally left blank 
This appendix explores the validity of treating capture cross section for fission products for "other" isotopes (the ones we treat as stable) as being constant. The following examples use UOX-51.

\section{Approximation}

Radioactive - for each isotope, cross section $\times$ mass $(t)$

Other - lumped cross section at shutdown $\times$ mass $(\mathrm{t}) / \operatorname{mass}(\mathrm{t}=0)$, mass only changes as radioactive isotopes decay into the "other" box

\section{Issues}

Short-lived isotopes changing the mass of "other"- not found to be an issue.

As radioactive isotopes decay into "other," it can raise the capture potential more than its fraction change in "other" mass.

Group 2 is underestimated by the approximation by a factor of 2.5 by 300 years. However, this is overwhelmed by Group 1 for any option in which Group 1 and 2 are kept together.

Lanthanides are underestimated by the approximation by a factor of 1.5 by 300 years.

\section{Options}

Live with the approximations as they now. Conduct off-line estimate of how much this impacts answers.

The fix (if required) would be to breakout a separate term for the "other" cross section to reflect the change in mass of that particular stable isotope. The two fixes would be:

1. Divide $\mathrm{Ba}$ into $\mathrm{Ba}$-other and $\mathrm{Ba}-137$ so that the impact of $\mathrm{Cs}-137$ decaying into stable $\mathrm{Ba}-137$ would be accounted for.

2. Split Gd-155 from other lanthanides so that the impact of Eu-155 decaying into stable Gd-155 would be accounted for.

\section{Group 1}

Stable isotopes dominate quite strongly and they do not increase significantly.

Approximation is fine, $2 \%$ error from 1 to 300 years. 


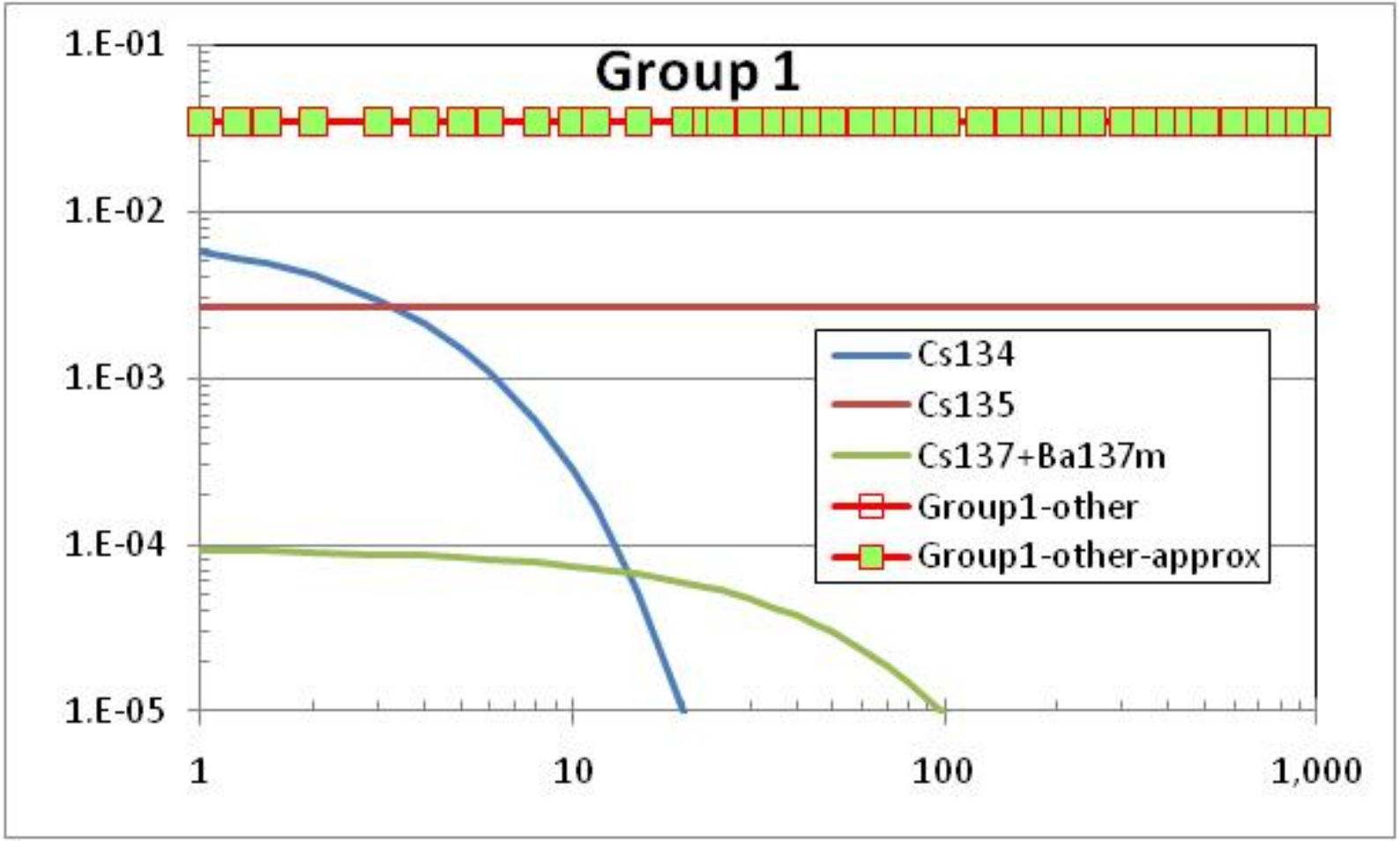

Figure E-1. Cross sections (in barns) of Group 1 as calculated by the isotope tool.

\section{Group 2}

Stable isotopes (especially $\mathrm{Ba}$, not $\mathrm{Sr}$ ) dominate but they increase as the Cs isotopes decay into them

At discharge, Ba-138 is $88 \%$ of Ba mass, Ba- 137 is only $4 \%$. By 300 years, Ba- 138 is only $46 \%$ of $\mathrm{Ba}$ mass and $\mathrm{Ba}-137$ is $45 \%$. The mass of $\mathrm{Ba}$ total increases a factor of two, mostly because of $\mathrm{Ba}-137$ growth as Cs-137 decays. Ba-137 mass increases a factor of 22.

Problem is that the cross section of $\mathrm{Ba}-137$ is 13 times higher than $\mathrm{Ba}-138$, so as $\mathrm{Ba}$ shifts from $88 \% \mathrm{Ba}-$ $138 / 4 \%$ Ba-137 to $46 \%$ Ba-138/45\% Ba-137, the approximation captures the increase in mass (2x) but not the isotopic change.

Approximation understates Sr-total capture potential by factor of 2.5 by 300 years.

However, if one considers Gruop1+Group2 (dominated by G1), then the error is fine. 


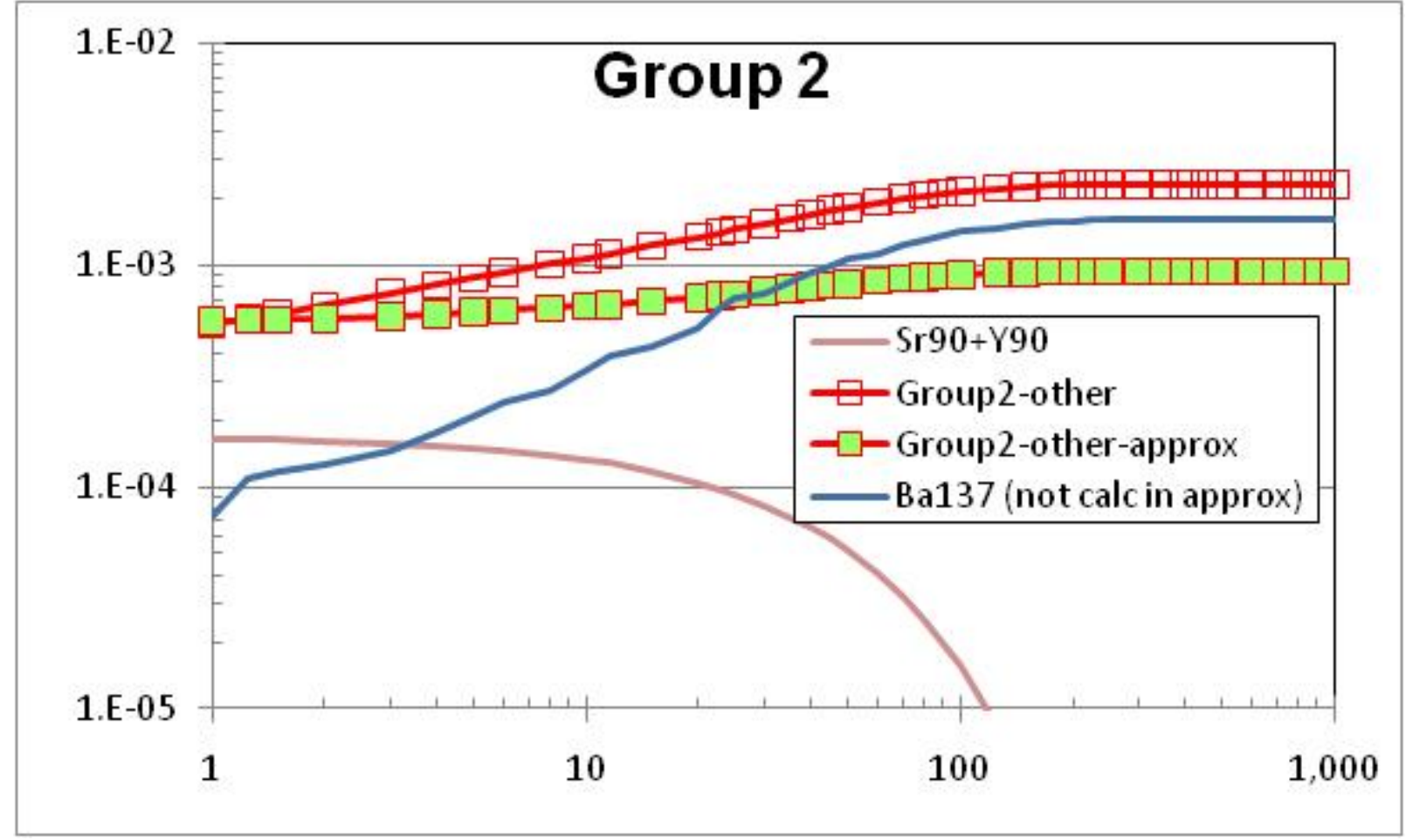

Figure E-2. Cross sections (in barns) of Group 2 as calculated by the isotope tool.

\section{Lanthanides}

First, Figure E-3 is a plot of all the lanthanide tracked isotopes and individual lanthanide elements. Figure E-4 zooms in on the most important lines to illustrate the details.

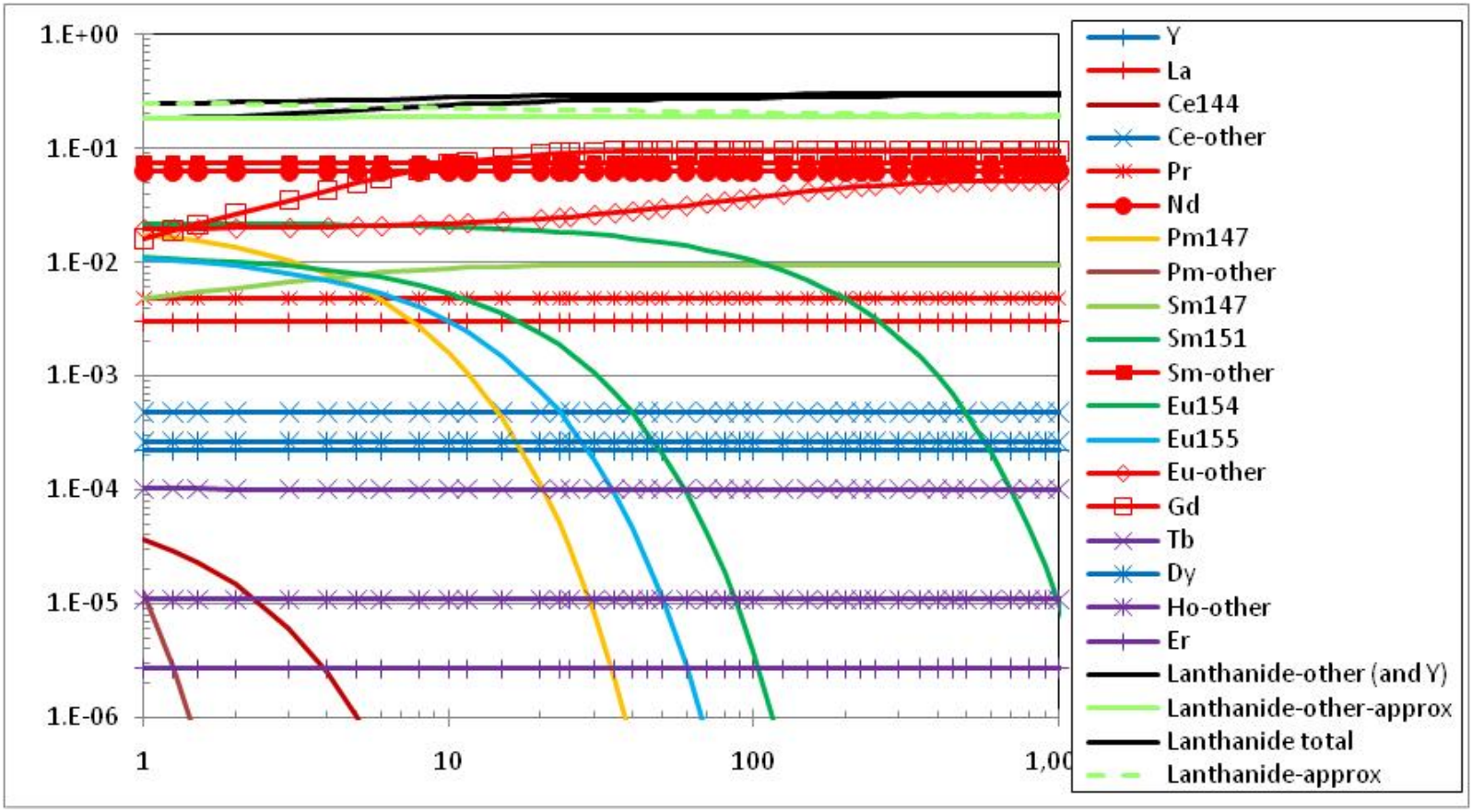

Figure E-3. Cross sections (in barns) of the lanthanides as calculated by the isotope tool 
This plot shows a few interesting things from 1 to 300 years.

Sm-147 increases 1.9x as Pm-147 decays into it. Since both are tracked isotopes, this effect is automatically accounted for.

The value of Eu-other increases 2.5x as Sm-151 decays into stable Eu-151.

Gd increases a factor of 5.9x as Eu-155 decays into stable Gd-155. Gd-155 itself increases a factor of 91, going from a minor part of Gd to a dominant part.

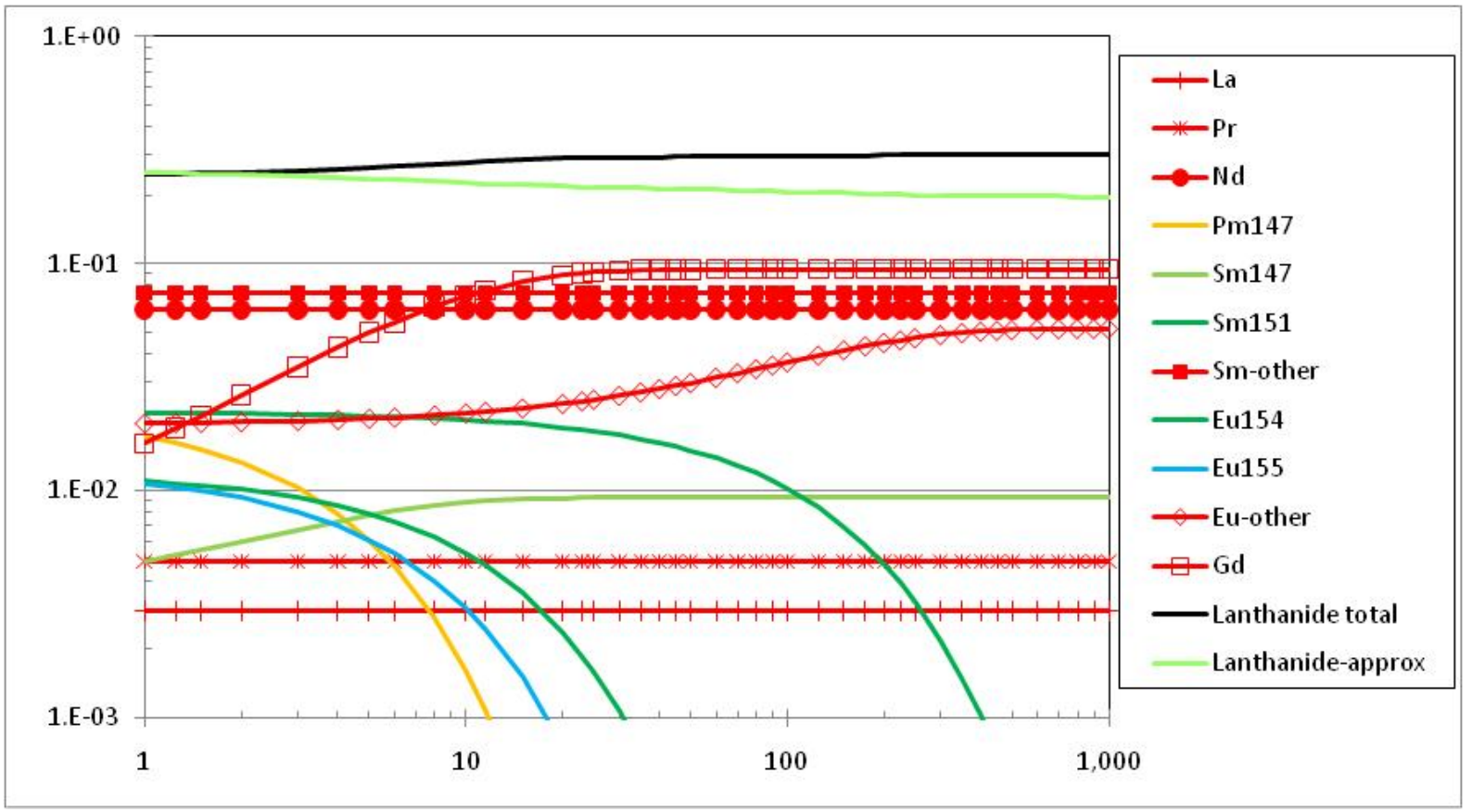

Figure E-4. Cross sections (in barns) of selected lanthanides as calculated by the isotope tool

So, essentially the lanthanide-total increases a factor of 1.21, but the approximation of lanthanide-total decreases by a factor of 0.80 (as tracked isotopes decay), so that by 300 years the approximation of lanthanide-total is underestimated a by a factor of 1.5 .

\section{Noble metals}

The approximation replicates the cross section to within 3\%, as illustrated in Figure E-5. 


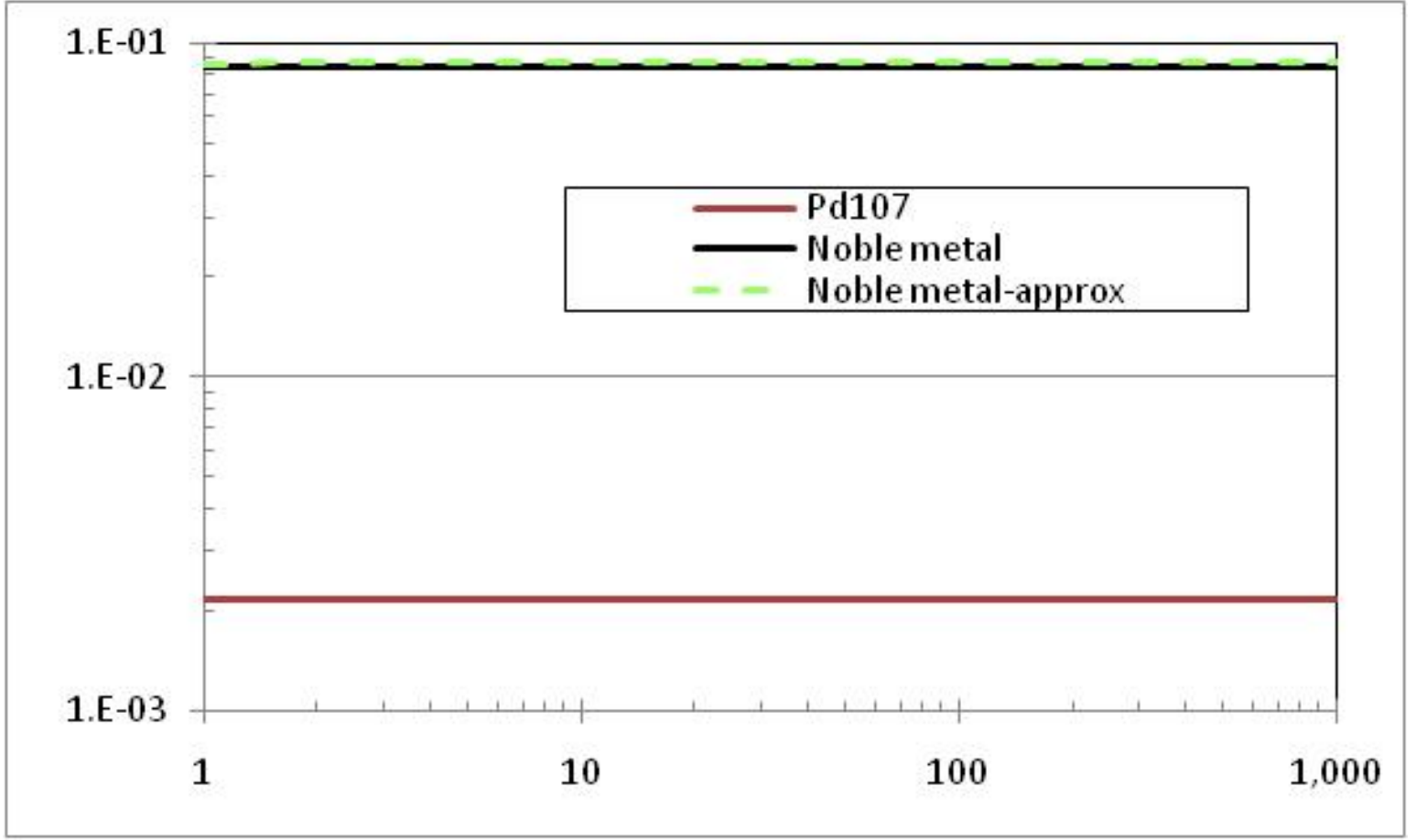

Figure E-5. Cross sections (in barns) of selected transition metals as calculated by the isotope tool

\section{Other metal}

The approximation matched within $1 \%$.

\section{Metalloids (antimony, tin)}

Figure E-6 shows the cross sections of metalloids. There is 5\% error through 300 years, due to Sb-125 decaying into Te-125. We consider this acceptable.

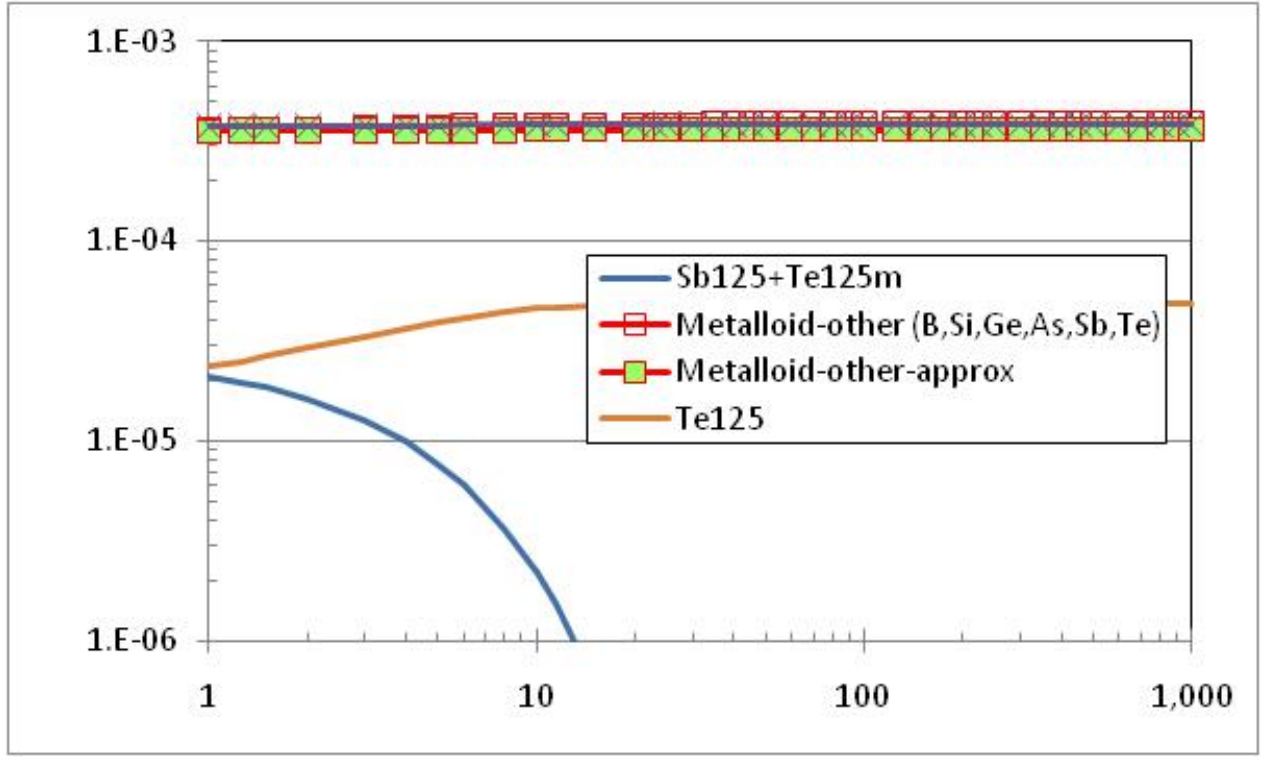

Figure E-6. Cross sections (in barns) of selected transition metals as calculated by the isotope tool 


\section{Group 17 (halogens)}

The approximation matched more exact calculations within $1 \%$.

\section{Group 18 (inert gases)}

The approximation matched more exact calculations within $1 \%$.

\section{Niobium}

The approximation matched more exact calculations within $1 \%$.

\section{Technetium}

Neutron capture by Tc is dominated by Tc-99, which is tracked.

\section{Cadmium}

The approximation matched more exact calculations within $1 \%$. 